\title{
International organizations and global migration governance
}

Citation for published version (APA):

McGregor - Lebon, E. (2020). International organizations and global migration governance. [Doctoral Thesis, Maastricht University]. Boekenplan. https://doi.org/10.26481/dis.20201005elm

Document status and date:

Published: 01/01/2020

DOI:

10.26481/dis.20201005elm

Document Version:

Publisher's PDF, also known as Version of record

\section{Please check the document version of this publication:}

- A submitted manuscript is the version of the article upon submission and before peer-review. There can be important differences between the submitted version and the official published version of record.

People interested in the research are advised to contact the author for the final version of the publication, or visit the DOI to the publisher's website.

- The final author version and the galley proof are versions of the publication after peer review.

- The final published version features the final layout of the paper including the volume, issue and page numbers.

Link to publication

\footnotetext{
General rights rights.

- You may freely distribute the URL identifying the publication in the public portal. please follow below link for the End User Agreement:

www.umlib.nl/taverne-license

Take down policy

If you believe that this document breaches copyright please contact us at:

repository@maastrichtuniversity.nl

providing details and we will investigate your claim.
}

Copyright and moral rights for the publications made accessible in the public portal are retained by the authors and/or other copyright owners and it is a condition of accessing publications that users recognise and abide by the legal requirements associated with these

- Users may download and print one copy of any publication from the public portal for the purpose of private study or research.

- You may not further distribute the material or use it for any profit-making activity or commercial gain

If the publication is distributed under the terms of Article $25 \mathrm{fa}$ of the Dutch Copyright Act, indicated by the "Taverne" license above, 


\section{International Organizations and}

Global Migration Governance 
(C) 2020 Elaine Lebon-McGregor

ISBN: 9789086665136

Publisher: Boekenplan

Cover page: Erik Scheele

All rights reserved. No part of this publication may be reproduced, stored in a retrieval system, or transmitted in any form, or by any means, electronic, mechanical, photocopying, recording or otherwise, without the prior permission in writing, from the author. 
International Organizations and Global Migration Governance

\section{DISSERTATION}

to obtain the degree of Doctor at Maastricht University, on the authority of the Rector Magnificus, Prof. Rianne Letschert in accordance with the decision of the Board of Deans to be defended in public on Monday, 5 October 2020 at 13.00

by

Elaine Lebon-McGregor 


\section{Supervisors:}

Prof. Dr. Ronald Skeldon

Prof. Dr. Melissa Siegel

\section{Co-Supervisor:}

Dr. Michal Natorski

\section{Assessment committee:}

Prof. Dr. Maarten Vink (Chair)

Prof. Dr. Des Gasper (Erasmus University Rotterdam)

Prof. Dr. Andrew Geddes (European University Institute)

Dr. Katherine Kuschminder 


\section{Abstract}

Recent years have seen migration rise to the top of political agendas around the world. A series of 'migration crises' in 2015 demonstrated the limits of the existing international architecture leading states to reconsider the global response to migration. In October 2016, in addition to the International Organization for Migration (IOM) joining the United Nations (UN), 193 UN Member States unanimously agreed upon the New York Declaration (NYD) at the closing of the High-Level Summit to Address Large Movements of Refugees and Migrants, to commit themselves to negotiate two Global Compacts by 2018, one on migration and the other on refugees. This decision commenced two years of consultations and negotiations, which concluded with the adoption of a Global Compact on Refugees (GCR) and a Global Compact for Safe, Orderly and Regular Migration (GCM) in December 2018. By bringing IOM into the UN system and endorsing a comprehensive set of, albeit non-binding, commitments, states acknowledged migration as a global governance issue and accepted the necessity of institutionalizing migration within the UN. Next to the migration crises of 2015, which provided the necessary 'window of opportunity' to pursue institutional change, however, this dissertation argues that reframing migration as a development issue by the UN was key to the process of institutionalizing migration into the UN. The inclusion of migration in the Sustainable Development Goals (SDGs) in 2015 was a key milestone securing consensus among UN Member States that migration, an issue previously held at arms-length from the UN, was indeed relevant to its mandate. Hence, the dissertation investigates how migration became a global governance issue, and the role played by the UN in this process.

Building on theoretical insights from the Advocacy Coalition Framework (ACF), and the methodological principles of process-tracing, the dissertation tells the story of how migration has evolved as a global policy issue since 1919. Framing analysis is used to analyse the different ways that migration has been framed, by whom, and to what end. Drawing on interviews with 43 key protagonists, actors involved in global-level discussions on migration, and the UN archives, the dissertation explores four case studies that shed light on how IOs have influenced global migration governance:

1) the creation of the Global Forum on Migration and Development (GFMD) (Chapter 5);

2) the inclusion of migration in the Sustainable Development Goals (SDGs) (Chapter 6); 
3) IOM's journey to becoming a UN agency (Chapter 7); and

4) the negotiation of the Global Compact for Safe, Orderly and Regular Migration (GCM) (Chapter 8).

The dissertation argues that a range of factors including the migration crises of 2015 which propelled migration into the political limelight; the reframing of migration as a development issue (Chapter 5) and the subsequent inclusion of migration in the Sustainable Development Goals (Chapter 6); coupled with the increasing likelihood that the UN would appoint or create a new body for migration within the UN, led IOM's Member States to conclude that it was necessary for IOM to become part of the UN system in 2016 (Chapter 7). However, while the migration crises of 2015 created the 'window of opportunity' to bring IOM into the UN, it also provided a fertile environment for advocates of the migrant rights frame to revive their struggle for universal norms to govern international migration (Chapter 8). 


\section{Acknowledgements}

The dissertation would not have been possible without the generosity of my interview participants. I am grateful to each and every individual who gave their time to share their experiences and reflections on the evolution of migration as a global policy issue. In addition there are a number of individuals who have played crucial roles and who I would like to take this opportunity to thank.

Throughout the PhD process I have been blessed with a dynamic supervision team without whom the journey would just not have been the same. Ron, you have been a rock. Sharp witted, patient and kind, you have been a steadfast source of inspiration throughout. Melissa, without your decision to offer me a job back in August 2012, a large part of the thesis would not have been possible. Your drive is infectious, and I would be happy with just half of the energy and passion that you put into what you do. Michal, after a change in direction, I was encouraged to add a third supervisor that could support me in the more theoretical aspects of my dissertation. You have added so much value to my learning process. I have appreciated your theoretical insights, your suggestions of reading material and your ability to make complex issues seem simple.

I would also like to take this opportunity to thank my assessment committee for their careful attention and critical feedback on my dissertation. Thank you Prof. dr. Maarten Vink (chair), Prof. dr. Andrew Geddes, Prof. dr. Des Gasper, and Dr. Katherine Kuschminder. Reflecting on your comments, and revisiting my dissertation was truly one of the most enjoyable phases of my $\mathrm{PhD}$ trajectory. Your insights not only helped me to improve the current manuscript, but also provided inspiration for my future research.

I started my $\mathrm{PhD}$ trajectory in the $\mathrm{GPAC}^{2}$ dual-career training programme in November 2015. Being part of GPAC gave me a platform to discuss my ongoing research with an incredible group of individuals. My thanks especially to Mindel for welcoming me into the programme and for her support and encouragement throughout the process. I am also grateful to Johan van Amersfoort for his helpful tips on my presentation style. In July 2018, I transferred into a full time $\mathrm{PhD}$ position. My thanks to Tatiana and Robin for admitting me into the programme. Special thanks to Eveline for all your help, guidance and wise words, particularly in the final stages of the process.

The cover art was inspired by the red carpet at the ILO headquarters in Geneva. I am very grateful to Erik Scheele for bringing this idea to life and creating such a 
beautiful cover for my dissertation. Special thanks to Ian McGregor and Sueli Brodin for proof-reading my dissertation. Any errors remain my own.

There are so many people that I am grateful to have met along the way and who have each helped in their own special way. My thanks to Ad, Bart, Danny, Diego, Evelien, Eric, Herman, Howard, Ingeborg, Ingrid, Janneke, Kim, Lutz, Marc, Marlies, Mieke, Mitie, Neil, Sueli, Susan, and Wilma - the backbone of the institute. Wilma, in my early days at Keizer Karelplein you were so generous with your time and helped me to navigate many the bureaucratic puzzle. Mieke, thank you for always offering a friendly smile and many a hug (and for graciously accepting defeat - I truly am worse at predicting football scores). Herman, thank you for all your help getting the newsletter going, and for helping me with endless website questions. Ad, thank you for tracking down numerous elusive publications for me.

To members of the migration group - past and present - thank you for being a source of inspiration: Agnes, Ayla, Biljana, Catherine, Charlotte, Clotilde, Craig, Eleni, Eli, Inez, Julia, Jenny, Katharina, Katie, Katrin, Laura, Levi, Lisa, Lika, Madeline, Michaella, Mohammad, Nasrat, Ortrun, Özge, Sabrina, Sarah L., Sarah R., Sonja, Talitha, Tamara, Veronika F., Veronika G, Vivianne, Zack, Zoë and to the many others who have been part of this group over the years. Katrin, I particularly enjoyed our shared fieldwork experiences, and our random late night side projects! Special thanks to Zoë and Talitha for taking care of our cats as we looked for a new place to live.

I feel truly lucky to have been surrounded by so many really inspiring people but special thanks go to two individuals who, in other circumstances, would have been my paranymphs. Michaella, you are unequivocally one of the most exceptional people that I have ever met. Thank you for being a constant source of inspiration, garden tips (and food!). You are a wonderful colleague, but more importantly - a really great friend! My dear Nora, we have spent countless hours discussing our work together. In the last months especially, we cheered each other on, and celebrated every milestone. Thank you for always being ready with an encouraging word, a smile and a hug.

Thinking back on my university career, there a few individuals who have played a particularly significant role in shaping the way I view science. At the University of Glasgow, I was particularly inspired by Prof. dr. Susan Deeley and was lucky to be part of her 'Values in Action' course. At Maastricht University, I had the privilege of being taught by Prof. dr. Hein de Haas. In the years since graduation I have been grateful for his feedback on my ongoing work and encouragement to keep on writing. My thanks also to the migration cohort of 2011/12 who were perfect sparring 
partners as I explored the field of migration for the first time. Albina, Eleni, Giota, Magda, Nina, Nora, and Xenofon, it was a real pleasure.

Working on a PhD can become all-consuming and I am therefore incredibly grateful to have an amazing group of friends with whom I can be Elaine the person, not Elaine the PhD student. I am grateful to have each of you in my life: Arianne, Arno Brenda, Cheryl, Eleni, Emmie, Laura, Michaella, Michiel, Naomi, Nora, Robbie, and Sanna.

I am also incredibly thankful for the support of my wonderful family. Mum and Dad, I am who I am because of you. From your book buying incentive scheme, to the correction of many a comma, you gave me a wonderful start in life. To my brothers, Stuart and David, I am grateful that I can count my siblings among my closest friends. Granny, I know you would have been proud of me and I am grateful for your financial support that greatly facilitated my move to the Netherlands and financed my further studies here.

And to my growing family. Jie and Ilona, you have become the sisters I never had, but always wanted! Isla, Aliyah, Iona and Iliyas, it is a real pleasure to watch you all grow up. Isla, our time spent writing stories together has been the highlight of my lockdown. Keep on writing!

Moving to the Netherlands in 2008 was a big step made easier by the warm embrace I received from my Dutch family. Wat heb ik geluk gehad met mijn schoonfamilie. Vanaf het eerste moment ben ik door jullie met open armen ontvangen en in jullie familie opgenomen. Jullie hebben mij enorm gesteund en ik voel me hier thuis dank zij jullie. Oma, Mam, Pap, Janet, Noël, Ilona, Rachid, Aliyah en Iliyas: ik hou van jullie allemaal.

Last but by absolutely no means least. To my incredible husband, Remco, who has weathered many storms in the making of this book. Zelfs je naam is mooi. 


\section{Table of Contents}

ABSTRACT ........................................................................................................ V

ACKNOWLEDGEMENTS ................................................................................... VII

LIST OF FIGURES ………………….................................................................. XIII

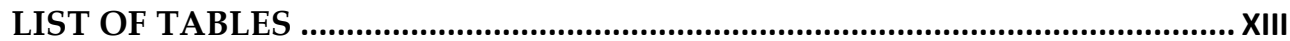

LIST OF ACRONYMS .........................................................................................

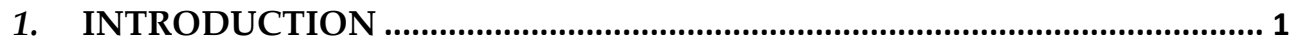

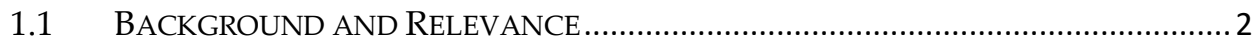

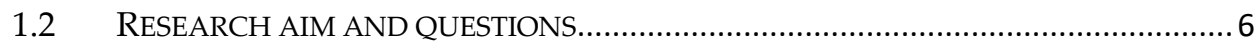

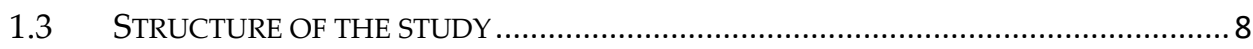

2. INTERNATIONAL ORGANIZATIONS AND GLOBAL MIGRATION

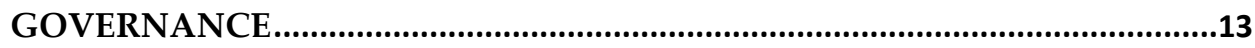

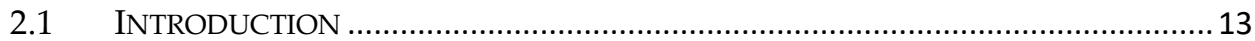

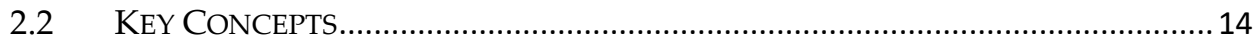

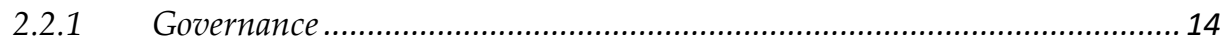

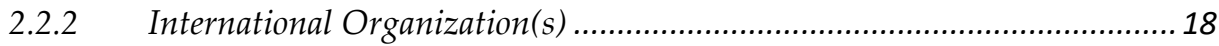

2.2.3 Conceptualizing Influence: Authority and Power.................................... 29

2.3 INTERNATIONAL ORGANIZATIONS AND STATES ............................................... 32

2.4 CONCLUSION: WHAT IS GLOBAL MigRATION GOVERNANCE? ............................. 36

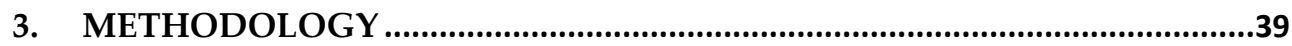

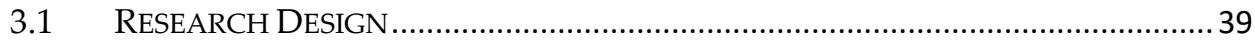

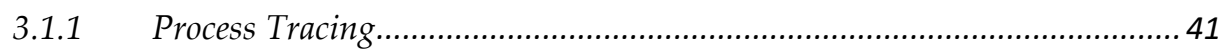

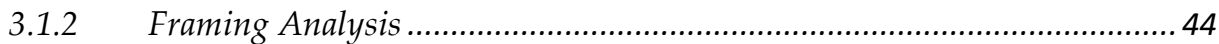

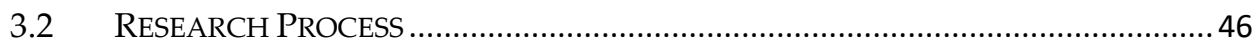

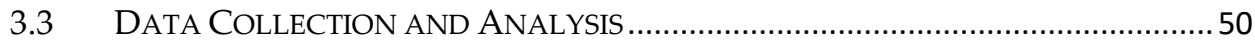

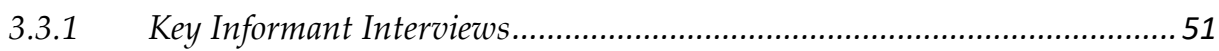

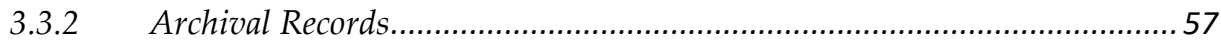

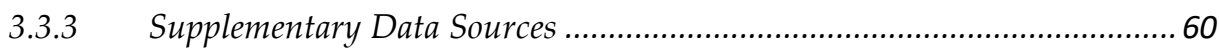

3.4 METHODOLOGICAL CHALLENGES AND ETHICAL CONSIDERATIONS .................65

4. THE HISTORY OF GLOBAL MIGRATION GOVERNANCE ........................67

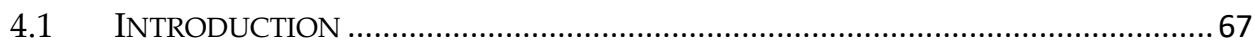

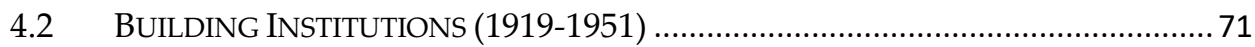

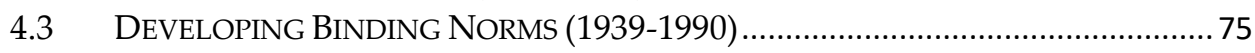

4.4 REGIONAL COOPERATION ON MigRATION (1985-PRESENT) ............................. 81 
4.5 THE QUEST FOR NEW GLOBAL ARRANGEMENTS (1991-2000)......................... 84

4.6 A NEW CENTURY: A NEW CHANCE? (2001-2006) ........................................... 87

4.7 THE ERA OF MIGRATION AND DEVELOPMENT (2006-2015)............................ 93

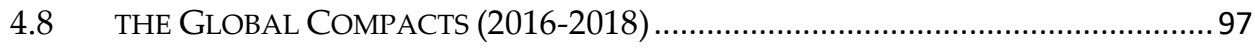

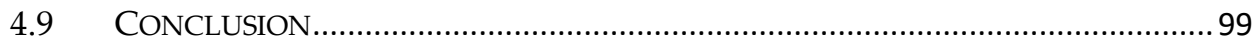

5. REFRAMING MIGRATION: THE GLOBAL FORUM ON MIGRATION AND

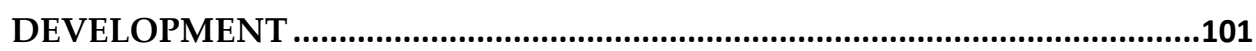

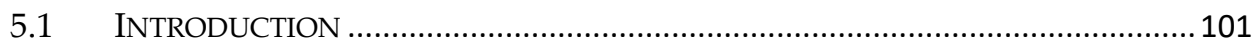

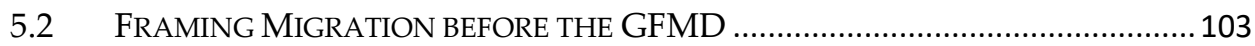

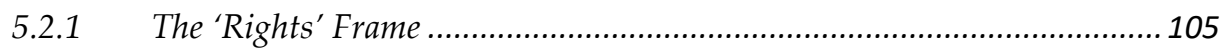

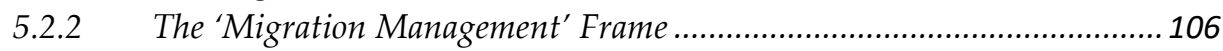

5.2.3 The 'Migration and Development' Frame .............................................. 108

5.3 THE GENESIS OF THE GLOBAL FORUM ON MigRATION AND DEVELOPMENT 110

5.4 THE ROLE OF PETER SUTHERLAND AS A POLICY BROKER ................................ 114

5.4.1 Breaking the Frame: Casting Doubt ........................................................ 116

5.4.2 Constructing the New Frame: Migration and Development.....................117

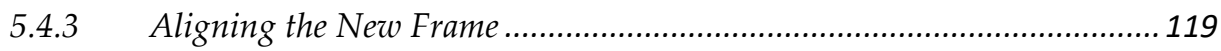

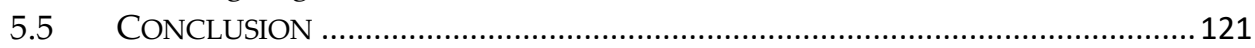

\section{MIGRATION AND DEVELOPMENT: A PASSING PHASE OR HERE TO}

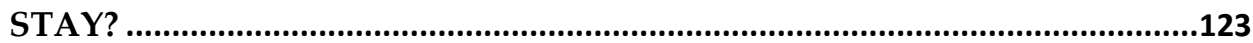

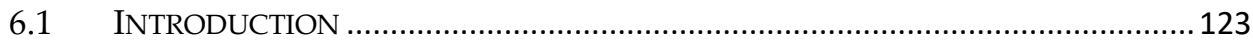

6.2 NEGOTIATING THE SUSTAINABLE DEVELOPMENT GOALS .............................. 125

6.3 ARGUING FOR THE INCLUSION OF MigRATION IN THE POST-2015

DEVELOPMENT AGENDA ....................................................................... 128

6.4 MigRATION IN THE SUSTAINABLE DEVELOPMENT GOALS.................................. 148

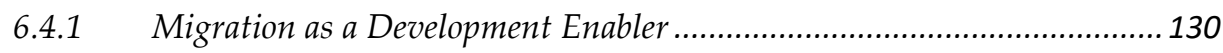

6.4.2 Migration as a Characteristic of Vulnerability........................................ 131

6.4.3 Migration as a Development Challenge................................................... 132

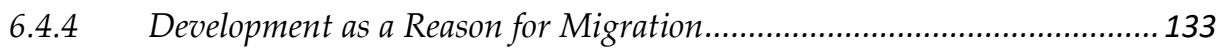

6.4.5 Displacement as a Development Challenge .............................................. 134

6.4.6 Migration and Development as a Unifying Frame.................................. 135

6.5 Negotiating a Place FOR MigRation in the Sustainable DEVELOPMENT

GOALS: THE ‘TWO-PRONGED’ APPROACH ................................................... 140

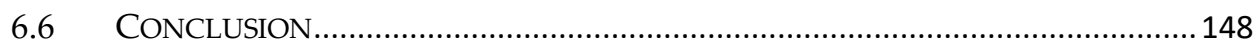

7. THE "PERFECT STORM"? FROM PROVISIONAL COMMITTEE TO UN MIGRATION AGENCY .......................................................................155

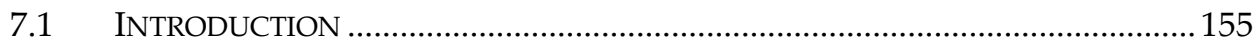

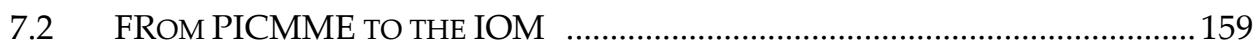


7.3 THE NINETIES: IOM MOVES CLOSER TO THE UN ………………………........ 164

7.4 IOM-UN RELATIONS AS `MIGRATION’ RECEIVES MORE ATTENTION ..............167

7.5 THE ROAD TO 2016: THE FEAR OF BEING LEFT BEHIND ...................................174

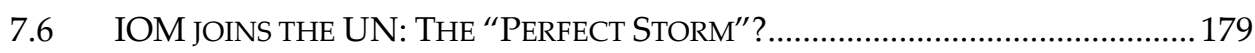

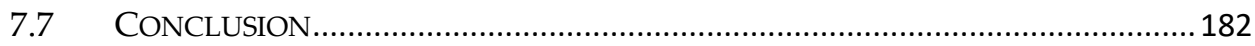

8. RESPONDING TO CRISIS? THE GLOBAL COMPACTS.............................185

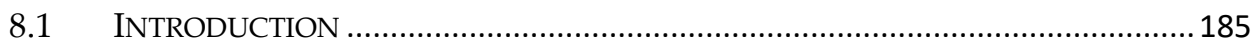

8.2 THE GENESIS OF AN IDEA: ONE COMPACT BECOMES TWO ………………....... 190

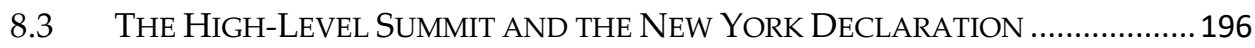

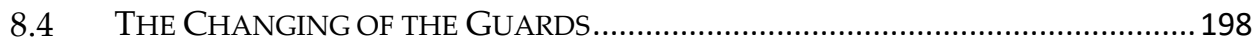

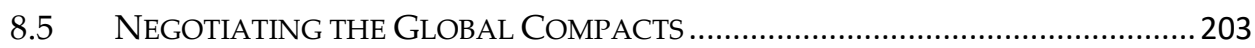

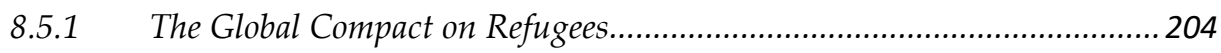

8.5.2 The Global Compact for Safe Orderly and Regular Migration.................. 206

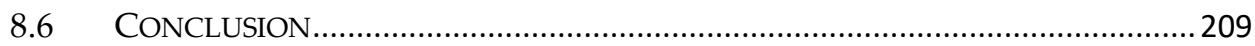

\section{CONCLUSION: INTERNATIONAL ORGANIZATIONS AND GLOBAL} MIGRATION GOVERNANCE ....................................................................211

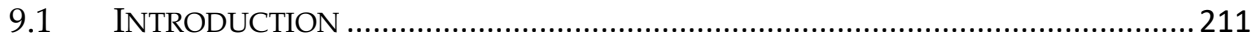

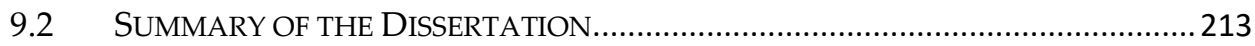

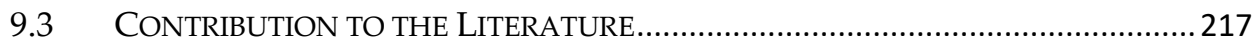

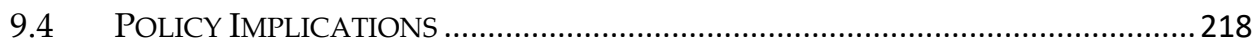

9.5 LIMITATIONS AND AVENUES FOR FUTURE RESEARCH .......................................219

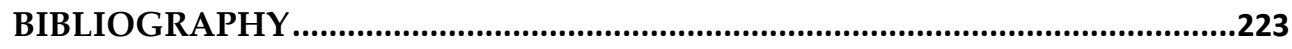

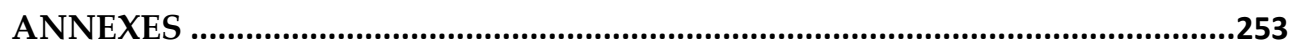

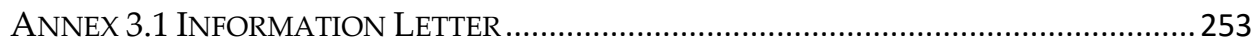

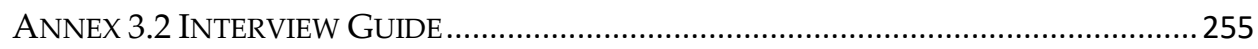

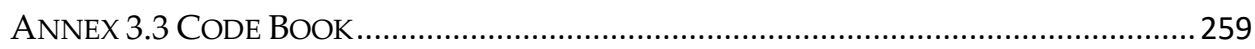

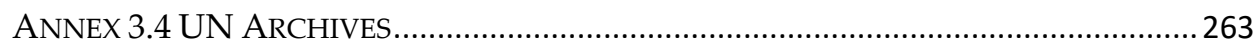

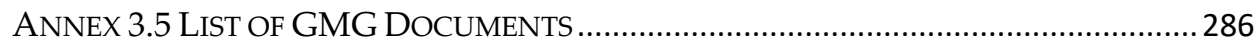

ANNEX 4.1 Timeline: THE History OF Global Migration GOVERnANCE............291

ANNEX 4.2 COMPARING THE MigRATION FOR EMPLOYMENT CONVENTIONS, ..........297

ANNEX 4.3: INTER-STATE CONSULTATION MECHANISMS ……………………….......299

ANNEX 6.1 SELECTED MigRATION REFERENCES IN THE SDGs...................................301

ANNEX 6.2 MigRATION REFERENCES IN UNTT THEMATIC THINK PIECES ..................305

ANNEX 8.1 COMPARING OBJECTIVES ACROSS GCM DRAFTS.........................................308

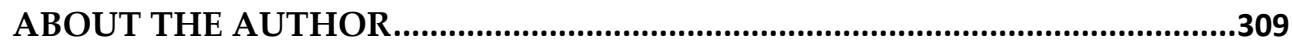

VALORIZATION ....................................................................................................311 


\section{List of Figures}

Figure 2.1 Number of International Organizations, 1919-2013 ........................... 24

Figure 2.2 Number of Conventional Intergovernmental Organizations, 1919-2013 25

Figure 2.3 The Relationship between States and IOs ........................................ 33

Figure 2.4 Contextualising the Relationship between States and IOs.................... 36

Figure 3.1 Documents Linking Migration to the Post-2015 Development Agenda 64

Figure 4.1 UN Membership, 1945-2019........................................................ 76

Figure 4.2 Word Frequency in GFMD Chair Reports, 2007-2016 ........................ 95

Figure 6.1 Arguments for Including Migration in the SDGs by Habermas' Categories

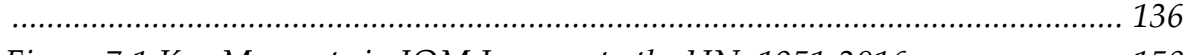

Figure 7.1 Key Moments in IOM Journey to the UN, 1951-2016 ....................... 158

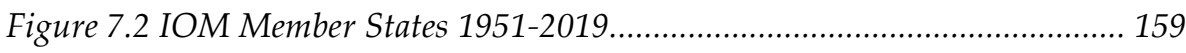

Figure 8.1 Global Compact Timeline ............................................................ 189 


\section{List of Tables}

Table 3.1 Factors Influencing Global Migration Governance .................................. 48

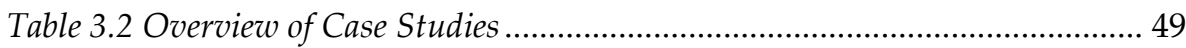

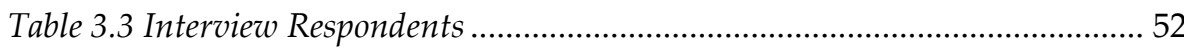

Table 3.4 Respondents, by Age Cohort and Sex ................................................... 54

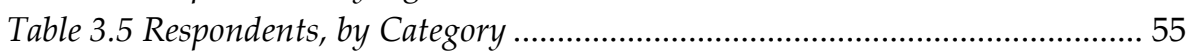

Table 3.6 Summary of Thematic Coding............................................................... 57

Table 3.7 The UN Archives, Building the Corpus ................................................ 58

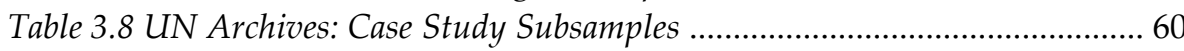

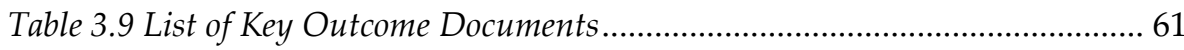

Table 3.10 SDG Documents, Inclusion and Exclusion Criteria ...................................... 63

Table 4.1: The History of Global Migration Governance ......................................... 70

Table 4.2 Ratifications of Key Migration Relevant Conventions.............................. 79

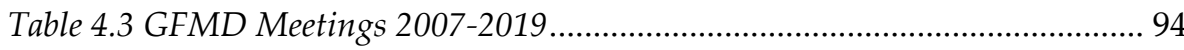

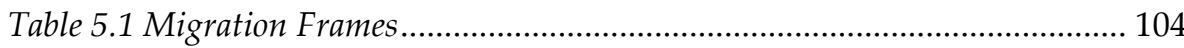

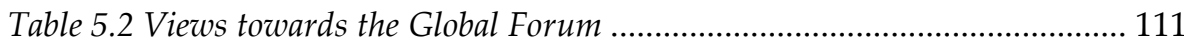

Table 6.1 Timeline of SDG Negotiations ........................................................... 126

Table 6.2 Explicit Migration References in the Sustainable Development Goals .. 149

Table 6.3 Arguments for Including Migration in the SDGs using Habermas...... 137

Table 7.1 Movements facilitated by ICEM, 1952-1961 ........................................ 161

Table 7.2 Pros and Cons of IOM Joining the UN Legal status for staff ................ 169

Table 8.3 Comparing the Negotiations of the GCR and GCM ............................. 204 


\section{List of Acronyms}

CEB Chief Executive Board for Coordination

DESA UN Department of Economic and Social Affairs

ECOSOC UN Economic and Social Council

EU European Union

FAO Food and Agricultural Organization

GATS General Agreement on Trade in Services

GATT General Agreement on Trade and Tariffs

GCIM Global Commission on International Migration

GCM Global Compact for Safe, Orderly and Regular Migration

GCR Global Compact on Refugees

GFMD Global Forum on Migration and Development

GMG Global Migration Group

HLD High-Level Dialogue

HLP High-Level Panel of Eminent Persons

HLPF High-Level Political Forum

ICEM Intergovernmental Committee for European Migration

ICM Intergovernmental Committee for Migration

ICMPD International Centre for Migration Policy Development

ICPD International Conference on Population and Development

ICRMW International Convention on the Protection of the Rights of All Migrant Workers and Members of Their Families

IDP Internally Displaced Persons

IFAD International Fund for Agricultural Development

IGC Intergovernmental Consultations on Migration, Asylum and Refugees

IGO Intergovernmental Organization

ILO International Labour Organization

IMF International Monetary Fund

IO International Organization

IOM International Organization for Migration 


\begin{tabular}{|c|c|}
\hline IRO & International Refugee Organization \\
\hline MDGs & Millennium Development Goals \\
\hline MICIC & Migrants in Countries in Crisis \\
\hline NGO & Non-Governmental Organization \\
\hline NYD & New York Declaration \\
\hline OCHA & UN Office for the Coordination of Humanitarian Affairs \\
\hline OECD & Organization for Economic Cooperation and Development \\
\hline $\mathrm{OHCHR}$ & $\begin{array}{l}\text { Office of the United Nations High Commissioner for Human } \\
\text { Rights, }\end{array}$ \\
\hline OWG & $\begin{array}{l}\text { Open Working Group (OWG) of the General Assembly on } \\
\text { Sustainable Development Goals }\end{array}$ \\
\hline PGA & President of the General Assembly \\
\hline PICMME & $\begin{array}{l}\text { Provisional Intergovernmental Committee for the Movement of } \\
\text { Migrants from Europe }\end{array}$ \\
\hline RCP & Regional Consultative Process \\
\hline SDGs & Sustainable Development Goals \\
\hline SRSG & Special Representative of the Secretary-General \\
\hline UK & United Kingdom of Great Britain and Northern Ireland \\
\hline UN & United Nations \\
\hline UN Women & $\begin{array}{l}\text { United Nations Entity for Gender Equality and the } \\
\text { Empowerment of Women }\end{array}$ \\
\hline UNAIDS & The Joint United Nations Programme on HIV/AIDS \\
\hline UNCT & UN Country Teams \\
\hline UNCTAD & United Nations Conference on Trade and Development \\
\hline UNDAF & UN Development Assistance Frameworks \\
\hline UNDG & UN Development Group \\
\hline UNDP & United Nations Development Programme \\
\hline UNEP & United Nations Environmental Programme \\
\hline UNESCO & $\begin{array}{l}\text { United Nations Educational, Scientific and Cultural } \\
\text { Organization }\end{array}$ \\
\hline UNFCCC & United Nations Framework Convention on Climate Change \\
\hline UNFPA & United Nations Population Fund \\
\hline UNGAOR & United Nations General Assembly Official Records \\
\hline UNHCR & United Nations High Commissioner for Refugees \\
\hline
\end{tabular}




$\begin{array}{ll}\text { UNICEF } & \text { United Nations Children's Fund } \\ \text { UNIDO } & \text { United Nations Industrial Development Organization } \\ \text { UNISDR } & \text { UN Office for Disaster Risk Reduction } \\ \text { UNITAR } & \text { United Nations Institute for Training and Research } \\ \text { UNODC } & \text { The United Nations Office on Drugs and Crime } \\ \text { UNOG } & \text { UN Office at Geneva } \\ \text { UNRRA } & \text { United Nations Relief and Rehabilitation Administration } \\ \text { UNRWA } & \text { United Nations Relief and Works Agency for Palestine Refugees } \\ \text { UNTT } & \text { Un the Near East } \\ \text { UNU } & \text { United Nations University } \\ \text { US } & \text { United States of America } \\ \text { WFP } & \text { World Food Programme } \\ \text { WHO } & \text { World Health Organization } \\ \text { WTO } & \text { World Trade Organization }\end{array}$





\section{Introduction}

Propelled into the spotlight by governments, primarily in Europe, facing increased numbers of migrants, including refugees, migration has not witnessed such sustained global attention in recent history. A series of 'migration crises' around the world in 2015 demonstrated the limits of the existing international architecture leading states to reconsider the international response to migration. In October 2016, in addition to the International Organization for Migration (IOM) joining the United Nations (UN), 193 UN Member States unanimously agreed upon the New York Declaration (NYD) at the closing of the High-Level Summit for Refugees and Migrants, to commit themselves to negotiate two Global Compacts by 2018, one on migration and the other on refugees. This decision commenced two years of consultations and negotiation, which concluded with the adoption of a Global Compact on Refugees (GCR) and a Global Compact for Safe, Orderly and Regular Migration (GCM) in December 2018. By bringing IOM into the UN system and endorsing a comprehensive set of, albeit non-binding, commitments, states acknowledged migration as a global governance issue and accepted the necessity of institutionalizing migration within the UN. Next to the migration crises of 2015, which provided the necessary 'window of opportunity' to pursue institutional change, however, this dissertation argues that reframing migration as a development issue by the UN was key to the process of institutionalizing migration into the UN. The inclusion of migration in the Sustainable Development Goals (SDGs) in 2015 was a key milestone securing consensus among UN Member States that migration, an issue previously held at arms-length from the $\mathrm{UN}$, was indeed relevant to its mandate. Hence, the dissertation investigates how migration became a global governance issue, and the role played by the $\mathrm{UN}$ in this process.

Building on theoretical insights from the Advocacy Coalition Framework (ACF), and the methodological principles of process-tracing, the dissertation tells the story of how migration has evolved as a global policy issue since 1919. In operationalizing the concept of constitutive power, framing analysis is used to analyse the different ways that migration has been framed, by whom, and to what end. Drawing on interviews with 43 key protagonists, actors involved in global-level discussions on migration, and the UN archives, the dissertation explores four case studies that shed light on how international organizations have influenced global migration governance: 
1) the creation of the Global Forum on Migration and Development (GFMD) (Chapter 5);

2) the inclusion of migration in the Sustainable Development Goals (SDGs) (Chapter 6);

3) IOM's journey to becoming a UN agency (Chapter 7);

4) the negotiation of the Global Compact for Safe, Orderly and Regular Migration (GCM) (Chapter 8).

The dissertation argues that the migration crises of 2015 which propelled migration into the political limelight; the reframing of migration as a development issue (Chapter 5) and the subsequent inclusion of migration in the Sustainable Development Goals (Chapter 6); coupled with the increasing likelihood that the UN would appoint or create a new body for migration within the UN, led IOM's Member States to conclude that IOM needed to become part of the UN system in 2016 (Chapter 7). However, while the migration crises of 2015 created the necessary 'window of opportunity' to bring IOM into the UN, it also provided a fertile environment for advocates of the migrant rights frame to revive their struggle for universal norms to govern international migration (Chapter 8). The remainder of this introductory chapter is structured as follows. First, the background and relevance of the dissertation are established (Section 1.1). Section 1.2 then outlines the research aims and questions (Section 1.2). The final section summarizes the overall structure of the dissertation (Section 1.3).

\subsection{Background and Relevance}

As recently as the 1990s, migration was mostly absent from international policy discussions. In the lead up to the adoption of the Millennium Development Goals (MDGs) in 2000, there were discussions among international actors regarding whether to include migration; however, it was not feasible to get states to agree on targets on migration (Skeldon, 2013). In the early 2000s, potentially as a result of (unfounded) optimism regarding the role of remittances in take-off development (de Haas, 2010), or due to the exclusion of migration from the Millennium Development Goals (MDGs), efforts to institutionalize migration as a UN issue witnessed new energy (Brønden, 2012). In 2002, then Secretary-General Kofi Annan identified a need to 'take a more comprehensive look at the various dimensions of the 
migration issue ${ }^{\prime 1}$ (para. 39). He thus requested his advisor, Professor Michael Doyle, to prepare a report on the possibilities for furthering international cooperation on migration. In his report, the so-named 'Doyle Report', several options were considered, including the creation of a new global organization for migration. However, the report largely concluded that consensus on migration issues at the international level was too weak and fragmented to support the idea of creating a new global organization, be it through the designation of an existing organization as 'lead agency', merging existing organizations, or creating a new one. The report concluded that the best interim solution would be to enhance inter-agency coordination and pay more attention to the management of international migration.

Although dismissed at the time, one of the main arguments for creating a global body on migration, or for either merging or appointing an existing body, related to the fragmented nature of global migration governance. According to Papademetriou (2011), global governance of migration can be 'loosely defined as the creation of a more or less formal set of norms and rules to regulate the behaviour of states with respect to the movement of people across international borders' (p.1; own emphasis). While definitions of global governance often focus on the 'norms, rules, principles and decision-making procedures that regulate the behaviour of states (and other transnational actors)' (Betts, 2011, p.4), Papademetriou's definition of global migration governance draws attention to the temporal, processual nature of governance and is adopted as the working definition of global migration governance in the dissertation.

The absence of an overarching global framework for the governance of international migration has been subject to ongoing discussions over the past decade (Newland, 2010; Koser, 2010; Marchi, 2010; Betts, 2011; Martin, 2015). In other fields, such as trade, finance, and health, frameworks for multilateral cooperation exist, generally within the context of the UN system. For a long time, this was not the case for migration; however, as Betts (2011) argued, 'this is not to say that there is no global migration governance. Despite the absence of a 'top-down' multilateral framework, there is a rapidly emerging 'bottomup' global migration governance' (p.2). Betts (2011) described bottom-up global migration governance as 'a complex and fragmented tapestry of overlapping, parallel, and nested institutions' (p.2). Fragmentation describes the different institutional arrangements that have emerged for different

${ }^{1}$ Report of the Secretary-General: Strengthening of the United Nations: an agenda for further change, UNGAOR, $5^{\text {th }}$ Session, UN Doc A/57/387 (9 December 2002) 
categories of migrants. For example, refugees fall under the mandate of the United Nations High Commissioner for Refugees (UNHCR), and the 1951 Refugee Convention and its 1967 protocol provide UNHCR with the normative authority to protect refugees. Similarly, migrant workers have fallen under the normative mandate of the International Labour Organization (ILO) since its creation in 1919. The ILO oversees several normative instruments designed to protect the rights of migrant workers, albeit with significantly lower rates of ratification than the Refugee Convention. The reality that policy categories such as 'refugee', 'migrant worker' or 'irregular migrant' do not always neatly match the reality of human mobility, added to the fact that policies in other areas, such as the labour market or human rights, have implications for the patterns and governability of population movements, has led to overlap and often competition between international organizations. The result of this overlap is the existence of many organizations, most of which are nested within the UN system, for whom migration is relevant to their mandate. Membership in the now-defunct Global Migration Group (GMG) provides substance to this statement. Before being superseded by the UN Migration Network in 2019, 22 organizations were members of the GMG.

Much of the literature on global migration governance has focused on understanding how it has emerged (Geddes, 2018; Korneev \& Kluczewska, 2018). The literature on multilevel governance has informed much of the research in this area (cf. Lavenex, 2016; Bisong, 2018; Caponio and JonesCorrea, 2018; Marti, 2018; Scholten et al., 2018; Panizzon, 2011; Panizzon and van Riemsdijk, 2018; Kunz, Lavenex, and Panizzon, 2011). A typical starting point in the literature on global migration governance is its fragmented nature (Martin, 2015; Betts, 2011; Miller, 2000). This relates in part to the distinctively separate refugee and migration regimes (Betts, 2011; Long, 2013; Karatani, 2005), as well as to how, in the absence of an overarching global framework, questions relating to migration have been addressed across countries and regions. In this context, regional governance has been conceptualized as a stepping stone for more global cooperation (Thouez \& Channac, 2005; Lavenex, 2018).

In recent years, however, an emerging body of literature has started to shift the focus away from the study of events to a more ideational and processual focus (Piper, 2015). Korneev and Kluckzewska (2018) conceptualize international organizations as global governors which, they argue, 'shifts the focus from global migration governance as an emerging structure to global migration governors as sources of agency and, consequently, to the outcomes 
that flow from interactions between various agents' (p.57). This view is reflected in a growing body of literature that examines the role of international organizations in migration governance ${ }^{2}$ and is also mirrored by a similar shift in the study of international organizations (Barnett and Finnemore, 2004). Generally speaking, these studies have focused on individual organizations, primarily UNHCR and IOM, with a few notable exceptions focusing on the interaction between two or more organizations (Elie, 2010; Hall, 2013, 2015; Koch, 2014; Korneev, 2013; Lavenex, 2016; Poutignat \& Streiff-Fénart, 2010; Wunderlich, 2012). Among the recurring arguments in this body of literature is the idea that the delegation of authority by states to IOs is a way of diffusing accountability and furthering the interests of developed countries (cf. Brachet, 2016; Valarezo, 2015; Ashutosh and Mountz, 2011; Andrew and Eden, 2011; Geiger and Pécoud, 2014). IOM, in particular, has faced criticism in the literature for their role in depoliticizing migration through its advocacy of the migration management approach (Brachet, 2016; Caillault, 2012; Collyer, 2012; Geiger \& Pécoud, 2014; Georgi, 2010; Georgi \& Schatral, 2012; Koch, 2014; Korneev, 2014). However, a theoretical contradiction is embedded here. On the one hand, international organizations are conceptualized as independent actors able to exert influence, reflecting the ideational shift in the study of international organizations (Barnett and Finnemore, 2004; Broome and Seabrooke, 2012); but on the other, they are still primarily viewed as instruments of powerful states (Keohane \& Nye, 1974; Mearsheimer, 1995). Less attention has been given to the role of IOs in framing migration as a global policy issue.

Although the framing literature has been used in the context of migration research, scholars primarily use its tools to study media representations of migrants (c.f. Van Gorp, 2005; Vliegenthart and Roggeband, 2007; Balabanova and Balch, 2010; Cheng et al., 2011; Pajnik, 2010; Sommer and Ruhrmann, 2010; Helbling, 2014; Brouwer, van der Woude, and van der Leun, 2017; Greussing and Boomgaarden, 2017; Lawlor, 2017; and Georgiou and Zaborowski, 2017) or to study the evolution of migration policy in different contexts (c.f. Boswell, 2007; Roggeband and Verloo, 2007; Helbling, 2014;

\footnotetext{
2 See for example: Amaya-Castro, 2012; Andrew and Eden, 2011; Andrijasevic and Walters, 2010; Ashutosh and Mountz, 2011; Barnett and Finnemore, 2004; Betts and Durieux, 2007; Brachet, 2016; Caillault, 2012; Elie, 2010; Feldblum, 1999; Frowd, 2014; Geiger, 2010; Georgi and Schatral, 2012; Hall, 2013; 2015; Hartigan, 1992; Hess, 2010; Hoffmann, 2016; Koch, 2014; Korneev, 2013; 2014; Lavenex, 2016; Loescher, 2001; Nieuwenhuys and Pécoud, 2007; Pécoud, 2010; Poutignat and Streiff-Fénart, 2010; Roper and Barria, 2010; Scalettaris, 2010; Schatral, 2011; Scheel and Ratfisch, 2014; Valarezo, 2015; Vollmer, 2016; and Wunderlich, 2012
} 
Menz, 2015; Ransan-Cooper et al., 2015; and Delgado Wise, 2018a). Another more diverse body of literature focuses on specific frames, albeit with less consistent application of framing analysis, often only using the term 'frame' descriptively (c.f. Bardsley and Hugo, 2010; Dyer, 2010; Balch and Geddes, 2011; Bleich, 2011; Boswell, Geddes, and Scholten, 2011; Scholten, 2011; Carrera and Hernanz, 2015; and Dehm, 2015). Three commonly studied frames are:

1. migration management (c.f. Carrera and Hernanz, 2015; Ashutosh and Mountz, 2011; Scheel and Ratfisch, 2014; Valarezo, 2015; Caillault, 2012; Dini, 2018; Georgi and Schatral, 2012; Oelgemöller, 2011;

2. migration and development (c.f. Bakewell, 2008; Skeldon, 2008; Raghuram, 2009; Schiller, 2009; de Haas, 2010; 2012; Gamlen, 2010; Brønden, 2012); and

3. human rights (c.f. Cook, 2010; Jordan, 2002; Pécoud and de Guchteneire, 2007; Rother, 2018; Cholewinski and Taran, 2009; Basok and Piper, 2012; Dyer, 2010).

While these frames are often studied in isolation, Boswell (2007) argues that limiting one's focus to a particular frame 'may constrain observation of alternative trajectories in the framing of migration issues' (p.592). What is missing from the existing literature is a systematic analysis of how migration has evolved as a global policy issue.

\subsection{Research aim and questions}

Beyond contributing empirical data to support a more comprehensive understanding of the evolution of global migration governance, and the role played by the UN herein, the dissertation also aims to make several theoretical and methodological contributions to the literature.

Explicitly, the dissertation assesses the appropriateness of the Advocacy Coalition Framework (ACF) to the global policy process and establishes connections between different disciplinary approaches to the study of governance. Furthermore, in addition to suggesting some theoretical augmentations to the $\mathrm{ACF}$ to increase its appropriateness as a theoretical framework through which to study the global policy process, it also tests a potential research design that could be replicated for other global policy areas. 
This dissertation also seeks to push forward thinking on international organizations by paying attention to the interaction of factors that have influenced the evolution of global migration governance with a specific focus on how international organizations have affected and been affected by these developments. In so doing, it takes migration as a global policy issue, conceptualized as the migration policy subsystem, as its central unit of analysis. By applying a governance lens (specifically resource exchange between actors in policy networks) to the question of the autonomy of international organization, the dissertation contributes to two distinct bodies of literature:

1) the literature on discursive institutionalism. Schmidt (2010) calls on researchers to focus on showing, by empirical means, 'how, when, where and why ideas and discourse matter for institutional change, and when they do not' (Schmidt, 2010, p.21). The literature on governance often focuses on the first two pillars of institutionalization, norms, and institutions, and less on the role of discourse in the process of institutionalization;

2) the literature on the behavioural logic of international organizations, which addresses a previous scarcity in research that treats IOs as actors in their own right (Barnett \& Finnemore, 2004; Broome \& Seabrooke, 2012).

By conceptualizing global governance as the site in which networks of actors, including international organizations, struggle to define and solve global problems, the dissertation offers a bridge between different disciplinary perspectives and brings power into the picture. Accordingly, the main research question addressed in this dissertation is as follows:

\section{How have international organizations influenced global migration governance?}

To address the main research question, the dissertation examines several theoretical and empirical sub-questions. In establishing the theoretical and conceptual framework for the dissertation:

a) What is global (migration) governance? (Chapter 2)

b) What are international organizations, and, specifically, what influences the autonomy of international organizations? (Chapter 2) 
c) How do international organizations exert influence? (Chapter 2)

In empirically addressing the research question:

d) How has global migration governance evolved over the past century? (Chapter 4)

e) How did international organizations mobilize the 'migration and development' frame in order to further international cooperation on migration in:

f) the creation of the Global Forum on Migration and Development? (Chapter 5)

g) the inclusion of migration in the Sustainable Development Goals (SDGs) (Chapter 6)

h) Why did IOM become a related agency of the UN in 2016? (Chapter 7)

i) How did the migration crises of 2015 affect how different actors framed migration as a global policy issue? (Chapter 8)

\subsection{Structure of the study}

The remainder of the dissertation is structured as follows. Chapter 2 provides the conceptual underpinnings of the thesis. The chapter first discusses our two main variables of interest: governance and international organizations. To ground the discussion of global migration governance within the broader governance literature, Chapter 2 develops the concept of governance drawing on and synthesizing research from different disciplinary perspectives, most notably, those of international relations and public policy. Having established that governance is both the process and product of the interaction of resourcedependent actors operating in networks around different policy issues of international relevance, international organizations are established as key actors in this process. However, the extent to which IOs can exert influence is determined by their level of autonomy, which is, in turn, shaped by states. States delegate authority to IOs to address challenges where intergovernmental cooperation is deemed more efficient than unilateral efforts and, increasingly, to achieve broader collaborative goals, such as global economic development or world peace. However, underpinning this relationship is the impulse of states to preserve their sovereignty. The 
relationship between states and IOs is therefore theorized as one in which a careful balancing act exists between states delegating enough authority for them to be effective, but not too much that it would challenge state sovereignty. However, it is neither sufficient to remove this relationship from its context nor to homogenize states or international organizations. The advocacy coalition framework assists us with situating the relationship between states and IOs into a framework that recognizes the factors that may influence the relationship, and thus governance as an outcome, at three levels: 1) factors internal to states and IOs; 2) factors specific to the policy subsystem; and 3) external factors.

Building on the theoretical framework, Chapter 3 outlines the methodological approach. The overall research design is inspired by process tracing, which is a family of methods often applied by historians and International Relations (IR) scholars in their efforts to understand why certain events occur. However, unlike traditional process tracing, which is often neo-positivistic, this dissertation follows an interpretive approach to adequately address the question of how IOs can exercise constitutive power. The concept of constitutive power is operationalized using framing analysis. With these broad design questions addressed, the chapter then outlines a five-stage research process: 1) soaking and poking; 2) constructing a timeline; 3) identifying key factors; 4) case selection; and 5) case study implementation. After constructing the initial timeline, four cases were selected for closer examination:

1) the creation of the Global Forum on Migration and Development (GFMD) at the first High-Level Dialogue on International Migration and Development (HLD) in 2006 (Chapter 5);

2) the inclusion of migration in the SDGs (Chapter 6);

3) IOM's journey to the UN (Chapter 7) and

4) the genesis of the Global Compacts (Chapter 8).

In Chapter 3, the rationale for selecting each case is explained. Two key data sources were used throughout the dissertation. Firstly, semi-structured qualitative interviews were conducted with 43 key actors involved in the journey. The interview material was complemented by the analysis of a corpus of documents $(n=510)$ extracted from the UN Archives. Supplementary data were also used to improve the analysis where appropriate.

Chapter 4 sets the context for the dissertation by critically analysing the evolution of the global migration governance landscape from 1919 to 2018, 
establishing a timeline for the several critical events that took place. In doing so, the chapter demonstrates that, while historical accounts of its evolution are often presented linearly, a degree of cyclicity exists through which certain 'trigger events', such as the 1973 Oil Crisis or the end of the Cold War, influenced the perceived need for international cooperation on migration. In addition to cyclicity, the chapter also provides evidence of different trajectories in the evolution of global migration governance, depending on whether one views migration as a matter of human rights or as a management issue.

Chapter 5 investigates the genesis of the GFMD. The GFMD is an annual informal, state-led, non-binding gathering during which states discuss migration-related topics. The GFMD was launched at the first HLD in 2006. The first meeting of the GFMD was held in Brussels, Belgium, in 2007, and it continues to happen on an almost annual basis. The late Sir Peter Sutherland, appointed by Kofi Annan to be his Special Representative to guide the HLD in 2006, essentially spearheaded the GFMD. The core argument of the chapter is that the 'migration and development' frame was deliberately used by the $\mathrm{UN}$ to overcome conflicts that had hindered previous efforts at international cooperation on migration. The argument that the GFMD presented an opportunity to reframe migration in a way that would allow progress in international dialogue on migration is neither new nor hidden (Sutherland, 2013a; Roldan and Gasper, 2010; Rother, 2018). However, researchers have rarely examined the emergence of the GFMD empirically. Hence, this chapter provides an empirical example of how IOs can exercise constitutive power.

The inclusion of migration in the SDGs is said to have brought migration more generally, and IOM specifically, into the UN. While the way migration has been included in the SDGs has been subject to empirical examination, the process leading up to their adoption, particularly from a framing perspective, is less well documented. Having argued in Chapter 5 that the reframing of migration as a development issue was instrumental in furthering international cooperation on migration, Chapter 6 examines how actors from different advocacy coalitions engaged rhetorically with the 'migration and development' frame. To achieve this, the chapter analyses the arguments put forward by various actors in the years preceding the adoption of the SDGs to justify why migration should be included in these goals. Chapter 6 demonstrates how the migration and development frame successfully galvanized the positions of different actors as they sought a place for migration in the Sustainable Development Goals. 
On 19 September 2016, then Secretary-General of the UN, Ban Ki-moon and Director-General of the IOM, William Lacy Swing, signed an agreement which, for the first time in its history, brought IOM into the UN system. Chapter 7 traces IOM's journey from the small, temporary intergovernmental organization created in 1951 as the Provisional Intergovernmental Committee for the Movement of Migrants from Europe (PICMME) to its entry into the $\mathrm{UN}$ as a 'related agency' in 2016. The chapter focuses on three key periods during which IOM's relationship with the UN was subject to intense discussion. In the early 1990s, IOM's relationship with the UN became more formal. IOM became a charter member of what would become the UN Office for the Coordination of Humanitarian Affairs (OCHA) in 1991. In 1992, IOM signed an agreement which gave the organization observer status at the UN, and, in 1996, signed a Cooperation Agreement to specify the parameters of the IOM-UN relationship further. In the early 2000s, the UN had started to take a more serious look at its portfolio on migration. Although the subject of IOM joining the UN was put on the agenda at IOM Council Meetings in 2002, IOM's Member States ultimately decided against formally entering the UN, and instead agreed to look at how to strengthen existing arrangements. However, in 2016, IOM became a UN 'related agency'. The core purpose of this chapter is to understand the factors that tipped the scales in favour of UN membership by focusing on each of these three moments. In line with the theoretical framework, IOM is conceptualized as a resource-dependent actor whose actions and decisions are a function of internal and external factors. Accordingly, specific attention is placed on how IOM reacted to external events that had implications for its survival as an organization.

In December 2018, 181 Member States voted in favour of the adoption of the Global Compact on Refugees (GCR), and 153 Member States voted in favour of the Global Compact for Safe, Orderly and Regular Migration (GCM) at the UN General Assembly. The Global Compacts represent the first time that states have explicitly negotiated an overarching framework for the governance of migration. Chapter 8 examines how the migration crises of 2015, primarily in Europe but also in the Andaman Sea and Central America, presented a window of opportunity for those seeking to strengthen the role of the UN in the area of migration. Paradoxically, while migration crises may be viewed as a failure of multilateralism, crises can also present the opportunity to deepen multilateral responses. However, in responding to the 'migration crises' of 2015, the fault lines between different coalitions of actors appear to have resurfaced. The chapter examines the emergence of the Global Compacts focusing on two areas where polarization seems to have become more pronounced because of the crisis: 1) between the refugee and migration 
regime; 2) between the human rights frame and the migration management frame.

The final chapter concludes the dissertation by summarizing the main academic findings of the research and its policy implications. The concluding chapter also highlights the limitations of the study and suggests avenues for future research. 


\section{International Organizations and Global Migration Governance}

\subsection{Introduction}

This chapter provides the conceptual and theoretical departure point for the research. As a reminder, the key question guiding this dissertation is as follows: how have international organizations influenced global migration governance? The question already establishes two variables of interest, international organizations and (global migration) governance, and assumes a relationship of dependency between them. The question also suggests that international organizations (IOs) influence governance. However, international organizations are also a constituent part of governance established by states to address particular challenges. Section 2.2 thus builds the conceptual underpinning of the dissertation by first exploring the concept of (global) governance (Section 2.2.1) and then the concept of international organization(s) (Section 2.2.2). With governance established as the dispersion of authority, often, but not exclusively to international organizations, Section 2.2.3 turns to consider two interrelated concepts that mediate the relationship between international organizations and governance: power and authority. Building on this, Section 2.3 conceptualizes the relationship between international organizations and states as being a two-way relationship in which states can exercise influence over international organizations, but the reverse can also be true. How these relationships play out in practice is the product of the interaction between factors that, in line with the advocacy coalition framework (ACF), can be categorized into three levels: internal factors, factors specific to the 'policy subsystem', and external factors. Equipped with this framework, Section 2.4 discusses the implication of the framework to the case of global migration governance. 


\subsection{Key Concepts}

\subsubsection{Governance}

A common starting place for defining a concept is its etymological roots. Governance finds its roots in the Greek verb kubernân meaning to pilot or to steer and in the Latin gubernare, which has similar connotations (Kjær, 2004). However, governance, as with many concepts in the social sciences, is an ambiguous term, used by both academics with different disciplinary alignments as well as practitioners in numerous ways. Conceptual ambiguity in the theoretical and practical applications of the term governance is well recognized (for just a few examples see Cruz, 2015; Finkelstein, 1995; Hewitt de Alcántara, 1998; Jessop, 1998). Whitman's (2009b) edited collection on global governance showcases this with chapters on governance as: 'international organization' (Weiss \& Kamran, 2009); 'configurations of state/non-state activity' (Porter, 2009); 'liberal hegemony' (Friedrichs, 2009); 'public policy networks and partnerships' (Steets, 2009); 'sector-specific management' (Whitman, 2009a); and as a 'summative phenomenon' (Knight, 2009). Given the complexities and expansive nature of the literature on governance, this section identifies core features of governance and approaches to its study, in order to inform the research design and subsequent analysis.

Although the application of the term has earlier roots $^{1}$, the revival of governance as a concept within the social and political sciences in the 1990s coincided with changes that challenged existing conceptualizations of the relationship between state and society in the post-Cold War context. Globalization, defined here as the increased interconnectedness of localities driven by, among other factors, advancements in technology (such as communication and transport), the proliferation of large international corporations and the transition towards market economies in most countries of the world (Friedman, 2000), has increased the complexity of policy problems and as such arguably reduced the ability of states to govern effectively. Another significant change in state-society relations accompanied concerns regarding the sustainability of the welfare state in many countries in

1 See for example Pagden (1998) on Kant's ius cosmopoliticum as the genealogy of global governance. 
the Global North. Many states began to follow in the footsteps of neoliberal figureheads such as Ronald Reagan and Margaret Thatcher, and a wave of privatization of previously public services ensued (George \& Wilding, 1994). With the addition of non-state actors in the policy process, governments faced increased challenges, particularly regarding policy implementation. With lessened control over policy outcomes, governing became more complex.

While an oversimplification, different strands of the governance literature speak broadly to these trends. The first relates to how states maintain control over policy outcomes in the presence of increasingly complex policy networks of public and private actors at the national, sub-national, and supra-national level. This complexity has arguably been the genesis of concepts such as 'new public management' (Hood, 1995), 'public-private partnerships' (Linder, 1999), and 'joined-up government' (Pollitt, 2003). Among public policy scholars, the work of Rod Rhodes has been particularly influential. In his 'hollowing out of the state' thesis, Rhodes argues that the delegation of state functions to private actors has fragmented service delivery posing coordination challenges that affect the ability of states to exert direct control over policy outcomes (Rhodes, 1994, 1997; Skelcher, 2000). Accordingly, Rhodes (1997) defined governance as 'self-organizing interorganizational networks characterized by interdependence, resource-exchange, rules of the game, and significant autonomy from the state' (p.15). From a government perspective, governance is what governments do to co-ordinate and exert influence over these networks of actors, often service providers, to achieve their policy goals.

One of the most cited analytical tools applied to the study policy networks is the advocacy coalition framework (ACF), which was first developed by Sabatier and Jenkins-Smith (1988) as an alternative to the policy cycle approach. The ACF has since developed, and it has been applied to a multitude of different polices areas (Sabatier \& Weible, 2007; Weible, 2008; Weible et al., 2009, 2011; Pierce et al., 2017). A core feature of the original ACF was that it 'purposely avoids a linear depiction of the policy process' (Weible et al., 2009, p.133). By taking the policy subsystem, defined by Sabatier (1988) as the 'set of actors who are involved in dealing with a policy problem' (p.138) as its unit of analysis, the ACF encourages scholars to focus on the interactions of actors belonging to different coalitions in order to understand policy change. In further operationalizing the concept of governance and the role of international organizations herein, the ACF will be discussed further in Section 2.3 and Chapter 3. 
On the other hand, governance, or perhaps more appropriately, global governance, has been used to describe the process of creating rules and structures that help to solve problems arising as a consequence of increasing interdependency. Rosenau's seminal definition of global governance, presented in the first issue of its eponymous journal, reads as follows:

'Global governance is conceived to include systems of rules at all levels of human activity - from the family to the international organization - in which the pursuit of goals through the exercise of control has transnational repercussions' (Rosenau, 1995, p.13).

This definition draws attention to the fact that it is not just governments or international organizations that can exercise authority, or steer, policy outcomes. However, it is also a broad definition, and, as Finkelstein (1995) noted, it is 'hard...to know what is excluded by that definition - or where to dig into the spaghetti bowl he puts on the table' (p.368). The broadness of Rosenau's (1995) definition is reflected in its diverse applications in the academic literature and in practice. Just a few examples include 'family governance' (cf. Miller and Le Breton-Miller, 2006; Berent-Braun and Uhlaner, 2012; Suess, 2014); 'higher-education governance' (cf. Dobbins, Knill, and Vögtle, 2011; Kerry, 2003) or 'corporate governance' (cf. Hart, 1995). Therefore, Finkelstein (1995) further specifies that 'global governance is governing, without sovereign authority, relationships that transcend national frontiers' (p.369; emphasis added). By this definition, global governance refers to the system of rules created outside of the national state context but with implications for policies relating to transnational problems

Thus, on the one hand, governance refers to the actions of governments navigating increasingly complex configurations of actors, and on the other to the solving of global problems through the creation of systems of rules for, and often by, these very same networks. Although these discussions have broadly taken place in disciplinary isolation, with the former being the focus of public policy scholars primarily working in national contexts, and the latter in international relations with a more global focus, interdisciplinarity in governance studies are increasingly commonplace. Nested 'between international relations and public policy' (Kjær, 2004, p.99) the multilevel governance model analyses the relationships between actors at different levels (sub-national, national, supranational) to understand how, and why, policy issues are governed in specific ways (Bache \& Flinders, 2004). This approach has been taken by many scholars who investigate global migration 
governance (Bisong, 2018; Caponio \& Jones-Correa, 2018; Kunz et al., 2011; Lavenex, 2016; Marti, 2018; Panizzon, 2011; Panizzon \& van Riemsdijk, 2018; Scholten et al., 2018). Where I depart from this literature is the testing of the suitability of the advocacy coalition framework, developed for the study of national policy development, to the global policy process.

While it is essential to consider the theoretical understandings of governance from the perspective of different disciplines, it is of equal importance to consider the application of the concept by practitioners. For some critics, 'global governance represents the aspirations of liberalism for hegemonic status, but given the shortage of social and political regulations at the global level, this aspiration is not borne out by reality' (Friedrichs, 2009 p.114). Hence, governance implies the shift of power from states to the market. This perspective is reflected in the ideologically driven perspectives of governance proposed by international financial institutions such as the World Bank and the International Monetary Fund (IMF), which, beginning in the 1980s, conditioned loans on governmental reform (Collier and Gunning, 1999), or socalled 'good governance' (Weiss 2000). In comparative politics, 'governance was brought into the equation with reference to the way in which institutions spanning the state-society divide were set up' (Kjær, 2004 p.124). Hence, governance is used to describe the roles that states play in society, the three main models being the economic liberal, the Keynesian, and the neoliberal. In these accounts, governance becomes more of a descriptive and technocratic term (de Senarclens, 1998). However, it also highlights the importance of acknowledging that actors with different ideological perspectives may seek to steer global governance as an outcome, in different directions (Weiss, 2000).

Despite different orientations, several characteristic features of governance can be derived from a comparison of approaches to governance research. The first is the role of networks of actors, both state and non-state, in the policymaking process (Rhodes, 1997; Rhodes, 2007; Dingwerth and Pattberg, 2009). Although international organizations are not the only actors involved in policy networks, they are a 'major centre of global governance' (Rosenau 1995 p.34), and thus, often the focus of research on global governance. The second is the centrality of 'authority' to governance definitions (Hewitt de Alcántara, 1998; Krahmann, 2003). Krahmann (2003) describes governance as 'the dispersion of authority' (p.13). This description is particularly apt since it fits both the idea of government outsourcing to private actors in the face of budgetary challenges, but also to the movement towards bilateral and multilateral responses to challenges that, owing to globalization, are firstly more pronounced, and secondly, more visible. 
The third characteristic feature of governance definitions, which is closely related to the notion of authority, is resources, or more precisely, the exchange of resources. This notion is often applied to draw attention to the power relations inherent in governance systems (Rhodes, 1997; Dingwerth and Pattberg, 2009). Dingwerth and Pattberg (2009) position resource exchange at the centre of their definition, operationalizing governance as 'the outcome of multiple resource exchanges among various actors' (p.42). By analysing patterns of resource exchanges in different policy networks, one can analyse the underlying factors that contribute to variations in governance as an 'end product'. The study of resources offers researchers an analytical path that goes beyond description and seeks to understand the power relations that underpin and sustain governance arrangements. Given that the notion of steering is so fundamental to the etymological roots of governance, it is surprising that power has not received more attention in contemporary governance research (Dingwerth \& Pattberg, 2009; Finnemore, 2014; Hurrell, 2017).

In framing the theoretical and methodological approach to this dissertation, global governance is conceptualized as the interactions of resource-dependent actors acting in networks to develop systems of rules to address policy problems that transcend national borders, as well as to the normative goals of these actors with respect to their vision of global problem-solving. With international organizations established as a 'major centre of global governance' (Rosenau, 1995 p.34), Section 2.1.2 turns to introduce the second variable of interest in the thesis: international organizations.

\subsubsection{International Organization(s)}

Claude (1964) makes the following distinction between international organization and international organizations:

International organization is a process; international organizations are representative aspects of the phase of that process which has been reached at a given time' (p.4; original emphasis).

Keeping in mind that global governance is broadly about solving problems that cannot be addressed by states alone, the notion of international 
organization as a process helps to conceptualize the role of international organizations, as actors. If international organizations are 'representative aspects' of progress in international organization as a process, then the study of international organizations is the study of global governance. However, international organization as a process and international organization as an entity require conceptual elaboration.

\section{International Organization as a Process}

International organization as a process can be understood differently depending on one's view of the state. On the one hand, international organization is the process of improving state efficiency through enhanced cooperation. On the other hand, international organization is a process of moving beyond the traditional system of nation-states towards a new political system (Claude, 1964). States likely favour international organization as a means of enhancing state efficiency rather than a predecessor to new forms of government that transcend the national level. Particularly before 1945, states established international organizations to tackle inefficiencies caused by a lack of cooperation. Examples include the postal service (Armstrong, 1982) or telegraphs (Ruggie, 1992). With the establishment of the League of Nations and later the UN, a new type of international organization emerged:

'...here were organizations based on little more than shared aspirations, with broad agendas in which large and small had a constitutionally mandated voice' (Ruggie, 1992, p.583).

The League of Nations, and later the UN, were organizations established to prevent further interstate wars and had broad collaborative mandates, which, in their essence, fell closer to the notion of international organization as a new political system.

Perhaps the most useful concept developed to understand the shifting nature of international cooperation in the twentieth century has been the concept of multilateralism. In the 1950s, Claude (1958) defined a number of different activities as multilateral:

'...mobilizing the collective condemnation of a state whose behaviour is alleged to fall below acceptable 
international standards, organizing a general colloquium on the problems of the global situation and on national policies for dealing with those problems, drafting conventions of the sort which have come to be known as "international legislation," and formulating arrangements for the establishment of international organizations and the initiation of international programs' (p.44).

While multilateralism is not a new phenomenon, the twentieth century has witnessed an increase in the 'breadth and diversity of multilateral arrangements across a broad array of issue-areas' particularly since the end of World War II (Ruggie, 1992, p.584). In the early 1990s, several seminal articles were written on the subject of multilateralism (Kahler, 1992; Keohane, 1990; Ruggie, 1992). Keohane (1990) defines multilateralism as 'the practice of coordinating national policies in groups of three or more states, through ad hoc arrangements or by means of institutions' (p.731). Ruggie (1992) adds that 'what is distinctive about multilateralism is not merely that it co-ordinates national policies in groups of three or more states...but that it does so on the basis of certain principles of ordering relations among those states' (p.567). Hence, it is not just about the number of states cooperating but also about the reason for their cooperation.

One of the fundamental principles guiding multilateralism from 1945, at least on paper, was the 'sovereign equality of states' (Kahler, 1992, p.681). Multilateralism was viewed as a way of moving beyond unilateral or bilateral decision making, which was believed to allow more powerful states to dominate weaker states. Although undermined somewhat by the rules governing membership of the UN Security Council, the notion of sovereign equality was reflected in the institutional set up of the UN whereby each Member State has the right to vote and, through formal governing bodies, collective decisions are made thus, at least theoretically, subsuming the interests of more powerful Member States (Browne, 2017; Keohane, 1990; Ruggie, 1992). The funding structure of the UN was initially based solely on mandatory, also referred to as 'assessed', contributions from its Member States to prevent wealthier states from exerting too much influence over the UN. Mandatory contributions were determined based on the 'capacity-topay' model, with contributions capped at minimum and maximum levels to prevent freeriding and over influence, respectively (Graham, 2017b). 
However, the vision of multilateralism, which was championed by the United States of America (US), was also politically motivated. The US was interested in forging alliances in Europe to protect itself against the threat of the spread of communism and an invasion from the former Soviet Union. Part of the vision was a 'United States of Europe' of sorts, that would act as another 'pole', or centre of power, and decrease the likelihood of a war between East and West (Weber, 1992). Hence, one cannot discuss multilateralism 'without referring to the world order and to the way international relations are organized in terms of power' (Van Langenhove, 2010, p.234). As Kahler (1992) argues: 'the levelling impulse of multilateralism simply does not fit the hierarchical power configuration of the international system' (p.682).

Even in the early days of the UN's existence, there were numerous examples of states seeking to exert more influence. For instance, Article 51 of the UN Charter accords its Member States the right to self-defence. Latin American countries drove the adoption of Article 51 because they wished to establish the Latin American Security Organization without US interference. The article was later used by the US to establish the North Atlantic Treaty Organization (NATO) in 1949 without being vetoed by the Soviet Union (Ruggie, 1992). Furthermore, early changes to the funding structure of the UN, which allowed voluntary contributions for specific interventions, were introduced because of the desire of some countries to move beyond the impasse that existed between the US and the then Soviet Union (Graham, 2017a). Post-1945 multilateralism was, therefore, heavily influenced by bipolarity in the international system.

Realists explain part of the deviation from pure 'multilateralism' as a response to the growing difficulty of cooperation in a world where the number of countries had increased through the process of decolonization in the 1950s and 60s (Kahler, 1992), and later through the dissolution of the Soviet Union in the 1990s. Realists argue that states, as rational actors, sought alternative forms of cooperation (Kahler, 1992; Olson, 1965). To describe these variations of multilateralism in practice, researchers have developed a range of different concepts. For example, Keohane (1990) used the concept of 'supralateralism' to describe cooperation among states that occurs above the level of bilateral cooperation but below the level of multilateral cooperation. The concept has not been widely applied empirically, although some scholars have used supralateralism to describe cooperation between the European Union (EU) and other countries and regional groupings (cf. Scott, 2013; Paoletti and Pastore, 2010; Henökl and Stemberger, 2016; Henökl and Webersik, 2016). 
The concept of 'minilateralism' has been more broadly applied to describe cases where 'coalitions of the willing' have cooperated to further international cooperation on a specific issue. In the early 1990s, Kahler (1992) offers several examples of "minilateral "great power" collaboration within multilateral institutions' (p.862) such as the US use of the Organization for European Economic Integration in its bid to create a new centre of power in Europe and the weighted voting systems in the Bretton Woods Organizations. The notion of 'minilateralism' as a means to overcome the problems of achieving collective action is a recurring argument that has found its place in discussions of global governance in policy fields such as climate (cf. McGee, 2011; Eckersley, 2012; Engelbrekt, 2015; von Lucke, 2019); peace (cf. Dian and Meijer, 2019; Ba, 2019); and migration (cf. Newland, 2012; Thouez, 2018; Ferreira, 2019).

The range of descriptors used to explain minilateralism points to more profound ideological views on whether minilateralism should be viewed positively or negatively. For example, from a neoliberal perspective, minilateralism offers a solution to the collective action problem (Kahler, 1992). Moisés Naím (2009) described minilateralism as 'the magic number to get real international action' (p.136). Naím (2009) essentially argued that trying to achieve agreement among all world states is a 'fool's errand' (p.135) and that only a certain number of states are needed to solve many global policy problems. As an illustration, the top 20 polluters emit approximately threequarters of all greenhouse gas emissions. Even with the best intentions, agreement between states on emissions that do not involve the world's main polluters will have limited impact. For example, without the implementation of the Paris Climate Accord by countries such as the US or China, the agreement is unlikely to achieve its goals. Thus, in the area of climate change, von Lucke (2019) describes minilateralism as 'principled pragmatism' (p.1). However, from a more critical perspective, minilateral cooperation can also be a means to sustain existing power structures. Sridar and Woods (2013), for example, coined the term 'Trojan multilateralism' to describe how funders use specific funding instruments to create 'the illusion of multilateral intent....[while] covertly introducing bilateral goals and interests in multilateral institutions' (p.326).

As the world has evolved, so too have the concepts used to describe it. Cohen (2018) argues that multilateralism has a life cycle and that the success of early multilateral efforts to shift the balance of power in the international system towards a multipolar model based on the principle of universality, has in fact made it increasingly difficult to reach agreement in a multilateral setting, an 
argument evident in the realist writings of the early 1990s (Kahler, 1992). Hence, multilateralism, as a 'problem solving strategy or organizing principle' (Cohen, 2018, p.4), has evolved and matured over time (Kahler, 1992; Weber, 1992; Van Langenhove, 2010). This has led to the emergence of concepts such as Multilateralism 2.0 (Van Langenhove, 2010), and 'new multilateralism' (Villanueva Ulfgard \& Alejo Jaime, 2014). The critical takeaway from this discussion is that any attempt to understand the roles that international organizations play in global governance must recognize that the process of international organization has evolved over time and is deeply embedded in the power-relations inherent to the world order. How international organizations have evolved is a product of how multilateralism has evolved.

\section{International Organization as an Entity}

With the proliferation of multilateral projects since the Second World War, it is unsurprising that significant growth in the number of international organizations has occurred. Over the past century, the number of international organizations has skyrocketed from 213 in 1907 to 66,298 in 2013 (Figure 2.1). Despite Ruggie's (1992) argument that international organizations 'require no conceptual elaboration' (p.573) other than in relation to the other concepts, such as multilateralism, it is argued here that a solid conceptualization of international organization as an entity is required to understand why organizations exhibit different behavioural logics (Barnett and Finnemore, 1999). Thus, this section first defines what is meant by international organizations before unpacking some of the factors that may be reasonably assumed to affect the degree to which international organizations can exercise influence over states, and consequently, global governance.

While scholars often apply the terms international organization and intergovernmental organizations interchangeably, the latter is a sub-category of the former. International organizations can be classified in two ways: as intergovernmental organizations (IGOs) and as non-governmental organizations (NGOs). The contemporary distinction between an IGO and an NGO, established by the 1950 UN Economic and Social Council (ECOSOC), Resolution $288(\mathrm{X})$, is based on the origin of an organization. An organization established by an intergovernmental agreement is an IGO. Any other international organizations are, by default, NGOs. At face value, therefore, IGOs are non-independent state actors, and NGOs are independent, non-state 
actors. However, as will be further discussed, the question of independence is not straightforward. The extreme growth in the number of international organizations can be attributed to the proliferation of INGOs: in any given year, the average ratio of IGOs to NGOs was approximately 9:1 (Figure 2.1).

Figure 2.1 Number of International Organizations, 1919-2013

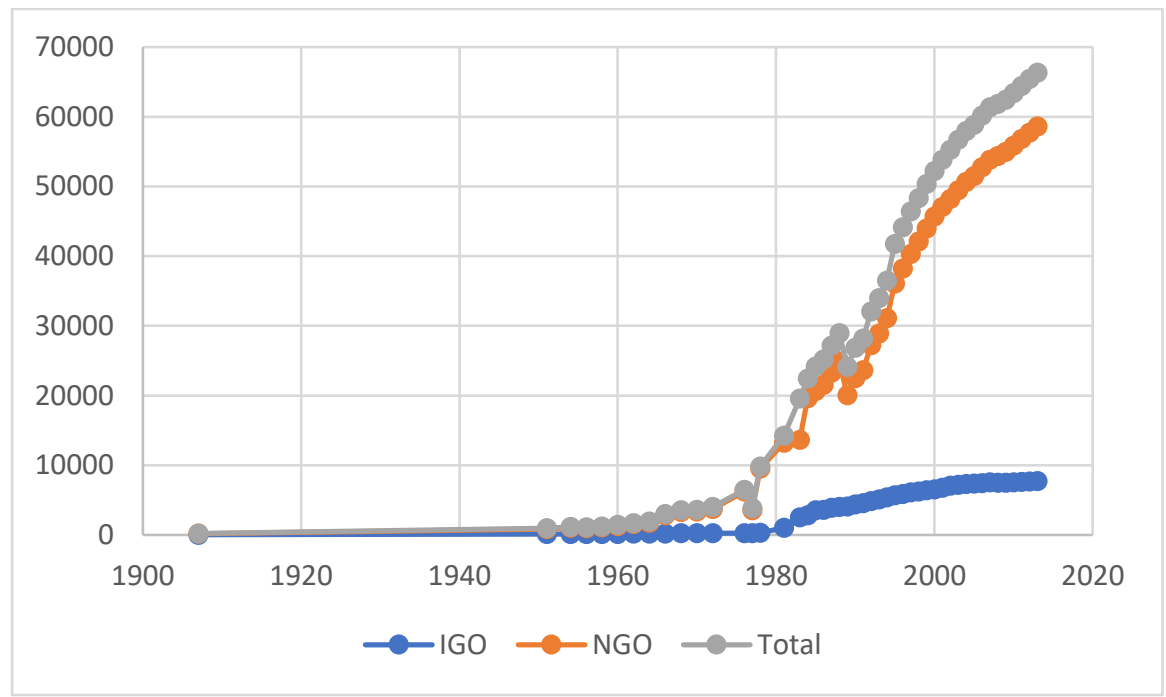

Source: Union of International Associations (2013)

The absolute growth in the number of organizations was accompanied by a diversification in the types of organizations. The Yearbook of International Organizations classifies organizations as one of 15 main types ${ }^{2}$, each of which can be either intergovernmental or non-governmental. Categories A through $\mathrm{D}$ are considered as 'conventional international bodies', while Categories E to G are considered as 'other international bodies.' The remaining categories are 'special types'. According to data from the Union of International Associations (UIA), there were 37 conventional intergovernmental organizations in 1909, a number which had increased to 123 by 1951, and peaked at 378 in 1985 before falling to 297 by the end of the Cold War in 1991

\footnotetext{
2 These are: A) federations of international organizations; B) universal membership organizations; C) intercontinental membership organizations; D) regionally defined membership organizations; E) organizations that have emerged from other organizations; F) organizations having a special form; G) internationally focused national organizations; $\mathrm{H}$ ) dissolved or inactive organizations; J) new bodies - still to be classified; K) subsidiary and internal bodies; N) national organizations; $\mathrm{R})$ religious orders and secular institutes; $\mathrm{S}$ ) autonomous conference series; T) multilateral treaties and intergovernmental agreements; and $U$ ) currently inactive non-conventional bodies.
} 
(Figure 2.2). In 2013, there were 265 conventional intergovernmental organizations recorded by the UIA. Part of the decline is due to a change in how organizations were classified. From 1983, the UIA expanded the categories it used to describe international organizations. However, it also points to diversification in the forms of international organizations, which in turn highlights the relevance of understanding how different characteristics may influence the ability of an organization to exert influence. Accordingly, aside from noting the increase in the number of INGOs, it is also important to point out that, between 1981 and 2013, regionally defined membership organizations represented an average of 73 per cent of all conventionally defined intergovernmental organizations.

The focus of this dissertation is primarily on the UN, which is the only federation of international organizations (Category A) reported by UIA, along with its members, which are generally universal membership organizations (Category B), organizations that have emerged from other organizations (Category E) and organizations with a special form (Category F). While the dissertation focuses on a subsample of IGOs, hereafter referred to as international organizations (IOs), it also recognizes the fact that the environment in which these IOs operate is increasingly populated by other internationally oriented actors (Van Langenhove, 2010).

Figure 2.2 Number of Conventional Intergovernmental Organizations, 1919-2013

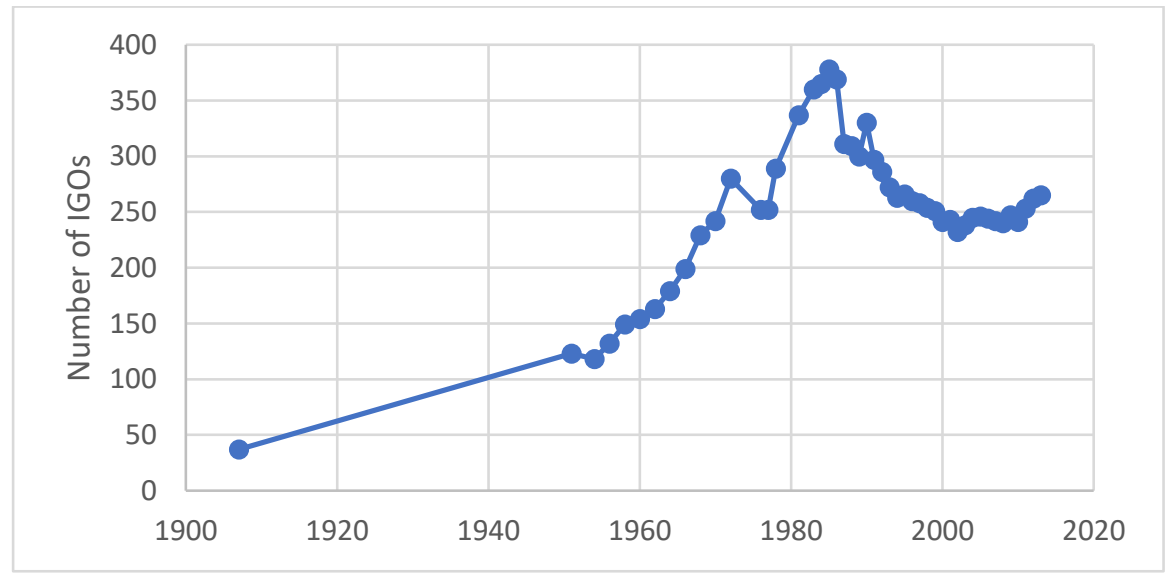

Source: Union of International Associations (2013)

The preoccupation with explaining existence and form has dominated much of the scholarship on IOs (Andreev, 2007). Claude (1964) offers two metaphors 
to explain different perspectives of the nature of international organizations. The first is called the 'seed approach' and makes the argument that just like a seed, the development of an international organization is mostly predetermined, albeit that its survival is dependent on external factors. The second, 'the building theory', argues that just as a building can be made and remade, IOs can also be remodelled to address changing interests and objectives (p.9-11). The extent to which IOs themselves can exert influence over their own evolution depends upon one crucial factor: autonomy.

Particularly in early studies of IOs, limited attention was paid to their role as independent actors (cf. (Huntington, 1973; Keohane \& Nye, 1974; Mearsheimer, 1995). From a realist perspective, 'intergovernmental organizations are merely instruments of governments, and therefore unimportant in their own right' (Keohane \& Nye, 1974, p.39). As Huntington (1973) argued, 'the United Nations and other international organizations have remained relatively weak because they are inherently the arenas for national actors; the extent to which they can become independent actors themselves is dependent on agreement among national actors' (p.338). However, Michael Barnett and Martha Finnemore, in their 2004 book, Rules for the World: International Organizations in Global Politics, have been particularly influential in challenging the 'preoccupation with creation at the expense of behaviour' (p.11). Their core thesis is that IOs can act independently and influence the behaviour of states through exercising authority using regulatory and constitutive power (Barnett and Finnemore, 2004). Having conceptualized IOs as resource-dependent governance actors, the remainder of this section will focus on unpacking how various resource-related factors might be expected to affect an organization's autonomy and, accordingly, its ability to exert influence over states (Section 2.2.3).

Resources themselves can be conceptualized in several different ways. Dingwerth and Pattberg (2008) distinguish between four different types of resources: political, financial, cognitive, and moral. Different actors will have varying levels of access to each of these types of resources. One might expect a state to have access to all kinds of resources since it is able to establish binding rules (political); distribute financial resources (financial); organize knowledge creation and gathering (cognitive) and, in democratic states, have a legitimacy associated with representing the electorate (moral) (Dingwerth and Pattberg, 2008). For IOs, the level of their resources will often depend on their organizational characteristics, such as their mandate or financial regulations. For an $\mathrm{IO}$, political resources will depend upon its mandate. For example, a normative body possesses political resources embedded in its role 
as the custodian of internationally agreed-upon norms. However, if the same organization is primarily financed by states, and reliant on states to permit its operations, the organization may face a dilemma whereby it has to make a trade-off between securing financial resources and exercising political influence.

The first factor that could, therefore, be expected to influence autonomy relates to the design of the organization. The mandate of an organization dictates its role vis-à-vis states. For example, if an organization is established to ensure state compliance with a specific convention, then that organization has been accorded a degree of autonomy in monitoring and reporting on the activities of states. In her work, Nina Hall (2013) developed a typology of international organizations running along a continuum from normative organizations to functional organizations. On one end of the spectrum, normative organizations 'have a legal authority to ensure norm compliance' (p.92) while functional organizations 'are not mandated to promote, or ensure compliance with, international norms' and instead exist 'to perform specific, discrete tasks and are often project-based organizations as a result' (p.92-93). Hall theorizes that normative and functional organizations will exhibit different behavioural logics. Functional organizations will be more likely to make cost-benefit assessments and opt for the option which brings the most significant material gain ('logic of consequence'), making them more susceptible to the interests of rich states. On the other hand, normative organizations act in accordance with the 'logic of appropriateness', meaning whether the specific action is in line with the norm they are tasked to uphold, theoretically granting them a degree of independence from states. Therefore, a normative organization might reasonably be expected to have more considerable influence because of its legally derived authority to ensure norm compliance.

A second key factor relates to the way in which an organization is financed. Researchers frequently use funding patterns as a proxy for 'institutional multilateralism' (Keohane, 1990); 'bureaucratic autonomy' (Ege \& Bauer, 2017) or the 'exercise of power' (Browne, 2017). One reason is that funding is empirically observable and, with advancements in the standardisation of accounting regulations, increasingly comparable. For example, in 2006, the UN adopted the International Public Sector Accounting Standards (IPSAS) to make the financial data of different organizations increasingly comparable. However, the study of funding also serves to fill a research gap where the link between the formal delegation of power and IOs' actual power to shape 
global governance outcomes has remained unclear due to a limited focus on IO capabilities' (Heldt \& Schmidtke, 2017, p.52).

In the early days of the UN, the principle of mandatory contributions was central to the funding of the new organization. Mandatory, or 'assessed' contributions, are a legal obligation associated with membership, and nonpayment usually results in a penalty such as the removal of voting rights. The very notion of voluntary contributions was not present in the UN Charter, and early funding rules prohibited the earmarking of funds for fear that funding could be used by wealthier states to exercise influence over the UN (Graham, 2017a). Already in the first decade of the UN's existence, however, programmes were created outside of the mandatory scheme, and, by 1960, voluntary contributions exceeded mandatory contributions for the first time (Graham, 2015). While voluntary contributions were quick to overtake mandatory contributions in terms of volume, until the 1990s, these contributions were still primarily unrestricted, hereafter unearmarked, meaning that decisions regarding how the money was spent rested with the governing body of the recipient organization. In what Graham (2017a) describes as a 'sea-change' (p.366), however, the 1990s witnessed a shift from unearmarked voluntary contributions towards the increasing use of earmarking stipulating how the contribution could be used. Between 1994 and 2009, unearmarked voluntary contributions were relatively stable, decreasing by just two per cent. On the contrary, earmarked funds increased by more than 200 per cent (Graham, 2015). Of the 49.3 billion USD contributed to the UN system in 2016, mandatory contributions represented less than a third $(28.3 \%)$ of total revenue for organizations within the UN system, while voluntary contributions represented some two-thirds (64.3\%) of total revenue. The remaining amount is derived from other sources, such as interest. Voluntary contributions were predominantly earmarked, representing 84.1 per cent of all voluntary contributions and more than half (54.1\%) of all contributions to the UN system (United Nations, 2018a).

Authors such as Graham (2015, 2017a, 2017b), Browne (2017), and Seitz and Martens (2017) have argued that shifts in the funding patterns of the UN towards earmarked funding, particularly since the 1990s, have disrupted the way it functions as a multilateral system by creating new governing relationships between funders and international organizations (IO) that circumvent formal governing bodies. The main argument here is best understood from the perspective of the principal-agent problem. In a pure multilateral model, the governing body of an organization would have the ability to allocate and distribute its revenue as it sees fit. By contributing 
funding earmarked for a specific purpose, funders reduce the ability of the governing body of an organization to make this decision. Thus, voluntary funding rules are more likely to create scenarios where the agent (the IO) is 'governed' by multiple principals (member states and other actors) thus undermining its multilateral character. Therefore, the proportion of earmarked funding influences the autonomy of an organization through either stipulating its activities or giving the organization the freedom to allocate funds as its governing body sees fit. An organization receiving primarily earmarked funds may therefore be expected to have less independence (or to rely on different strategies to obtain authority) than one with more fiscal autonomy. However, organizations that receive higher levels of earmarked funding might also be expected to experience more volatility in their revenue and as such be more entrepreneurial in how they make use of their cognitive resources to define problems in a way that legitimizes their organization's interventions (Barnett and Finnemore, 2004).

The important takeaway from this brief discussion of the international organization as an entity is the importance of recognizing that not all international organizations are the same. The ability of organizations to exert influence depends, in part, on internal characteristics that affect their ability to acquire resources and, as such, to act as autonomous actors.

\subsubsection{Conceptualizing Influence: Authority and Power}

Having established that governance is both the process and the product of the interaction of resource-dependent actors operating in networks around different policy issues of international relevance and that international organizations are key actors in this process, this section critically considers what is meant by our mediating concept: influence. At its core, the research question is about power, and more specifically, the power of international organizations to establish norms and rules to govern the behaviour of states regarding specific global policy problems. To understand how IOs might influence states, and by extension global governance, two related concepts merit further elaboration: authority and power.

In the act of creating an $\mathrm{IO}$, states accord them the authority to act in the areas stipulated by its mandate. The power to influence is derived, in part, from this delegated authority. However, the authority to act does not guarantee influence: 'IO authority is intensified to the extent that others perceive the IO 
as being both an authority and in authority' (Barnett and Finnemore, 2004, p.35). This definition largely accords with a Weberian conceptualization of authority as legitimate power, which in turn makes it a social phenomenon (Natorski, 2018). Authority cannot exist without the social relations that legitimize it:

'The essence of authority is a relationship between two or more actors in which the commands of certain actors are treated as binding by the others' (Weber 1954, p.328 in Spencer 1970, p.124).

However, authority can take different forms, some of which are more visible in terms of their translation into influence than others. Barnett and Finnemore (2004) outline four types of authority: rational-legal, delegated, moral, and expert. Rational legal authority refers to the basic form and vocabulary of the organization, usually predefined by its creators. This type refers to the authority to act. Delegated authority occurs when a specific task is assigned to an organization. States may delegate specific tasks, such as the regulation of the international postal service, to IOs. Moral authority and expert authority each allow IOs to play a depoliticizing role in their handling of specific issues and generally refer to how IOs exercise authority. Moral authority is derived from the notion of placing specific collective interests above national interests and can be enacted particularly by IOs with a normative mandate. Expert, or cognitive authority, on the other hand, is derived from knowledge, which is often acquired experientially. Broome and Seabrooke (2012) argue that the way the international organizations 'see' the world through developing and applying different measurement and benchmark standards requires them to have 'cognitive authority' that allows them to 'measure, analyse and prescribe institutional changes for states' (Broome \& Seabrooke, 2012, p.2). Hence, while an IO may be created to address a specific challenge, the way in which that challenge is interpreted, defined, and operationalized may lead IOs to act in ways contrary to the initial expectations of their creators.

These different types of authority also largely rhyme with different conceptualizations of power. Parsons (1967) defined power as 'a generalized capacity to secure the performance of binding obligations by units in a system of collective organization when the obligations are legitimized with reference to their bearing on collective goals...' (p.308, in Lukes, 1974, 31). This approach is distinct from approaches to power that focus on the relationships through which power is exercised. Instead, it draws attention to the interlinkages between power and authority, considering power as an inherent 
part of social systems. Following this reasoning, an IO established by states to respond to a specific challenge, read 'collective goal', would represent one source of authority for an IO to exercise power. However, power is a complex concept. Lukes (1974) argues that power can be both overt and covert. At a basic level, power, was conceived by Dahl in 1957 as follows: 'A has power over $\mathrm{B}$ to the extent that he can get $\mathrm{B}$ to do something $\mathrm{B}$ would not otherwise do' (Lukes, 1974, p.16). Luke described this as overt power. However, power can also be exercised covertly: 'A may exercise power over B by getting him to do what he does not want to do, but he also exercises power over him by influencing, shaping or determining his very wants' (p.27).

In a similar vein, Barnett and Finnemore (2004) argue that IOs can exercise both regulative and constitutive power. Regulative power relates to the power of IOs to monitor and report on the activities of states and represent, in the words of Merlingen (2003), the 'international conduct of the conduct of countries' (p.367). The most obvious example of this in the context of international organizations would be the creation of legally binding international conventions. By ratifying international conventions, states accord their custodian organizations the authority to monitor their conduct, report on non-compliance, and provide policy prescriptive advice. However, given that states may initiate the development of such conventions, are involved in their formulation and initial adoption, have the sovereign right to choose whether to ratify a convention, and can withdraw themselves from all or some of their provisions, the adequacy of such agreements, particularly for intractable policy problems, has come under increasing scrutiny. Hence, the changing nature of multilateralism has resulted in IOs adopting new tactics with respect to influencing the conduct of states.

Constitutive power relates to the way that IOs create, define, and map social reality. IOs, through the creation of narratives, frame problems in specific ways (Broome \& Seabrooke, 2012). The way a problem is defined has implications for the way solutions are designed. This point resonates with the definition of symbolic power proffered by Pierre Bourdieu, as the 'power of constructing reality' (Bourdieu, 1991, p.166); and to Lukes (1974) definition of covert power as the ability to exercise control through shaping preferences. IOs can, through the collection of data and the crafting of narratives, exert influence on how problems are defined, thus influencing the policies designed to address them (Broome \& Seabrooke, 2012).

The main takeaway from this section is that influence can be broadly defined in two ways. First, IOs can influence states using overt, regulative power, 
where they use their legal and delegated authority to influence the decisions of states with regards to policies of international relevance using instruments such as international conventions. Second, IOs can influence states using covert, constitutive or symbolic power by framing problems in a specific way, which in turn compels states to act in specific ways. It can be reasonably assumed that the different IOs, along with states and other governance actors, will have different levels and configurations of authority, and thus, that the extent to which IOs can exercise influence will vary. While harder to measure, I would expect that IOs increasingly seek to wield covert power since the collective action challenge of a growing, multipolar world has made reaching agreements of a legally binding nature more complex.

\subsection{The Relationship between International Organizations and States}

Based on the conceptual discussion in Section 2.2, several core principles underpin the development of the theoretical framework presented here. First, states delegate authority to IOs to address challenges where intergovernmental cooperation is deemed more efficient than unilateral efforts and increasingly with the purpose to achieve broader collaborative goals, such as global economic development or world peace. Second, IOs can exercise influence over states through the creation and enforcement of legal norms, but also at the level of reality construction. The relationship between states and 'their' international organizations is therefore theorised as one in which a careful balancing act exists between states delegating enough authority to international organizations for them to be effective, but not too much that it would challenge state sovereignty or disrupt the existing power hierarchies.

To develop this argument further, it is necessary to look first at the relationship between states and international organizations. The framework (Figure 2.3) assumes that the relationship between states and international organizations is bidirectional, meaning that while states influence and exert power over international organizations, the reverse can also be true. Authority is considered both as something that can be bestowed as well as something that can be exercised. States delegate authority to an IO through the delegation of tasks, usually defined in the organization's mandate.. However, given that mandates are often broad and general, the role of 
operationalizing a mandate requires interpretation (Evans \& Finnemore, 2001). This provides space for IOs to exercise regulative and constitutive power through the collection of data on a specific topic and through the development of narratives that define policy problems (Barnett and Finnemore, 2004) but also to build up expertise in specific operational areas that allows them to exercise expert authority further enhancing their authority.

Figure 2.3 The Relationship between States and IOs

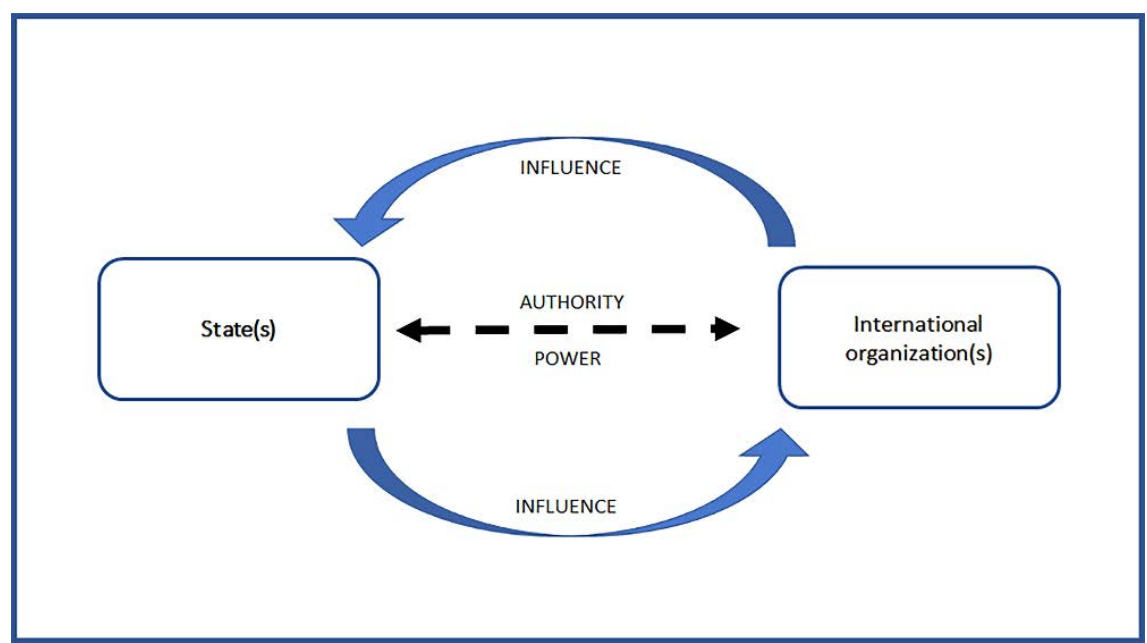

Source: Author's own

However, it is not sufficient to remove this relationship from its context nor to homogenise states or international organizations. The discussion on multilateralism established that international organization as a process is a product of the evolving distribution of power in the global system, and the discussion on international organizations highlighted considerable differences in their nature and form. Next to acknowledging the likelihood that more powerful states may use IOs to exert influence over less powerful states, therefore, the discussion on the relationship between states and international organizations needs to be embedded within a broader theoretical framework that accounts for these factors.

Nay (2011) argues that, to understand reforms in the international system, it is necessary to look at the external environment which presents both opportunities and threats to an organization; as well as to analyse the 
'interests, intentions and strategies of actors who contribute to channel external pressure into appropriate functional responses within the organization (p.694). However, factors specific to a policy area may also affect the relationship between states and international organizations. It can be assumed that many of the same external factors would place pressure on international organizations operating in that policy area. However, as demonstrated by Hall (2016), the way in which organizations respond to changes in the external environment may vary depending upon institutional specific characteristics, thus supporting Nay's (2011) assertion that the behaviour of IOs is a function of external pressure and internal dynamics.

The advocacy coalition framework (Sabatier, 1988) helps to incorporate these complexities into our conceptual framework. While Sabatier (1988) developed the advocacy coalition framework to study policy change over time and in a national context, it holds promise for understanding how international organizations and states interact in their responses to global policy problems His framework departs from three core principles. First, that one must look at policy change temporally, taking a research period of at least ten years. Second, he identifies the existence of policy subsystems, which he defines as 'a set of actors who are involved in dealing with a policy problem' (Sabatier 1988, p.138). Within each policy subsystem, different 'advocacy coalitions' exist, typically between two and four, which are 'composed of people from various organizations who share a set of normative and causal beliefs and who often act in concert' (p.133). Sabatier's (1988) third principle is that public policy can be viewed in terms of belief systems. Members of different advocacy coalitions can hold different views on how to define and address not only a specific policy problem, but also potentially their normative assumptions regarding how the process of international organization should be pursued. In his framework, policy change is the product of negotiations between resource-dependent actors in different coalitions within a policy subsystem, sometimes facilitated by a 'neutral' policy broker.

One aspect of the ACF that has been relatively understudied in its empirical applications is the role of policy brokers in the policy process. Policy brokers are 'policy actors operating between coalitions' (Pierce et al., 2017, p.4). Individuals have long been considered as a key factor contributing to organizational behaviour and thus change (Evans \& Finnemore, 2001). Schmidt (2008) argues that individuals can act as 'entrepreneurs' (Finnemore \& Sikkink, 2001) or 'mediators' (Jobert, 1989) 'who serve as catalysts for change as they draw on and articulate the ideas of discursive communities and coalitions' (Schmidt, 2008, p.310). 
Accordingly, how negotiations play out between actors will be a product of the resources available to, and constraints encountered by each actor in the policy subsystem, the presence of policy brokers, as well as to how different organizations react to one another. As DiMaggio \& Powell (1983) argued:

'Organizations...respond to an environment that
consists of other organizations responding to their
environment, which consists of organizations
responding to an environment of organizations'
responses' (p.149).

Beyond the policy subsystem, external factors will also influence these negotiations. Sabatier (1988) makes a distinction between 'relatively stable' (p.134) and 'dynamic' factors (p.136). Stable factors might include characteristics of the specific policy problem, cultural values and social systems, global resource distribution, and legal structures. Dynamic factors, or 'system events', could include changing socio-economic conditions (such as the oil crisis of 1973); the advancement of technology (such as jet aircraft); change in the governing coalition; and policy decision in other policy subsystems. In a later revision of the advocacy coalition framework, Sabatier and Weible (2007) added an additional element external to the policy subsystem: 'coalition opportunity structures'. The addition, inspired by the literature on political opportunity structures, highlighted the role of factors mediating the relationship between external and internal factors. An external event can create the necessary consensus needed to push forward a policy change that, regardless of whether consensus existed within the policy subsystem, may not have otherwise occurred (Sabatier \& Weible, 2007). This notion is similar to that of Kingdon's (1995) 'windows of opportunity', which occur when problems, policy proposals, and politics converge at a specific point in time.

The advocacy coalition framework, therefore, assists us in situating the relationship between states and IOs into a framework that recognizes the factors that may influence the relationship, and thus governance as an outcome, at three levels: 1) factors internal to states and IOs; 2) factors specific to the policy subsystem; and 3) external factors (Figure 2.4). 
Figure 2.4 Contextualising the Relationship between States and IOs

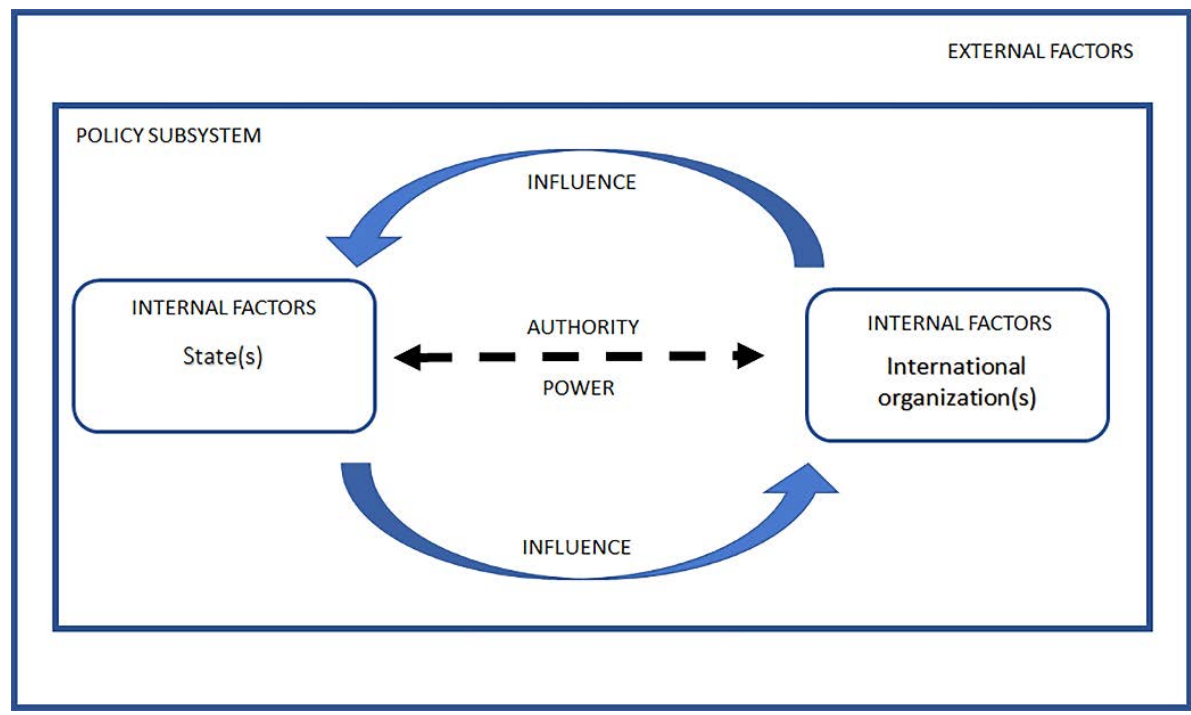

Source: Author's own

\subsection{Conclusion: What is Global Migration Governance?}

Having disaggregated the main research question by defining (global) governance, international organization as a process and as an entity, and considering how the concepts of authority and power can be applied to understand the extent to which IOs can influence global governance, this chapter closes with a discussion of what the conceptual and theoretical approach implies for the dissertation.

Section 2.2.1 defined global governance as the interactions of resourcedependent actors in networks to develop systems of rules to address policy problems that transcend national borders, as well as to the normative goals of these actors concerning their vision of global problem-solving. Section 2.2.2 highlighted that the process of international organization has evolved and is deeply embedded in the power-relations inherent to the world order. These developments have also resulted in diversification in the nature and form of IOs. Hence, the ability of organizations to exert influence depends, in part, on internal characteristics, which affect their ability to act as autonomous actors, which in turn is a product of their external environment. With these observations in mind, Section 2.3 theorised the relationship between states 
and IOs as one in which a careful balancing act exists between states delegating enough authority for an IO to be effective, but not so much that it would challenge state sovereignty.

Defining global governance in this way implies a need to analyse how migration has evolved as a global policy issue over time through the interaction and exchange between different actors. Although developed to deal with 'wicked policy problems' in a national context, the advocacy coalition framework (Sabatier, 1988, 1998; Sabatier \& Weible, 2007) offers a theory of the policy process that assists in this task. By applying the advocacy coalition framework, migration is defined as a 'policy subsystem'. The framework suggests policy changes will be the product of the interactions between states, IOs, and other actors operating in 'advocacy coalitions' and facilitated by policy brokers. In line with Sabatier, I would expect to identify at least two or three 'advocacy coalitions' with distinctly different approaches to migration as a global policy issue. From the literature on global migration governance, three competing 'coalitions' can already be identified: 1) migration management; 2) migrant rights; and 3) migration and development (Piper, 2017; Delgado Wise, 2018a). Accordingly, the extent to which specific arguments gain acceptance, and lead to a policy change, is determined by the access of IOs to different kinds of resources, notably authority, as well as to the external environment. Accordingly, in examining the history of global migration governance, I pay close attention to how different factors have influenced how different actors have defined migration as a global policy issue and the role that IOs have played in the framing of migration as a policy problem. 



\section{Methodology}

This chapter situates the overall methodological approach of the dissertation within broader research paradigms, discusses the overall research design, introduces the primary sources of data used throughout, and how they were gathered and analysed. The chapter first discusses the overall research design strategy (Section 3.1) and provides an overview of the research process (Section 3.2). Section 3.3 then describes how the data were collected and the broad analytical strategy. Section 3.4 concludes with some reflections on the methodological challenges encountered.

\subsection{Research Design}

At a broad level, the methodological approach taken in this dissertation is a case study. By taking the case of migration, I hope to offer some broader observations about the evolving nature of multilateral problem-solving over the past century. The selection of migration as a case study is appropriate for several reasons. Migration policy has always stood out as an area where the politics of policymaking are at their most present. Migration can be an emotive policy issue, and, as the past few years have shown, can topple governments ${ }^{1}$, divide electorates ${ }^{2}$, and challenge the very notion of multilateralism. Often the discussions around migration at the political level are not even about migration, but rather reactions to broader socio-economic change in which migrants are scapegoated and treated as the cause, rather than the consequence, of broader societal change. However, even seemingly innocuous policy problems, such as those that the Global Postal Union seeks to address, face similar issues ${ }^{3}$. Lessons learned from an examination of global policymaking in the area of migration can have broader applicability to the understanding of how other intractable policy problems, such as

\footnotetext{
${ }^{1}$ Belgium (Guild et al., 2019)

2 Brexit (Betts and Collier, 2017) Belgium (Guild et al., 2019)

${ }^{2}$ Brexit (Betts and Collier, 2017)

3 Trump's negotiations with the Global Postal Union (Abrams, 2019)
} 
climate change, can be best addressed. Furthermore, the discussion concerning the UN's role in the area of migration has been subject to intense debate, particularly since the early 2000s.

Before discussing the overall research design, a few words regarding my background are appropriate. My anthropology training proved useful during my years working as a contract researcher from 2012 until 2017, during which I was both a participant and an observer in global discussions, albeit at a relatively junior level. More specifically, I participated in three Global Forums on Migration and Development meetings (Civil Society Days and Common Space) in Turkey (2015), Bangladesh (2016), and Germany (2017) alongside several preparatory meetings. Although it would have been of value to participate in the Government Days of the GFMD, access to these days was more restricted. Nevertheless, participating in the Civil Society Days, and, in 2017 being part of the International Steering Committee for this event, allowed me to follow the dialogue, and, while not the focus of this dissertation, to gain insight into the role of global civil society actors in the process. I was also the assistant coordinator of the United Nations University (UNU) Migration Network from January 2016 until June 2017 as the UNU was preparing to take over as chair of the Global Migration Group (GMG). In addition to these specific processes, I was involved in numerous research and evaluation projects for a range of different international actors.

In the relatively short period that I was actively engaged with global-level discussions on migration, I witnessed several reorientations in how different actors were framing migration. Perhaps the most illustrative example of this is work that I was commissioned to do for the World Bank's Global Knowledge Partnership on Migration and Development (KNOMAD) in 2014. The task was to construct a dashboard of indicators that would measure policy coherence in the area of migration and development. After submitting an initial draft of the dashboard in the summer of 2014, we entered a period of consultations, testing, refinement, and reframing. The creation of an indicator is arguably one of the most obvious ways in which IOs can exercise constitutive power. If you can shape data collection on a specific topic, then you can shape how governments and other actors view a particular issue. Next to yearlong discussions on how to define specific indicators, we repackaged the dashboard on multiple occasions. On the first occasion, we repackaged the dashboard as a tool for measuring the implementation of the migration-related Sustainable Development Goal (SDG) commitments. On the second, it was the implementation of commitments in the New York 
Declaration, and recently it has become about the Global Compact for Safe, Orderly and Regular Migration. A similar toolkit, which was born at around the same time, is now used by IOM to offer countries 'insights on policy levers that countries can use to develop their migration governance' (IOM, 2020a). Aside from the material benefits to IOs of having specific issues included in frameworks such as the SDGs, connecting indicators to frameworks that states have endorsed through intergovernmental processes is also arguably integral to the functioning of non-binding agreements as norm-setting instruments.

I joined the field of migration at a time when there was a concerted effort at the international level to deepen the UN's role in migration. The experience of working on the dashboard and other projects highlighted the competitive and reactive nature of global discussions surrounding migration and awoke a curiosity to investigate how, and why, the international landscape on migration had evolved in the way that it had. Furthermore, these experiences introduced me to the various actors operating at the global level, the protagonists in my story, as well as to the dominant narratives that I saw reproduced repeatedly. They also introduced me to some of the tensions and politics at play at the level of global policymaking. Scores of notebooks of reflections - field notes - from this time, have provided input to the dissertation. Without this experience, it is unlikely that I would have been able to access and interview as many relevant individuals as I ultimately managed to do.

\subsubsection{Process Tracing}

Process tracing provides the methodological point of departure for the research design. Process tracing refers to the analysis of a process to establish how and why a particular outcome occurred (Bennett and Checkel, 2015). I am interested in understanding the process of institutionalising migration into the UN. I will argue that the UN and other international organizations exercised constitutive power to shape the dialogues surrounding migration to achieve a consensus that migration should be a global governance issue. The justification for choosing process tracing as a guiding framework for the research design is threefold. First, it is an appropriate methodology for case study research, described by Bennett and Checkel (2015) as a 'central within- 
case method' (p.4). Second, process tracing has been used by scholars to examine the role of specific ideas in influencing policy outcomes (Jacobs, 2015). Given the specific focus on how IOs can exercise constitutive power to exert influence over states through their ability to frame policy problems in specific ways, this proves to be an appropriate method. Third, as Checkel (2014) notes: 'the potential for process tracing to help scholars produce integrative frameworks about international institutions, combining insights from different social-theoretic toolkits remains unfulfilled' (p.74-75). As discussed in Chapter 2, the implementation of process tracing will be guided by theoretical insights about the policy process from the advocacy coalition framework. Furthermore, the concept of constitutive power will be operationalized using framing analysis (Section 3.1.2).

Process tracing is often implemented by scholars in an unsystematic way, who rely more on intuition than on a clearly defined analytical strategy, which increases the risk of inferential errors (Collier, 2011). A common error made in the application of process tracing is the lack of consideration of equifinality, which is that there could be an alternative explanation for the observed outcome. Thus, a key component of good process tracing is the collation and critical consideration of alternative explanations (Bennett and Checkel, 2015). Researchers can identify alternative explanations by analysing data from a range of sources, including archival records, academic and grey literature, and observations from practitioners. In the design of my research, I tried to ensure that I had representation from different advocacy coalitions in order to identify potential differences in the way practitioners recounted the history of global migration governance. However, as discussed in Sections 3.3.1 and 3.4, the attempt to generate alternative explanations was somewhat limited by bias in the interview sample. Future research could extend the present study and test its findings through the inclusion of other voices, particularly those from the Global South, who, while present in the sample, are underrepresented.

Process tracing is often implemented in a neo-positivistic manner, within which researchers collate evidence from a range of sources, and test predetermined hypotheses. However, a challenge with these neo-positivistic approaches is that the processes that lead to outcomes can be multi-causal. For example, an individual or organization may be instrumental in bringing about a policy change, but had other conditions been different, the policy change may not have occurred. The risk with considering various causes, but not how they interact with one another, is that process tracing results in a list 
of potential causal factors without discriminating among the relationships that exist between them (Bennett \& Checkel, 2015). Here the advocacy coalition framework (discussed in detail in Section 2.3) helps us to critically theorise how various internal, external, and mediating factors interacted to produce different outcomes, notably the inclusion of migration in the SDGs, IOM entry into the UN, and the adoption of the Global Compacts.

Additionally, my interest in understanding how IOs exercise constitutive power to preserve and extend their role in global governance poses challenges to neo-positivistic process tracing. Particularly when one seeks to identify the influence of ideas on behaviour, this task becomes more challenging because the influence of ideas on actions is generally unobservable. However, scholars such as Robinson (2017) have also demonstrated the compatibility of process tracing with interpretive research design. A central feature of an interpretive approach involves 'making (the) interpretation of events endogenous to the analysis itself' (Robinson, 2017, p.509). Accordingly, researchers investigate how meanings and narratives are constructed (Collier, 2011). A vital element of the research design thus becomes the collection of accounts of the evolution of global migration governance from the perspective of actors closely engaged in discussions at the global level. A common way of collecting such data is through interviews. However, this approach also has challenges. For example, because of the political nature of the field, a pressure 'for actors to employ verbal communication to strategically misrepresent the reasoning underlying their choices' emerges (Jacobs, 2015, p.45). Although one cannot eliminate this challenge, offering anonymity to respondents can be conducive to eliciting more open responses. Furthermore, one can triangulate interview data using other sources of data, such as archival records.

The principles of process tracing are employed throughout the dissertation. They provided structure to the research process and aided in the selection of case studies (outlined in Section 3.2). In Chapters 5 and 6, I use framing analysis to operationalize the concept of constitutive power. In addition to this, the advocacy coalition framework (Chapter 2) provides analytical guidance in Chapters 7 and 8 where I examine why IOM became a UN agency, and why states decided to negotiate a Global Compact on migration, despite historic resistance to handle matters related to migration within the context of the UN. Owing to the prominence of framing analysis, I turn now to briefly consider the main aspects of the framing approach that have guided the research before outlining the broad research process (section 3.2), the data 
collection and analytical strategies (section 3.3) and the limitations of the approach taken (section 3.4).

\subsubsection{Framing Analysis}

Complementing the process tracing approach with framing analysis offers researchers an analytically fruitful method to explore how IOs exercise constitutive power. Scholars from several disciplines have applied the concept of frames and framing, notably communication studies (Entman, 1993), social movement studies (Snow et al., 1986; Snow et al., 1988; Snow and Benford, 1992), sociology (Goffman, 1974) and public policy (Rein \& Schön, 1996). The attention given to frames by scholars from various disciplines has produced a rich body of literature exploring frames in different contexts, including in the area of migration. However, even within disciplines, disparate approaches have, in the words of Vliegenthart and van Zoonen (2011), produced 'a cacophony of new definitions, divergent operationalizations and a wide, often incompatible range of empirically established content features' (p.105). Hence, it is necessary to establish how framing analysis will be defined and operationalized in this dissertation.

In his seminal writings on frame analysis, Goffman defines frames (and frameworks) as 'schemata of interpretation' (1974, p.21). Hence, frames are a way of viewing and making sense of the world. Building on the work of Goffman (1974), Snow and his colleagues argued that that 'by rendering events or occurrences meaningful... (frames) function to organize experience and guide action, whether individual or collective' (Snow et al. 1986, p.464). Thus, frames relate to how information is presented, interpreted, and acted upon at all levels of social interaction. In the policy context, Khaneman and Tversky (1984) famously demonstrated the power of framing when presenting policy options for a fictitious disease outbreak. They received vastly different results depending on whether the proposed solutions were framed in terms of how many people would live, compared to how many people would die.

In recent years, a call for researchers to shift their focus from the study of 'frames' to the analysis of the process of 'framing' has emerged to draw attention the power dynamics inherent to the process of defining policy problems (Carragee \& Roefs, 2004; Snow et al., 2014; van Hulst \& Yanow, 
2016). Snow and Benford (1992) define framing as 'an active, process-derived phenomenon that implies agency and contention at the level of reality construction' (p.136). Given growing acceptance that international organizations can exercise constitutive power through their ability to shape reality (Barnett and Finnemore, 2004; Broome and Seabrooke, 2012), it is surprising that scholars have not paid more attention to understanding the mechanisms through which international actors frame specific policy problems and the implications that this has for governance. Hence, framing analysis allows the operationalization of the concept of constitutive power. Specifically, the dissertation draws a connection between the 'policy broker' in advocacy coalition framework theory and the 'reframer' in the framing literature to assess not only how the way migration has been framed as a global policy issue has evolved, but also by whom, and to what end.

The framing literature provides a particularly suitable framework for studying global migration governance, given that 'intractable social problems are characterized by a multiplicity of problem frames' (Scholten, 2011, p.78). In line with advocacy coalition theory, one would assume that different coalitions of actors organize themselves around different 'frames' or ways of defining a particular policy problem competing with one another in order to influence the direction taken by policymakers operating in their specific area of concern. Accordingly, one would expect to find evidence of the framing act in the recollections of the process by key protagonists as well as in archival records. In turn, acting between advocacy coalitions, one would expect to identify individuals or organizations acting as policy brokers.

Thus in Chapter 5, the process of reframing migration as a development issue is analysed through the application of Abolafia's (2004) temporal model of framing to the analysis of interview data and archival records relating to the creation of the Global Forum on Migration and Development (GFMD) which was launched in 2006 and held its first meeting in 2007. Abolafia's (2004) model involves three stages: 1 ) breaking the frame; 2) constructing the new frame; and 3) adjusting the frame. In short, Abolafia (2004) argues that to change the way an issue is framed, reframers must first cast doubt on preexisting frames. In constructing the new frame, the reframer must then be careful to ensure that the new frame resonates in some way with adherents of the frames they are attempting to move beyond because frames are ultimately about the underlying values through which actors view and interpret the world. When seeking to resolve frame conflicts, ambiguity in the frame design is crucial. As Rein and Schön (1996) argue: 'behind most 
political agreements, there lurks a misunderstanding: ambiguity may facilitate consensus' (p.90). For this reason, once a new frame has been established, a process of adjustment, or 'frame alignment' (Snow et al., 1986), ensues in which adherents of different frames can identify their place within the new frame. Frame alignment is a necessary condition for the frame to invoke action (Snow et al., 1986).

In Chapter 6, I look for evidence of 'frame alignment' by examining how different IOs incorporated the 'migration and development' frame into their rhetoric when advocating for the inclusion of migration in the SDGs. I do this by examining the arguments put forward in the writings of various IOs in the run-up to the adoption of the SDGs informed analytically by Habermas (1993) and Sjursen (2002), which I further explain in Section 3.3.3.

\subsection{Research Process}

While the research process itself was mostly iterative, some linearity to its implementation emerged. This section describes five key sequential stages of the research: 1 ) soaking and poking; 2 ) creating a timeline; 3 ) identifying key factors; 4) selecting within-case case studies; 5) implementing the case studies.

\section{Step 1: 'Soaking and Poking'}

Bennett and Checkel (2015) describe the first step of process tracing as 'soaking and poking' (p.18). One immerses oneself in the case while identifying different explanations from a range of sources such as academic and grey literature and the first-hand accounts of individuals directly involved. Part of this step involved the active participation in global-level discussions on migration. Herein, I was aware of my position as a relatively junior participant. I was able to observe specific groups of actors interacting with one another in between sessions but I was not privy to their conversations. 


\section{Step 2: Creating a Timeline}

Collier (2011) suggests that a good starting point for process tracing is the creation of a narrative or timeline within which one can 'explore the causal ideas embedded in the narratives, consider the kinds of evidence that may confirm or disconfirm these ideas, and identify the tests appropriate for evaluating this evidence' (p.828-9). Thus, early in the research process, I constructed a timeline of events in the history of global migration governance based on an initial review of relevant academic literature (c.f. Ashutosh and Mountz 2011; Bakewell 2008; Georgi 2010; Hess 2010; Skeldon 2008; Bhagwati 2003; Marchi 2010; Newland 2010; and Berne Initiative 2005). The initial timeline included events ranging from the establishment of the ILO in 1919 to IOM's entry into the UN system in 2016. I further refined and extended the timeline based on an extensive literature review, key informant interviews, and archival research (Chapter 4; Annex 4.1).

\section{Step 3: Identifying Key Factors}

Guided by the theoretical framework developed in Chapter 2 (Section 2.3) and key informant interviews, I then identified factors driving how different actors discussed migration at the global level. Nay (2011) argued that reforms in the international system are a function of internal and external factors that influence how IOs behave and categorized these into material, legal-political and cultural factors. The conceptual addition of the advocacy coalition framework (Sabatier, 1988, 1998; Sabatier \& Weible, 2007) shifted the unit of analysis from IOs to the policy subsystem in which they operate. In the advocacy coalition framework, policy change is the product of definitional struggles between groups (advocacy coalitions) of resource-dependent actors holding different beliefs about how best to tackle a specific policy problem.

In the migration governance literature, three main frames have dominated international discussions on migration: migration management, the rightsbased approach, and migration and development. Behind each frame, groups of actors, advocacy coalitions, seek to influence global discussions in a way that furthers their interpretation of the problem. How these interactions play out in practice is a function of how successfully framers can mobilize resource and how much their frame resonates and inspires others to act. System events change the playing field upon which these discussions occur and hence provide an opportunity to push for a frame shift. In presenting the overall 
timeline of key developments relevant to global migration governance, Chapter 4 analyses external factors that have influenced how global migration has evolved. Table 3.1 summarizes the main factors that have theoretically influenced how global migration governance has evolved.

Table 3.1 Factors Influencing Global Migration Governance

\begin{tabular}{|c|c|c|c|}
\hline & Material & Legal-Political & Cultural \\
\hline $\begin{array}{l}\text { Internal } \\
\text { (to IOs) }\end{array}$ & $\begin{array}{l}\text { Financial Capacity } \\
\text { Staff }\end{array}$ & $\begin{array}{l}\text { Mandate } \\
\text { Organizational } \\
\text { Characteristics }\end{array}$ & Individuals \\
\hline $\begin{array}{l}\text { Mediating } \\
\text { Factors }\end{array}$ & \multicolumn{3}{|c|}{$\begin{array}{l}\text { Advocacy Coalitions and Policy Brokers } \\
\text { System Events (Coalition Opportunity Structures) }\end{array}$} \\
\hline \multirow[t]{2}{*}{$\begin{array}{l}\text { External } \\
\text { (to IOs) }\end{array}$} & $\begin{array}{ll}\text { Funding Source } & \\
\text { Other } & \text { IOs } \\
\text { (Competition } & \text { and } \\
\text { Cooperation) } & \end{array}$ & $\begin{array}{l}\text { Politics } \quad \text { (State } \\
\text { Interests) }\end{array}$ & Ideology \\
\hline & \multicolumn{3}{|c|}{$\begin{array}{l}\text { Subsystem specific factors which directly or indirectly influence } \\
\text { migration patterns } \\
\text { (e.g., demography, economy, technology, conflict) }\end{array}$} \\
\hline
\end{tabular}

Source: Author's own

Step 4: Case Selection

Collier (2011) suggests that the data collection strategy should focus on 'taking good snapshots at a series of specific moments' (p.824). In identifying these moments, Bennett and Checkel (2015) suggest a 'bracketing strategy' (p.15) whereby the researcher identifies shorter periods within a longer timeline for closer examination. Based on the initial literature review and my observations, I identified several moments as particularly relevant to the evolution of global migration governance: 1 ) the creation of the GFMD (20052007); 2) the inclusion of migration in the SDGs (2012-2015); 3) IOM's journey to the UN (1951-2016); and 4) the genesis of the Global Compact for Safe, Orderly and Regular Migration (2015-2018). Table 3.2 summarizes the 
justification for selecting each of these cases and outlines the key factors (Step 3) and the primary unit of analysis explored in each chapter.

Table 3.2 Overview of Case Studies

\begin{tabular}{|c|c|c|c|}
\hline Case & Time & Reason for Selection & Key Factors \\
\hline GFMD & $\begin{array}{l}2005- \\
2006\end{array}$ & $\begin{array}{l}\text { Multiple authors have pointed to the } \\
\text { significance of the GFMD as a pivot point in } \\
\text { international cooperation on migration, } \\
\text { where migration was reframed in order to } \\
\text { advance international cooperation (cf. Betts } \\
\text { and Kainz, 2018; Roldan and Gasper, 2010; } \\
\text { Rother, 2018). This case study focuses on the } \\
\text { process of how migration was reframed as a } \\
\text { development issue, and by whom. The case } \\
\text { focuses on the role played by the late Sir } \\
\text { Peter Sutherland as a policy broker. }\end{array}$ & $\begin{array}{l}\text { Mediating Factors: } \\
\text { the role of different } \\
\text { actors in reframing } \\
\text { migration } \\
\text { brokers). }\end{array}$ \\
\hline SDGs & $\begin{array}{l}2012- \\
2015\end{array}$ & $\begin{array}{l}\text { While in 2000, migration, along with human } \\
\text { rights more broadly, did not make it into the } \\
\text { Millennium Development Goals, the } \\
\text { inclusion of migration in the SDGs is } \\
\text { celebrated by many observers as being the } \\
\text { moment when states recognized migration } \\
\text { as a matter meriting UN intervention. The } \\
\text { way migration has been included in the } \\
\text { SDGs has been subject to empirical } \\
\text { examination; however, the process leading } \\
\text { up to their adoption is less well documented. } \\
\text { Examining the arguments made for why } \\
\text { migration should be included in the SDGs } \\
\text { sheds light into how the migration and } \\
\text { development frame has functioned as a } \\
\text { unifying frame. }\end{array}$ & $\begin{array}{l}\text { Mediating Factors: } \\
\text { the role of the frame. } \\
\text { Internal Factors: IO } \\
\text { characteristics. }\end{array}$ \\
\hline IOM & $\begin{array}{l}1951- \\
2016\end{array}$ & $\begin{array}{l}\text { IOM's entry to the UN as a 'related agency' } \\
\text { in } 2016 \text { represented a sea-change in terms of } \\
\text { the UN's role in migration. After decades of } \\
\text { discussion, an organization with a sole } \\
\text { migration mandate was part of the UN. Next } \\
\text { to calls for more rigorous investigations of } \\
\text { IOM (Elie, 2010; Andrijasevic \& Walters, } \\
2010 \text {; Pécoud, 2018), this case study employs } \\
\text { a bracketing strategy to examine three } \\
\text { moments in time when the IOM Member } \\
\text { States considered IOM's relationship with } \\
\text { the UN more intensely. It then discusses the } \\
\text { factors most relevant to the decision taken by } \\
\text { the IOM Member States in } 2016 \text { to bring IOM } \\
\text { into the UN system. }\end{array}$ & $\begin{array}{l}\text { Mediating Factors: } \\
\text { the role of system } \\
\text { events (coalition } \\
\text { opportunity } \\
\text { structures). } \\
\text { External Factors: } \\
\text { Resources. }\end{array}$ \\
\hline
\end{tabular}




\begin{tabular}{|c|c|c|c|}
\hline Case & Time & Reason for Selection & Key Factors \\
\hline $\begin{array}{l}\text { Global } \\
\text { Compact }\end{array}$ & $\begin{array}{l}2015- \\
2018\end{array}$ & $\begin{array}{l}\text { The Global Compact for Safe, Orderly and } \\
\text { Regular Migration represents the first time } \\
\text { that states have explicitly negotiated an } \\
\text { overarching framework for the governance } \\
\text { of migration. Given historical resistance, this } \\
\text { case study analyses the genesis of the Global } \\
\text { Compact discussion. While the archival data } \\
\text { available to investigate this topic entirely is } \\
\text { limited because the archives of António } \\
\text { Guterres are not yet available, the case looks } \\
\text { at the potential role that the migration crises } \\
\text { played in the negotiation of new, albeit non- } \\
\text { binding, norms for the governance of } \\
\text { migration. }\end{array}$ & $\begin{array}{l}\text { Mediating Factors: } \\
\text { the role of system } \\
\text { events (coalition } \\
\text { opportunity } \\
\text { structures). }\end{array}$ \\
\hline
\end{tabular}

Step 5: Implementing the Case Studies

In implementing each case study, I repeated Step 1 and 2. Thus, for each case, I consulted relevant academic and grey literature and constructed timelines. I reviewed the interview transcripts and relevant documents from the archives for each case study. In Chapters 5 and 6, I used framing analysis to analyse the act of framing (Chapter 5) and then the functioning of the frame (Chapter 6). For Chapter 7, after constructing the initial timeline, the same bracketing strategy employed to identify the case studies (Step 4) was used to select different moments in time when IOM's Member States discussed IOM's relationship with the UN. In Chapter 8, I drew on the advocacy coalition framework in order to understand how an external system event migration crises - changed the playing field.

\subsection{Data Collection and Analysis}

A key aspect of process tracing is the collation of data from different sources such as key informant interviews, archival records, participant-observation, and grey literature. This section turns to look at how the data were gathered and analysed. There were two primary sources of data: key informant interviews (Section 3.3.1) and the UN Archives (Section 3.3.2). In addition to this, I gathered supplementary data for Chapter 6 (Section 3.3.3). 


\subsubsection{Key Informant Interviews}

The thesis draws heavily on 43 interviews conducted with representatives of different IOs, governments, and civil society actors between October 2016 and January 2019. Interviews commenced shortly after the New York Declaration was signed in September 2016.

Table 3.3 presents the summary statistics of the sample. When interview data are referenced in the dissertation, they are identified by the category of the actor (IO, GOV, OTHER), which is further explained in Table 3.5 below, and a reference number. For example, interview number eight which was conducted with a representative of an international organization is referenced as INT-IO-008.

The majority of the interviews took place during two rounds of data collection: 1) from January to March 2017 and 2) from September 2018 to January 2019. The disadvantage of carrying out interviews at different times is that the responses may have been shaped by what was then a rapidly evolving landscape as the negotiations of the two Global Compacts were in full swing. It is crucial to remain aware that interviews capture the views of an individual at a specific point in time. For example, during my early interviews, few respondents discussed the Global Compacts process in any detail. Had I interviewed these individuals at a later date, their account of the evolution of migration as a global policy issue may have evolved.

I prepared an initial list of 30 potential informants based on my network and observations from attending relevant events. I contacted another 34 potential informants based on the recommendations of other informants. The sampling method, purposive with snowballing, was appropriate because I wished to interview individuals who had specific experience working on migrationrelated policy issues at the global level. All individuals contacted received an information letter (Annex 3.1) outlining the purpose of the study, the time commitment required, and crucially, how data would be recorded, stored, and used. At the start of each interview, this information was summarized, and informed consent obtained. Respondents were promised anonymity to promote an open environment during the interview. Thus, in the thesis, the selected quotations used are only identified by sector (international organization; government; or other actors (academia, civil society, think tanks, and foundations). 
Table 3.3 Interview Respondents

\begin{tabular}{|c|c|c|c|c|c|c|}
\hline No & Sex & $\begin{array}{l}\text { Age } \\
\text { Cohort }\end{array}$ & Category & Informal* $^{*}$ & $\begin{array}{l}\text { Interview } \\
\text { Format }\end{array}$ & Interviewed \\
\hline 01 & $\mathrm{M}$ & $35-49$ & Other & No & In-Person & Oct-16 \\
\hline 02 & M & $35-49$ & $\mathrm{IO}$ & Yes & In-Person & Dec-16 \\
\hline 03 & $M$ & $35-49$ & $\mathrm{IO}$ & No & In-Person & Mar-17 \\
\hline 04 & $\mathrm{~F}$ & $35-49$ & $\mathrm{IO}$ & Yes & Skype/Phone & Mar-17 \\
\hline 05 & $M$ & $50-64$ & GOV & No & In-Person & Mar-17 \\
\hline 06 & $\mathrm{~F}$ & $35-49$ & $\mathrm{IO}$ & Yes & Skype/Phone & Mar-17 \\
\hline 07 & $\mathrm{~F}$ & $65+$ & IO & No & In-Person & Mar-17 \\
\hline 08 & $\mathrm{M}$ & $65+$ & $\mathrm{IO}$ & No & In-Person & Mar-17 \\
\hline 09 & $\mathrm{M}$ & $65+$ & Other & No & In-Person & Mar-17 \\
\hline 10 & $\mathrm{M}$ & $65+$ & $\mathrm{IO}$ & No & In-Person & Mar-17 \\
\hline 11 & $\mathrm{M}$ & $65+$ & IO & No & In-Person & Apr-17 \\
\hline 12 & M & $65+$ & $\mathrm{IO}$ & No & In-Person & Mar/May-17 \\
\hline 13 & $\mathrm{M}$ & $50-64$ & Other & No & Skype/Phone & Nov-17 \\
\hline 14 & $\mathrm{M}$ & $65+$ & $\mathrm{IO}$ & No & Skype/Phone & Aug-18 \\
\hline 15 & $M$ & $50-64$ & IO & No & Skype/Phone & Sep-18 \\
\hline 16 & $\mathrm{M}$ & $35-49$ & $\mathrm{IO}$ & Yes & Skype/Phone & Sep-18 \\
\hline 17 & M & $65+$ & Other & Yes & Skype/Phone & Sep-18 \\
\hline 18 & $\mathrm{~F}$ & $50-64$ & $\mathrm{IO}$ & No & Skype/Phone & Sep-18 \\
\hline 19 & M & $65+$ & IO & No & Skype/Phone & Sep-18 \\
\hline 20 & $\mathrm{~F}$ & $65+$ & Other & Yes & Skype/Phone & Sep-18 \\
\hline 21 & M & $50-64$ & $\mathrm{IO}$ & Yes & Skype/Phone & Sep-18 \\
\hline 22 & M & $65+$ & IO & No & Skype/Phone & Sep-18 \\
\hline 23 & $\mathrm{M}$ & $50-64$ & Other & Yes & Skype/Phone & Sep-18 \\
\hline 24 & $\mathrm{M}$ & $50-64$ & $\mathrm{IO}$ & Yes & Skype/Phone & Sep-18 \\
\hline 25 & $\mathrm{M}$ & $65+$ & IO & No & Skype/Phone & Sep-18 \\
\hline 26 & $\mathrm{M}$ & $50-64$ & $\mathrm{IO}$ & No & Skype/Phone & Sep-18 \\
\hline 27 & M & $65+$ & GOV & No & Skype/Phone & Oct-18 \\
\hline 28 & $\mathrm{M}$ & $35-49$ & $\mathrm{IO}$ & Yes & Skype/Phone & Oct-18 \\
\hline 29 & M & $50-64$ & $\mathrm{IO}$ & Yes & Skype/Phone & Oct-18 \\
\hline 30 & $\mathrm{M}$ & $65+$ & Other & No & Skype/Phone & Oct-18 \\
\hline 31 & $\mathrm{~F}$ & $50-64$ & GOV & Yes & Skype/Phone & Oct-18 \\
\hline 32 & $\mathrm{M}$ & $35-49$ & GOV & Yes & Skype/Phone & Oct-18 \\
\hline 33 & $\mathrm{~F}$ & $50-64$ & GOV & No & Skype/Phone & Oct-18 \\
\hline 34 & $\mathrm{~F}$ & $65+$ & Other & Yes & Skype/Phone & Oct-18 \\
\hline
\end{tabular}




\begin{tabular}{lllllll}
\hline 35 & M & $65+$ & GOV & No & Skype/Phone & Oct-18 \\
\hline 36 & M & $50-64$ & GOV & No & Skype/Phone & Oct-18 \\
\hline 37 & M & $35-49$ & IO & Yes & Skype/Phone & Oct-18 \\
\hline 38 & M & $65+$ & IO & No & Skype/Phone & Nov-18 \\
\hline 39 & M & $65+$ & Other & No & In-Person & Nov-18 \\
\hline 40 & F & $35-49$ & IO & Yes & Skype/Phone & Jan-19 \\
\hline 41 & F & $50-64$ & IO & No & Skype/Phone & Jan-19 \\
\hline 42 & F & $50-64$ & IO & Yes & Skype/Phone & Jan-19 \\
\hline 43 & M & $65+$ & IO & No & Skype/Phone & Jan-19
\end{tabular}

Note: The 'informals', further discussed below, was a group of actors convened by Peter Sutherland in the lead up to the adoption of the SDGs. Members were identified from an email addressed to the 'informals' shared with the researcher. The email was sent on 30 October 2014 to 59 recipients.

In total, I contacted 64 individuals for interviews. Of this group, 13 did not respond, seven initially agreed to participate, but it was not possible to schedule an interview, and one individual declined. Contact with a potential participant was stopped after three reminders did not elicit any response. The remaining 43 were interviewed. The response rate was thus relatively high, at 67.2 per cent. I stopped the interviews based on diminishing returns, and the recognition that I had achieved saturation. Saturation was defined in two ways. First, when respondents were asked to provide suggestions for other individuals to contact as part of the snowballing sampling strategy, and no new names were emerging. Second, saturation was defined in terms of the types of answers received. However, several notable omissions from the interview sample exist. It would have been ideal to interview the late Sir Peter Sutherland and the late Kofi Annan, particularly given the significance accorded to these individuals by the majority of my respondents. In addition to this, the sample overrepresents male voices from the Global North. Despite efforts to engage with policymakers in the Global South, I received a higher rate of non-response from this group.

Of the 43 interviews conducted, the vast majority $(n=31)$ took place virtually (skype or telephone) or in writing $(n=1)$. The biggest challenge with virtual interviews, particularly over the telephone, is the inability to read the body language of one's respondent, which can make it more challenging to interpret what is being said. Although virtual interviews have limitations, however, it can be assumed that the target group was generally well versed in digital communication owing to the nature of their work. The advantage of virtual interviews for my target group was the ability to offer greater 
flexibility and to reach a higher number of respondents. While 11 interviews were conducted face to face at the margins of various events - in Dhaka, Geneva, London, and Maastricht - this environment also gave less room to ensure that the setting for the interview was conducive to a deep conversation. Of the 43 interviews, 37 interviews were recorded and fully transcribed. Five interviews were not recorded, all of which took place face to face, and one interview was conducted in writing. During all interviews, I took extensive notes and, particularly for those interviews which were not recorded, I wrote up summary notes as soon as possible after the interview to retain as much information as possible.

Approximately three-quarters of those interviewed were male $(n=32)$, and the remaining quarter was female $(n=11)$. Just less than one-quarter of the sample was aged 35 to 49 at the time of interview $(n=10)$, just short of a third between 50 and $64(n=14)$, with the largest group $(n=19)$ being aged 65 or above. While I made an effort to increase the number of female informants, the purposive nature of the sampling strategy made this challenging to achieve, which may be reflective of the, particularly historically, male-dominated nature of highlevel policymaking. In support of this, male respondents were particularly overrepresented in the 65+ age cohort (Table 3.4).

Table 3.4 Respondents, by Age Cohort and Sex

\begin{tabular}{llll}
\hline & Male (\%) & Female (\%) & Total (\%) \\
\hline $\mathbf{3 5 - 4 9}$ & $7(70.0 \%)$ & $3(30.0 \%)$ & $10(100.0 \%)$ \\
$\mathbf{5 0 - 6 4}$ & $9(64.3 \%)$ & $5(35.7 \%)$ & $14(100.0 \%)$ \\
$\mathbf{6 5 +}$ & $16(84.2 \%)$ & $3(15.8 \%)$ & $19(100.0 \%)$ \\
& $32(74.4 \%)$ & $11(25.6 \%)$ & $43(100 \%)$ \\
\hline
\end{tabular}

Although many individuals have switched categories over the course of their careers, moving, for example from a government or academic posting to an $\mathrm{IO}$, the categorization of key informants is based upon the position held by the individual for the majority of the period covered by the interview (Table 3.5). Given the specific interest of the thesis in exploring the role of IOs in migration governance, the vast majority of participants $(n=28)$ were representatives of various IOs including IOM (7), ILO (6), UNDESA (3), ICMPD (1), UNHCR (1), UNITAR (1), OHCHR (1), UN Women (1) and the World Bank (1); as well as five individuals who were part of Sir Peter Sutherland's team. Because of the smaller number of respondents from academia (6), think tanks (1), foundations (1) and civil society organizations 
(2), I grouped these into one category in the interest of protecting the anonymity guaranteed to participants in the information letter (Annex 3.1). Academic respondents were purposively selected based on their engagement at the multilateral level, and several had careers involving frequent shifts between academic and IO or GOV positions. Government representatives came from Denmark, the Republic of Ireland, Mexico, Sweden, Switzerland, and the US. Seventeen key informants were part of the informal group convened by Peter Sutherland in the years preceding the adoption of the SDGs in 2015. The 'informals' was a group of actors drawn from IO, governments, and civil society that developed a common messaging relating to the place of migration in the SDGs. Having proper representation from individuals in this group, as well as those who were not engaged, was essential to ensure that the views elicited were representative of a broader group of actors.

Table 3.5 Respondents, by Category

\begin{tabular}{lll}
\hline Category & Code & Number \\
\hline International Organizations & IO & 28 \\
Academia, Think Tanks, Foundations, Civil Society & Other & 9 \\
Government & GOV & 7 \\
\hline
\end{tabular}

The interviews were semi-structured, in that an interview guide was prepared (see Annex 3.2), but space was left to ask follow-up questions. As the research progressed, the interviews became less structured. Initially, I asked respondents to identify key events, individuals, and organizations that had influenced how different actors discussed migration at the global level. However, it became evident that these factors came forth organically in broader questions regarding how international discussions on migration had evolved throughout their careers situated earlier in the interview guide. The interviews broadly covered three areas:

- The respondent's view of how international cooperation on migration had evolved over the course of the individual's career

- The respondent's view on the main factors influencing the way migration had been discussed at the international level (including prompts relating to key individuals, organizations, events, governments, funders, publications, and other possible factors) 
- $\quad$ Targeted questions on:

- IOM's journey into the UN system;

- The inclusion of migration in the Sustainable Development Goals (SDGs);

○ The Global Compacts

I transcribed all of my recorded interviews ${ }^{4}$ were fully transcribed and imported into NVivo 12, along with detailed notes of the interviews that had not been recorded. I subsequently thematically coded the interview transcripts in NVivo 12. This process involved several rounds of coding, during which I read through the transcripts multiple times.

The initial coding strategy involved the identification of several thematic categories that would be useful for different parts of the thesis. While I developed a set of 'parent nodes' (Table 3.6) to guide my coding of the transcripts, I identified additional nodes, along with child nodes (Annex 3.3) while coding. As Richards notes: 'coding is not merely to label all the parts of documents about a topic but rather to bring them together so they can be reviewed, and your thinking about the topic developed' (Richards, 2010, p.94). For example, by coding all references to different 'initiatives' such as the GFMD (Chapter 5), the Sustainable Development Goals (Chapter 6), or the Global Compacts (Chapter 8), it was possible to revisit these excerpts when analysing the data for each of these chapters. It was also helpful in constructing the timeline (Chapter 4 ) in the sense that it was possible to see how different respondents discursively connected various initiatives. Beyond the explicit example of frame conflicts cited by respondents, this also helped to uncover implicit frame conflicts identified through different ways of explaining how global migration governance had evolved. A full codebook, including coding guidelines, can be found in Annex 3.3.

\footnotetext{
${ }^{4}$ With the exception of three transcripts where I gratefully acknowledge research support provided by Catherine Hutchison.
} 
Table 3.6 Summary of Thematic Coding

\begin{tabular}{|c|c|c|c|}
\hline $\begin{array}{l}\text { Parent } \\
\text { Node }\end{array}$ & Description & Files & References \\
\hline Frames & $\begin{array}{l}\text { This node captures examples of how } \\
\text { migration has been framed in different ways, } \\
\text { including examples of the migration } \\
\text { management, the migration and } \\
\text { development, and the human rights frames. }\end{array}$ & 42 & 419 \\
\hline $\begin{array}{l}\text { Global } \\
\text { Initiatives }\end{array}$ & $\begin{array}{l}\text { This node captures all references to various } \\
\text { milestones in the evolution of migration as a } \\
\text { policy issue. }\end{array}$ & 41 & 464 \\
\hline $\begin{array}{l}\text { Governance } \\
\text { Drivers }\end{array}$ & $\begin{array}{l}\text { This node captures the factors that are } \\
\text { considered to be drivers of changes in the way } \\
\text { migration has been discussed at the } \\
\text { international level. }\end{array}$ & 42 & 642 \\
\hline Individuals & $\begin{array}{l}\text { This node captures ALL mentions of } \\
\text { individuals by interviewees. and was used to } \\
\text { identify potential interviewees (snowball } \\
\text { sampling) }\end{array}$ & 40 & 643 \\
\hline IOM & This node captures all mentions of IOM & 39 & 428 \\
\hline $\begin{array}{l}\text { Specific } \\
\text { Individuals }\end{array}$ & $\begin{array}{l}\text { Based on the 'individuals node', the most } \\
\text { commonly mentioned individuals were then } \\
\text { coded to capture accounts of how these } \\
\text { individuals were viewed in terms of the role } \\
\text { in migration governance. }\end{array}$ & 36 & 201 \\
\hline
\end{tabular}

\subsubsection{Archival Records}

Archival records supplemented the interview data. On several occasions, this allowed 'off-the-record' information to be taken into consideration where evidence was found within the publicly available United Nations Archives. Documents were primarily sourced from the personal archives of SecretaryGenerals Kofi Annan (1997-2006) and Ban Ki-moon (2007-2016). Since the Global Compacts were negotiated in 2017 and 2018, limited archival documents discussed the Global Compacts. Future research can make use of the personal archives of António Guterres after he concludes his term as Secretary-General. Documents which, like for Guterres' predecessors, will likely include personal communications, memos, and briefs shared with the Secretary-General capturing significant developments in the ongoing debates 
on migration-related matters. An initial search for the term 'migration' in the archives of Kofi Annan and Ban Ki-moon returned 1772 and 1630 documents, respectively. An initial review of these documents revealed much irrelevant material where the term migration was used in a different context, such as the migration of data or birds and animals, and duplicate documents. Thus, in order to narrow down these documents further, specific search terms were employed to gather documents relevant to each case study, namely, 1) IOM's journey to the UN ; 2) the GFMD; 3) the SDGs; 4) the Global Compacts. Having noted the significance of Peter Sutherland's role during the interviews, I added a further search to locate files related to his role as the Special Representative of the Secretary-General for International Migration and Development (SRSG) (Table 3.7). Except for the inclusion of full folders (searches 7-9), no checks were done for duplications across categories. After checking for overlap between categories, the resulting corpus contained 510 unique files. Of these documents, 425 appeared in one search; 58 in two searches, 21 in three searches, and the remaining six in four searches. Table 3.7 summarizes the nine searches, including details on how many documents were ultimately included from each search and the reasons why documents were excluded.

Table 3.7 The UN Archives, Building the Corpus

\begin{tabular}{|c|c|c|c|c|c|c|}
\hline \multirow[t]{2}{*}{$\#$} & \multirow[t]{2}{*}{ Date } & \multirow[t]{2}{*}{ Search Terms } & \multirow[t]{2}{*}{ Files } & \multicolumn{2}{|r|}{ Exclusion } & \multirow{2}{*}{$\begin{array}{l}\text { Inclu } \\
\text { ded }\end{array}$} \\
\hline & & & & \# & Exclusion Reasons & \\
\hline 1 & 22.01 .19 & IOM & 1126 & 882 & $\begin{array}{l}\text { Passing reference to } \mathrm{IOM}^{5}(361) \\
\text { Operational } \\
\text { Does not mention } \mathrm{IOM}^{7}(150) \\
\text { Duplicates (50) }\end{array}$ & 244 \\
\hline 2 & 12.02.19 & Peter Sutherland & 194 & 69 & $\begin{array}{l}\text { Not relevant }{ }^{8}(54) \\
\text { Duplicates (14) } \\
\text { Not within correct date range (1) }\end{array}$ & 125 \\
\hline 3 & 22.03.19 & GFMD & 71 & 8 & $\begin{array}{l}\text { Not relevant (1) } \\
\text { Duplicates (7) }\end{array}$ & 63 \\
\hline 4 & 07.08.19 & $\begin{array}{l}\text { SDGs/Post-2015 } \\
\text { Development } \\
\text { Agenda }\end{array}$ & 273 & 154 & $\begin{array}{l}\text { Duplicates (17) } \\
\text { No explicit references }^{9}(137)\end{array}$ & 119 \\
\hline
\end{tabular}

${ }^{5}$ IOM mentioned in a list of organizations with no other significant mention of migration.

${ }^{6}$ Documents that included no more than 1-2 paragraphs describing IOM activities.

${ }^{7} \mathrm{IOM}$ is not mentioned and there are no other significant references to migration.

${ }^{8}$ Does not relate to migration. Mentions Sutherland only in passing (e.g. as a past speaker in a series) or refers to a different Sutherland.

${ }^{9}$ No discursive connection is made between migration and the post-2015 development agenda and there are no other significant references to migration. 


\begin{tabular}{|c|c|c|c|c|c|c|}
\hline \multirow[t]{2}{*}{$\#$} & \multirow[t]{2}{*}{ Date } & \multirow[t]{2}{*}{ Search Terms } & \multirow[t]{2}{*}{ Files } & \multicolumn{2}{|r|}{ Exclusion } & \multirow{2}{*}{$\begin{array}{l}\text { Inclu } \\
\text { ded }\end{array}$} \\
\hline & & & & $\#$ & Exclusion Reasons & \\
\hline 5 & 11.07.19 & $\begin{array}{l}\text { Global Compact } \\
\text { Migration }\end{array}$ & 34 & 20 & $\begin{array}{l}\text { No mention of compact (15) } \\
\text { Not within the correct date range } \\
\text { (1) } \\
\text { Duplicates (4) }\end{array}$ & 14 \\
\hline 6 & 11.07.19 & $\begin{array}{l}\text { Global Compact } \\
\text { Refugees }\end{array}$ & 39 & 37 & $\begin{array}{l}\text { Duplicates of GCM search (23) } \\
\text { No Mention of Compacts (10) } \\
\text { Not within the correct date range } \\
(2) \\
\text { Duplicate File (1) } \\
\text { Folder Cover (1) }\end{array}$ & 2 \\
\hline 7 & 12.02.19 & $\begin{array}{l}\text { Folder: } \\
\text { Development } \\
\text { initiatives } \\
\text { migration }\end{array}$ & 12 & 6 & $\begin{array}{l}\text { Already in Other Searches (4) } \\
\text { Folder Cover (1) } \\
\text { Duplicate (1) }\end{array}$ & 6 \\
\hline 8 & 12.02.19 & $\begin{array}{l}\text { Folder Human } \\
\text { Rights refugees, } \\
\text { migrants, } \\
\text { displaced persons }\end{array}$ & 48 & 5 & $\begin{array}{l}\text { Folder Cover (3) } \\
\text { Duplicate (1) } \\
\text { Already in Another Search (1) }\end{array}$ & 43 \\
\hline 9 & 12.02.19 & $\begin{array}{l}\text { Folders: IGOs - } \\
\text { IOM }\end{array}$ & 47 & 35 & $\begin{array}{l}\text { Already in Other Searches (34) } \\
\text { Not relevant (1) }\end{array}$ & 12 \\
\hline & TALS & & 1844 & $\begin{array}{l}121 \\
6\end{array}$ & $\mathrm{n} / \mathrm{a}$ & 628 \\
\hline
\end{tabular}

Despite my effort to ensure that the corpus was comprehensive, some documentation may have been omitted due to the limitations of the search engine to capture keywords in documents where the quality of the scan was suboptimal. In addition to this, where some documents may be archived in folders of relevance to migration, occasionally human error results in inaccurately stored files. For example, several documents found in a folder, entitled 'IGOS-IOM' contained no references to IOM but were nevertheless relevant to the thesis. Other searches could have included, for example, the International Conference on Population and Development (ICPD), the Global Commission on International Migration (GCIM), the GMG, or the Berne Initiative. In terms of organizations, searches could have been done to gather documents from other actors such as UNHCR, UNDESA, ILO, or other relevant actors. The sample is, therefore, not a census of all documentation on migration housed in the UN archives. Despite this, given the selection of four case studies, it made sense to restrict the searches to those particular subjects. The UN Archives provide a wealthy source of data for future research. 
After creating the archival corpus, I imported the relevant documents $(\mathrm{n}=510)$ into NVivo 12. I manually reviewed the documents, and recorded descriptive information in an Excel Sheet. This file included the date, language, author, and a brief description of the document (Annex 3.4). Using the query function in NVivo12, I identified subsamples that were of specific relevance to different chapters (Table 3.8). I analysed these subsets in their respective chapters.

Table 3.8 UN Archives: Case Study Subsamples

\begin{tabular}{|c|c|c|}
\hline Chapter & Specific Search Term & $\begin{array}{l}\text { Number of } \\
\text { Documents }\end{array}$ \\
\hline $\begin{array}{l}\text { 5. IOM: } \\
\text { Journey to } \\
\text { the UN }\end{array}$ & International Organization for Migration, IOM & 261 \\
\hline 6. GFMD & $\begin{array}{l}\text { GFMD, Global Forum on Migration and Development, } \\
\text { Global Forum }\end{array}$ & 122 \\
\hline 7. SDGs & $\begin{array}{l}\text { Post-2015, Agenda 2030, SDGs, sustainable } \\
\text { development goals }\end{array}$ & 99 \\
\hline $\begin{array}{l}\text { 8. Global } \\
\text { Compacts }\end{array}$ & $\begin{array}{l}\text { GCM, GCR, Global Compact, Global Compact } \\
\text { Migration. Global Compact Refugee }\end{array}$ & 35 \\
\hline
\end{tabular}

\subsubsection{Supplementary Data Sources}

While the interview and archival data pointed towards procedural aspects of the negotiation of the SDGs, they were not suited to understanding how different IOs framed the relationship between migration and development in advocating for the inclusion of migration in the SDGs. Thus, in addition to the interviews and archival records, I constructed two further sets of documents to support the analysis in Chapter 6. The first set of documents consists of the key outcome documents from the various bodies involved in the negotiations of the SDGs (Table 3.9). I coded these documents using NVivo 12 to identify passages relating to migration in order to analyse how migration was reflected throughout the SDG negotiations. 
Table 3.9 List of Key Outcome Documents

\begin{tabular}{|c|c|c|}
\hline Author & Description & Published \\
\hline UNTT & $\begin{array}{l}\text { Realizing the Future We Want for All } \\
\text { (UNTT, 2012) }\end{array}$ & Jun-12 \\
\hline UN General Assembly & $\begin{array}{l}\text { Rio Outcome Document: The Future } \\
\text { We Want }{ }^{10}\end{array}$ & Jul-12 \\
\hline UNTT & $\begin{array}{l}\text { A Renewed Global Partnership for } \\
\text { Development (UNTT, 2013) }\end{array}$ & Mar-13 \\
\hline Member States & Dhaka Declaration $^{11}$ & Mar-13 \\
\hline HLP & $\begin{array}{l}\text { A New Global Partnership (High-Level } \\
\text { Panel of Eminent Persons, 2013) }\end{array}$ & May-13 \\
\hline SDSN & $\begin{array}{l}\text { Action Agenda for Sustainable } \\
\text { Development (SDSN, 2013) }\end{array}$ & Jun-13 \\
\hline UN General Assembly & HLD Declaration ${ }^{12}$ & Oct-13 \\
\hline UN Secretary-General & $\begin{array}{l}\text { Secretary-General Report for ICPD } \\
\text { review }^{13}\end{array}$ & Jul-14 \\
\hline OWG & $\begin{array}{l}\text { Report of the Open Working Group } \\
\text { (OWG) of the General Assembly on } \\
\text { Sustainable Development Goals }{ }^{14}\end{array}$ & Jul-14 \\
\hline UN Secretary-General & $\begin{array}{l}\text { Synthesis report of the Secretary- } \\
\text { General on the post- } 2015 \text { sustainable } \\
\text { development agenda }^{15}\end{array}$ & Dec-14 \\
\hline SDSN & $\begin{array}{l}\text { Indicators and a Monitoring } \\
\text { Framework (SDSN, 2015) }\end{array}$ & Jun-15 \\
\hline UN & Addis Ababa Action Agenda ${ }^{16}$ & Jul-15 \\
\hline
\end{tabular}

The second source of supplementary data was a sample of documents $(\mathrm{n}=121)$ written by the member organizations of the GMG in which they presented

${ }^{10}$ The Future We Want, GA Res 66/288, UNGAOR, UN Doc A/RES/66/288 (11 September 2012).

${ }^{11}$ Dhaka Declaration of the Global Leadership Meeting on Population Dynamics in the context of the Post-2015 Development Agenda (13 March 2013)

${ }^{12}$ Declaration of the High-Level Dialogue on International Migration and Development, UNGAOR, $68^{\text {th }}$ Session, UN Doc. A/68/L.5 (1 October 2013)

${ }^{13}$ Report of the Secretary-General: Recurrent Themes and Key Elements identified during the Sessions of the Commission on Population and Development, UNGAOR, 69 $9^{\text {th }}$ Session, UN Doc. A/69/122 (15 July 2014)

${ }^{14}$ UNGA, Report of the Open Working Group of the General Assembly on Sustainable Development Goals, UNGAOR, 68th Session, UN Doc. A/68/970 (12 August 2014)

${ }^{15}$ Report of the Secretary-General: The Road to Dignity by 2030: Ending Poverty, Transforming all Lives and Protecting the Planet, UNGAOR, UN Doc. A/69/700 (4 December 2014)

${ }^{16}$ Addis Ababa Action Agenda, UNGAOR, 69th Session, UN Doc. A/RES/69/313 (17 August 2015) 
arguments for why the drafters of the post-2015 development agenda should include migration. International Organizations write prolifically. Google site searches for PDF documents on the websites of 17 GMG members ${ }^{17}$ identified just shy of three million documents, of which approximately 200,000 referenced migration and just over 10,000 referred to both 'migration' and the 'post-2015' development agenda. There are limitations to this approach. Next to the fact that PDF documents are only one medium through which IOs engage in discussions, the results that one receives may also be contingent on both location and past search history. Accordingly, I ran searches after clearing the cache of the computer to limit potential bias. Additionally, articles may be posted multiple times (duplicates) on different parts of a website. A Google algorithm that automatically detects and removes possible duplicate texts from the results it displays (although the user can override this function if desired) partially resolves this issue. After implementing these exclusions, approximately 2500 documents remained. Based on the assumption that the first search results on Google will show the most relevant ${ }^{18}$ results, I downloaded the top 20 articles for each organization for further analysis, which resulted in an initial set of 340 documents. All documents were downloaded within one week (9 to 16 February 2017).

Documents were excluded from the in-depth review if they did not meet all of the following requirements: (1) the document was produced before the adoption of the SDGs; (2) the document was produced by the organization; (3) the document discursively connects 'migration' and the 'post-2015' development agenda. Documents containing no narrative text (for example, conference programmes with no text other than the time and location of specific sessions) or those relating to alternative post-2015 processes were also excluded. In total, 219 documents were excluded (Table 3.10). Documents, where the specific IO was not the (sole) author of a document, were also excluded $(n=92)$.

\footnotetext{
17 The 17 members of the GMG included in the analysis were FAO, ILO, IOM, OHCHR, UN Women, UNCTAD, UN-DESA, UNDP, UNESCO, UNFPA, UNHCR, UNICEF, UNITAR, UNODC, UNU, World Bank, and WHO. The regional commissions were excluded. Additionally, members who joined the GMG after the adoption of the SDGs were also excluded (UNIDO, WFP).

${ }^{18}$ Relevance is defined as those documents where the keywords appeared most frequently or were well described in the search engine optimisation (SEO) description) of the document.
} 
Table 3.10 SDG Documents, Inclusion and Exclusion Criteria

\begin{tabular}{ll}
\hline Exclusion Reason & Documents \\
\hline Published after October 2015 & 57 \\
Agency is not the (sole) author of the document & 92 \\
$\begin{array}{l}\text { Does not discursively link migration and post-2015 } \\
\text { development agenda }\end{array}$ & 59 \\
$\begin{array}{l}\text { No narrative text (e.g., event schedule) } \\
\text { Refers to a different post-2015 process (e.g., TB Strategy) }\end{array}$ & 2 \\
Duplicate & 3 \\
Total & $\mathbf{2 1 9}$ \\
\hline
\end{tabular}

The resulting set of documents ( $\mathrm{n}=121)$ were all published between 2012 and 2015 and consisted of 3,892 pages of text. Sixty-one $(50.4 \%)$ of these documents were published before the release of the Open Working Group (OWG) report on 18 July 2014, and 57 (47.1\%) were published after. For three undated documents, I was not able to deduce whether it was prepared before or after 18 July 2014 from its contents. The significance of this date is that, while further negotiations had been anticipated, the 17 goals and 169 targets that comprise the SDGs were released and the window for bringing issues into the agenda were limited after this date. For three documents, the precise publication date is not available and cannot be deduced from the content of the document. A list of these documents is located in Annex 3.5.

The documents were subsequently subdivided into three categories: 1) documents which made a passing reference to migration and the post-2015 development agenda; 2) documents that solely focused on the post-2015 development agenda (e.g., education and the post-2015 development agenda); and 3) documents that focused solely on migration and the post2015 development agenda. Just over half (55.4\%) of the documents belonged to the first category. Just short of a third (31.4\%) were documents focused on the post-2015 development agenda but without a specific migration focus. The remaining articles (13.2\%) focused on migration and the post-2015 development agenda. The 16 documents that solely focused on migration and the post-2015 development agenda were produced by four organizations: IOM (7 documents), ILO (6 documents), UNU (2 documents), and UNITAR (1 document) (Figure 3.1). 
Figure 3.1 Documents Linking Migration to the Post-2015 Development Agenda

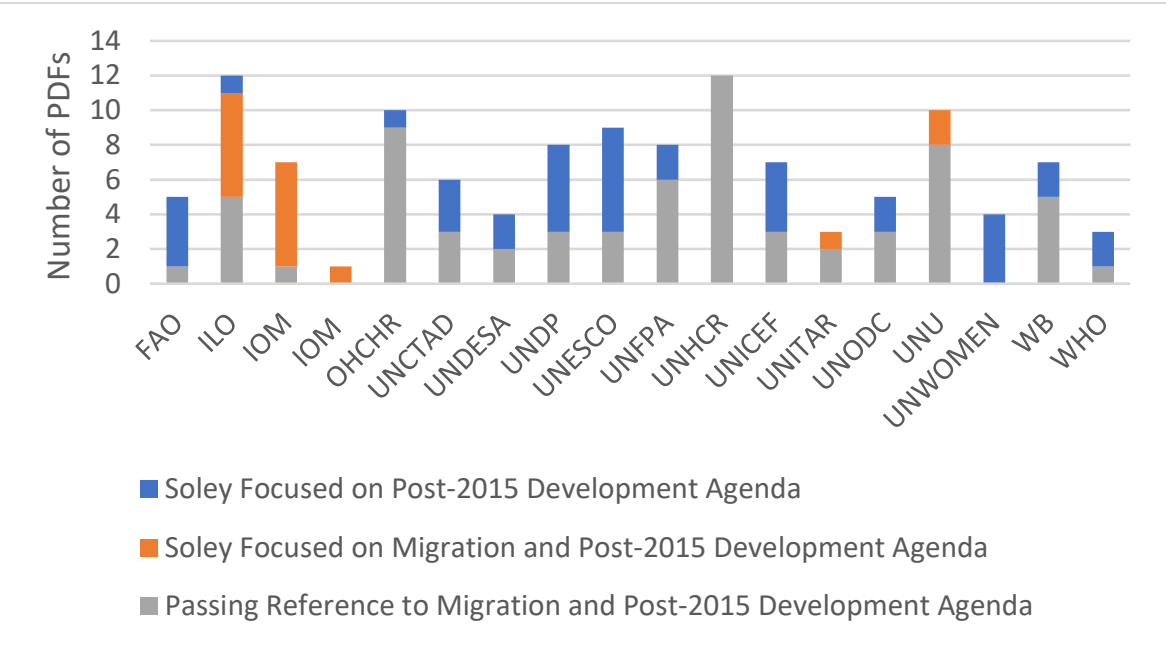

Source: Author's Own

Note: $\mathrm{n}=121$

In each document $(n=121)$, relevant passages where discursive linkages were made between migration and the sustainable development goals or the post2015 development agenda were identified and coded in NVivo12. For documents making a passing reference to migration and the post-2015 development agenda $(\mathrm{n}=67)$, relevant passages were identified by doing keyword searches ${ }^{19}$. Only passages where migration and the post-2015 development agenda were discursively connected were coded. Documents that were coded as 'solely focusing on the Post-2015 development agenda' $(n=38)$ were searched for migration-related keywords on the assumption that any reference to migration in the context of these reports was, by nature of the document, discursively connected to the post-2015 development agenda. For documents where migration and the post-2015 development agenda were the sole focus $(n=16)$, only passages explicitly offering arguments for why migration should be included were coded. After identifying the key arguments why migration should be included in the post-2015 development agenda, a secondary round of coding looked at the argumentation style

\footnotetext{
${ }^{19}$ Migration-related keywords included migr*, remittances, diaspora; and SDG related keywords included post-2015, post 2015, Agenda 2030, SDG, and sustainable development goal.
} 
employed by different organizations in order to identify the frames underlying specific formulations.

The analytical strategy for the second round of coding was informed by the work of Habermas (1993) and employed the operational definitions developed by Sjursen (2002). Habermas (1993) distinguished between three different approaches to argumentation: the pragmatic, the ethical-political, and the moral. The pragmatic approach is 'based on a means-ends type of rationality where actors are considered to take decisions made on calculations of utility based on a given set of interests' (Sjursen 2002, p.494). Pragmatic argumentation focuses on 'technical and strategic direction for action' (Habermas, 1993, p.10). The interests of the agent making the argument are central to the pragmatic approach. In the ethical-political approach, 'justification would rely on a particular conception of the collective 'us' and a particular idea of the values represented by a specific community' (Sjursen 2002, p.494). Ethical-political argumentation focuses on offering 'clinical advice' (Habermas 1993, p.9) based on an established set of mutually recognized rules. The moral approach, while similar to an ethical approach, differs in that 'justifications rely on universal standards of justice, regardless of the utility of the policy to the particular actors involved in the decision or the specific values or perceptions of the "good life" embedded in the community outlining the policy' (Sjursen 2002, p.494). Moral arguments offer some form of judgement about what one 'ought' to do.

\subsection{Methodological Challenges and Ethical Considerations}

In addition to the challenges already outlined in this chapter, this final section reflects on some of the broader challenges, one of which is related to the fact that the migration governance landscape was in a period of intense activity during the implementation of the study. This context made it challenging to organize interviews with individuals working in the field. Many of those I spoke to were actively engaged in fast-moving discussions as governments around the world negotiated the Global Compacts. On the one hand, this meant that many framed the evolution of global migration governance to explain the current developments without being asked to do so. However, on 
the other hand, it meant that, had the interview been conducted at a different point in time, the same respondent may have given different answers.

The politicised nature of the migration policy landscape also presented a challenge. To encourage an open environment for discussion, I guaranteed anonymity to all participants. Political sensitivities led several participants to request that the information shared during the interview or documents shared afterwards remained off the record. Ethically speaking, as a researcher, one must respect the wishes of one's respondents. The use of the UN archives, however, allowed information that respondents had shared 'off the record' to be included with attribution only made to archives. The additional advantage of using multiple data sources was that this allowed information to be crosschecked, triangulated, increasing the robustness of the findings.

A final notable consideration that merits reflection relates to the sample of respondents included in the thesis. I have already indicated that the sample reflects a significantly higher proportion of individuals from Western Europe and North America, as well as more males than females. The question arises as to whether this reflects a bias in the sample or bias in the composition of the particular group of actors engaging in global policy discussions relating to migration. Given that the same names were generally being suggested for interviews towards the end of the process, it is fair to assume that a degree of bias does exist in the group's composition. It is likely that people from the Global South would have suggested different names altering the composition of the overall sample and reducing the Eurocentricity of the research findings. Given that I am also from Western Europe, it is important to state this upfront. While there was a higher proportion of non-responses from actors in the Global South, if given the opportunity to repeat the research, I would pay far more attention to ensuring better representation of actors from the Global South. 


\section{A History of Global Migration Governance}

\subsection{Introduction}

In December 2018, almost a century after the end of the First World War and the signing of the Treaty of Versailles, states adopted two Global Compacts, one on migration and one on refugees, establishing roadmaps for the future of international cooperation relevant to population movements. While commentators often attribute these developments to the 'migration crises' of 2015 (Newland, 2019; Betts, 2018; Guild, 2018; Klein Solomon and Sheldon, 2019), they are also the product of more than one hundred years of institution-building during which the world has evolved tremendously. The world in 2018 looked very different from that of 1919. Rapid population growth, the advancement of technologies, war and conflicts, decolonization, economic crises, and other significant events have had implications for the patterns and governability of population movements. The environment within which IOs, states, and other actors operate has also dramatically changed.

While there is a body of literature that investigates the history of various aspects of the global migration governance landscape (c.f. Bauloz 2017; Betts and Kainz, 2017; Martin, 2014; 2015; Koser, 2010; Chamie and Mirkin, 2013; Newland 2010; Pécoud and de Guchteneire 2007; Thouez 2018; de Wenden 2012; Karatani, 2005; Long, 2013; Crush, 2013; Ghosh, 2005; Thouez and Channac, 2005; Böhning, 1991; Doyle, 2004; Miller, 2000; Martin, Martin, and Cross, 2007; and Widgren, 1990), few studies focus on providing a picture of its overall development. Notable exceptions include Martin (2014) who, in 'International Migration: Evolving Trends from the Early Twentieth Century to the Present', traced the evolution of an 'international migration "regime"' (p.1) and Betts and Kainz (2017) who traced the evolution of global migration governance from 1919. While Martin (2014) drew attention to the cyclical aspects of the evolving regime, such as the role of conflict in catalysing action at the international level, her analysis is still often framed in terms of a linear journey towards a coherent regime. For example, she described the emergence of coordinative mechanisms such as the Global Forum on Migration and Development (GFMD) and the Global Migration Group (GMG) as 'incipient regime-forming steps' (p.2). Betts and Kainz (2017) were 
perhaps even more linear in their approach. They divided the history of migration governance into four time periods: 1) early migration governance (1919-1989); 2) taking stock (1994-2006); 3) the era of migration and development (2007-2015); and 4) the New York Declaration and Global Compact Process (2016-2018).

The challenge with adopting an overly linear view of the evolution of the global migration governance landscape is that one may 'fall into progressive narratives in which global solutions build upon themselves, in which bilateral arrangements beget regional ones, regionals ones beget global multilateral ones, and multilateral solutions should and will deepen over time' (Cohen, 2018, p.48). Cohen (2018) argued that that the success of early multilateral efforts, which shifted the balance of power in the international system towards a multipolar model, have made it increasingly difficult to reach agreement in a multilateral setting. Hence, multilateralism, as a 'problem-solving strategy or organizing principle' (Cohen, 2018, p.50), has evolved and matured over time (c.f. Kahler 1992; Weber 1992; Van Langenhove, 2010). Accordingly, the governance of international migration may have become less multilateral over time. However, these broader theoretical considerations are rarely explicitly examined in the context of studies seeking to explain why global migration governance has evolved in the way it has. A need exists to consider the evolution of global migration governance in a way that accounts for these broader changes and which does not disconnect global migration governance from the context within which it evolved.

Departing from the traditional linear accounts of the evolution of global migration governance, therefore, this chapter addresses the following subquestions:

How has global migration governance evolved over the past century?

What factors have broadly affected the way that global migration governance has evolved?

After constructing a basic timeline of key events in the evolution of global migration governance, (Annex 4.1), I identified seven distinct, yet overlapping, phases, which provide structure to the remainder of the chapter (Table 4.1). Section 4.2 reviews the period between 1919 and 1951, which was an era of institution building. The majority of the institutions with a mandated 
role in migration governance today were established by 1951. With the institutional landscape largely in place, Section 4.3 reviews the period between 1939 and 1990, during which various attempts were made to develop binding norms to govern population movements. Attempts to develop international conventions on migration have generally failed to gain traction, with the finalization of one convention shortly followed by the negotiation of a new instrument, with none receiving significant ratification, particularly among key countries of destination. Thus, from the mid-1980s, one begins to see attempts to govern migration proliferating in regional and informal as opposed to in global and formal settings (Section 4.4).

After the fall of the Berlin Wall in 1991, renewed optimism for international cooperation saw the UN host a flurry of conferences on a range of different issues, which culminated in the adoption of an ambitious plan to tackle poverty, the Millennium Development Goals. Attempts to organize a conference on migration did not garner the necessary support, which, along with human rights more broadly, was omitted from the new agenda (Section 4.5). While efforts to organise a conference on migration in the 1990s did not succeed, by the turn of the century, interest in migration had increased, perhaps as a result of $9 / 11$ or the realization that remittances represented a more significant source of income to developing countries than development aid. Accordingly, former Secretary-General Kofi Annan placed migration high on the UN agenda (Section 4.6). However, next to the continuation of regional cooperation on migration outside of the $\mathrm{UN}$, two distinct trajectories in migration's journey as a global policy issue are apparent from the early 2000s: a slow-moving trajectory focused on migrant rights within the UN system (Section 4.6), and, particularly from 2006, a rapidly evolving trajectory focused on migration and development which took place chiefly externally to the UN but with a degree of UN involvement. The developments from 2006 arguably resulted in the acceptance of migration as a global policy issue through the inclusion of several migration relevant targets in the unanimously adopted Sustainable Development Goals (SDGs) in 2015 (Section 4.7). However, a series of migration crises around the world in 2015 demonstrated the limits of the existing international architecture, which led states to discuss new global arrangements. These discussions ultimately led to IOM entering the UN as a 'related agency' and states to decide to negotiate two Global Compacts (Section 4.8). 


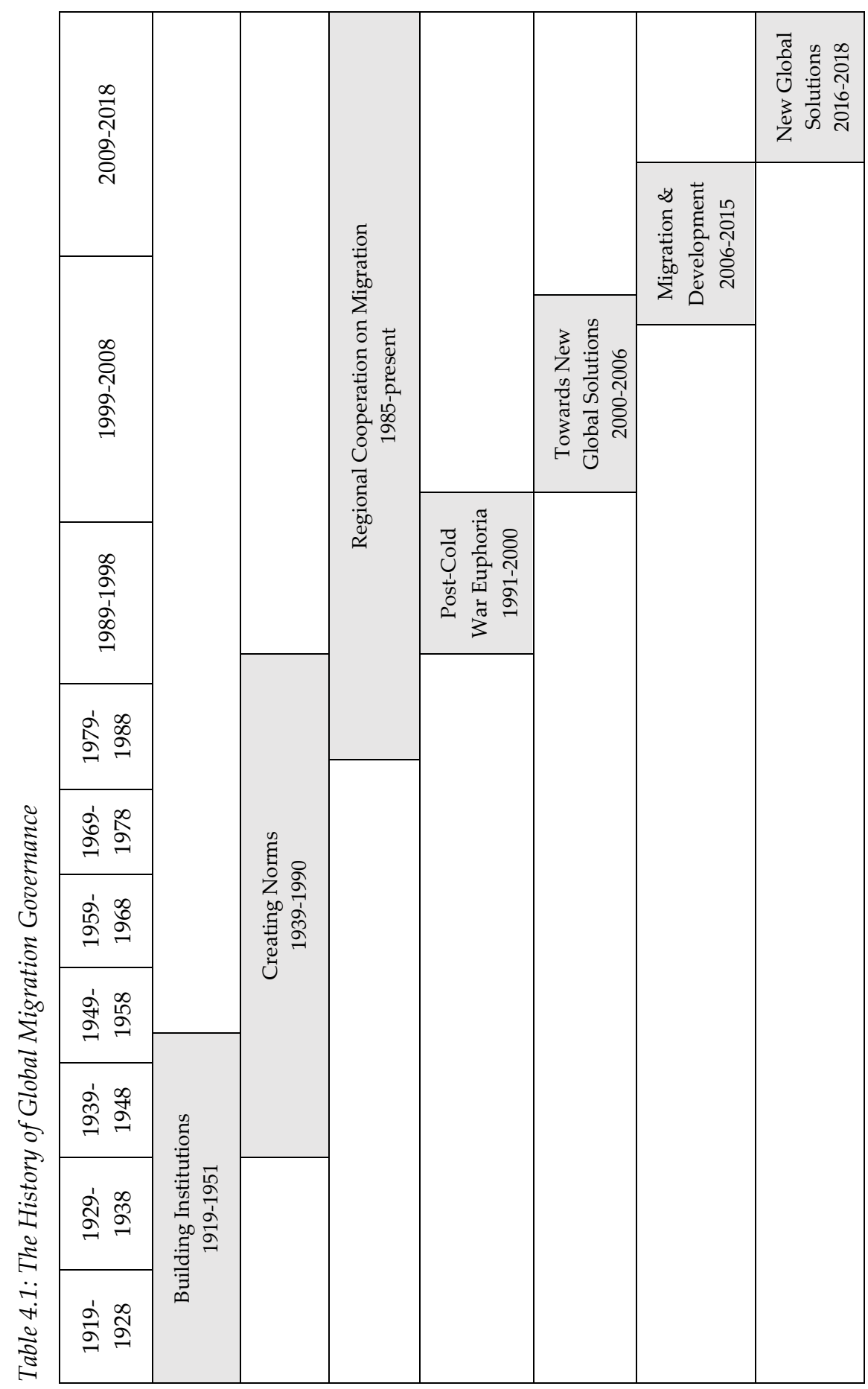




\subsection{Early Global Migration Governance: Building Institutions (1919-1951)}

Although a desire to control population movements can be traced far back in history, for example, to the birth of the concept of state sovereignty in the 17th century, many of the international institutions that exist today were created by states in the early 20th century. A general trend towards international cooperation on a range of issues characterized the 20th century, and the number of international organizations increased exponentially (Section 2.2.2). Two particularly noteworthy attempts at intergovernmental cooperation were the League of Nations, founded in 1920 as a concrete outcome of the Paris Peace Conference, which marked the end of the First World War, and the UN, established shortly before the end of the Second World War. Both the League of Nations and the UN were efforts to encourage states to cooperate with the stated aim of achieving world peace. Hence, one should view the evolution of global migration governance in the context of ongoing efforts to shape and define the contours of what should fall under the remit of these respective organizations, a discussion influenced profoundly by the experiences of two World Wars.

The creation of the ILO by the Treaty of Versailles in 1919 marked a key starting point for the journey of migration as a global policy issue (cf. Karatani, 2005; Long, 2013; Martin, 2014; Betts and Kainz, 2017). The preamble of ILO's Constitution identified the 'protection of the interest of workers when employed in countries other than their own' as one of the 'conditions of labour' that needed to be improved to address the injustice that can 'imperil' peace (ILO, 1919). The constitutional role of the ILO in labour migration was quickly operationalized. At the first meeting of the General Conference in 1919, two bodies were created within ILO tasked with migration matters: a special section in the International Labour Office dealing with questions relating to worker migration and their conditions in destination countries; and an international commission focusing on measures to regulate and protect migrant workers (Martin, 2014).

Although mandated to work on labour migration, the ILO was soon called upon to assist Fridjolt Nansen in his role as High Commissioner for Refugees for the League of Nations. Nansen's position was initially created to support Russians affected by the Denationalisation Decree of the then Soviet Union in 1921, although in subsequent years, his mandate expanded to include 
Armenian (1924), Assyrian and Assyro-Chaldean (1928) refugees (Long, 2013; Martin, 2014). One of Nansen's most notable contributions was the introduction of the Nansen Passport in 1922, which facilitated the international travel of refugees and is the antecedent of the modern-day passport. The Nansen Stamp Fund was established to facilitate the cost of obtaining this document but, between 1927 and 1930, also offered small business loans to refugees to help their integration in their new destinations. These measures reflected the nature of refugee protection of the time, which was focused on the economic inclusion of displaced populations driven primarily by development concerns (Long, 2013). Reflecting this focus, and on Nansen's initiative, the ILO assumed operational responsibility for refugees, supporting Nansen's office between 1925 and 1929. After Nansen died in 1930, his position as High Commissioner ceased to exist. However, the Nansen International Office for Refugees was created, working under the authority of the League of Nations for the best part of the next decade (Long, 2013; Martin, 2014).

From 1938, states created a series of temporary organizations to carry on Nansen's work with refugees. In July 1938, a conference convened by US President Franklin D. Roosevelt in Evian brought together 32 states and other actors to discuss solutions for Jewish refugees (Martin, 2014). Many commentators look back at the Evian conference with scepticism arguing that 'some delegates spent far more time enjoying the Alps than they did discussing the plight of refugees' (Martin, 2014, p.55). A concrete outcome of the Evian conference was the establishment of the Intergovernmental Committee on Refugees (IGCR). However, the IGCR 'became inactive as soon as it was founded' (Karatani, 2005, p.523). Karatani (2005) argues that its creation was more about establishing an institutional framework for addressing refugee matters to demonstrate US compassion for refugees and willingness to cooperate internationally while drawing attention away from US domestic policies. Amid the war, the US organized a conference in Bermuda to 'revitalise the dormant IGCR' (Karatani, 2005, p.527), which resulted in the creation of the United Nations ${ }^{1}$ Relief and Rehabilitation Administration (UNRRA) which would become part of the UN upon its establishment in 1945. In 1947, in the wake of displacement caused during the

\footnotetext{
${ }^{1}$ Although founded before the United Nations as we know it today, the use of United Nations in this context was a reference to a term coined by US President Franklin D. Roosevelt to describe the 26 nations that formed the 'Allied Powers' who were united against the Axis Powers (Germany, Italy and Japan) during the Second World War.
} 
Second World War, the International Refugee Organization (IRO) was established to replace the UNRRA. After a series of other temporary organizations, the United Nations High Commissioner for Refugees (UNHCR) was established in December 1950, followed shortly by the adoption of the UN Convention Relating to the Status of Refugees in July 1951.

While historically ILO had provided operational support to the High Commissioner under the League of Nations, the politics of the Cold War came into play as states and other actors discussed how the international system should respond to displacement caused by the Second World War. The separation of the migration and refugee regimes, a separation that continues to influence the migration governance landscape today, occurred in the post-Second World War period (Karatani, 2005). To understand the separation further, one must take a step back and follow ILO's journey at that time. In 1944, the Declaration of Philadelphia reinforced ILO's mandate to work on programmes relating to migrant workers. In the years following World War II, the ILO continued to assert its place as the key institutional actor with a constitutional mandate to coordinate the international community's response to migration. An ILO-UN plan on international coordination in the area of migration makes a distinction between different institutional actors operating in the area of migration based on their longevity and mandates. In the first category, the ILO and the UN are defined as being 'of permanent character and are charged by their constitutional characters with the responsibility for considering and solving international problems of an economic and social nature, and whose activities and programmes of work demonstrate their direct and major interest in migration problems' (ILO, 1947 in Karatani 2005, p.523). The second category included organizations that were 'not of a permanent character or whose consideration of migration problems is only incidental to their other responsibilities and programmes' (ILO, 1947 in Karatani 2005, p.523). The second category included the newly established IRO, the United Nations Educational, Scientific and Cultural Organization (UNESCO), the Food and Agricultural Organization (FAO), the World Health Organization (WHO), and the International Bank for Development and Reconstruction (IBDR).

In the years to come, ILO continued to assert its role, and, in 1951, organized a conference to lay out a proposal for the relocation of those displaced during the Second World War: 
'In 1951, ILO had proposed a flagship programme, which would have been huge in dollars of the day. The reaction from certain states was to boycott the big conference and instead to organize a meeting in Brussels to set up the Intergovernmental Committee on European Migration, which, as you know, was the genesis of $\mathrm{IOM}^{\prime}$ (INT-IO-012).

However, as the quotation highlights, ILO's proposal to be the central coordinator of international responses to migration was not to bear fruits. At a conference in Naples in October 1951, the ILO proposal to organize migration was rejected, mainly due to opposition from the US (Perruchoud, 1989). Shortly after the conference, a Congressional Decision made their objections to ILO's involvement clear:

'The US Congress was not prepared to release $\$ 10$ million in funding to an organization whose members included the Soviet bloc states Czechoslovakia and Poland, and instead favoured the establishment of a much more tightly controlled inter-governmentalrather than international-organization which would focus solely on the transportation of migrants and refugees' (Long, 2013, p.18).

Shortly after the rejection of ILO's plan, an intergovernmental organization, the Provisional Intergovernmental Committee for the Movement of Migrants from Europe (PICMME), was established to provide support to the newly established UNHCR. In an arrangement not dissimilar to that established between Nansen's office and the ILO in the 1920s, PICMME was designed to provide operational support to UNHCR (Elie, 2010). Although initially also created as a temporary body, PICMME would eventually become a permanent institution, known as the International Organization for Migration (IOM) since 1989.

By 1951, therefore, the institutional blueprints for global migration governance were mostly in place. Although new actors have since joined the ranks, ILO, UNHCR, and IOM continue to be the three IOs specifically mandated to deal with matters related to population movements. In the case of ILO, the focus is on labour migrants, for UNHCR it is refugees, and IOM has a broad mandate to work on migration-related matters. The US played a 
significant role in establishing this institutional framework driven by the politics of the Cold War. The US viewed the League of Nations and the ILO as unsuitable venues within which to discuss refugee matters. Hence, as the dominant political power in the post-World War II era, the US used its financial power to establish new institutions, at first temporary in nature, to handle these matters. The US therefore influenced the separation between the refugee regime within the $\mathrm{UN}$, and the migration regime largely external to the UN.

\subsection{Early Global Migration Governance: Developing Binding Norms (1939-1990)}

From an initial attempt in 1939 that failed because of the outbreak of war to the adoption of the International Convention on the Protection of the Rights of All Migrant Workers and Members of Their Families in 1990, various attempts to create binding norms in the area of migration have generally failed to gain traction. It is critical to view these developments in the context of a rapidly changing world. Next to the implications of Cold War politics in the establishment of the central institutions that remain relevant in the contemporary landscape of global migration governance, the end of the Second World War also marked the start of a process of decolonization which was to change the nature of labour migration:
'There was this issue of labour moving within the colonies, which was never seen as international migration because it was moving within the territory of, by and large, European countries' (INT-IO-021).

Previously the movement of an individual between the different territories was not considered to be international migration and therefore was excluded from the original migrant workers convention adopted by the ILO in 1939 . As countries became independent, and Europe required workers for their post-war reconstruction, the question of governing international labour migration became increasingly pertinent. Externally to the UN, many industrialized countries started to institutionalize migration-related matters into their policy frameworks. While in the United Kingdom of Great Britain and Northern Ireland (UK) workers were still able to move within the 
boundaries of the disintegrating Empire until the Commonwealth Immigrants Act 1962, many other countries in Europe established guest worker programmes to facilitate the migration of labourers to, and within, Europe. However, the 1973 oil crisis, which essentially put a stop to the postwar guest worker programmes, changed the playing field, with countries in Europe increasingly concerned about irregular migration, joined by the US in the 1980s (Castles, 1986; Freeman, 1992).

Next to increasing the number of individuals qualifying as international migrants, decolonization was also to change the balance of power in the global system. As Van Langenhoven (2010) notes, 'when the UN was founded, two-thirds of its current members did not even exist as sovereign states as their people were still living under colonial rule' (p.264). As more states joined the multilateral system, reaching an agreement that aligned with the interests of a greater diversity of states became increasingly tricky (Kahler, 1992). As countries gained independence, many became new members of the UN (Figure 4.1). Given that the UN was founded based on multilateral principles, that of the sovereign equality of states, the increased membership due to decolonization altered the playing field upon which international relations occurred. The end of the Cold War and the dissolution of the Soviet Union and Yugoslavia in 1991 saw the UN membership grow even further. Furthermore, many Pacific Island states joined the UN in the 1990s. It is within this evolving context that one should view the evolving normative framework that sought to govern population movements.

Figure 4.1 UN Membership, 1945-2019

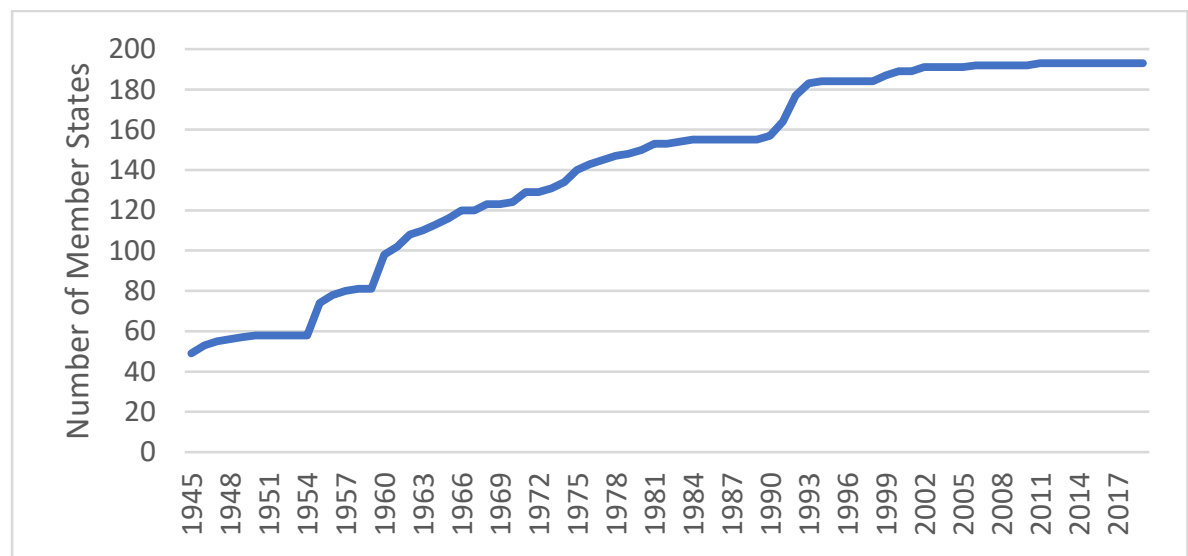

Source: United Nations (2019c) 
The negotiation of ILO's first international convention for labour migration began before the Second World War (Miller, 2000). The convention responded to concern among countries of origin, most notably Italy, that 'migrants were primarily viewed as an exploitable labour force' (INT-IO012). The Migration for Employment Convention, 1939 (No. 66), was adopted at the $25^{\text {th }}$ Session of the International Labour Conference in June 1939. However, because of the outbreak of the Second World War, the convention did not receive one single ratification. A decade later, with new concerns primarily relating to the need for workers to rebuild Europe, the ILO adopted the Migration for Employment Convention (Revised), 1949 (No. 97) to revive interest in its pre-war attempt at creating binding norms in the area of labour migration. While the new convention reflected the essence of its antecedent convention, it gave more prominence to the notion of equal treatment and discrimination, as well as provisions relating to social security, remittances, and the health of migrant workers at all stages of the migration process (Annex 4.2). Convention No. 97 has arguably been the most successful attempt at creating binding standards in the area of labour migration:

'The 1949 instrument has quite a few ratifications
amongst Western European countries, as well as
countries like Israel and New Zealand reflecting that
achieving agreement on binding standards relating to
labour migration was once then less problematic than it
became' (INT-IO-021).

However, viewed against other international conventions, it remains poorly ratified.

After Convention No. 97, the focus of ILO's next convention was on irregular migration. Between 1945 and 1974, many European countries, such as Belgium, France, the Netherlands, Switzerland, and, Germany from 1948, organised the recruitment of migrant workers to fuel post-war reconstruction efforts. Following the 1973 oil crisis, recruitment stopped, and migration from countries outside of the European Community was banned (Castles, 1986). However, migration continued, mainly through family reunification and formation at first, but then asylum increasingly became a de facto immigration channel for migrant workers (Freeman, 1992), which provided the rationale to develop a complementary convention that would address irregular migration (INT-IO-042). The Migrant Workers (Supplementary Provisions) Convention 1975 (No. 143) placed even more emphasis on ensuring the rights 
of migrant workers. In addition to requiring states to repeal discriminatory legislation and practice, the new Convention also requires states to adopt 'positive actions in order to promote equality of treatment and opportunity' (Chetail, 2019, p.209), which perhaps reflected the changing composition of UN membership. When the Migration for Employment Convention (Revised), 1949 (No. 97) was adopted, the UN had 57 Member States, a number which had more than doubled to 134 by the time the Migrant Workers (Supplementary Provisions) Convention 1975 (No.143) was adopted in July 1975.

However, Convention No. 143 was not well received. Just as the US' decision to fund PICMME had thwarted ILO's efforts in the 1950s, the ILO was sidelined, this time by developing countries concerned that the Convention No. 143 would restrict overseas employment opportunities and remittances (Böhning, 1991). Furthermore, the US and the UK, still the main centres of power in the international system, had little interest in the Convention. As noted, they still had policies in place to facilitate migration. For the US, it was not until the late 1980s that the US started to face increased irregular migration from Mexico and introduced employer sanctions coupled with an amnesty campaign in 1986 in an unsuccessful bid to tackle irregular flows (Freeman, 1992). For the US and the UK, this led to the exploration of alternative forms of intergovernmental cooperation, which will be explored further in Section 4.4. However, for many developing countries, what Böhning (1991) describes as 'the battle for the UN Convention' (p.699) arose from dissatisfaction with Convention No. 143. As Böhning (1991) described, 'the ink on ILO Convention No. 143 had hardly dried when the Mexican and Moroccan governments began to join hands in UN circles but outside the ILO to launch the elaboration of a new Convention on illegal migrants and their employment' (Böhning, 1991, p.699). In 1977, Mexico sponsored a General Assembly Resolution' ${ }^{2}$ on 'Measures to Improve the Situation and Ensure the Human Rights and Dignity of All Migrant Workers'. Two years later, the UN formed an Open-ended Working Group of the General Assembly to develop a new UN convention on migration ${ }^{3}$.

\footnotetext{
${ }^{2}$ Measures to Improve the Situation and Ensure the Human Rights and Dignity of All Migrant Workers, UNGAOR, 32nd Session, UN Doc. A/RES/32/120 (16 December 1977)

${ }^{3}$ Measures to Improve the Situation and Ensure the Human Rights and Dignity of All Migrant Workers, UNGAOR, 34 ${ }^{\text {th }}$ Session, UN Doc. A/RES/34/172 (17 December 1979)
} 
Böhning (1991) posits that the reasons Mexico and Morocco wished to pursue a convention within the UN as opposed to through the ILO was because they did not enjoy an 'automatic majority' within the ILO, making the UN an easier venue within which to achieve their goals. By the time the International Convention on the Protection of the Rights of All Migrant Workers and Members of Their Families (ICRMW) was adopted, the UN had 157 Member States. It took nine years from the presentation of the first draft of the ICRMW in 1981 before the text was finalized - a testament to the difficulty of achieving consensus within the expanded UN. It took a further 13 years for the Convention to receive the 20 ratifications required for the Convention to come into force (Ghosh, 2005). The ICRMW further solidified the distinction between refugees and migrants, by explicitly excluding refugees from its definitions where Convention No. 97 and Convention No. 143 had included them (Chetail, 2019). This exclusion likely was to appease actors such as the US and UNHCR who wished to keep the refugee and migration regimes separate (Pécoud, 2017).

The controversy surrounding the ICRMW and ILO conventions resulted in a relatively low rate of ratification, particularly among key destination countries. As of 20 August 2019, less than half ( $n=91)$ of UN Member States had ratified at least one of the three migration-related conventions ( $C 97$, C143, and the ICRMW) (Table 4.2).

Table 4.2 Ratifications of Key Migration Relevant Conventions

\begin{tabular}{|c|c|c|c|}
\hline \multicolumn{2}{|c|}{ Convention } & \multirow{2}{*}{$\begin{array}{l}\text { Description } \\
\text { Primarily relates to ensuring the } \\
\text { rights of migrants in destination } \\
\text { countries and regulating the } \\
\text { recruitment process. }\end{array}$} & \multirow{2}{*}{$\begin{array}{l}\text { Ratification } \\
0\end{array}$} \\
\hline C66 & $\begin{array}{l}\text { Migration for Employment } \\
\text { Convention, } 1939 \text { (No. 66) }\end{array}$ & & \\
\hline C97 & $\begin{array}{l}\text { Migration for Employment } \\
\text { Convention (Revised), } 1949 \\
\text { (No. 97) }\end{array}$ & $\begin{array}{l}\text { Primarily relates to ensuring the } \\
\text { rights of migrants in destination } \\
\text { countries and facilitating } \\
\text { migration. Annexes } 1 \text { and } 2 \text { relate } \\
\text { to the regulation of recruitment } \\
\text { and Annex } 3 \text { to the transfer of } \\
\text { personal effects. }\end{array}$ & 50 \\
\hline C143 & $\begin{array}{l}\text { the Migrant Workers } \\
\text { (Supplementary Provisions) } \\
\text { Convention } 1975 \text { (No. 143) }\end{array}$ & $\begin{array}{l}\text { Primarily relates to ensuring the } \\
\text { rights of migrants in destination } \\
\text { countries and on 'illegal' } \\
\text { migration. }\end{array}$ & 24 \\
\hline
\end{tabular}




\begin{tabular}{|c|c|c|c|}
\hline \multicolumn{2}{|c|}{ Convention } & Description & Ratification \\
\hline ICRMW & $\begin{array}{l}1990 \text { International } \\
\text { Convention on the } \\
\text { Protection of the Rights of } \\
\text { All Migrant Workers and } \\
\text { Members of Their Families } \\
\text { (ICRMW) }\end{array}$ & $\begin{array}{l}\text { Focuses on the rights of migrant } \\
\text { workers, primarily in destination } \\
\text { countries. }\end{array}$ & $55^{4}$ \\
\hline
\end{tabular}

Source: C66, C97, and C143 (ILO, 2019); ICRMW (United Nations, 2019a)

Of these states, 61 Member States had ratified one convention, and 24 had ratified two conventions. Six states had ratified all three conventions (Albania, Burkina Faso, Madagascar, the Philippines, Tajikistan, and the Bolivarian Republic of Venezuela). No EU5 Member State had ratified the 1990 ICRMW. Among EU Member States, four countries had ratified the other two conventions (Cyprus, Italy, Portugal, and Slovenia), and six had ratified C97 (Belgium, France, Germany, the Netherlands, Spain, and the UK of Great Britain and Northern Ireland). Sweden had ratified C143. It is of note that ratifications in Europe mainly came from countries that were historically countries of emigration such as Italy and Portugal. Some evidence suggests that these countries warned others not to ratify the ICRMW and that the EU also put pressure on countries not to ratify the ICRMW (Pécoud, 2017). The remaining 17 EU Member States had not ratified any of the conventions. Of the traditional destination countries outside of Europe - the US, Canada, Australia, and New Zealand - only New Zealand had ratified Convention No. 97.

Since the adoption of the ICRMW, efforts to establish universally binding norms in the area of migration have waned. Instead, states have pursued minilateral solutions to the challenges of migration at the regional level (Section 4.4); and, at the global level, through informal multilateralism in the form of non-binding norms and guidelines (Section 4.5 to 4.7 ).

\footnotetext{
${ }^{4}$ In addition, 13 countries are signatories to the convention but have not ratified it: 'the signature qualifies the signatory State to proceed to ratification, acceptance or approval. It also creates an obligation to refrain, in good faith, from acts that would defeat the object and the purpose of the treaty' (OHCHR, 2014).

${ }^{5}$ At time of writing this included the UK.
} 


\subsection{Regional Cooperation on Migration (1985-present)}

With many states reluctant to subscribe to binding norms in the area of migration, from the mid-1980s, a trend towards interstate cooperation on migration at the regional level through Regional Consultative Processes (RCP) emerged, first in Europe but then in other parts of the world. This change ushered in a period of informal collaboration on international migration in regional settings, and with limited formal engagement with the UN. Two key factors have likely driven this development. The first factor is the increasing complexity of migration patterns (Miller, 2000; Thouez \& Channac, 2005; Von Koppenfels, 2001). The process of decolonization significantly increased the number of individuals qualifying as international migrants and created the need for migration policies to govern movements within the former territories. Additionally, the fall of the Berlin Wall in November 1991 and the resulting collapse of the Soviet Union and the removal of exit restrictions from many former Soviet States ushered in liberal economic policies (Bhagwati 1998; Von Koppenfels 2001; de Haas, Natter, and Vezzoli 2018).

The second factor is the deepening of regional integration projects, starting in Europe. Von Koppenfels (2001) argues that RCPs are both a product and a facilitator of regional integration. The process of European integration started in the immediate post Second World War period. European integration was partly sponsored by the US, who was interested in establishing a unified Europe as a centre of power able to resist the potential threat of war between East and West (Dedman, 2006; Weber, 1992). The idea of a common market originated in the European Coal and Steel Community (1951) and gradually expanded as European integration deepened, first with the European Economic Community (1958-1986), then the European Community (19861991), and finally, the European Union (Dedman, 2006). As the Cold War drew to a close, European integration accelerated. The Single European Act of 1986 established the goal of a common market by 1992. Combined with the dismantling of the internal borders in Europe, a process starting with the Schengen Agreement in 1985 led to the Maastricht Treaty and the creation of the EU in 1992. In other parts of the world, similar processes emerged. For example, in 1991, the Southern Common Market (MERCOSUR) was created. In 1992, the North American Free Trade Agreement (NAFTA) was signed, and the Association of Southeast Asian Nations (ASEAN) created a Free 
Trade Area (AFTA). In 1994, the Common Market for Eastern and Southern Africa (COMESA) was founded.

Given these contextual factors, it is unsurprising that the first RCP originated in Europe. As discussed, the 1980s in Europe had seen an increased number of asylum applications. The closure of the guest worker programmes in Europe in the mid-1970s had led to increasing migration through other channels, first family reunification, and later through asylum channels. The economic recession, coupled with growing unemployment, led to a 'xenophobic backlash' against immigrants that heightened the political salience of migration (Thouez \& Channac, 2005). Given that many European countries were facing similar challenges, intergovernmental cooperation became an increasingly logical choice. To discuss these challenges, Poul Hartling, then High Commissioner for Refugees, convened 'Consultations on the Arrivals of Asylum-Seekers and Refugees in Europe', a meeting attended by 35 Member States of the UNHCR Executive Committee in May 1985. In response to a call for ad hoc consultations between states, the then Under Secretary of State to the Swedish Minister for Migration Affairs, Jonas Widgren, called a meeting in Stockholm in November 1985 which was attended by seven European governments: Sweden, Denmark, France, Germany, the Netherlands, Switzerland and the UK (Wall, 2018). This meeting was retrospectively considered the first meeting of the Intergovernmental Consultations on Migration, Asylum and Refugees (IGC), the world's first RCP on migration (Wall, 2018). A key feature of the IGC was its independence from the UN even though UNHCR, and from 1993, IOM, hosted its Secretariat.

By 1990, the IGC had more than doubled in size as Australia, Austria, Belgium, Canada, Finland, Italy, Norway, and the US joined its ranks. With the addition of Australia and the US, the IGC became a group of likeminded states, defined not by geography but by shared experiences and an interest in finding solutions. Although membership has fluctuated, it has remained relatively constant, with between 14 and 17 participating countries at any given point (Wall, 2018, p.34-35). Significantly, the IGC expanded beyond its European focus, with the participation of three traditional countries of immigration (Australia, Canada, and the US), arguably creating a new, more international, if not global, dynamic for discussion.

Coupled with its independence, several core features of the IGC, such as its informal, non-binding and confidential nature, provided the blueprint for 
other RCPs, which proliferated in the years to come (Von Koppenfels, 2001). Early examples include the Central American Commission of Migration Directors (OCAM) (1990); the Budapest Process (1993); the Puebla Process (1996); the Inter-Governmental Asia-Pacific Consultations on Refugees, Displaced Persons and Migrants (APC) (1996); The Pacific Immigration Directors' Conference (1996); and the now-defunct Manila Process (1996) and CIS Conference (1996). The trend continued, and today there are at least 28 active RCPs (Annex 4.3).

The place of RCPs in the evolution of global migration governance is the subject of some debate within the literature. Some observers view RCPs as a step towards the creation of an international regime for migration:

'My interpretation is that states concluded that migration was too complex and politically sensitive a topic for them to address at the global level, and so they instead chose to meet in much smaller regional circles. Since these circles were informal and non-binding, it was possible to have a conversation. At the global level, it was apparent that the cleavage between North and South, between developed and developing, countries was too big a matter to bridge at that time' (INT-IO-015).

The argument was that, by establishing networks (Koser, 2010) and promoting policy convergence (Thouez \& Channac, 2005; Von Koppenfels, 2001), RCPs 'could be valuable building blocks towards the establishment of a new international regime for better management of migration' (Ghosh 2000, p.239), primarily because they could overcome the collective action challenge that characterized cooperation within the evolving multilateral system (Section 2.2.2).

However, Klein Solomon (2005) argues that, while RCPs have 'helped to create a climate conducive to the formation of other non-binding and informal platforms on migration management...(they) should not necessarily be seen as direct building blocks for the creation of formal institutions or a binding migration regime at the regional or global level' (p.19). The argument is that RCPs occupy a logical place in a multilevelled system of governance. Not all aspects of migration governance merit a global response. Following the principle of subsidiarity, issues should be managed at the lowest logical level (Lavenex, 2018). Much migration occurs within regions, making RCPS 
logical venues within which to discuss regional migration dynamics, explaining why RCPs have different thematic foci across the world (Klein Solomon, 2005; Von Koppenfels, 2001) and why, despite the further development of international fora on migration, RCPs and increasingly Interregional Forums (IRFs) continue to exist.

Critics of RCPs and other informal, non-binding intergovernmental fora argue that they represent a shift towards 'soft modes of network governance' (Lavenex et al., 2016, p.459). They encourage members to emulate the policies and practices of regional or global hegemons regardless of whether their practices are in line with international standards. The tension between informality with action, and formality with inaction, has characterized many of the discussions on global migration governance in the post-Cold War era.

\subsection{Post-Cold War Euphoria: The Quest for New Global Arrangements (1991-2000)}

The 1990s was a decade of transformation for multilateralism. Particularly after the international response to the Gulf War in the late 1980s, there was optimism regarding what could be achieved through international cooperation (Kamau et al., 2018). This optimism led to a flurry of UN conferences on a range of different issues. Perhaps the most concrete outcome of these conferences was the adoption of the Millennium Declaration ${ }^{6}$ on 8 September 2000, which led to the formulation of eight Millennium Development Goals (MDGs) in 2001. However, the post-Cold War euphoria also led to the diffusion of liberal economic policies around the world. The 1980 s had witnessed the rise of neoliberalism, particularly in Western Europe, where the Post-Second World War welfare state projects were under strain (George \& Wilding, 1994). The rise of neoliberalism led to a wave of privatization of previously public services as well as the injection of marketbased principles into state-run services. This trend was transferred around the world through the structural adjustment programmes of organizations such as the IMF and the World Bank (Collier \& Gunning 1999). As Miller

${ }^{6}$ United Nations Millennium Declaration, UNGAOR, 55 ${ }^{\text {th }}$ Session, UN Doc. A/RES/55/2 (18 September 2000) 
(2000) argued, 'the collapse of communism and the crisis of socialism accentuated the power of market forces' (p.34).

The liberal expansion is possibly most observable in the further evolution of the global trade regime. In 1994, the Uruguay Round of General Agreement on Trade and Tariff (GATT) Trade Talks concluded, which led to the General Agreement on Trade in Services (GATS) and the establishment of the World Trade Organization (WTO) in 1995. Although the 'movement of natural persons' was included as the fourth mode of service provision across borders in the GATS, commitments were initially limited to intra-company transferees with management or technical appointments that were considered essential to the functioning of the business; and to short-term business visitors. In 1996, the Negotiating Group on Movement of Natural Persons concluded their work, which modestly increased the coverage of Mode 4 through the addition of new categories of service providers and, in some cases, increased the permitted duration of stay (WTO, 2020). However, while no data exist to measure the extent of mobility facilitated through Mode 4 , it is not believed to represent a significant proportion of international migration flows (Nielson \& Taglioni, 2003). Hence, it was amidst these changes that a discussion began about whether migration should be subject to similar agreements (Ghosh, 2000a).

Following an initial presentation in an ILO working paper in 1991 (Böhning, 2004), Thomas Straubhaar $(1993,2000)$ elaborated on the idea of a Global Agreement on Migration Policy (GAMP) similar to the GATT and GATS. Straubhaar's premise was that the free movement of people is generally beneficial to the migrants but also to countries of origin and countries of destination. Thus, his vision for a GAMP was an agreement that would facilitate the entry and exit of individuals while also addressing externalities caused by international migration. However, as Böhning (2004) noted, the idea of an international organization that would actively promote more or free movement was never likely to receive political support. In a piece originally published in 1992 in the Christian Science Monitor, Jagdish Bhagwati, like Straubhaar, described the GATT as being 'a worthy model' for a World Migration Organization. He suggested that, akin to the trade policy reviews published by GATT officials, periodic migration policy reviews could 'embarrass countries into more human and liberal ways of dealing with influxes of aliens' (Bhagwati, 1998, p.316). Although not explicitly stated in his 1998 essay, the notion of state sovereignty is present in his reflection on the piece six years later: 'the organization could not tell nations what to do, 
since control of the border is regarded as an essential part of a nation-state' (Bhagwati, 1998, p.1). In 1993, Bimal Ghosh brought similar ideas to the Commission on Global Governance with a paper entitled 'Movements of People: The Search for a New International Regime' (Ghosh, 2000a). These debates were further fuelled by the New International Regime for Orderly Movement of People (NIROMP) project when it launched in 1997, with financial support from the Swedish government (Ghosh, 2000a).

Despite attempts to further institutionalise migration, however, even efforts to organise a conference on migration failed to gain the necessary support. In 1993, a General Assembly Resolution discussed convening a UN Conference for the 'Comprehensive Consideration and Review of Refugees, Returnees, Displaced Persons and Migrants' (RES/48/113). States also discussed the idea for an international conference on migration at the 1994 International Conference on Population and Development (ICPD) in Cairo, where, again, no consensus was reached. The Programme of Action endorsed by 179 states at the conference did, however, devote an entire chapter to international migration and development, and internal migration (including forced displacement) was covered in the context of urbanization. For this reason, the ICPD conference is often considered to be the genesis of contemporary discussions on global migration governance (c.f. Newland, 2010; Betts, 2011). After the conference, the UN Population Division surveyed Member States on four occasions, in 1995, 1997, 1999, and 2003, finally reaching agreement on the organisation of a High-Level Dialogue on Migration and Development (HLD) which was held in New York in 2006 (Chamie and Mirkin 2013) (Section 4.7).

As these discussions were ongoing, and in a further reflection of the expansion of liberal policies, aid agencies experienced a reduction in their budgets as donors from both ends of the political spectrum responded to concerns about the effectiveness of aid by reducing Overseas Development Assistance (ODA) (Carbone, 2013). Facing organisational downsizing, the high-level meeting of the Organization for Economic Cooperation and Development's (OECD) Development Assistance Committee (DAC) in 1995 focused on reframing development cooperation as an investment. An outcome of this meeting was the formation of the Groupe de Réflexion, which, although it had no clear end goal at inception, was tasked with the reinvigoration of the aid discussion. One of the concrete outputs of the group was a set of goals - the International Development Goals (IDGs), which were 
a culmination of a review and synthesis of the declarations agreed upon at the many UN summits of the early 1990s.

Concerned that the DAC was 'taking control of a UN agenda' (Hulme 2009, p.19), the idea of development goals was taken up by the UN towards the end of the 1990s. In preparation for the Millennium Assembly of the UN, Kofi Annan appointed John Ruggie to help him prepare a report based on previous UN conferences and summit declarations that would be acceptable to UN members. This report became 'We the Peoples: the Role of the United Nations in the 21st Century'. The UN also collaborated in the publication of another report, entitled '2000: A Better World for All: Progress towards the International Development Goals' alongside, in alphabetical order, IMF, OECD, and the World Bank. The UN's involvement in the report accorded legitimacy to the IDGs, although there was still some concern that donor countries were over-influencing the agenda (Hulme, 2009). After negotiations, which primarily took place behind closed doors, the Millennium Declaration ${ }^{7}$ was unanimously accepted by the UN Member States on 8 September 2000, closely followed, in 2001, by the announcement of the Millennium Development Goals (MDGs), which strongly resembled the IDGs (Bernstein, 2005). Migration, along with human rights, was excluded.

\subsection{A New Century: A New Chance? (2001-2006)}

On the one hand, the new century opened with renewed optimism regarding the ability of the international community to solve the world's biggest challenges. Described as 'the world's biggest promise', the Millennium Development Goals (MDGs) were a set of eight goals, 18 targets and 48 indicators with the broad aim of reducing poverty around the world (Hulme, 2009). On the other hand, however, Zürn (2018) argues that two events in 2001 'wrecked the liberal hopes that dominated the 1990s' (p.1). The first was the attack on the World Trade Centre on 11 September, and the second was the coining of the term 'BRIC' by Goldman Sachs to describe the growth of

7 United Nations Millennium Declaration, UNGAOR, 55 ${ }^{\text {th }}$ Session, UN Doc. A/RES/55/2 (18 September 2000) 
new economic powers (Brazil, Russia, India, and China ${ }^{8}$ ). The latter arguably symbolizes the completion of a global shift to a multipolar world. Whereas the world in which the UN was created was largely bipolar, by the turn of the century, it was multipolar. There had also been a shift from an open system, in which states were still being defined, towards a relatively closed system (Cohen, 2018). With Switzerland joining the UN in 2002, having previously opted to remain outside owing to its professed neutrality, hopes for genuine multilateral problem-solving based on the principle of the sovereign equality of states (Kahler, 1992) were renewed.

Against this backdrop, and despite the challenges encountered concerning the organisation of a conference on migration in the 1990s, by the turn of the century 'migration was everywhere one looked in the UN system and beyond' (Newland 2010, p.333) and calls for a Global Migration Organization witnessed new energy (Bhagwati, 2003; Ghosh, 2000a; Helton, 2003). Several possible explanations that relate to external system events can be offered for the increased attention on migration at the global level.

The first possible explanation is that migration's exclusion from the MDGs had drawn attention to a lacuna in the development agenda. Despite not being included in the Millennium Development Goals, migration was explicitly mentioned in the Millennium Declaration alongside other goals in areas deemed 'too difficult to measure unambiguously or too sensitive to handle politically' (Browne \& Weiss, 2014, p.6). This mention took the form of a commitment:

'to take measures to ensure respect for and protection of the human rights of migrants, migrant workers, and their families, to eliminate the increasing acts of racism and xenophobia in many societies and to promote greater harmony and tolerance in all societies ${ }^{9 \prime}$ (para. 25, p.7).

Given that the MDGs provided structure to development financing, it is plausible that the exclusion of migration provided the necessary impetus for the migration community to renew its efforts in the new millennium (INT-

\footnotetext{
${ }^{8}$ Later becoming the BRICS with the addition of South Africa.

9 United Nations Millennium Declaration, UNGAOR, 55 ${ }^{\text {th }}$ Session, UN Doc. A/RES/55/2 (18 September 2000)
} 
IO-002) (Section 4.6). As Steven Sinding stated of reproductive health, 'if you are not an MDG, you're not on the agenda' (cited in Hulme 2009, p.25).

Related to this, was the 'rediscovery' (INT-IO-024) of remittances by the World Bank in the early 2000s:

'If you look at the 1990s you hardly find any work by the World Bank. There were one or two papers on migration. What triggered this new development was the role of remittances. Suddenly people started noticing remittances' (INT-IO-011).

'It really only took off when the World Bank jumped on it with the remittances issue' (INT-IO-019).

Remittances represented a tangible way of discussing migration-related phenomena without descending into discussions that had previously polarized countries:

'The developing countries did not want to say that people were leaving because they could not provide them with jobs, and the people in the North did not want to say that their border controls were broken. There was a polarized view in those days. Remittances brought fresh air to the whole thing by saying that remittances are more of a lifeline for developing countries, for poor people, than official aid' (INT-IO-024).

In light of the spread of liberalism, and the reduction of aid budgets, the recognition of the volume of remittances by the World Bank also drew attention to an alternative source of development financing. While remittances are private money, the shifting focus of neoliberalism towards reduced state involvement arguably carved the path for the revival of discussions regarding the relationship between migration and development (de Haas, 2012).

Another possible explanation for heightened international interest in migration is that the attack on the World Trade Centre on 11 September 2001 $(9 / 11)$ provided the necessary 'coalition opportunity structure' to reassert the 
importance of the international community addressing matters of relevance to migration, from a security perspective.

'The $9 / 11$ events raised national security risks
significantly, or, to describe it more accurately, national
security risk perception went up significantly in many
developed countries. That put a shine on migrants.
There were more border controls, more checks, and
more worries about terrorists' (INT-IO-024).

While a significant body of literature exists, that asserts that the 9/11 attack contributed to the securitization of migration policy, Boswell (2007) challenged this assertion. She argued that 9/11 increased awareness of migration as a political issue, which was in line with a pre-existing process of securitization that had already started in Europe in the 1970s (Boswell, 2007). By 2001, migration had already been included in the UN's security pillar through the addition of two protocols to the United Nations Convention against Transnational Organized Crime in 2000: 1) the Protocol to Prevent, Suppress and Punish Trafficking in Person, Especially Women and Children; and 2) the Protocol against the Smuggling of Migrants by Land, Air and Sea (Ghosh, 2005). Significantly, these protocols have received much higher levels of support than the various migration-related conventions discussed in Section 4.3.

Regardless of the precise reasons, from the early 2000s, migration started to receive more attention at the global level. However, two distinct trajectories in migration's journey as a global policy issue are apparent: one focused on migrant rights within the UN system, and the other on migration management primarily outside of the UN.

Within the UN, the legitimacy of a rights-based approach to migration was affirmed by the appointment in 1999 of Ms Gabriela Rodríguez Pizarro from Costa Rica as the first Special Rapporteur on the Human Rights of Migrants. The rights-based approach to migration was further reinforced by the commitment made in the Millennium Declaration in 2000, and again in 2003 when the International Convention on the Protection of the Rights of All Migrant Workers (ICRMW) received the necessary ratifications to come into effect (Section 4.3). However, efforts to further the normative architecture for a rights-based approach to migration were hindered by low ratification rates. In this context, the ILO sought to develop a non-binding multilateral 
framework for labour migration. At the $92^{\text {nd }}$ Session of the International Labour Conference in 2004, a Governing Body Resolution called for an ILO Plan of Action on Labour Migration (ILO, 2004). As part of the Plan of Action, the Governing Body agreed that the ILO should develop a Multilateral Framework for Labour Migration (MLF), which, after expert meetings in November 2005, was adopted at the $295^{\text {th }}$ session of the ILO Governing Body in 2006 (ILO, 2006). While at the time, some states feared that the MLF would become a 'backdoor convention' (INT-IO-021), it ultimately became little more than a programmatic tool (Siegel et al., 2013). Some evidence suggests that this was because the ILO was instructed not to push the framework for fear that it would undermine efforts to galvanize support for international cooperation on migration that were being pursued by the Secretary-General (INT-IO-021).

With heightened global attention to migration, the formula developed by the IGC in the 1980s was applied at the global level through the creation of informal state-led dialogues that promoted intergovernmental cooperation regarding migration. In 2001, the Swiss government launched the Berne Initiative which was a 'states-owned consultative process with the goal of obtaining better management of migration at the global level through cooperation between states' (Martin 2015, p.71) which led to the adoption of the non-binding International Agenda for Migration Management in 2004. Although a less often discussed process, the Berne Initiative is viewed by many observers as the first attempt to pursue global level cooperation on migration:

'the Berne Initiative Process was, put as simply as possible, a test of whether the global international community could identify some principles of governance that may apply to all' (INT-IO-015).

At the same time, and also outside of the UN, the IOM launched the International Dialogue on Migration (IDM) in 2001 (Martin 2015; Newland 2010).

With increased attention on migration, and potentially concerned that states may bypass the UN, then Secretary-General Kofi Annan expressed a desire to develop a comprehensive response to migration at the international level. In his 2002 report, 'Strengthening of the United Nations: An Agenda for Further Change', Kofi Annan noted: 'I also believe that it is time to take a 
more comprehensive look at the various dimensions of the migration issue' (para. 39, p.10). In 2001, Kofi Annan tasked Prof. Michael Doyle to lead a working group on migration. Doyle's report reviewed the opportunities for international cooperation on international migration, assessing, in particular, the feasibility of a global organization for migration, be it through the designation of an existing organization as 'lead agency', merging existing organizations, or creating a new one. The report concluded that not enough consensus on migration existed at the international level. Thus, the best interim solution was to enhance inter-agency coordination and to pay more attention to the 'management' of international migration.

On 9 December 2003, Kofi Annan, at the behest of Member States, and in response to Doyle's report, launched the first-ever global panel addressing international migration. The Global Commission on International Migration (GCIM) was comprised of 19 members from across the world and it was cochaired by Hon. Jan O. Karlsson (former Swedish Minister for Migration and Development) and Dr. Mamphela Ramphele (South Africa and former World Bank Managing Director). The Commission's report, 'Migration in an interconnected world: New directions for action', was published in 2005 (GCIM, 2005). Next to a comprehensive overview of migration-related issues, the report led to the formalisation and enlargement of the Geneva Migration Group, which became the Global Migration Group (GMG) in 2006 when its founding members were joined by the World Bank, the United Nations Department of Economic and Social Affairs (UNDESA), the United Nations Development Programme (UNDP), and the United Nations Population Fund (UNFPA) (Pécoud \& de Guchteneire, 2007).

After the GCIM report, and in response to the 2003 agreement to hold an international conference on international migration ${ }^{10}$, Kofi Annan in 2006 appointed the late Sir Peter Sutherland to be his Special Representative on Migration and Development. As a former and the youngest Attorney General of Ireland, Director of the General Agreement on Tariffs and Trade (GATT) and the WTO and Chairman of BP plc and Goldman Sachs International, Peter Sutherland came with international authority and a strong message:

'Migration can be an enormous force for good: one of the great drivers of economic growth, individual liberty and

\footnotetext{
${ }^{10}$ International migration and development, UNGAOR, 58th Session, UN Doc. A/RES/58/208 (23 December 2003)
} 
personal prosperity. As such, I am delighted to undertake this assignment for Kofi Annan. The goal is to maximise the benefits of migration and minimise potentially negative impacts' (United Nations, 2006).

One of Sutherland's first tasks was the organisation of the first HLD on International Migration and Development in New York in 2006 (United Nations, 2006). One of the most significant outcomes of the HLD was the agreement by Member States to organize a Global Forum on Migration and Development (GFMD). The first GFMD took place in Brussels in 2007 which arguably ushered in 'the era of migration and development' (Betts and Kainz 2017, p.1).

\subsection{The Era of Migration and Development (2006-2015)}

From 2007, interest in migration among UN agencies increased. The GMG witnessed several rounds of enlargement, the largest of which took place in 2007 when UNESCO, the United Nations Children's Fund (UNICEF), the United Nations Institute for Training and Research (UNITAR) and the UN's five Regional Commissions joined the group. The World Health Organization (WHO) and UN Women joined in 2010 and UNU and FAO in 2014. Many attribute this growth in interest to the framing of migration as a development issue. Although the theoretical link between migration and development predated 2007 (Section 4.2), its significance as an international policy field became particularly prominent with the establishment of the GFMD in 2007, arguably at the expense of some of the rights-based initiatives, discussed in Section 4.6, that had gained momentum since the turn of the millennium (INT-IO-011; INT-IO-021; INT-IO-040, INT-IO-042).

The first meeting of the GFMD took place in Brussels, Belgium, on 9-11 July 2007, and it has continued on an almost annual basis ever since rotating between developed and developing countries. Since its inception in 2007, the GFMD has become the most important meeting of states with regards to migration at the international level (INT-IO-013). The conversations at the GFMD have evolved, often influenced by external events such as the 2008 financial crisis, the elaboration of the post-2015 development agenda, and the Syrian crisis (Table 4.3). 
Table 4.3 GFMD Meetings 2007-2019

\begin{tabular}{|c|c|c|}
\hline Year & Location & Theme \\
\hline 2007 & Brussels, Belgium & Migration and socio-economic development \\
\hline 2008 & Manila, Philippines & Protecting and Empowering Migrants for Development \\
\hline 2009 & Athens, Greece & $\begin{array}{l}\text { Integrating Migration Policies into Development } \\
\text { Strategies for the Benefit of All }\end{array}$ \\
\hline 2010 & $\begin{array}{l}\text { Puerta Vallarta, } \\
\text { Mexico }\end{array}$ & $\begin{array}{l}\text { Partnerships for Migration and Human Development: } \\
\text { Shared Prosperity, Shared Responsibility }\end{array}$ \\
\hline 2011 & $\begin{array}{l}\text { Geneva, } \\
\text { Switzerland }\end{array}$ & $\begin{array}{l}\text { Taking Action on Migration and Development - } \\
\text { Coherence, Capacity and Cooperation }\end{array}$ \\
\hline 2012 & Port Louis, Mauritius & $\begin{array}{l}\text { Enhancing the Human Development of Migrants and } \\
\text { their Contribution to the Development of Communities } \\
\text { and States }\end{array}$ \\
\hline $\begin{array}{l}2013- \\
2014\end{array}$ & Stockholm, Sweden & $\begin{array}{l}\text { Unlocking the Potential of Migration for Inclusive } \\
\text { Development }\end{array}$ \\
\hline $\begin{array}{l}2014- \\
2015\end{array}$ & Istanbul, Turkey & $\begin{array}{l}\text { Strengthening Partnerships: Human Mobility for } \\
\text { Sustainable Development }\end{array}$ \\
\hline 2016 & $\begin{array}{l}\text { Dhaka, } \\
\text { Bangladesh }\end{array}$ & $\begin{array}{l}\text { Migration that works for Sustainable Development of } \\
\text { all: Towards a Transformative Migration Agenda }\end{array}$ \\
\hline $\begin{array}{l}2017 \\
2018\end{array}$ & $\begin{array}{l}\text { Berlin, Germany and } \\
\text { Marrakesh, Morocco }\end{array}$ & $\begin{array}{l}\text { Towards a Global Social Contract on Migration and } \\
\text { Development }\end{array}$ \\
\hline 2019 & Ecuador & $\begin{array}{l}\text { Sustainable approaches to human mobility: Upholding } \\
\text { rights, strengthening state agency, and advancing } \\
\text { development through partnerships and collective } \\
\text { action. }\end{array}$ \\
\hline
\end{tabular}

Over time, traditional 'migration and development' topics such as remittances and diaspora engagement have played a less central role in the discussions at the GFMD. One explanation for this is that the 'migration and development' framing was used instrumentally to bring states together. Once less controversial topics had been discussed, states could turn their attention to more controversial matters, such as the rights of migrants. This view is perhaps why Skeldon (2008) argued that 'migration and development' was 'a passing phase' and Gamlen (2010) suggested that UNDP's Human Development Report on migration would represent a 'high-water mark' in international discussions on 'migration and development' (p.421).

Many observers note that, over time, the topic of human rights became more prevalent at the GFMD. However, while there was a deliberate decision to exclude human rights from the discussions at the GFMD as it was being conceptualised (Chapter 5), human rights was treated as a cross-cutting theme at the first GFMD in 2007 'seen throughout the meeting as an essential prerequisite to migrants contributing to development' (GFMD 2008, p.22). 
The topic of human rights was more concretely addressed during the second meeting of the GFMD in the Philippines, probably due to the host's interest in protecting its significant number of emigrants abroad. At the Mexican GFMD, human rights were brought even more into the foreground, because of Mexico's interest in protecting its migrants in the US:

'Mexico put the human rights of migrants on the table because Mexicans were mistreated in the US and they wanted, as representative of the South, to bring the issue of the human rights of migrants onto the table' (INT-IO013).

From a review of the Chair reports of the GFMD from Belgium in 2007 to Bangladesh in 2016, rights are, with the exception of Belgium, most frequently mentioned in the reports of countries in the South (Figure 4.2).

Figure 4.2 Word Frequency in GFMD Chair Reports, 2007-2016

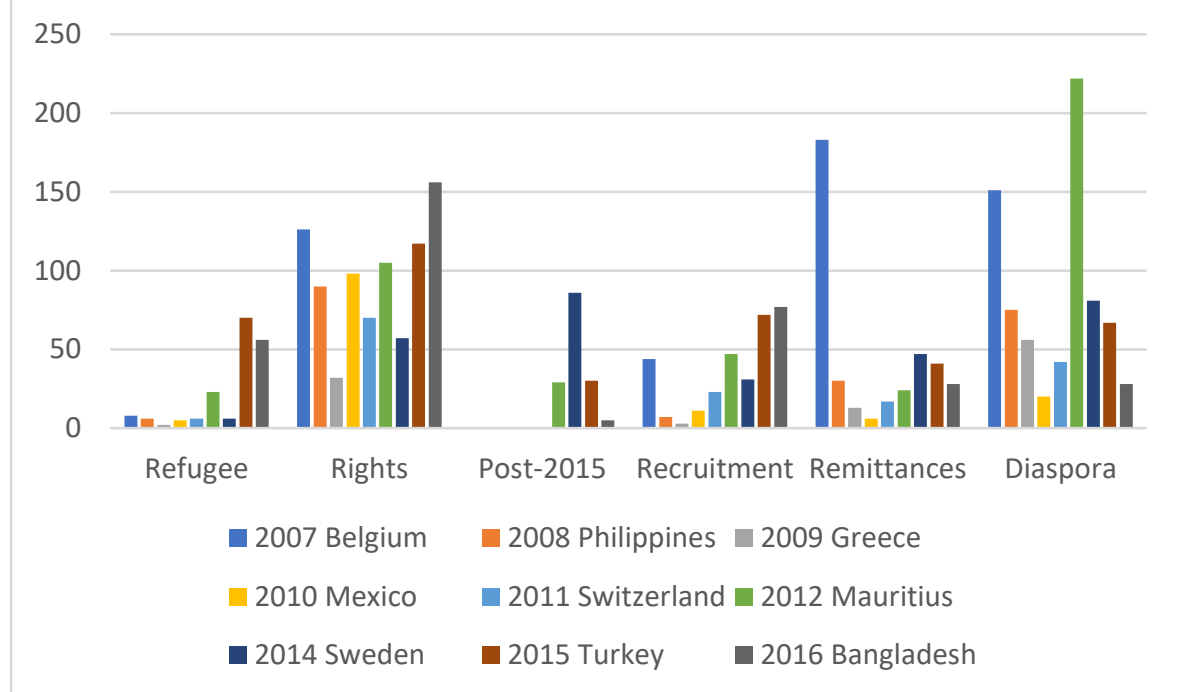

Source: Author's own, based on GFMD Chair Reports, 2007-2016

However, despite the suggestion that the era of migration and development might be coming to an end, and as the deadline for the Millennium Development Goals approached, the discussion turned to ensure that migration was reflected in the Post-2015 development agenda: 
'Different constituencies saw an opportunity. Sutherland and the GFMD crowd saw this as a way to elevate the issue of migration from their personal perspective, which was this treasured 'migration and development' framing' (INT-IO-040).

Discussions regarding the place of migration in the post-2015 development agenda began at the GFMD in Mauritius in 2012 and were finalized during the Swedish chairmanship of the GFMD in 2013/14, which coincided with the second High-Level Dialogue on International Migration and Development in 2013. The inclusion of migration in the Post-2015 development agenda was one of the most concrete policy commitments made at the second HLD. In the country statements made at the HLD 'the most commonly mentioned policy priority was integrating migration into the post-2015 development agenda' (UNDESA, 2014, p.9). Unlike the first HLD, a final declaration ${ }^{11}$ emerged from the second HLD on the initiative of Mexico (INT-IO-016; INT-IO-029):

\begin{abstract}
'The declaration of the second High-Level Dialogue in 2013 was critical because it signified that we had arrived at a consensus in the United Nations on the links between migration and development. This no doubt facilitated the General Assembly to agree with migration being mainstreamed into the Sustainable Development Goals' (INT-IO-029).
\end{abstract}

In the HLD Declaration ${ }^{12}$, Member States acknowledged 'the important contribution of migration in realizing the Millennium Development Goals' and recognised that human mobility is a key factor for sustainable development which should be adequately considered in the elaboration of the post-2015 development agenda' (para. 8, p.2). Accordingly, on 25 September 2015, the Member States of the UN unanimously adopted Sustainable Development Goals ${ }^{13}$. In addition to a paragraph devoted to migration in the preamble, migration was explicitly mentioned in four of the

\footnotetext{
11 Declaration of the High-Level Dialogue on International Migration and Development, UNGAOR, 68 ${ }^{\text {th }}$ Session, UN Doc. A/68/L.5 (Oct. 1, 2013)

12 Declaration of the High-Level Dialogue on International Migration and Development, UNGAOR, 68 ${ }^{\text {th }}$ Session, UN Doc. A/68/L.5 (Oct. 1, 2013)

${ }_{13}$ Transforming our World: the 2030 Agenda for Sustainable Development, UNGAOR, 70th Session, UN Doc. A/RES/70/1 (25 September 2015)
} 
SDGs targets (8.8, 10.7, 10.c. and 17.18). Furthermore, some argue that migration is implicit across the entire development agenda, a point that will be returned to in Chapter 6 .

However, already at the second HLD, the conversation started to shift from a focus on development. On the first day of the second HLD, 3 October 2013, a boat capsized off the coast of Lampedusa, which resulted in the deaths of at least 368 people. In his opening remarks, Ban Ki-moon stated the following:

\begin{abstract}
'Before I begin, let me just note that we need to look no further than this morning's headlines to see the great importance of this dialogue. Dozens of African migrants are reported to have perished in the Mediterranean after the ship on which they were travelling sank' (Ki-moon, 2013).
\end{abstract}

One of the concrete actions taken after the second HLD was the Migrants in Countries in Crisis (MICIC) initiative, which was established by the Philippines and the US in 2014 and was born out of the challenges faced during the 2011 Libyan crisis.
'Libya was a bold example. There were lots of international workers trapped during the outbreak of the civil war. We wanted to move the discussion from a talking shop and to focus on implementation and that is why we designed the Migrant in Countries in Crisis Initiative' (INT-IO-037).

In 2015, the number of deaths due to unsafe sea crossings increased as the Syrian Crisis escalated (IOM, 2020). The focus shifted, as it had in the late 1980s towards the mass displacement of people. In this context, states began to look for new international solutions to migration-related challenges.

\title{
4.8 Towards New Global Arrangements: the Global Compacts (2016-2018)
}

In October 2016, in addition to IOM joining the UN as a 'related agency', Member States unanimously agreed upon the New York Declaration (NYD) at the closing of the High-Level Summit for Refugees and Migrants, where 
states committed themselves to negotiate two Global Compacts, one on migration and the other on refugees, by 2018. This commenced two years of consultations and negotiation, which concluded in December 2018. However, these negotiations took place in a considerably complex context. On 23 June 2016, the British public voted in a referendum on their membership in the European Union. The resulting vote, marginally in favour of leaving the EU, triggered several years of negotiations, which ultimately resulted in the UK leaving the EU on 31 January 2020. In January 2017, Donald Trump became the 45th president of the US, which marked the start of a period of American isolationism. Trump's withdrawal from the Global Compact for Safe, Orderly and Regular Migration (GCM), citing concerns that it was a 'back-door convention' incompatible with the sovereign right of states to control their borders, is emblematic of a crisis in multilateralism (Ferris and Martin, 2019; Ferris and Donato, 2019). However, unlike in the 1950s, when the US used its power to steer migration outside of the UN, in a markedly different world, the negotiations went ahead without the US.

The withdrawal of the US is one explanation for the distinctly separate nature of the negotiations. The NYD had initially envisaged more overlap between the two Compacts in recognition of the fact that refugees are also migrants, and that a group of individuals exists who do not qualify as refugees under the 1951 Convention and its 1967 protocol and yet face similar vulnerabilities. However, while UNHCR led the GCR negotiations, states retained more control over the GCM negotiations. The Global Compact on Refugees was adopted by consensus, receiving 181 votes in favour, two against (Hungary and the US) and three abstentions (Eritrea, Liberia, and Libya) at the General Assembly of the UN on 17 December 2018. After being adopted by 164 Member States at an Intergovernmental Conference in Marrakesh, Morocco, on 10 December 2018, the Global Compact for Safe, Orderly and Regular Migration was endorsed by the General Assembly on 19 December 2018. At the General Assembly, the GCM received slightly less support, with 152 Member States voting in favour of endorsing the GCM, five voting against it (Czech Republic, Hungary, Israel, Poland, and the US). Twelve Member States abstained ${ }^{14}$.

Since the adoption of the GCM, several initiatives have been launched to support its implementation. The UN Migration Network, which replaced the GMG and is chaired by IOM, was launched by António Guterres at the

\footnotetext{
${ }^{14}$ For a full list of the votes see United Nations (2018c).
} 
Marrakesh meeting. In May 2019, the Migration Multi-Partner Trust Fund (MPTF) was launched to provide financial support to Member States in implementing the commitments outlined in the GCM (United Nations, 2019b). The non-binding nature of the Compacts does, however, point to the fact that, while states have accepted the institutionalization of migration into the UN, they remain hesitant to create legally binding norms. While much remains to be seen in terms implementation, the GCM marked a defining moment in the journey of migration as a global policy issue.

\subsection{Conclusion}

From this review of the evolution of global migration governance, it is evident that the process of institutionalising migration into the UN has not been linear:

'It looks in hindsight as quite linear, but if you have been involved and living the day-to-day, it was not really very linear. It reacted to external factors: what was happening in the real world, and to the way that international organizations operate' (INT-IO-040).

The way migration has been framed as an international policy issue has changed over time, driven by external (dynamic and stable) factors such as decolonization which definitionally changed the meaning of international migration; economic crises which, among other impacts, altered the demand for migrant labour; and conflict. Furthermore, as the multilateral system has evolved, the environment within which migration is discussed at the global level has also evolved as the power hierarchy has shifted from a bipolar to a multipolar system. Accordingly, since the end of the Cold War, and particularly since the turn of the millennium, migration has gained prominence as an issue that should be more clearly institutionalized within the UN. In the remainder of the dissertation, I will examine four case studies that seek to uncover the extent to which framing migration as a development issue has been at the centre of IO's efforts to convince states to deal with migration within the context of the UN. However, without the existence of 
external system events, notably the migration crises of 2015, the results of IO framing efforts may not have led to the same outcome.

Multiple authors have pointed to the significance of the GFMD as a pivot point in international cooperation on migration, where the problem of migration was reframed as a development issue in order to advance international cooperation (cf. Betts and Kainz 2017; Roldan and Gasper 2010; Rother 2018). Accordingly, Chapter 5 examines the genesis of the GFMD. The inclusion of migration in the SDGs is said to have brought migration more generally, and IOM specifically, into the UN. Hence, Chapter 6 examines how actors from different advocacy coalitions engaged with the migration frame to convince the architects of the SDGs that migration should be reflected in the new development agenda. The dissertation then turns to look at the next aspect of the institutionalization of migration into the UN: the designation of IOM as the UN's lead agency for migration. Chapter 7 examines IOM's journey to the UN from its creation as a temporary intergovernmental committee in 1951 to its entry as a 'related agency' of the UN in 2016 and critically analyses the factors contributing towards the decision that IOM should be part of the UN system. Finally, Chapter 8 looks at the most recent attempt of the UN to develop norms to guide states in the governance of migration. The GCM represents the first time states have explicitly negotiated an overarching framework for the governance of migration. Given historic resistance to developing norms in the area of migration, this case study analyses the genesis of the Global Compact discussion. 


\section{Reframing Migration: the Global Forum on Migration and Development}

\subsection{Introduction}

The Global Forum on Migration and Development (GFMD) was established at the UN High-Level Dialogue (HLD) on International Migration and Development in September 2006. While the agreement to hold the HLD represented a degree of progress in the willingness of states to discuss migration within a UN setting, the provision that it would have no binding outcome highlighted a continued resistance to the idea of full UN engagement on the topic. There was thus some concern about what would happen after the HLD in 2006. Within this context, the idea of a global consultative forum on international migration began to take shape. The first meeting of the GFMD was hosted by the Government of Belgium in Brussels in July 2007, and most recently, the $12^{\text {th }}$ GFMD meeting took place in Quito, Ecuador in early 2020.

Scholars often describe the GFMD as a pivot point, or 'stepping stone' (Rother 2018, p.854), in the evolution of international cooperation on migration when the problem of migration was reframed in order to advance international cooperation (cf. Betts and Kainz, 2017; Roldan and Gasper, 2010; Rother, 2018). As Kofi Annan's opening remarks at the first HLD make clear, the argument that the GFMD presented an opportunity to reframe migration to foster progress is neither new nor hidden:

'I am especially delighted that so many of you have embraced my proposal for a Global Forum on Migration and Development, and asked me to help set it up. And I am particularly grateful to the Government of Belgium for offering to host the first meeting next year. I believe such a Forum can foster practical, evidence-based cooperation among governments. It can give you a chance to frame the issues in a way that allows you to move forward together, to discover areas where you agree, and to find ways of improving cooperation' (Annan 2006). 
The GFMD provides a concrete example of how the UN exercised constitutive power to influence intergovernmental cooperation on migration. However, the GFMD has rarely been the subject of empirical analysis. An exception is the work of Roldan and Gasper (2010). They use both frame-reflective policy analysis and discourse analysis to analyse Kofi Annan's opening address at the HLD in 2006 and the Chairman's report of the second meeting of the GFMD in Manila in 2008. Roldan and Gasper (2010) focus primarily on the rhetorical devices through which Kofi Annan frames the GFMD as a solution to 'entrenched disagreements and mistrust' (p.24) that had characterized international cooperation on migration.

This chapter investigates the role played by the UN and specifically Peter Sutherland, as a policy broker in the conceptualization of the GFMD. Sabatier (1998) defined policy brokers as actors 'whose principal concern is to find some reasonable compromise which will reduce intense conflict' (p.133). Accordingly, this chapter employs Abolafia's (2004) temporal model of framing to investigate the role of policy brokers in the global policymaking process. In doing so, the chapter also responds to a common criticism of framing research, which is that researchers often anthropomorphize frames to the neglect of the role played by different actors in (re)framing efforts (Benford, 1997).

Having identified the GFMD as a relevant case study that will help us to understand how international organizations have influenced the evolution of global migration governance, this chapter will address the following subquestions:

How was migration framed as a global policy issue before the establishment of the GFMD?

What was the role of different actors in promoting or opposing a frame shift after the establishment of GFMD?

What factors influenced the adoption of the 'migration and development' frame?

To address these questions, the chapter draws on two primary sources of data $^{1}$. The first is a subsample of documents collated from the UN Archives

\footnotetext{
${ }^{1}$ Section 3.3 provides details on how the data were collected.
} 
$(\mathrm{n}=110)$, which refer to the GFMD. Particular attention was given to documents published before the first GFMD in July 2007. During this time, various actors interacted with then-Secretary-General Kofi Annan regarding the conceptualization and realization of the forum. Additionally, the chapter draws on key informant interviews. The majority $(n=35)$ of respondents discussed the GFMD. The documents and interview transcripts were coded in NVivo 12. The codebook is located in Annex 3.3.

The remainder of the chapter is divided in three parts. Building on the discussion in Chapter 4, the first part of the chapter outlines the way different actors framed migration before the first GFMD (Section 5.2). The second part of the chapter (Section 5.3) focuses on early discussions centred on the creation of a Global Forum, which began in the months preceding the first High-Level Dialogue on International Migration and Development. Having established in Section 5.3 that Sir Peter Sutherland's vision of the global forum came into fruition, the third part of the chapter (Section 5.4) examines Sutherland's role in more detail. Specifically, it applies Abolafia's (2004) temporal model of framing to analyse the framing/rhetorical devices employed by Sutherland to galvanize support for his vision and to mobilize action.

\subsection{Framing Migration before the GFMD}

In the early part of the 21st century, there were two distinct trajectories in migration's journey as a global policy issue: one focused on migrant rights and the other on migration management (Section 4.5 and 4.6). A third frame, 'migration and development', also started to gain traction as a policy field in the early 2000s (Section 4.7). Although overlap exists, distinct groups of actors, or advocacy coalitions, promote these policy frames:

'There is a huge constituency in the UN that is all about migration and human rights. There is large support for that agenda. There is also support for an agenda that is about migration management and strengthening the capacity of states to manage migration. But there is actually a small group of countries that has any interest 
in the migration and development agenda' (INT-GOV031).

With limited interest by states in the migration and development agenda, one might wonder why it gained such prominence in global policy discussions. This section introduces each frame, the actors supporting each frame, and the central premises of each frame (Table 5.1).

Table 5.1 Migration Frames

\begin{tabular}{|c|c|c|c|}
\hline & Rights & Management & Development \\
\hline $\begin{array}{l}\text { Problem } \\
\text { Definition }\end{array}$ & $\begin{array}{l}\text { Migrant rights are } \\
\text { human rights. } \\
\text { Migrants are } \\
\text { vulnerable to } \\
\text { exclusion. }\end{array}$ & $\begin{array}{l}\text { Migration is a } \\
\text { phenomenon that } \\
\text { needs to be } \\
\text { managed. }\end{array}$ & $\begin{array}{l}\text { Migration and } \\
\text { development are } \\
\text { inextricably linked. }\end{array}$ \\
\hline Solutions & $\begin{array}{l}\text { International law - } \\
\text { conventions and } \\
\text { guidelines with a } \\
\text { preference for } \\
\text { binding norms }\end{array}$ & $\begin{array}{l}\text { Knowledge } \\
\text { sharing, informal } \\
\text { guidelines, sharing } \\
\text { good practices, } \\
\text { partnerships, }\end{array}$ & $\begin{array}{l}\text { Knowledge sharing, } \\
\text { informal guidelines, } \\
\text { sharing good } \\
\text { practices, } \\
\text { partnerships, }\end{array}$ \\
\hline $\begin{array}{l}\text { Frame } \\
\text { Characteristics }\end{array}$ & $\begin{array}{l}\text { Normative, } \\
\text { formal, binding } \\
\text { norms }\end{array}$ & $\begin{array}{l}\text { Pragmatic, } \\
\text { informal, good } \\
\text { practice }\end{array}$ & $\begin{array}{l}\text { Pragmatic, informal, } \\
\text { good practice }\end{array}$ \\
\hline $\begin{array}{l}\text { Key Frame } \\
\text { Supporters } \\
\text { (Advocacy } \\
\text { Coalitions) }\end{array}$ & $\begin{array}{l}\text { ILO, OHCHR, civil } \\
\text { society (mainly } \\
\text { rights-based } \\
\text { organizations), } \\
\text { Countries in the } \\
\text { Global South (e.g., } \\
\text { Philippines, } \\
\text { Mexico, Morocco) }\end{array}$ & $\begin{array}{l}\text { IOM, ICMPD, } \\
\text { Countries in the } \\
\text { Global North (e.g., } \\
\text { the US, Australia, } \\
\text { EU Member States) }\end{array}$ & $\begin{array}{l}\text { World Bank, UNDP, } \\
\text { Sutherland, civil } \\
\text { society (mainly } \\
\text { development and } \\
\text { diaspora), countries } \\
\text { in both the Global } \\
\text { North and South } \\
\text { (e.g., Sweden, } \\
\text { Switzerland, } \\
\text { Philippines, } \\
\text { Bangladesh) }\end{array}$ \\
\hline
\end{tabular}




\subsubsection{The 'Rights' Frame}

Framing migration as an issue of rights has a long tradition, particularly within the UN. The driving force behind the development of norms in the area of migration was an interest, particularly among countries of origin, to protect the rights of migrant workers in countries of destination (Section 4.3). Proponents of the migrant rights frame argue that, if migrants rights are protected, then many of the problems associated with migration will be solved. By focusing on migrants as individuals, the human rights frame often deals with issues such as working and living conditions, labour standards, access to justice, and detention. A by-product of the focus on ensuring rights is the question of vulnerability of those whose rights are not respected. However, particularly since welfare state retrenchment and the diffusion of structural adjustment policies around the world in the 1980s, the accordance of rights to non-citizens has become an increasingly sensitive electoral issue:

'Migrants have rights like anyone else. States accept that, except they do not want to do the speech act of ratifying a convention that says so' (INT-IO-013).

The framing of migration as a matter of human rights has been most strongly advocated by countries in the South. Mexico and Morocco were the countries that put their weight behind the ICRMW. Thinking back to our discussion of the international organization as an entity (Section 2.2.2), one would expect normative organizations such as ILO, the Office of the United Nations High Commissioner for Human Rights (OHCHR), and UNHCR to be more likely to support a rights frame. Additionally, organizations focusing on specific population groups such as UNICEF (children) and UN Women, which each are custodians of widely accepted international human rights instrument, ${ }^{2}$ might be expected to frame their work with migrants in terms of human rights. A rights-based frame is also a natural position for many civil society actors advocating for migrants around the world (Piper, 2017).

Historically the elaboration of legally binding international instruments has been the cornerstone of the human rights approach. Particularly in the early

\footnotetext{
${ }^{2}$ Except for the United States, all UN Member States are party to the Convention on the Rights of the Child (CRC). One hundred and eighty-nine Member States are party to the Convention on the Elimination of All Forms of Discrimination against Women (CEDAW).
} 
2000s, this is evident in the way proponents of the human rights frame describe the evolution of migration as a global policy issue. Of the Berne Initiative, one observer noted:

'They had regional consultations, then came up the International Agenda for Migration Management, which is a terrible document that talks about migrant rights but does not refer to any of the international migration instruments' (INT-IO-011).

However, developing such norms has been a challenge in the area of migration (Section 4.3), and thus proponents of the human rights frame have often found themselves side-lined (Piper, 2017).

\subsubsection{The 'Migration Management' Frame}

Just as the human rights framers criticize the migration management frame, the same is true of the management framers, with the caveat that they acknowledge the necessity of respecting human rights without placing norm adherence at the centre of their proposed solutions:

'As important as rights are, and they are important, unless we have the technical wisdom, and expertise, to deal with the phenomenon of migration, we will not go anywhere' (INT-IO-015).

The 'frame' pursued through many of the regional consultative processes (Section 4.4) and amplified through IOM's International Migration Dialogues (IMD) and the state-led Berne Initiative (Section 4.6) was 'migration management.' Discussions focused on logistical aspects of human mobility that states could theoretically address more efficiently in cooperation with one another, often focused on topics such as irregular migration, border management, smuggling, and trafficking. In simpler words, migration management is about 'migration' as a phenomenon more than it is about 'migrants' as individuals. 
Hess (2010) describes migration management as 'a catch-all term used by scientists in an analytical sense as well as policy practitioners in a positivistic or descriptive way' (p.97). The concept is often considered to have emerged in the 1990s; however, as Dutch historian Marijke van Faassen (2014) argued, migration management finds its roots in international discourse in the late 1940s describing efforts made by the international community to organize migration from Post-war Europe. IOM defines migration management as:

'A term used to encompass numerous governmental functions within a national system for the orderly and humane management for cross-border migration, particularly managing the entry and presence of foreigners within the borders of the state and the protection of refugees and others in need of protection. It refers to a planned approach to the development of policy, legislative and administrative responses to key migration issues' (IOM 2016).

Migration management thus consists of an eclectic collection of policies and practices implemented by governments across time and space, but with the specific objective of exerting influence over cross-border movements. Migration management is a technocratic rather than a normative term. The specific goals of migration management can change over time, and vary by context shifting, for example, from policies intended to halt immigration to those focused on the selection of immigrants (Hess, 2010).

Countries in the North have most strongly advocated the framing of migration as a management issue. Thinking back to the discussion of international organizations as entities (Section 2.2.2), one would expect functional organizations to be more likely to support the migration management frame. By rejecting ILO's plan and planting the seed of the future IOM as the PICMME outside the UN system in 1951 to provide operational support to UNHCR, the US arguably initiated a parallel trajectory for the governance of migration that was based on politically motivated concerns more than normative goals.

The concept of migration management is not without criticism, described by critics as a way to depoliticize migration (Geiger \& Pécoud, 2012) and part of a broader neoliberal project ushering in the principles of New Public Management to the area of migration policy (Georgi \& Schatral, 2012). Civil 
society actors often organize themselves in opposition to the migration management frame (Piper, 2017). Opposition to the migration management frame was particularly prominent in the early 2000s when civil society actors mobilized against IOM organizing protests and marches in 2002 in Berlin, Vienna, and Helsinki, and in 2003 in Geneva and Bonn (Georgi \& Schatral, 2012).

\subsubsection{The 'Migration and Development' Frame}

The early 2000s also witnessed a revival of discussions on migration and development. While the conceptual linkage of migration and development is not new (Ravenstein, 1885), the migration and development discourse has been subject to much academic reflection in the past decade (cf. Bakewell, 2008; Skeldon, 2008; Delgado Wise, Márquez Covarrubias, and Puentes, 2013; Brønden, 2012; Schiller, 2009; de Haas, 2010; 2012; Vammen and Brønden, 2012; Gamlen, 2014). Hein de Haas (2010) argues that views on migration and development, both in academic narratives and policy discussions, have swung back and forth like a pendulum (p.67). Before 1973, de Haas (2010) identifies optimism in the academic discourse, which led to the view that migration could lead to 'take-off development' in developing countries through capital and knowledge transfers. However, when a more pessimistic narrative emerged after the 1973 oil crisis, with discussions on brain drain and dependency, the view that migration could lead to take-off development disappeared. From the 1990s to the early 2000s, slightly more positive accounts arose, coinciding with the new economics of labour migration school of thought. At this time, migration was primarily considered as a livelihood strategy for households but could not overcome broader structural constraints. Post-2000, de Haas (2010) describes 'a resurgence of migration and development optimism under the influence of (a) remittance boom' (p.230).

The central premise of the 'migration and development' frame is that migration can be both positive and negative for development, although with a general emphasis on the potentially positive developmental impacts of migration. Through policies targeting remittances, such as the famed tres por uno programme in Mexico, migrants can contribute towards development in their countries of origin. The interest in potential development contributions 
that migrants can bring has created interest in diaspora engagement policies, which, as Gamlen (2014) observed, have mushroomed around the world. Migration and development as a policy field is thus most often associated with topics relating to remittances, diaspora engagement, and the mobility of the highly skilled (Skeldon, 2008). The 'migration and development' frame has been most concretely advocated by the World Bank and the IMF, from an economic development perspective, and UNDP, from a human development perspective. However, as Chapter 6 demonstrates, a wide range of different actors have engaged with the 'migration and development' frame.

Next to being a frame in its own right, the 'migration and development' frame can also be viewed as a paradigm within which advocates of different policy frames can find common ground. Some critical commentaries suggest that states have used migration and development as a 'smokescreen' for immigration control (Bakewell, 2008; Gamlen, 2014; Korneev, 2013; Pian, 2010). Hence, the 'migration and development' frame has been used to further the interests of those who view and frame migration as an issue of management at the expense of a more rights-based discussion. For advocates of a management frame, it offers a way of justifying their goals in a more palatable way. For example, well-managed migration can lead to positive development outcomes. Similarly, however, from a human rights perspective, a migrant whose rights are protected is more able to contribute to, and experience, development. Thus, in a quote attributed to one of the GCIM Commissioners, Mary Robinson, former President of the Republic of Ireland and former UN High Commissioner for Human Rights:

'If you do not want to do it for the right reasons, do it for the reasons that benefit you. As long as people are on the side-lines, they are not benefiting the societies in which they live' (INT-IO-004).

Therefore, the 'migration and development' frame can be viewed as both a frame in its own right and as a unifying frame that has been cleverly employed by policy brokers because it resonates with advocates of the 'human rights' and 'management' frames. Having defined our three main frames, Section 5.3 examines the discussions that ensued as preparations were underway for the first HLD. 


\subsection{The Genesis of the Global Forum on Migration and Development}

The earliest use of the term 'global forum' in the context of international migration can be traced back to the end of 2005 as then-Secretary-General Kofi Annan was looking for ways to follow up on the recommendations made by the Global Commission on International Migration (GCIM). Writing to the former chairs of the GCIM on 21 November 2005, he noted:

'The Dialogue provides a unique opportunity, indeed, a
test of whether the United Nations can establish itself as
the global forum where governments may discuss,
negotiate and build consensus on international
migration issues' (United Nations Archives 2005, p.2).

Kofi Annan appointed Peter Sutherland to be his Special Representative for International Migration and Development (SRSG) to ensure that, after the struggle to garner the necessary consensus to hold the first HLD, it would mark the start of increasing intergovernmental cooperation on migration, within the context of the UN.

Different actors sought to influence the early conceptualization of the global forum in the months preceding the first HLD. Early discussions focused on whether the global forum should be established within the UN, if at all. At the centre of this discussion were the SRSG, Peter Sutherland, and the former Director of the UN Department of Economic and Social Affairs (DESA), José António Ocampo. Each man submitted regular reports on the ongoing conceptualizations of the forum to Kofi Annan. Both men supported the idea of a global forum, although differed in their views on the role that the UN should play. Ocampo promoted a global forum implemented under the auspices of the UN Economic and Social Council (ECOSOC) (United Nations Archives, 2006a). Sutherland, on the other hand, promoted a light-link model' whereby states would take ownership of the forum with support from the UN (United Nations Archives 2006b, p.1).

Other actors are also referred to in this documentation, notably where they advocated against the global forum as being either duplicative or premature. These actors included several states (the US, Australia, Bulgaria) and IOs (ILO, IOM, OHCHR, UNCTAD, UNFPA, UNHCR, the World Bank). Their 
different views towards the forum are summarized in Table 5.2 and further discussed below.

Table 5.2 Views towards the Global Forum

\begin{tabular}{|c|c|c|}
\hline Actor & Position & Description \\
\hline DESA & Supportive & UN-led; DESA as Secretariat \\
\hline Peter Sutherland & Supportive & State-led; 'Light link model.' \\
\hline $\begin{array}{l}\text { Core Group of } \\
\text { Countries* }\end{array}$ & Supportive & $\begin{array}{l}\text { Southern States plus Spain = UN-led } \\
\text { Northern States = state-led }\end{array}$ \\
\hline ILO & $\begin{array}{ll}\text { Neutral to } \\
\text { Negative }\end{array}$ & $\begin{array}{l}\text { Premature; States will not support; undermines } \\
\text { GMG }\end{array}$ \\
\hline UNHCR & $\begin{array}{l}\text { Neutral to } \\
\text { Negative }\end{array}$ & $\begin{array}{l}\text { Premature; States will not support; undermines } \\
\text { GMG }\end{array}$ \\
\hline World Bank & $\begin{array}{l}\text { Neutral to } \\
\text { Negative }\end{array}$ & Premature; undermines GMG \\
\hline OHCHR & $\begin{array}{l}\text { Neutral to } \\
\text { Negative }\end{array}$ & Premature; undermines GMG \\
\hline UNFPA & $\begin{array}{l}\text { Neutral to } \\
\text { Negative }\end{array}$ & Premature; undermines GMG \\
\hline IOM & $\begin{array}{l}\text { Neutral to } \\
\text { Negative }\end{array}$ & Duplicative; undermines GMG; concern for own role \\
\hline UNCTAD & $\begin{array}{l}\text { Neutral to } \\
\text { Negative }\end{array}$ & Duplicative \\
\hline US & Against & Mistrust in the UN \\
\hline Australia & Against & No reason stated in the documentation \\
\hline Bulgaria & Against & No reason stated in the documentation \\
\hline
\end{tabular}

Sources: United Nations Archives 2006a; 2006e; 2006f; 2006g; 2006h; 2006i

Notes: *The core group of countries is a group of Member States that Peter Sutherland has engaged in early thinking on the global forum. Its members were Belgium, Brazil, Canada, Mali, Mexico, Morocco, the Netherlands, Nigeria, Philippines, Spain, Sweden, and Switzerland (United Nations Archives, 2006h).

With 'the mandate of carrying out all substantive work related to international migration and development as well as providing substantive support to any United Nations body dealing with the subject' (United Nations Archives 2007, pp.1-2), Ocampo's view of a forum established under ECOSOC is self-evident. DESA had a long history of supporting the Secretary-General in matters relating to international migration, such as organizing annual Coordination Meetings on International Migration since 2002. Sutherland's advocacy of a 'light link model' on the other hand, related to his mandate to further the dialogue on migration within the UN, while recognizing the difficulties of doing so given past experiences in the area. His arguments pointed to a more incremental process whereby states would first 
discuss the least controversial area of migration and, in doing so, build the necessary trust to engage in its more challenging aspects.

The main concerns related to the establishment of the global forum came from the many UN entities with competencies, and often mandates, to work on migration-related issues. Several UN entities were concerned that the GFMD would undermine the newly expanded Global Migration Group (GMG). Duplicative efforts were the Director-General of United Nations Conference on Trade and Development (UNCTAD) Supachai Panitchpakdi's primary concern when he wrote to Deputy Secretary-General, Mark Malloch Brown, on 20 April 2006 (United Nations Archives, 2006e). The relationship between the GMG and the GFMD became a key topic of discussion between Peter Sutherland and Kofi Annan. Sutherland wished to see the GMG established as the secretariat for the forum; however, this idea failed to gain any currency among GMG members (United Nations Archives, 2008). The main reason given for this was that the GMG was 'not in a position to provide secretariat support for the Forum since it is not ready to set up a secretariat for itself over the medium-term future' (United Nations Archives 2006b, p.1).

What is perhaps surprising is the 'neutral to negative' view of IOM on the GFMD, given that, from 2009, IOM hosted the GFMD Support Unit, which continues to provide secretariat support to the Chair-in-Office of the Forum. However, IOM's resistance towards the GFMD can be viewed in the context of its relationship with the UN. As further elaborated in Chapter 7, by the time the GFMD was being conceptualized, IOM's relationship with the UN had been discussed several times. In response to Kofi Annan's desire to see the UN more comprehensively respond to migration issues in the early 2000s, then Director-General of IOM, Brunson McKinley, had explored UN membership with the UN Council. However, the Member States of IOM voted against UN membership. There was perhaps a fear on the part of IOM that, if the GFMD were pursued within the UN, it would lose relevance.

While states generally supported the idea of having a global consultative forum with 82 UN Member States indicating their support at the HLD (United Nations Archives, 2006i), the main differences in opinion related to its relationship with the UN. Before the HLD, the core group of countries that Peter Sutherland had engaged in garnering support for the forum, was itself divided in terms of whether the forum should be a UN initiative: 
'A North/South divide (with only Spain aligning itself with the South) has emerged on the issue of the Forum's linkage to the UN. Many Southern countries stressed the importance of setting up the Forum under UN auspices. Both Mali and Nigeria argued that the Forum needed the 'umbrella of legitimacy' of the UN. Likewise, the Philippines and Mexico argued for a clear linkage between the Forum and the UN. Canada and the Netherlands stressed the need for the Forum to be 'staterun' and avoid being tied too closely to the UN' (United Nations Archives 2006h, p.1).

Although not part of the core group of countries, the main Member State opponents to the global forum were the US, Australia, and Bulgaria. While the objections of Australia and Bulgaria are not explicitly stated in the documentation, they are likely similar to the US. In a submission to the Policy Committee on migration, the following comment is made:

'Considering the growing wariness with the UN in the US, advancing a multilateral approach to international migration through the UN could evoke some negative reactions. There is a need to allay the concerns of key players in order to further a balanced approach to the migration issue and the follow-up to the Dialogue' (United Nations Archives 2006a, p.6).

The objection was, therefore, less about multilateral cooperation on migration, which was already underway through the various Regional Consultative Processes (RCPs) that had emerged since the creation of the Intergovernmental Consultations on Migration and Asylum (IGC) in 1985 (Section 4.4), and more about it being conducted under the auspices of the $\mathrm{UN}$. The position of the US on the forum is perhaps the most compelling reason why Sutherland's vision of a state-led forum ultimately came into fruition. In his address to the HLD, Kofi Annan outlines his vision for the forum:

'The Forum must be led and overseen by states. But the United Nations System, and I personally, stand ready to support it. I have decided to extend the mandate of my 
Special Representative on Migration beyond this Dialogue. I trust that the Special Representative will form an essential link between the proposed Forum and the entire United Nations system' (Annan, 2006).

The GFMD provides a concrete example of how a policy decision with regards to intergovernmental cooperation on migration has been influenced by the UN balancing its desire to remain involved in the conversation without being perceived as a threat to states, particularly the US, who remained a significant funder of their work.

\subsection{The Role of Peter Sutherland as a Policy Broker}

Another notable aspect of the way the GFMD was framed was its focus on development. Although the 'migration and development' frame has earlier roots, its operationalization as a means of furthering international cooperation is generally associated with the GFMD and the work of Peter Sutherland. The notion that individuals can drive specific ideas is not new in the literature. What Weiss (1989) refers to as 'policy entrepreneurs' or Fligstein (2001) calls 'institutional entrepreneurs' is described by framing scholars as 'frame sponsors' (Rein and Schön 1996, p.90) or 'reframers' (Abolafia 2004, p.354), and in the advocacy coalition framework as 'policy brokers' (Sabatier, 1988, p.133). The vast majority $(n=30)$ of interviewees identified Peter Sutherland as being a, if not the key figure in global migration governance for ensuring the success of the first HLD, establishing the GFMD; advocating for the inclusion of migration in the Sustainable Development Goals (SDGs) (Chapter 6) and his role in IOM becoming a related agency of the UN (Chapter 7).

Peter Sutherland came to his post as SRSG with a remarkable CV. His experience in both the policy and business realms, and especially the successful negotiation of the Uruguay Round establishing the World Trade Organization, gave him the credibility in the eyes of many states:

'He was the attorney general of Ireland, he was European Commissioner, he was the last Director- 
General of the GATT, the first Director-General of WTO, he was Chair of the Board of Goldman Sachs, and he was Chair of the Board of the London School of Economics. That was someone that states trusted' (INT-IO-013).

However, this also meant that he was viewed with suspicion, particularly by adherents to the 'human rights' frame:

'Peter Sutherland was mainly a private sector person, WTO chief, affiliated to Goldman Sachs. He was not the right person for that role in my personal view because he really did not promote a rights-based approach to migration' (INT-IO-011).

This position is understandable since, in early conversations about the GFMD, Peter Sutherland did advise that the global forum be steered away from controversial issues, primarily human rights. In a letter addressed to Kofi Annan on 3 April 2006, Sutherland writes:

'I have heard, indirectly, of a number of governments that have been told of a "parallel event" 3 to take place during September's High-Level Dialogue. Apparently, a letter has been received from you regarding this and it would focus on 'migrant rights.' Whilst undoubtedly migrants rights have to be referred to in the Report the response I have heard to this suggestion, from a number of developed countries that would normally be sympathetic, is extremely negative that may lead to down-grading of ministerial participation at the HLD itself - out of concern that it would degenerate into a 'shouting match' about rights. Everything that I have heard from delegations suggests that we would be much better advised focusing on the economic aspects of migration while making the obligatory references to the rights issue. Anything other than this will inevitably

\footnotetext{
${ }^{3}$ The parallel event that he is referring to is the annual treaty event held on the sidelines of the General Assembly. In 2006 this was called 'Crossing Borders' and focused on advocating ratifications of conventions relevant to migrants.
} 
result in a failure of the HLD' (United Nations Archives, 2006b).

Thus, it can be argued that the omission of human rights was tactical, a strategic manoeuvre in order to first build trust before reintroducing the concept of human rights.

'Peter Sutherland was very strategic in bringing states slowly to the issue and, and then progressively, the human rights issues of migrants became part of the conversation' (INT-IO-013).

Having established that Peter Sutherland acted as a policy broker, the chapter now examines how he reframed migration as a development issue using Abolafia's (2004) temporal model of framing. Abolafia's model involved three stages: 1) breaking the frame; 2) constructing the new frame; and 3) adjusting the frame. (p.90).

\subsubsection{Breaking the Frame: Casting Doubt}

According to Abolafia (2004), in the first stage of a reframing effort, 'reframers attempt to establish that existing practices are no longer viable' (p.354). As different actors were discussing the GFMD, Sutherland made frequent references to the limitations of past attempts to further migration governance within the UN system as the rationale for his 'light-link' model. For example, Sutherland communicated the following to Kofi Annan on 3 April 2006:

'This informal Forum idea is vital because earlier debates in the Second and Third Committees, the Population and Development Commission, the Social Development Commission and the Cairo Conference have been seen to be unproductive, politicised, uninformed and ultimately quite marginal' (United Nations Archives 2006c, p.2). 
In breaking the frame, Sutherland reminded his audience of the failures of past endeavours to justify his proposal. He undermines Ocampo's proposal by pre-emptively assuming that it will fail, as similar endeavours had in the past. Rather than migration being the problem, a lack of constructive international cooperation on migration is instead framed as the problem. This position was particularly prominent in Kofi Annan's address to the HLD (Roldan \& Gasper, 2010) as well as in Ban Ki-moon's opening address to the first GFMD in 2007 in Brussels in which he noted:

‘For many years, Member States of our United Nations found it hard to discuss the sensitive issue of migration in the international arena. So the topic was never high on the UN agenda -- until the High-Level Dialogue at UN Headquarters in New York last September. Even then, some sceptics predicted that positions would be too entrenched, that north and south would become hopelessly embattled, and that genuine dialogue would be impossible. The past nine months have proved those sceptics wrong. As we have grasped migration's powerful potential for good, old stereotypes have crumbled, and new opportunities have captured our imaginations' (Ban, 2007, p.1).

His moral judgement on the correctness of the decision to hold the GFMD is an example of motivational framing (Snow et al. 1988). He praised the audience for doing something that was deemed impossible.

\subsubsection{Constructing the New Frame: Migration and Development}

Abolafia (2004) argues that in the next stage of reframing, 'reframers must move interested actors' attention beyond the past and into the future to construct an image of the new policy frame and its superior efficacy' (Abolafia, 2004, p.258). After reframing the issue of migration as an issue of a lack of international cooperation, the matter of what would be covered within the forum came to the fore. As a member of Peter Sutherland's team noted: 
'We gave a lot of thought to the name of the Global Forum. It was not a Global Forum on Migration. It was a Global Forum on Migration and Development because that was a way to dull the politics around migration' (INT-IO-037).

Although the 'migration and development' frame had earlier roots (Section 5.2.3), its operationalization as a means of furthering international cooperation is often associated with the first HLD and the GFMD. Betts and Kainz, (2017), for example, argued that the 'migration and development era' began in 2006. The notion that the 'migration and development' frame acted as a 'unifying narrative' bridging different interests is generally accepted by the interviewees". See, for example, the following illustrative quote:
'At the time, it was often said that the reason to link migration with development was a way to bring all of the international community to the table. The Southern countries were interested in development, and the Northern countries were interested in stopping migration. Speaking crudely' (INT-IO-040).

Sutherland specifically advocated a positive framing of migration that built on the already growing optimism which was fuelled, in part, by the 'rediscovery' of remittances by the World Bank (de Haas 2010). A key feature of the reframing of migration was its portrayal as a 'triple win' phenomenon, which is often attributed to Kofi Annan:

'The focus on migration and development was very,
very intentional in the sense that Kofi Annan and his
people thought that migration and development would
be the least contentious aspect of the migration issue.
Kofi Annan came out with this phrase, which I never
really liked, when he talked about migration as a win-
win-win situation: a win for countries of origin, a win for

${ }^{4}$ INT-IO-008, INT-IO-013, INT-IO-016, INT-IO-025, INT-IO-021, INT-IO-026, INT-GOV-031, INT-GOV-032, INT-OTHER-034, INT-GOV-036, INT-IO-037, INT-IO-038, INT-IO-040 
countries of destination, and a win for migrants themselves' (INT-IO-008).

Knowing that the GFMD is still organized on an annual basis, that migration has been included in the Sustainable Development Goals (SDGs) (Chapter 6), and that IOM has now become a 'related agency' of the UN (Chapter 7), it is evident that, while still an 'ill-defined' link in 2006 (United Nations Archives, 2008), the 'migration and development' frame was successful in sustaining international dialogue on migration.

\subsubsection{Aligning the New Frame}

Abolafia (2004) noted that 'the rejection of old and valued frames is not likely to go unchallenged' (p.357). As already discussed above, the main frame conflict evident in the commentaries of the GFMD occurred between advocates of a 'human rights' frame and the 'migration and development' frame. The reasons for this conflict is perhaps because the 'migration and development' frame resonated more with adherents to the migration management frame owing to its more practical nature.

'The creation of the Global Forum for Migration and Development, and this is very much a personal view, took us off track a little bit... it was very consistent with IOM's particular world view at the time, which was that you do not engage in "politically sensitive issues" like the rights of people on the move, you look at it from a very broad migration and development framing' (INTIO-040).

The main fear was that the GFMD was an initiative of Northern States to pursue their interests in the area of migration:

'The relation between development and migration was political and conceptually a bit difficult to grasp in the UN historically, especially by countries of origin. The concept was not originally put forward as a way simply to recognize the fact that there is a link between 
development and migration, but it was perceived as a North-South issue, it was perceived as Europeans mainly, and the US, pushing for that notion of creating a sense of responsibility in countries of origin. At least, this is how countries of origin, at that time, used to see it' (INT-GOV-036).

The fear that the GFMD would lead to the furtherance of Northern interests, is arguably what drove the organizations of the UN with human rights mandates as well as many civil society actors to push for the inclusion of human rights on the GFMD agenda:
'At the first GFMD, there was a strong suspicion that it was something that the wealthy governments of the North were putting to deflect attention away from injustices. From the beginning, there has been an outside civil society tactic...(to) bring human rights to the fore' (INT-OTHER-023).

Perhaps to offer reassurances to the supporters of a human rights frame, the topic of human rights was already introduced into the discussions at the GFMD in Manila. However, this was done in a way that kept the interests of those resistant to efforts to promote a human rights frame engaged. In a memo sharing updates on the GFMD with Ban Ki-moon on 9 January 2008, Peter Sutherland noted:

'The main theme to be discussed (at the second GFMD in Manila) will be Migration, Development and Human Rights. In spite of the potentially divisive nature of this subject, I am confident that the organizers will handle it in a non-confrontational manner.... Esteban Conejos emphasized that upholding the human rights of migrants - a potentially controversial issue - was to be considered as a shared responsibility by all governments involved. This approach, complemented by my encouragement to avoid any North-South divide, allayed the apprehension of those countries either wanting more, or, at the opposite, less engagement of the 
GFMD on the human rights terrain' (United Nations Archives 2008, pp.1-2).

While the topic of human rights has been discussed at the GFMD, therefore, many observers, including former Special Rapporteur on the Human Rights of Migrants, François Crépeau remained concerned that its coverage, if at all, is either cursory or 'dismissed as divisive ${ }^{5}$ (para. 50. p.10). Assuming different interests within one frame does not guarantee that differences will be resolved. In this case, reframing migration as a development issue in order to move discussions on migration forward may have only served the interests of Northern States. One key informant went as far as to describe the GFMD as a 'consolation prize' for countries in the South who had long been calling on the UN to hold a global conference on migration (INT-IO-028). This is, in fact, one of the major critiques evident in the academic literature on the 'migration and development' frame arguing that it has been used as a 'smokescreen' for immigration control (Bakewell, 2008; Gamlen, 2014; Korneev, 2013; Pian, 2010).

\subsection{Conclusion}

It is without dispute that there are different ways of looking at migration as a global policy issue. The two dominant approaches are the 'rights-based' approach and the 'migration management' approach. The rights-based approach is more rigid in the sense that its cornerstone is the UN's human rights architecture. Actors within the rights-based community are focused on international norms, preferably legally binding, that, if upheld, are believed to result in the achievement of a broader common goal: peace. This rigidity was often commented upon and frequently dismissed, by actors who approached migration from a management perspective. Advocates of the migration management frame argue that it is much more flexible because it is based on identifying operational solutions to problems. Technocratic as opposed to than dogmatic. However, this, in turn, has raised the concern that the migration management frame is set on depoliticizing migration to further

${ }^{5}$ UNGA, Report of the Special Rapporteur on the Human Rights of Migrants: Human Rights of Migrants, UNGAOR, 68th Session, UN Doc. A/68/283 (7 August 2013) 
the interests of Northern states. These opposing frames reflect underlying belief systems concerning the role of IOs in global governance (Section 2.2.2). From the human rights perspective, international cooperation is about the achievement of broader common goals. From the migration management perspective, it is about increasing state efficiency in the handling of matters with a cross-border component. The clever framing of migration as a development issue offered the UN a way of exercising constitutive power to maintain the UN's role in migration governance without alienating either group.

By first reframing migration as an issue of international cooperation before using the 'migration and development' frame to calm the fears of certain Member States wary of the idea that the GFMD would lead to the creation of some kind of World Migration Organization, Peter Sutherland successfully acted as policy broker. By focusing on migration and development, rather than the human rights of migrants, or management-related issues, he facilitated the creation of a space for actors with different frames of reference to come together, to build trust, so as to further international cooperation on migration. The core argument of this chapter is therefore that, in line with ACF, Peter Sutherland acted as a 'policy broker' helping to achieve a level of cooperation and coordination between adherents of different advocacy coalitions through the cultivation of a pre-existent, if less dominant coalition under the umbrella of the migration and development frame.

Given the instrumentalization of the 'migration and development' frame as a means of furthering international cooperation on migration, it is unsurprising that several commenters have proposed that the optimism of migration and development as a policy field may be a 'passing phase' (Skeldon 2008). However, as the next chapter will demonstrate, the migration and development frame has continued to be of importance to international discussions on migration. The inclusion of migration in the Sustainable Development Goals brought migration squarely into the UN (Chapter 6) and arguably led IOM to become a 'related agency' of the UN (Chapter 7). 


\section{Migration and Development: A Passing Phase or Here to Stay? ${ }^{1}$}

\subsection{Introduction}

On 25 September 2015, Member States of the UN unanimously adopted a Resolution called 'Transforming our World: The 2030 Agenda for Sustainable Development'2. In a follow up to the Millennium Development Goals (MDGs), the resolution set out 17 Sustainable Development Goals (SDGs) and 169 targets laying the blueprint for development efforts for the next 15 years. Where the MDGs had been far more streamlined, with its eight goals and 18 targets focused primarily on developing countries, the SDGs reflected broader shifts in the global system and, as such, were designed for all countries, regardless of their level of development (Kamau et al., 2018). Although the Millennium Declaration contained a commitment 'to take measures to ensure respect for and protection of the human rights of migrants, migrant workers and their families ${ }^{3 \prime}$ (para. 25, p.7), migration, along with other issues deemed 'too difficult to measure unambiguously or too sensitive to handle politically' (Browne and Weiss 2014, p.6) did not appear in the MDGs. However, with the developments since the adoptions of the MDGs (Section 4.6 and 4.7), in particular the GFMD (Chapter 5), there was more optimism regarding the possibility of seeing migration included in the post-2015 development agenda:

\footnotetext{
1 This chapter develops the ideas presented in two previous publications. First, it draws on a conference paper presented at the Migrating out of Poverty Conference 'From Evidence to Policy' which was held on 28-29 March 2017 at the School for Oriental and African Studies (SOAS) in London (McGregor, 2017). I am grateful for the helpful comments received from Manolo Abella (discussant) and other participants at the conference. These ideas were further developed in McGregor (2020). Here I am grateful to Ronald Skeldon, Tania Bastia and Michaella Vanore for their helpful comments on the draft.

2 Transforming our World: the 2030 Agenda for Sustainable Development, UNGAOR, 70th Session, UN Doc. A/RES/70/1 (25 September 2015)

3 United Nations Millennium Declaration, UNGAOR, 55 $5^{\text {th }}$ Session, UN Doc. A/RES/55/2 (18 September 2000)
} 
'With discussions underway on the post-2015 development agenda and a new set of goals for sustainable development, the time is ripe to present a compelling case about why migration matters for development' (Ban, 2013).

As efforts mounted to define the successor to the MDGs, the migration (and development) community moved swiftly into action. While their arguments were not always the same, the migration community united around one objective: to see migration reflected in the SDGs. While different actors were united in their desire to see migration included in the new development agenda, however, the complexity of how migration is included in the SDGs is a testament to the utility of the 'migration and development' frame in unifying disparate interests under one umbrella. This chapter examines the arguments put forward by various actors in the years preceding the adoption of the SDGs for why migration should be included. The chapter assesses the extent to which the 'migration and development' frame has acted as a unifying frame by resolving frame conflicts or merely served to mask the underlying conflicts in the interest of furthering international cooperation.

The chapter draws on several data sources. First, it draws on interview data. Of the 44 interviews, 27 key informants, including several actors who were very close to the negotiation process, were able to comment on the process of negotiating the inclusion of migration in the SDGs. Next to the key informant interviews, a subsample of the UN archival records was examined $(n=37)$. This review primarily revealed procedural aspects of the process of developing the SDGs as they related to migration. However, it was also the source of several interagency collaborative texts arguing for the inclusion of migration in the SDGs. To understand the different arguments being put forward by different actors, and the outcomes of these efforts, however, further data were required. Thus, in addition to the interviews and archival records, I constructed two further sets of documents. The first set of documents included the key outcome documents that emerged throughout the negotiation of the SDGs, as listed in Section 3.3.3. The second source of supplementary data was a sample of documents $(n=121)$ written by members of the Global Migration Group (GMG) between 2012 and 2015 in which arguments are made for the inclusion of migration in the post-2015 development agenda. 
The remainder of the chapter is structured as follows. Section 6.2 sets the context by briefly summarizing the process leading up to the adoption of the SDGs. Section 6.3 then deconstructs the different arguments made for why migration should be included in the post-2015 development agenda by examining the documents produced by individual IOs in the lead up to the adoption of the SDGs. Section 6.4 then examines the specific efforts of different constellations of actors, namely an informal working group established by Peter Sutherland, the GMG, and the GFMD, to galvanize support for the inclusion of migration in the post-2015 development agenda. Section 6.5 discusses how migration was ultimately included in the SDGs. Section 6.6 concludes the chapter.

\subsection{Negotiating the Sustainable Development Goals}

To understand how different actors lobbied for migration to be reflected in the SDGs, it is useful to offer a brief overview of the process leading to their adoption, which was ultimately the product of two parallel processes (Table 6.1). The first was a process initiated by the UN to define a successor agenda to the MDGs, dubbed the post-2015 development agenda. The second emerged from the UN Conference on Sustainable Development (Rio+20).

Discussions about the successor to the MDGs began in earnest within the UN in 2012. In January 2012, UN Secretary-General Ban Ki-moon formed the UN System Task Team on the Post-2015 Development Agenda (UNTT). The UNTT brought together more than $60 \mathrm{UN}$ entities, agencies, and IOs to provide technical support to state-led multi-stakeholder consultations on the post-2015 development agenda. The UNTT prepared numerous background reports, including 28 thematic think pieces. Next to the UNTT, Ban Ki-moon also created the High-Level Panel of Eminent Persons on the Post-2015 Development Agenda (HLP) in July 2012. The HLP had the goal of providing recommendations on the development agenda post-2015. The group, which was headed by Liberia, Indonesia, and the UK, finalized their work in May 2013 with a report suggesting 12 indicative goals and targets. 
Table 6.1 Timeline of SDG Negotiations

\begin{tabular}{|c|c|c|}
\hline \multicolumn{2}{|l|}{ Year } & SDG/Post-2015 Processes \\
\hline \multirow[t]{7}{*}{2012} & Q1 & UN Task Team on Post-2015 Development Agenda (UNTT) Created (January) \\
\hline & \multirow[t]{3}{*}{ Q2 } & UNTT release 18 Thematic Think Pieces (May) \\
\hline & & UNTT releases report 'Realizing the Future We Want' (June) \\
\hline & & Rio+20 Conference (20-22 June) \\
\hline & \multirow[t]{2}{*}{ Q3 } & High-Level Panel (HLP) of Eminent persons created (July) \\
\hline & & Open Working Group (OWG) created (September) \\
\hline & Q4 & \\
\hline \multirow[t]{8}{*}{2013} & \multirow[t]{3}{*}{ Q1 } & UNTT release 10 Thematic Think Pieces (January) \\
\hline & & UNTT release report 'A renewed global partnership for development' (March) \\
\hline & & OWG Thematic meetings and 100 Country meetings (March 2013-January 2014) \\
\hline & \multirow[t]{3}{*}{ Q2 } & \\
\hline & & High-Level Panel releases Report (May) \\
\hline & & OWG Thematic meetings and 100 Country meetings (continued) \\
\hline & Q3 & The High-Level Political Forum is founded and holds its first meeting (July) \\
\hline & Q4 & OWG Thematic meetings and 100 Country meetings (continued) \\
\hline \multirow[t]{6}{*}{2014} & Q1 & \\
\hline & \multirow[t]{2}{*}{ Q2 } & OWG negotiate co-facilitators draft report. (March - July) \\
\hline & & HLPF Meeting (30 June-9 July) \\
\hline & \multirow[t]{2}{*}{ Q3 } & \\
\hline & & OWG negotiations continue including finalization of the report on 18 July \\
\hline & Q4 & \\
\hline \multirow[t]{7}{*}{2015} & Q1 & SDG Negotiations (January - August) \\
\hline & \multirow[t]{2}{*}{ Q2 } & \\
\hline & & HLPF Meeting (26 June-8 July) \\
\hline & \multirow[t]{4}{*}{ Q3 } & \\
\hline & & Financing For Development Conference (July) \\
\hline & & SDGs text adopted by acclamation (2 August) \\
\hline & & SDG Adoption (September) \\
\hline
\end{tabular}

Notes: The table is colour coded as follows: post-2015 process (yellow); Rio+20 process (blue) SDG process (green) 
In a parallel process, the idea of Sustainable Development Goals started to take shape. The idea of Sustainable Development Goals was first put forward by Paula Caballero of Columbia in 2011. Her proposal, made ahead of the Rio+20 conference, was a vision for a set of goals that, unlike the Millennium Development Goals (MDGs), would apply to all countries. Her proposal initially faced fierce opposition, particularly from those fearing that it would undermine the MDG process. However, at an informal preparatory event for Rio+20, attended by a group of around 40 states gathered in Bogota, Colombia, her proposal slowly gained support. By January 2012, the concept of having sustainable development goals had made it into the zero draft of the Rio+20 outcome document (Dodds et al., 2017).

Rio+20 led to the establishment of the High-Level Political Forum on Sustainable Development (HLPF), which held its first meeting on 24 September 2013 and met again twice throughout the negotiations, from 30 June to 9 July in 2014 and from 26 June to 8 July in 2015. The main tasks of the HLPF were to 'provide political leadership, guidance and recommendations for sustainable development, follow up and review progress in the implementation of sustainable development commitments, enhance the integration of the three dimensions of sustainable development in a holistic and cross-sectoral manner at all levels and have a focused, dynamic and action-oriented agenda, ensuring the appropriate consideration of new and emerging sustainable development challenges' ${ }^{\prime 4}$ (para. 2., p.3).

Rio+20 also led to the creation of the Open Working Group (OWG) in September 2012. The OWG form was a compromise between the US and the $\mathrm{EU}$, who wanted to establish a small technical working group; and the G77, who wanted an open-ended working group. The compromise was an Open Working Group with 30 seats but, owing to the immense interest, resulted in a total of 70 countries sharing the 30 seats. The President of the General Assembly appointed Hungary and Kenya to co-host the meetings, and UNDESA and UNDP provided an interagency technical support team. From March 2013 to February 2014, the OWG held monthly meetings covering different thematic areas. From March to July 2014, the OWG discussed a draft set of goals prepared by the co-chairs. A critical difference between the negotiations of the MDGs and the SDGs was the space given to different actors to define what would become an SDG. Where the UN Secretariat had

${ }^{4}$ Format and Organizational Aspects of the High-Level Political Forum on Sustainable Development, UNGAOR, 77th Session, UN Doc. A/RES/67/290 (9 July 2013) 
primarily driven the efforts to define the MDGs, states retained control over the drafting of the SDGs (McGregor, 2020). Throughout the OWG deliberations, 'new proposals kept coming in from all sources. Governments, UN agencies, NGOs and many others all wanted their favourite issues to be part of the new framework' (Dodds et al. 2017, p.36). Many of these proposals also emanated from the post-2015 development agenda process, including the work of the HLP.

On 18 July 2014, the OWG agreed upon a final text that included 17 goals and 169 indicators. While many had anticipated further rounds of negotiations, there was a fear that 'any attempt to reopen individual goals or targets could lead to very protracted and difficult negotiations' (Dodds et al. 2017, p.70). As a result, the WOG decided to 'seal' the goals and to make only minor refinements as required. The decision not to reopen the goals and targets during negotiations meant that the window for influencing the SDGs was relatively short. By 18 July 2014, the stage was set. The majority of the negotiations on the SDGs themselves took place between January and July 2015. The process was co-facilitated by David Donoghue of Ireland who had co-facilitated the 2013 General Assembly Special Event reviewing progress made on the Millennium Development Goals, and Macharia Kamua of Kenya who had co-chaired the OWG. This pairing ensured that, while initially parallel processes, the post-2015 discussions and the SDG discussions were brought together to avoid unnecessarily duplicative efforts. The zero draft was distributed on 1 June 2015, and, after several rounds of negotiations, the sixth and final text of the SDGs was adopted by acclamation on the 2 August 2015 and as a General Assembly resolution on 25 September $2015^{5}$.

\subsection{Arguing for the Inclusion of Migration in the Post- 2015 Development Agenda}

Section 5.2 discussed how actors frame migration as a global policy issue in different ways, which in turn has implications for the solutions they offer. The mobilization of the 'migration and development' frame as a unifying frame, subsuming the interests of actors from conflicting frames, was also

\footnotetext{
5 Transforming our World: the 2030 Agenda for Sustainable Development, UNGAOR, 70th Session, UN Doc. A/RES/70/1 (25 September 2015)
} 
discussed. Where countries in the North had primarily viewed migration through the migration management frame, countries in the South had long advocated for a rights-based approach to migration at the international level. Normative agencies, such as ILO and UNHCR, tasked with upholding specific conventions, and with rights-based mandates, historically found themselves side-lined (Chapter 4) when Northern States, often the US, used their power to steer international collaboration on migration towards interventions that focused on the logistical aspects of population movement, such as the facilitation of transport, and largely rejected the pursuit of a normative approach to migration at the international level (Section 4.3). The function of the GFMD was to bridge these conflicts, and, by focusing on migration and development, Peter Sutherland and others were certain that states could build trust to the point that they would be able to discuss some of the more controversial migration-related challenges (Section 5.3). Hence, the 'migration and development' frame was instrumentalized in order to bring the topic of migration under the mandate of the UN.

If the purpose of the 'migration and development' frame was to galvanize support for migration as an international policy issue, then an examination of the arguments put forward for why migration should be in the post-2015 development agenda should provide a fruitful source of data on the evolution of the narrative. While different actors agreed that migration should be in the post-2015 development agenda, considerable diversity in argumentation points to the unifying power of the 'migration and development' frame. The thematic coding of relevant passages of the IO documents $^{6}$ identified five distinct arguments why migration should be included in the post-2015 development agenda. The two most commonly cited arguments were: first, migration can be an enabler of development under the right conditions (33\%); and second, that migrants are at risk of being excluded from development owing to vulnerabilities arising from their migration status (33\%). The three other, less cited reasons included the conceptualization of migration as a development challenge (19\%), migration as a response to (under)development (11\%), and forced displacement as a development challenge (4\%).

\footnotetext{
${ }^{6}$ For a description of how these excerpts were identified please refer to Section 3.3.3
} 


\subsubsection{Migration as a Development Enabler}

The prominence of the argument that migration enables development is not entirely surprising given that the concept of 'development enablers' was given a prominent place in the debate by the UNTT (2012). The majority of these arguments focused on the economic benefits that migration can have for countries of origin and destination, as well as for the migrants and their families. The basic premise of this argument is that migration, under the right conditions, can contribute towards the achievement of development goals through, for example, the transfer of remittances or knowledge. For example:

'Migration and remittances can be leveraged to raise development financing via reducing remittance costs, lowering recruitment costs for low-skilled migrant workers, and mobilizing diaspora savings and diaspora philanthropic contributions. Remittances can also be used as collateral, through future-flow securitization, to facilitate international borrowings with possibly lower costs and longer maturities. And they can facilitate access to international capital markets by improving sovereign ratings and debt sustainability of recipient countries' (World Bank, 2015, p.1).

The extent to which migration can be an enabler of development is often conditioned on migration being 'well-managed' (cf. IOM, n.d.a.; UNDP, 2013); or the human rights of migrants being respected (cf. ILO, 2013; IOM, 2013; UNFPA, n.d.; World Bank, 2014); or both:

'The positive impact of migration is neither predetermined nor guaranteed. On the contrary, comprehensive, and well-managed migration policies are crucial, and ideally these should be developed and implemented through close cooperation between the countries of origin and destination, to ensure orderly mobility with full respect for the human rights of all migrants. Only development initiatives such as these will be able to unleash the development potential of migration and allow migrant diaspora resources to be 
fully utilized, beginning with the benefits accruing to the migrants themselves' (IOM, n.d.b, p.4).

\subsubsection{Migration as a Characteristic of Vulnerability}

The central premise of the 'vulnerability' argument is that migrants, as a social group alongside other groups such as women, persons with disabilities, ethnic minorities, are at risk of being excluded from development.

'Disaggregated data will be essential for monitoring equity gaps, strengthening social accountability and ensuring that the gaps between the most and least advantaged groups are narrowing. Data should also be disaggregated by all grounds of discrimination prohibited by international human rights law, including inter alia by sex, age, race, ethnicity, income, location, disability, and other grounds most relevant to specific countries and contexts, for example: caste, minority groups, indigenous peoples, migrant or displacement status' (UNICEF, 2014, p.6).

The identification of migrant status as a characteristic of vulnerability lent weight to the argument that migration should be a cross-cutting issue across the new development agenda, which aligned with the notion of an inclusive development agenda in which no one would be left behind. 'Leave no one behind' was the slogan of the HLP and was 'popularized by the OWG' (Kamau et al., 2018, p.124). This narrative also addressed the concern that certain groups had been excluded from the MDGs by nature of its design:

'The MDGs allowed overall progress to be recorded as the main indicator, despite slower progress experienced by certain segments of society and the growing exclusion and marginalization of vulnerable groups. Without an incentive to record their situation, some groups with limited or no political capital, such as migrants, were rendered invisible to the development agenda. As a new post-2015 development agenda is 
being debated, OHCHR has consistently stressed that another method of measuring progress is needed, one which will provide more information about how progress is distributed while also providing incentives to focus on those groups which are being left behind' (OHCHR, 2013, p.64).

However, the vulnerability of migrants was also framed in connection to migrants as 'development enablers', providing that they experience the right conditions. These vulnerabilities related primarily to conditions in countries of destinations linked, in particular, to access to services but were also used to refer to the vulnerabilities of migrants to unethical recruitment practices or human traffickers, in the absence of legal opportunities to migrate. For example:

'A proactive approach to the protection of migrant workers towards improving development outcomes requires the formulation and implementation of gendersensitive labour migration policies, establishing effective labour migration institutions, and adopting and enforcing legislation and policies guided by international labour standards, which apply to all migrant workers unless otherwise stated' (ILO, 2013, p.4).

‘Universal health coverage, including for marginalized populations, can help to leverage the positive development impacts of migration' (IOM, n.d.a, p.3).

\subsubsection{Migration as a Development Challenge}

The third most commonly cited argument was population movements, both internal and international, can undermine development. This argument was often paired with the argument that migration can support development, when well managed. In the context of urban growth, migration is argued to undermine rural development through the departure of human capital and to threaten urban development by placing pressure on public services. In the context of international migration, migration (human trafficking and 
smuggling) is often positioned next to other transnational organized crimes as a challenge to establishing enabling environments for development. See, for example:

'Climate change and other environmental threats, rapid population growth and migration are putting disproportionate pressure on livelihoods in rural areas where poverty is already entrenched and people have the least resilience' (FAO, 2014a, p.6; 2014b, p.2).

'On the other hand, crime-related violence, transnational organized crime, including trafficking in persons and smuggling of migrants, as well as drug trafficking not only caused losses in terms of human resources and future productivity, but also negatively affected the enabling environment for the realization of development goals, the rule of law, business and finance and human security' (UNODC, 2012, p.2).

\subsubsection{Development as a Reason for Migration}

The impact of development, or lack thereof, on migration, was a far less prominent argument for the inclusion of migration in the post-2015 development agenda. The basic premise of this argument is that migration is the product of a lack of development in one's place of origin. It is an argument with a long history and it fuelled the notion of 'aid in place of migration' (Böhning and Schloeter-Paredes 1994). Although never directly arguing that migration should have a place in the post-2015 development agenda, FAO is most clear in referring to migration as a product of underdevelopment. FAO argued that rural development, such as the creation of livelihood opportunities and investments in public services, will prevent what it refers to as 'distress migration', which deprives rural areas of skills and puts pressure on infrastructure and services in urban areas (FAO, 2014, 2015). Similar arguments appear in the writings of UN Women concerning the impacts of migration on rural poverty rates (UN Women, 2013a, 2013b).

However, critics have highlighted the folly of this argument, since, development can also increase migration (Skeldon 1997; de Haas 2010). 
Arguments implying that underdevelopment leads to migration were therefore primarily framed in terms of the notion of migration out of choice rather than a necessity, a mantra that Pécoud (2015) attributed to the work of GCIM in the early 2000s and that was popularized by the ILO:

'The UN post-2015 development agenda is an
opportunity to give renewed impetus to the shared
responsibility to promote decent jobs and social
protection everywhere. There is no corresponding
responsibility on any one country to compensate
demographic shortfalls in any other. This is what gives
meaning to the idea that migration should be an option
available to individuals and not an obligation imposed
upon them' (ILO, 2014, p.6).

In a working paper commissioned by IOM ahead of the 2013 World Migration Report, Philip Martin made a similar argument that development enabled migration is likely to have more significant developmental impacts:

'Faster development will enable some of those now too poor to migrate to move to better opportunities, so that international migration and the potential for faster development may increase together' (Martin, 2012, p.1).

\subsubsection{Displacement as a Development Challenge}

Although a less prominent narrative, displacement has increasingly been viewed as a development challenge, both for those displaced, but also for the localities into which displaced persons arrive. The framing of displacement as a development challenge in the years preceding the adoption of the SDGs focused primarily on the promotion of partnerships between humanitarian actors and development actors to limit the potentially disruptive impacts that displacement could have on development:

'As was noted in a joint statement from OCHA, UNHCR, and IOM in July, protracted displacement is a driver of inequality and may hinder the sustainable 
development of both individuals and host communities, in addition to triggering conflict relapses. With forced displacement at its highest level since World War II, this is not a concern to be overlooked' (IOM, 2014a, p.4).

The depiction of displacement as a development challenge is, unsurprisingly, particularly prominent in the documents of UNHCR. However, references to displacement as a challenge to development do also appear in the texts of other agencies, perhaps in response to the increasing attention given to displacement in light of the Syrian crisis.

\subsubsection{Migration and Development as a Unifying Frame}

Based on the operational definitions of Habermas (1993) developed by Sjursen (2002) and discussed in Section 3.1.2, the theoretical discussion of IOs as an entity (Section 2.2.2) and the comparison of the human rights and management frames (Section 5.2), one can derive some expectations about the types of argumentation that different organizations will employ. Organizations with a preference for multilateral solutions to migration based on the principle of increasing state efficiency may be reasonably expected to employ pragmatic reasoning. In contrast, organizations that operate under the principle of international organization to achieve some shared goal may be more likely to employ moral and legal-ethical argumentation. Given the general resistance of Northern States to binding norms in the area of migration, one would expect limited use of legal-ethical arguments except for the writings of organizations with a normative mandate. However, given the interest of many developing countries in promoting rights within the context of global discussions on migration, one would still expect moral arguments to be prevalent. Hence, normative organizations are more likely to employ moral rather than ethical-political argumentation given general resistance to binding norms

Figure 6.1 shows the distribution of pragmatic, ethical-political, and moral argumentation employed by the members of the GMG in the run-up to the 
adoption of the SDGs ${ }^{7}$. Pragmatic argumentation was the most commonly employed argumentation style by all organizations but was particularly dominant in the writings of FAO, UNCTAD, UNDESA, UNITAR, UNU, and the World Bank. Moral argumentation was identified in the publications of 13 of the 17 organizations, and was most prominent in the writings of OHCHR, UNICEF, and WHO. Ethical-political arguments were the least common and identified in the writings of just three organizations: ILO, OHCHR, and the United Nations Office on Drugs and Crime (UNODC). ILO primarily made ethical-political argumentation. UNODC employed both ethical political and pragmatic arguments with equal frequency. OHCHR made the occasional ethical-political argument but primarily made moral arguments (Figure 6.1). A summary of the arguments put forward by each organization can be found in Table 6.3.

Figure 6.1 Arguments for Including Migration in the SDGs by Habermas' Categories

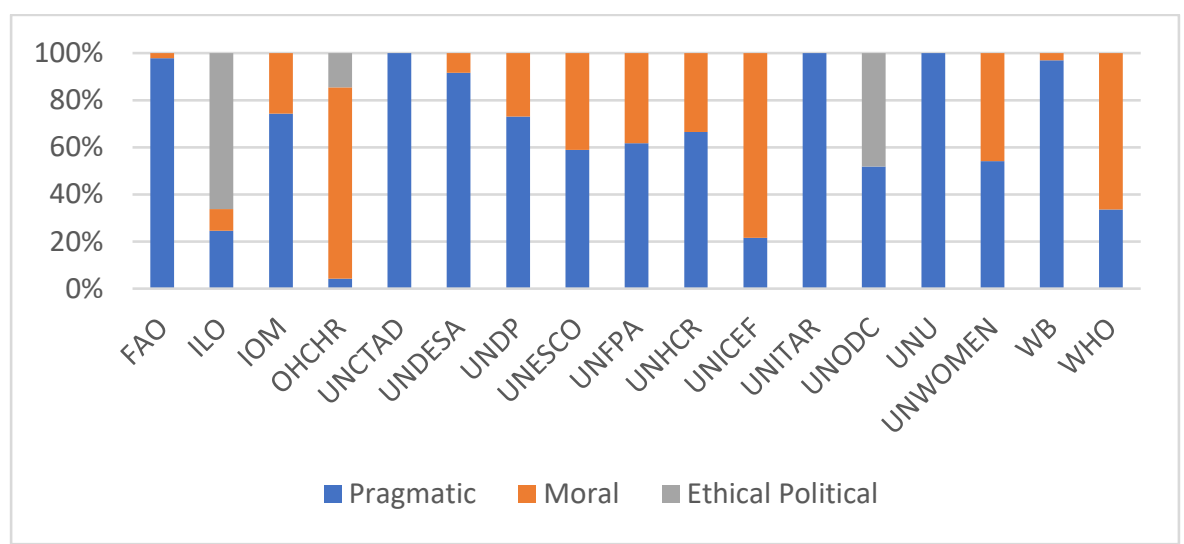

Source: Author's Own

${ }^{7}$ The percentages were calculated based on the total coding density represented by each coding categories per organization. Coding density is the percentage of the text covered that is coded to a particular node. Two key limitations of this approach are that it captures the length of the argument and is dependent upon the length of the document.

Thus, one must be careful with the interpretation of the figure. While this is an imperfect method, it provides an indicative overview of the argumentative style of different IOs, that largely corresponds with the findings of the qualitative content analysis (Table 6.3) 
Table 6.2 Arguments for Including Migration in the SDGs using Habermas

\begin{tabular}{|c|c|c|c|c|}
\hline IO & Summary of arguments & $\begin{array}{l}\text { Pragm- } \\
\text { atic }\end{array}$ & $\begin{array}{l}\text { Ethical- } \\
\text { Political }\end{array}$ & Moral \\
\hline ILO & $\begin{array}{l}\text { Arguments are predominantly ethical } \\
\text { political and outline the costs of non- } \\
\text { adherence to labour standards from the } \\
\text { perspective of migrant workers. Pragmatic } \\
\text { argumentation is used to propose policies } \\
\text { related to decent work which contribute to } \\
\text { sustainable development. }\end{array}$ & $\checkmark$ & $\checkmark$ & \\
\hline IOM & $\begin{array}{l}\text { Broad range of arguments including the } \\
\text { positive relationship between 'well- } \\
\text { managed' migration and development; the } \\
\text { risk of migrants being excluded from } \\
\text { development; with a focus on } \\
\text { 'mainstreaming' migration across different } \\
\text { areas (health, education, environment etc). }\end{array}$ & $\checkmark$ & & $\checkmark$ \\
\hline OHCHR & $\begin{array}{l}\text { Arguments very much based on an appeal } \\
\text { to universal standards: 'A post- } 2015 \\
\text { development agenda must therefore be a } \\
\text { global agenda, based on universal norms } \\
\text { and universal objectives' (OHCHR, 2012, } \\
\text { p.5). }\end{array}$ & & $\checkmark$ & $\checkmark$ \\
\hline UNCTAD & $\begin{array}{l}\text { Focus is on remittances as a means of } \\
\text { enhancing trade/development linkages } \\
\text { primarily through regulating the } \\
\text { remittance transfer market and financial } \\
\text { inclusion. }\end{array}$ & $\checkmark$ & & \\
\hline
\end{tabular}

\begin{tabular}{|c|c|c|}
\hline UNHCR & $\begin{array}{l}\text { References to the post- } 2015 \text { development } \\
\text { agenda primarily relate to the recasting of } \\
\text { displacement as not only a moral, } \\
\text { normative issue, but also a development } \\
\text { challenge. }\end{array}$ & $\checkmark$ \\
\hline UNODC & $\begin{array}{l}\text { Focus primarily on smuggling as a } \\
\text { phenomenon undermining sustainable } \\
\text { development with references made to the } \\
\text { UN Protocol against the Smuggling of } \\
\text { Migrants by Land, Sea and Air and related } \\
\text { conventions. }\end{array}$ & $\checkmark$ \\
\hline
\end{tabular}

UN-DESA Arguments are largely focused on the
importance of taking demographic
dynamics into consideration within the
agenda. A recurring argument is the need
to avoid viewing migration as a
development solution.




\begin{tabular}{|c|c|c|c|c|}
\hline IO & Summary of arguments & $\begin{array}{l}\text { Pragm- } \\
\text { atic }\end{array}$ & $\begin{array}{l}\text { Ethical- } \\
\text { Political }\end{array}$ & Moral \\
\hline UNDP & $\begin{array}{l}\text { Given UNDP's role in facilitating the post- } \\
2015 \text { development agenda consultations, it } \\
\text { is unsurprising to find a diversity of } \\
\text { arguments. Many relate to the absence of } \\
\text { clear governance structure on migration } \\
\text { alongside the role of migration as a } \\
\text { development enabler, a challenge to } \\
\text { development, and a product of } \\
\text { development. }\end{array}$ & $\checkmark$ & & $\checkmark$ \\
\hline UNFPA & $\begin{array}{l}\text { Generally arguments focus on migration } \\
\text { being part of development with both } \\
\text { positive and negative aspects that require } \\
\text { consideration }\end{array}$ & $\checkmark$ & & \\
\hline $\begin{array}{l}\text { World } \\
\text { Bank }\end{array}$ & $\begin{array}{l}\text { Primarily focused on migrants as } \\
\text { development enablers through } \\
\text { remittances, with a particular focus on } \\
\text { reducing the cost of remitting and diaspora } \\
\text { bonds. }\end{array}$ & $\checkmark$ & & \\
\hline UNESCO & $\begin{array}{l}\text { Focus on education - access, effect on } \\
\text { attitudes towards migrants, effect on } \\
\text { labour markets. }\end{array}$ & $\checkmark$ & & $\checkmark$ \\
\hline UNICEF & $\begin{array}{l}\text { Migration as a risk to children fulfilling } \\
\text { their development potential }\end{array}$ & & & $\checkmark$ \\
\hline UNITAR & $\begin{array}{l}\text { Focus on the relevance of cities to the post- } \\
2015 \text { development agenda. Largely relates } \\
\text { to the pragmatic policy directions taken by } \\
\text { cities. }\end{array}$ & $\checkmark$ & & \\
\hline $\begin{array}{l}\text { UN } \\
\text { Women }\end{array}$ & $\begin{array}{l}\text { Focus largely on the negative impacts of } \\
\text { migration on women (either those who are } \\
\text { 'left behind' or women migrants) and the } \\
\text { importance of a human rights framework. }\end{array}$ & $\checkmark$ & & $\checkmark$ \\
\hline WHO & $\begin{array}{l}\text { Focus is primarily on universal health care } \\
\text { access as well as the retention of health care } \\
\text { professionals. }\end{array}$ & $\checkmark$ & & $\checkmark$ \\
\hline FAO & $\begin{array}{l}\text { Migration as a consequence of rural } \\
\text { underdevelopment as justification for rural } \\
\text { development projects. No direct } \\
\text { arguments for the inclusion of migration in } \\
\text { SDGs. }\end{array}$ & $\checkmark$ & & \\
\hline UNU & $\begin{array}{l}\text { Focus is on the evidence on the migration- } \\
\text { development relationship and what this } \\
\text { says about the place for migration in the } \\
\text { post- } 2015 \text { development agenda. }\end{array}$ & $\checkmark$ & & \\
\hline
\end{tabular}

A characteristic feature of the majority of arguments is the centrality of the agent, the hallmark of the pragmatic argument. The relationship between 
migration and development was framed in terms of the mandate of the organization. This provides support for the argument that IOs frame the world in a way that justifies their existence (Barnett and Finnemore, 2004). For example, the World Bank and UNCTAD both focus on remittances as an enabler of development. The World Bank view is from the perspective of development financing, whereas UNCTAD focuses on the trade links that can be established through migration.

Although it was expected that organizations with a normative mandate would be more likely to employ ethical-political arguments, this was only true for the ILO and, to a lesser extent, for OHCHR and UNODC. For example, UNHCR's arguments were more pragmatic, calling for the development community to recognize displacement as a development challenge and to put their efforts (and money) behind interventions supporting durable solutions for displaced populations. While UN Women could have drawn on the Convention on the Elimination of All Forms of Discrimination Against Women (CEDAW), their arguments primarily focused on the need to protect the vulnerabilities of migrant women.

Overall, there were limited appeals to international standards when advocating for a place for migration in the SDGs. While the subject of human rights for migrants was more often part of ethical-political and moral arguments, pragmatic arguments for the protection of the rights pointed to the utility of protecting rights. For example, immigration reform to allow more labour mobility through regular channels can increase migrant remittances (UNDP, 2013). Additionally, migrants with equitable access to health care can reduce the cost of emergency care and pose fewer challenges to public health (IOM, n.d.a).

The key takeaway from this discussion is that the degree of consistency across the writings of different IOs, suggests that the 'migration and development' frame resonated with actors with fundamentally different views concerning the purpose of international organization, and in turn, the best way to approach to migration in an intergovernmental setting. Drawing attention to the efficacy of protecting the rights of migrants from a development perspective appealed to adherents of both the migration management and migrant rights frames demonstrating the unifying power of the 'migration and development' frame. The high degree of consistency in the writing of IOs before the adoption of the SDGs points to a degree of coordination. As in Chapter 5, we now turn to specifically examine the role of policy brokers in 
the curation of a shared narrative to convince the architects of the SDGs that migration should be reflected in the new agenda.

\subsection{Negotiating a Place for Migration in the Sustainable Development Goals: The 'Two-Pronged' Approach}

Thus far, this chapter has focused on why migration should be in the post2015 development agenda, noting the role of migration as an enabler of development and the role of migrants as subjects of development. However, counter-arguments on why migration should not be in the post-2015 development agenda also merit consideration since they fuelled the effort to convince the architects of the SDGs to include migration. I observed two main points of contention. The first point of contention related to migration being 'too toxic' (INT-GOV-032) and very unlikely to be agreed upon by the UN Member States in the negotiations. Nothing fundamental had changed since the early 2000s in the sense that migration remained a topic touching on state sovereignty with only limited coverage within the UN system. However, among the actors participating in the GFMD and GMG, a shared narrative had emerged, as well as new and compelling evidence that migration could have a noticeable impact on development (INT-IO-003; INT-IO-015;.INTGOV-032).

The second reason relates to the views of the development community, whose absence from the GFMD is often noted (INT-GOV-028). The development community, as reflected in the arguments of FAO and others, had long viewed migration as the product of failed development. Peter Sutherland voiced this concern at the Twelfth Coordination Meeting on International Migration in February 2014 (UNDESA 2014). The necessity of going beyond a one-dimensional view of the migration was what had led the GCIM to forward the idea of 'migration out of choice' (Pécoud 2015, p.73). This message was also prominent in a think piece submitted to the UNTT by UNDESA and IOM in 2012. The primary task of those wishing to see migration in the SDGs was convincing development actors, and reluctant states of the salience of migration as an enabler of development, while simultaneously balancing the differing interests of GMG constituents through the incorporation of both a management and human rights 
perspective. Deputy Secretary-General Jan Eliasson and later Michael Doyle referred to this vision as a 'two-pronged' approach:

\begin{abstract}
'Mr Eliasson advocated for a two-pronged approach on migration and development that would both unlock the development potential of migration as well as ensure the dignity and rights of all migrants and their families'. (UNDESA 2014, p.1).
\end{abstract}

There was, therefore, a decided effort among international actors to develop consistent messaging on migration and the post-2015 development agenda to be fed into the ongoing process to ensure that migration would be included. The second HLD in 2013 lent further legitimacy to these efforts. In the country statements at the HLD, 'the most commonly mentioned policy priority was integrating migration into the post-2015 development agenda' (UNDESA 2014). In the HLD Declaration", Member States 'acknowledge the important contribution of migration in realizing the Millennium Development Goals, and recognize that human mobility is a key factor for sustainable development which should be adequately considered in the elaboration of the post-2015 development agenda' (para. 8, p.2). There was also a call for the UN system and other relevant IOs to cooperate 'in order to adopt a comprehensive and coordinated approach, and to consider migration issues in their contributions to the preparatory process that will establish the post2015 development agenda' (para. 31, p.4). Three specific efforts merit further elaboration.

The first is the creation of an informal multi-stakeholder group - 'the informals' - by Peter Sutherland in December 2012 'to discuss and strategize how to lobby governments to have key references to migration included in the SDGs' (INT-IO-004). The group included government representatives (Bangladesh, Belgium, France, Germany, Mexico, Sweden, and Switzerland), UN agencies (such as UNDP, the World Bank, DESA, UNICEF) and other IOs such as IOM (before it became a related agency of the UN) and OECD; funding bodies (such as the Open Society Foundation and the MacArthur Foundation); civil society actors and other experts. As one participant observed:

8 Declaration of the High-Level Dialogue on International Migration and Development, UNGAOR, 68 ${ }^{\text {th }}$ Session, UN Doc. A/68/L.5 (Oct. 1, 2013) 
'We managed to carve out a separate discussion on migration. The SRSG's office convened a regular informal group, which was comprised of international agencies, the SRSG's office, those few governments who were interested, civil society actors, and so on, who were able to put together different messaging on migration. We were doing a lot of advocacy, writing a lot of papers. Peter Sutherland and the IOM Director General, William Lacy Swing, published a few things. Through that and especially with the help of the governments which were involved and were very much interested in putting migration on the agenda in the intergovernmental discussions as well, we were able to start chipping away and get it in there as a standalone issue. Not a standalone goal, of course, but just something to be considered as one of the cross-cutting issues to be considered across the whole agenda' (INT-IO-016).

While there are plenty of other examples, the best-documented example of the work of the informals is a submission sent by Peter Sutherland to Ban Kimoon's Special Advisor on post-2015 Development Planning, Amina Mohammed on 18 June 2013. It is not insignificant that Amina Mohammed was a former Chair of the IOM Council and had played a significant role in the discussion of IOM-UN relations in the early 2000s (Chapter 7). In his letter, Sutherland thanked Amina Mohammed for her 'extraordinary efforts to include migration in the recently released HLP report' (United Nations Archives, 2013a) and asked for her support to ensure that migration would also be featured in the Synthesis report of the Secretary-General on the post2015 sustainable development agenda9. To this end, he shared inputs prepared by the informal working group, which included: a paragraph on the impact of migration on development; a proposal for the formulation of

\footnotetext{
${ }^{9}$ Report of the Secretary-General: The Road to Dignity by 2030: Ending Poverty, Transforming all Lives and Protecting the Planet, UNGAOR, UN Doc. A/69/700 (4 December 2014)
} 
migration targets and indicators ${ }^{10}$; and a review of the evidence on how migration had contributed to the achievement of the MDGs.

The paragraph, which has been replicated in its near entirety in several places including the UNFPA's Deputy Executive Director of Management statement at the OWG Meeting in June 2013 (cf. Albrectsen 2013; Sutherland 2013a; 2013b), neatly captured a multitude of the arguments already identified from various other sources and encapsulated the 'two-pronged' approach:

'Today, more than a billion people rely on international
and internal migration to escape poverty and conflict,
adapt to environmental and economic shocks, and
improve the income, health, and education of their
families. Annual remittances to developing countries
alone approach $\$ 500$ billion, triple the amount of ODA,
while potential savings from reducing migration costs
could be of a similar scale. There is clear evidence that if
states make more informed policy choices, they can
generate large economic and social gains from
migration, while ensuring decent living and working
conditions for migrants. Partnerships among
governments, the private sector, and civil society should
be built on mobility policies that: i) reduce
discrimination against migrants and protect their rights;
ii) lower the human, social, and economic costs of
migration, including those related to recruitment,
remittances, and obtaining documentation such as visas
and residency permits; iii) expand opportunities for
migrants to more productively invest their earnings and
share their knowledge; and iv) enlist migrants and
diaspora organizations in enhancing development in
their communities of origin and destination' (United
Nations Archives $2013 a$ a. p.3).

\footnotetext{
${ }^{10}$ A sample of these include reducing the transaction cost of remittances; reducing the cost of recruitment, eliminating discrimination, reducing human trafficking, ensuring migrants have access to financial services, enhancing skills recognition and reducing irregular migration (United Nations Archives, 2013a).
} 
The efforts of this group thus helped to galvanize efforts to create consistent messaging around the relevance of migration to any discussions of development at the global policy level.

The second example is the efforts to develop consistent messaging by the GMG. During the negotiations, the GMG was chaired by IOM in 2013, the ILO in 2014, and the World Bank in 2015. Together, the GMG prepared several position papers and made joint statements regarding the place of migration in the post-2015 development agenda. Their work also reflected the 'two-pronged' approach: if human rights were respected, then the positive development impacts of migration could be enhanced. In their first position paper on the topic, ahead of the second HLD in October 2013, this view was evident:

'The GMG has long taken the view that if the human and labour rights of migrants are effectively respected and migration is well governed throughout the entire migration process, including through enhanced access to affordable, safe and regular migration channels, substantially improved human development outcomes will result for migrants, their families, communities and countries' (GMG 2013, p.3)

Nevertheless, controversy remained within the GMG over how migration should be included:

'...we had some joint GMG positioning around the SDGs and migration, and there was always the kind of tension between the rights-based agencies, and the more pragmatic, if you will, development or migration actors...but I think we did manage to have joint GMG positioning on the issue' (INT-IO-006).

The third example is the work of the GFMD. Although discussions regarding the post-2015 development agenda started in Mauritius, it was the primary focus of the Swedish Chair. The seventh meeting of the GFMD in May 2014 in Stockholm was also one of the last gatherings of different stakeholders before finalization of the OWG goals in July 2014. The theme of the Swedish GFMD was 'Unlocking the Potential of Migration for Inclusive Development', and its main focus was on how to ensure that migration would 
be included in the post-2015 development agenda. As a member of the informals, and with a place on Amina Mohammed's High-Level Panel, Sweden was well placed to galvanize and communicate clear and consistent messaging to the negotiators. In a letter addressed to Ban Ki-moon on 28 May 2014, Ambassador Eva Åkerman Börje, Chair of the Swedish GFMD writes:

'I recall your suggestion in the opening remarks that our "voices can impress upon those drawing up the post2015 framework" and your encouragement, when we met with the GFMD Troika on 21 February 2014, to feed in the results from the GFMD Summit Meeting to the continued post-2015 process. In response, I hereby submit the recommendations that came out of the GFMD Summit Meeting on including migration in the post-2015 development agenda. These were endorsed at the meeting and the Swedish Chair was requested to submit them to your esteemed office' (GFMD 2014, p.109).

The Swedish Chair's recommendations were underpinned by two principles:

'1. Migration is first and foremost about human beings and the protection of their human rights and fundamental freedoms, irrespective of their migration status, needs to be included in the post-2015 development agenda.

2. There is consensus that migrants and migration should be recognized as enablers of development and should be included as such' (GFMD 2014, p.110).

These recommendations carried significant weight because 140 states had endorsed them. The state recommendations were further strengthened by the 'Stockholm Agenda' which was a document prepared and endorsed by 312 civil society organizations. The Stockholm Agenda communicated the necessity of including migration from both a human rights perspective and a development perspective (GFMD Civil Society, 2014). 
An examination of references to migration in the key outcome documents throughout the process offers support to the success of the 'two-pronged' strategy. References to migration in the first report of the UNTT and the outcome document of the Rio+20 Conference ${ }^{11}$ anchored migration in both sets of discussions. Much of the thinking in the UNTT report was based upon 18 think pieces that had been prepared by different constellations of actors in May 2012. Next to a think piece solely focused on migration and human mobility, co-authored by DESA and IOM, migration was referred to in ten other think pieces: on countries with special needs; health; human rights; inequalities; growth and employment; peace and security; population dynamics; social protection and urbanization (see Annex 6.2) The UNTT report contained 11 substantive references to migration primarily centred around the argument that well-managed migration, where the rights of migrants are upheld, can contribute to development:

'The dynamism of migrants and their economic and
other contributions to both their countries of origin and
host countries need to be more fully harnessed, above all
by recognizing migrants as positive agents of innovation
with human rights. Better managing migration, both in
countries of origin and destination, will be essential'
(UNTT, 2012, p.30).

The report also positioned migration as an 'enabler' of development in its 'integrated framework for realizing the "future we want for all" in the post2015 UN development agenda' (UNTT, 2012, p.24).

The Rio+20 outcome document made three references to migration namely the importance of ensuring the participation of migrants and their families in the process; the need to consider population trends (including migration) systematically; and the need to respect the rights of migrants regardless of their status through interregional, regional and bilateral cooperation. Several key informants acknowledge the role played by IOM along with the US Government, the EU delegation, and the Vatican in securing a place for migration in the outcome document (INT-IO-28; INT-OTHER-034). Of note was the reframing of migration from a 'scare tactic to galvanize attention to

${ }^{11}$ The Future We Want, GA Res 66/288, UNGAOR, UN Doc A/RES/66/288 (11 September 2012). 
the need for environmental change' (INT-OTHER-034) towards the view of migration evident in the Rio Declaration. As one key informant noted:
'We were relatively happy with the Rio Declaration where there was both a strong push to look at migration as a contributor towards economic development, but also a strong call for the human rights of the people that were part of these migration movements' (INT-IO-040).

Between December 2012 and March 2013, migration was discussed within the context of the Global Consultations on Population Dynamics, which was coled by Bangladesh and Switzerland, and supported by UNFPA, UNDESA, UN-HABITAT and IOM (in collaboration with UNDP, UNAIDS, UN Women, OHCHR, ILO, FAO, and the WFP). The consultations involved both face-to-face and digital consultations with academics (November 2012), the private sector (January 2013), civil society (February 2013), and Member States (March 2013) and resulted in the Dhaka Declaration ${ }^{12}$. The Dhaka Declaration was the outcome document of the Member State consultations on 13 March 2013 and contained several references to migration. Five of the 11 overarching recommendations mentioned migration, particularly concerning international cooperation, alongside eight thematic recommendations on migration and human mobility. The specific recommendations on migration capture a diversity of the arguments for the inclusion of migration, with a focus on maximizing the role that migrants can play as 'agents of development' through the systematic consideration of migration across the new development agenda.

The next reference to migration was in the report of the High-Level Panel of Eminent Persons (HLP) in May 2013. While migration was not one of the HLP's suggested goals or targets, their report did contain several references to migration, including a paragraph devoted to international migration as a key factor for sustainable development:

'The universal human rights and fundamental freedoms of migrants must be respected. These migrants make a positive economic contribution to their host countries,

\footnotetext{
${ }^{12}$ Dhaka Declaration of the Global Leadership Meeting on Population Dynamics in the context of the Post-2015 Development Agenda (13 March 2013)
} 
by building up their labour force. Sending countries benefit from getting foreign exchange in the form of remittances and from greater trade and financial flows with countries where they have a large diaspora. By 2030 , as global population rises, there could be 30 million more international migrants, remitting an additional $\$ 60$ billion to their home countries through low cost channels' (HLP, 2013, p.18).

This reference again reinforced the argument that the contributions of migrants to development could be enhanced if their human rights were respected and protected. After the release of the OWG report in July 2014, in which migration was referenced in several targets, there was a shift in the focus of advocacy efforts from promoting the inclusion of migration, to discussing how the migration-related goals could be measured.

\subsection{Migration in the Sustainable Development Goals}

The result of these efforts was a place for migration in the Sustainable Development Goals, including an entire paragraph in the preamble devoted solely to migration:

'We recognize the positive contribution of migrants for inclusive growth and sustainable development. We also recognize that international migration is a multidimensional reality of major relevance for the development of countries of origin, transit, and destination, which requires coherent and comprehensive responses. We will cooperate internationally to ensure safe, orderly, and regular migration involving full respect for human rights and the humane treatment of migrants regardless of migration status, of refugees and of displaced persons. Such cooperation should also strengthen the resilience of communities hosting refugees, particularly in developing countries. We underline the right of 
migrants to return to their country of citizenship, and recall that States must ensure that their returning nationals are duly received ${ }^{13^{\prime}}$ (para. 29, p.8).

Next to an entire paragraph devoted to migration in the preamble, migration is explicitly mentioned under the goals on reducing inequality (Goal 10 Targets 7 and c), promoting decent work and economic growth (Goal 8 Target 8 ) and the context of data disaggregation (Goal 17 Target 18) (Table 6.2).

\section{Table 6.3 Explicit Migration References in the Sustainable Development Goals}

\begin{tabular}{l}
$\begin{array}{l}8.8 \text { Protect labour rights and promote safe and secure working environments for } \\
\text { all workers, including migrant workers, in particular women migrants, and those } \\
\text { in precarious employment }\end{array}$ \\
\hline $\begin{array}{l}10.7 \text { Facilitate orderly, safe, regular and responsible migration and mobility of } \\
\text { people, including through the implementation of planned and well-managed } \\
\text { migration policies }\end{array}$ \\
\hline $\begin{array}{l}\text { 10.c By 2030, reduce to less than } 3 \text { per cent the transaction costs of migrant } \\
\text { remittances and eliminate remittance corridors with costs higher than } 5 \text { per cent }\end{array}$ \\
\hline 17.18 By 2020, enhance capacity-building support to developing countries, \\
including for least developed countries and small island developing states, to \\
increase significantly the availability of high-quality, timely and reliable data \\
disaggregated by income, gender, age, race, ethnicity, migratory status, disability, \\
geographic location and other characteristics relevant in national contexts
\end{tabular}

Source: Transforming our World: the 2030 Agenda for Sustainable Development, UNGAOR, 70th Session, UN Doc. A/RES/70/1 (25 September 2015)

In addition to this, the Addis Ababa Action Agenda, which complements Goal 17, contained four substantive references to migration. The first reference is the positive contributions of migrants to development primarily through remittances with the caveat that any approach should not equate remittances with other international financial flows but instead focus on reducing transfer costs and promoting financial inclusion. The second focused on ensuring that migrant and refugee children have access to education. The third focused on the need for international cooperation 'to ensure safe, orderly and regular migration, with full respect for human rights'

\footnotetext{
${ }^{13}$ Transforming our World: the 2030 Agenda for Sustainable Development, UNGAOR, 70th
} Session, UN Doc. A/RES/70/1 (25 September 2015) 
and enhance the development benefits of migration. The last reference focused on ensuring that statistics are disaggregated by migratory status.

Further references to mobility-related phenomena included human trafficking, mentioned in the context of Goal 5 on achieving gender equality (Target 2), Goal 8 on decent work and economic growth (Target 7), and Goal 16 on promoting peaceful and inclusive societies (Target 2). Mobility in the context of higher education was captured in Goal 4 (target $4 \mathrm{~b}$ ). Migrants were also indirectly represented by the pledge to 'leave no one behind', and with this in mind, migration relevant goals and targets could be increased to include all goals and targets where inclusive language is used. In total, seven Goals $(3,4,5,6,7,8$, and 16) and 27 Targets stipulate that the specific goal or target is 'for all', thus inclusive of migrant populations.

The way migration has been included in the SDGs reflects the 'two-pronged' approach advocated for by key actors such as Michael Doyle and Jan Eliasson (UNDESA, 2014; 2015). The dominant narrative is arguably that of migrants as a distinct social group at risk of being excluded from development, as opposed to migration being conceptualized as an enabler of development. However, this latter narrative is captured in SDG 10 (reducing inequalities). The proposed indicators for measuring Target 10.7 include a measure of recruitment cost, for which ILO is responsible, and an indicator on the number of countries that have implemented 'orderly, safe, regular and responsible' migration policies. Target 10.c focuses on reducing the cost of migrant remittances.

The reactions to the inclusion of migration in the SDGs have been varied. Some commentators view the SDGs as a missed opportunity for the 'indicators to be linked much more explicitly to the human rights architecture' (INT-IO-018). On the other hand, almost any conceivable issue has made it into the 17 goals and 169 targets of the agenda, and thus policymakers and practitioners can make of the SDGs what they like. The way migration is covered can be interpreted in different ways (McGregor, 2020) and thus is actually 'quite vague in terms of what states committed themselves to' (INT-IO-006). As was also true of the MDGs (Skeldon, 2008), it is possible to connect almost all goals to migration in one way or another (McGregor, 2020). As one interviewee noted, 'you can ask five people and get five different answers as to which things are relevant' (INT-IO-016). However, the fact that migration was included is arguably far more significant than how it was included: 
'What is important is that it is there. That created a political umbrella if you like that helped us to keep moving forward' (INT-GOV-036).

Thus, the inclusion of migration in the SDGs marked a significant moment in the institutionalization of migration as a global policy issue.

\subsection{Conclusion}

The title of this chapter is a reference to a 2008 paper written by Prof. Ronald Skeldon in which he proposed that the 'migration and development' optimism that had characterized the international policy world since the turn of the millennium, further fuelled by the HLD and GFMD, may be coming to an end (Skeldon, 2008). Given the instrumentalization of the 'migration and development' frame to further the process of institutionalizing migration within the UN, it is plausible that the inclusion of migration in the SDGs marked the beginning of the end of the migration and development era.

What can be deduced from the comparison of the arguments made for the GFMD, with the calculated omission of human rights, to the arguments made for the inclusion of migration in the SDGs which captured human rights within a broader migration and development perspective, is that frames are not static but evolve. Framing migration as a development issue has been a vehicle for bringing migration into the UN. By focusing on economic development and the positive societal contributions that migration can make through monetary and social transfers, a series of events unfolded that have culminated in the acceptance of migration as a global policy issue. The inclusion of migration in the SDGs reflects this acceptance. The way migration is included in the SDGs points to the ability of the 'migration and development' frame to assume, if not resolve, frame conflicts.

The importance that IOs accorded to seeing migration included in the SDGs is a testament to the increasingly important role that non-binding frameworks play in global governance. Throughout the process, a select group of individuals sought to insert carefully crafted paragraphs into key documents. Not having migration in the MDGs made it harder for IOs to justify interventions in the area of migration. The inclusion of migration in 
the SDGs provided a 'hook' (INT-IGO-002) for various actors operating in the area of migration to legitimize their ever-expanding portfolios. The active role played by IOs to shape the language used to describe migration in the context of a new development agenda lends credence to the argument that IOs seek to influence states through constitutive power. The GFMD (Chapter 5) and the SDG negotiations have demonstrated that particular individuals within IOs have actively shaped global migration narratives to ensure that both the human rights of migrants and the multifaceted relationship between migration and development have been included in a political declaration, and hence accorded legitimacy. Crucially, the way that migration has been reflected has been crafted in a way that was ambiguous enough not to alienate any states, but which still allowed for further international dialogue on migration.

However, it would be too straightforward to leave the argument there. Focusing on the act of framing, as Benford (1997) warns, risks reifying the individual, or in this case, the organization. We have only really examined the struggle between IOs to develop a common language that would be accepted by states. However, states were also involved in the process. Given that almost any conceivable issue found a place within the SDGs, the SDGs may be symbolic of a broader state-driven shift in multilateralism, away from legally binding norms and towards creatively worded non-binding agreements which can be interpreted and adapted in different ways, dependent upon the adopter's particular interests and objectives. Furthermore, just because Member States have agreed upon a text does not automatically guarantee their effective implementation. After all, the SDGs are not legally binding, and a cleverly framed commitment assuming multiple interests through 'constructive ambiguity' (INT-IO-037) does not negate the power dynamics underpinning them.

One cannot decontextualize the process of advocating a place for migration in the post-2015 development agenda from the broader story of migration at the multilateral level. Seeing migration included in the SDGs was about furthering international cooperation on migration. For some states, such as Ecuador, Mexico, and Switzerland, bringing migration into the post-2015 development agenda was a way of furthering the institutionalization of migration within the UN (INT-IO-015; INT-GOV-032; INT-GOV-036; INT-IO037). However, the conflict between adherents to the human rights and management frames remains. For some, the inclusion of migration in the SDGs was the step required to bring IOM, mostly unaltered, into the UN, 
lending weight to the migration management frame. For adherents of the human rights frame, it was an opportunity to establish migration as a human rights issue. Like the first HLD, 2015 marked another pivot year in the journey of migration as a global policy issue. The next two chapters explore this argument in more detail. Chapter 7 examines IOM's journey to the UN and the role of the SDGs herein. Chapter 8 looks at the negotiations leading to the Global Compacts. 



\section{The "Perfect Storm"? From Provisional Committee to UN migration agency}

\subsection{Introduction}

On 19 September 2016, then Secretary-General of the UN, Ban Ki-moon and Director-General of IOM, William Lacy Swing, signed an agreement which, for the first time in its history, brought IOM into the UN system as a 'related agency'. IOM's entry into the UN was a remarkable development in the evolution of global migration governance, and for many signified the acceptance of migration as a policy area of relevance to the UN's mandate, which as has been demonstrated was, as recently as the early 2000s, still subject to much contention. As the UN had looked for ways to address migration-related issues better in the early 2000s, IOM had considered the option of becoming a 'related agency' of the UN. However, the option was taken off the table by the UN who instead offered IOM 'specialized agency' status. The main difference between a specialized agency and a related agency is that the latter is excluded from Articles 57 and 63 of the UN Charter (United Nations Archives, 2014a). The main difference, therefore, is that the UN 'may co-ordinate the activities of the specialized agencies through consultation with and recommendations to such agencies and through recommendations to the General Assembly and to the Members of the United Nations' (United Nations, 1945, p.13) while a related agency, although illdefined, retains more autonomy from the UN.

Prior to 2010, little academic attention was given to IOM. The relative absence of IOM from previous studies of IOs is potentially due to IOM being viewed as an instrument of state (Mearsheimer, 1995). As Feldblum (1999) argues, as 'a creation of Cold War politics, (the organization) was largely dominated by US interests and has been dismissed by scholars as a significant international actor in its own right' (p.5). IOM, because of its history, was generally thought of as little more than a 'travel agency' (Caillault, 2012; Elie, 2010; Feldblum, 1999). However, there have been increasing calls for the more substantial investigation of IOM (Andrijasevic \& Walters, 2010; Elie, 2010; Pécoud, 2018). 
While a burgeoning body of literature on IOM has emerged since $2010^{1}$, the majority of these studies have focused on a specific aspect of IOM's work, for example: in implementing information campaigns (Nieuwenhuys \& Pécoud, 2007; Pécoud, 2010); human trafficking (Schatral, 2011) and irregular migration (Brachet, 2016; Caillault, 2012); return migration (Caillault, 2012; Collyer, 2012; Koch, 2014); temporary migration (Gabriel \& Macdonald, 2018; Valarezo, 2015); or border control (Andrew \& Eden, 2011; Frowd, 2014) using primarily qualitative methods (archival analysis, ethnography and key informant interviews). There has been less focus on understanding IOM from the perspective of its evolution as an IO. This chapter uses archival records and key informant interviews to trace the history of IOM from its origins as a small, temporary, intergovernmental organization in 1951 to its entry into the UN as a 'related agency' in September 2016 (Figure 7.1). In doing so the chapter addresses the following research question:

Why did IOM become a related agency of the UN in 2016?

In line with the theoretical framework, IOM is conceptualized as a resourcedependent actor whose actions and decisions are a function of internal and external factors. Specific attention is, therefore, placed on how IOM reacted to external events that had implications for its survival as an organization.

In order to address the main research question, the remainder of the chapter is structured as follows. Section 7.2 provides the reader with a brief synopsis of IOM's history, from its origins as the Provisional Intergovernmental Committee for the Movement of Migrants from Europe (PICMME) in 1951 to becoming the IOM in 1989. In line with process tracing, I then use a bracketing strategy to focus on three distinct points in time during which IOM's relationship with the UN was the subject of intense discussion. The first moment comes in the early 1990s when IOM moved closer to the UN and became a founding member of what would become the Office for the Coordination of Humanitarian Affairs (OCHA) in 1991. It became a UN

\footnotetext{
${ }^{1} \mathrm{cf}$. Andrew and Eden 2011; Ashutosh and Mountz 2011; Andrijasevic and Walters 2010; Brachet 2016; Bradley 2017; Caillault 2012; Collyer 2012; Elie 2010; Feldblum 1999; Frowd 2014; Gabriel and Macdonald 2018; Geiger 2010; Georgi 2010; Georgi and Schatral 2012; Guild, Grant, and Groenendijk 2017; Hall 2016; Koch 2014; Korneev 2013; Lavenex 2016; McGregor 2019; Morris 2005; Nieuwenhuys and Pécoud 2007; Pécoud 2010; Poutignat and Streiff-Fénart 2010; Schatral 2011; Valarezo 2015; Wunderlich 2012.
} 
observer in 1992 and signed a cooperation agreement with the UN in 1996 (Section 7.3). Shortly after the turn of the millennium, IOM-UN relations were again under discussion. The idea of IOM joining the UN was put on the agenda at the IOM Council Meetings in 2002, and a Working Group was created. However, IOM's Member States ultimately decided not to join the UN (Section 7.4). In 2016, after migration had been accorded legitimacy as a relevant global policy issue in the SDGs, states were faced with several migration crises across the globe. IOM-UN relations were again the subject of debate, and this time IOM joined the UN (Section 7.5). Section 7.6 concludes with a discussion of the factors that have influenced IOM-UN relations as the organization journeyed towards the UN. 


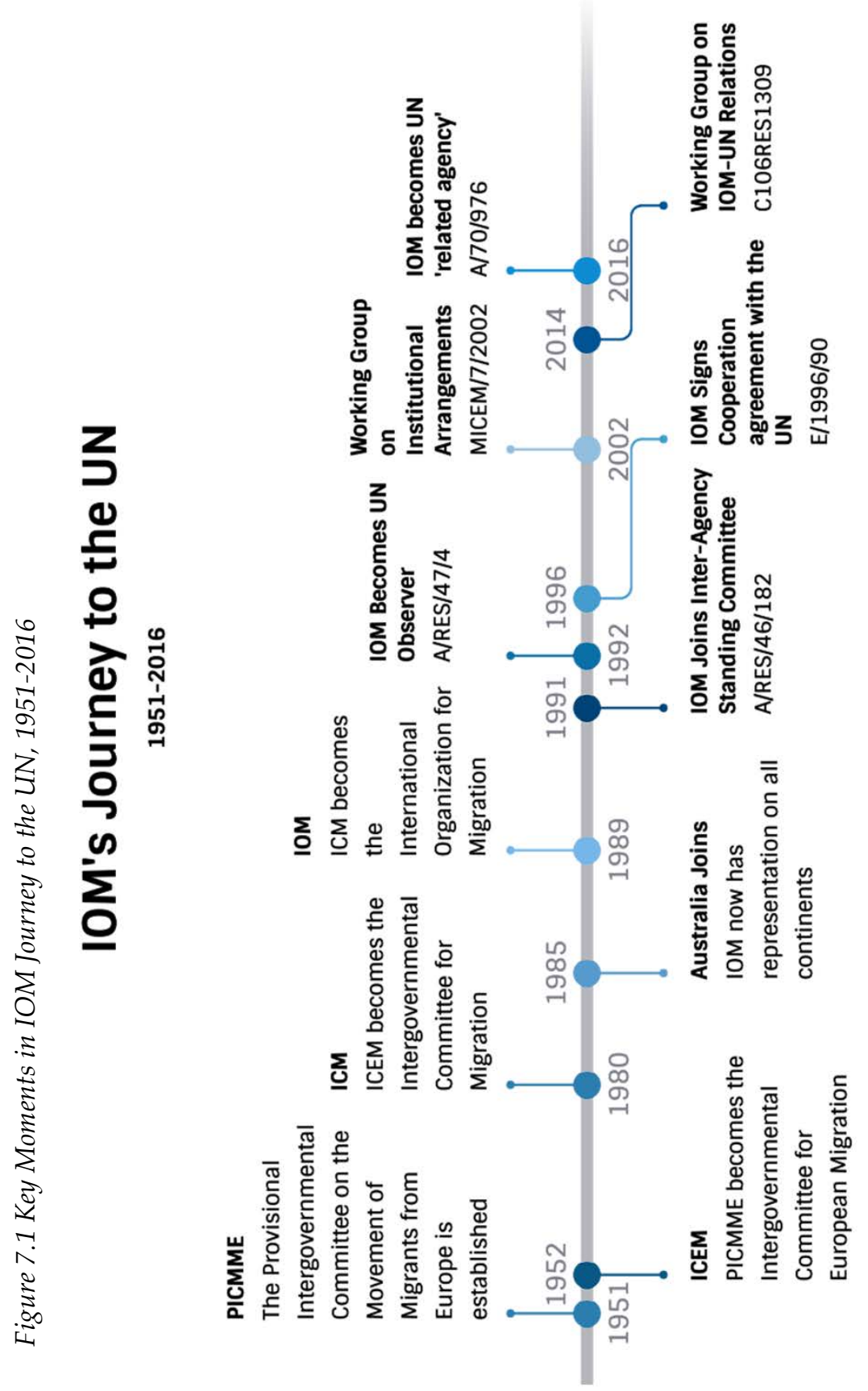




\subsection{From the Provisional Committee for the Movement of Migrants from Europe to the International Organization for Migration}

From humble beginnings, IOM has grown from a temporary committee with limited membership established to address a particular problem in post-War Europe, to an organization with a broad mandate and a membership approaching universal (Figure 7.2). IOM's story begins as the curtains rose on the Cold War. The organization began its life at the Migration Conference of Brussels on 5 December 1951 as the Provisional Intergovernmental Committee for the Movement of Migrants from Europe (PICMME). The original purpose of the organization was to provide operational support to the newly established UNHCR in achieving its normative protection mandate by facilitating 'the orderly migration of large numbers of displaced, unemployed or under-employed persons in Western Europe' (Carlin 1989, p.35). As discussed in Chapter 4, the ILO was poised to take on this function, as it had in the 1920s for Nansen, but its proposal was rejected, mainly due to opposition from the US (Ducasse-Rogier, 2001; Perruchoud, 1989). Fuelled by the politics of the Cold War, the US made its position clear on how intergovernmental cooperation on migration should be organized, by funding PICMME, as opposed to ILO, or any other UN agency (Long, 2013).

Figure 7.2 IOM Member States 1951-2019

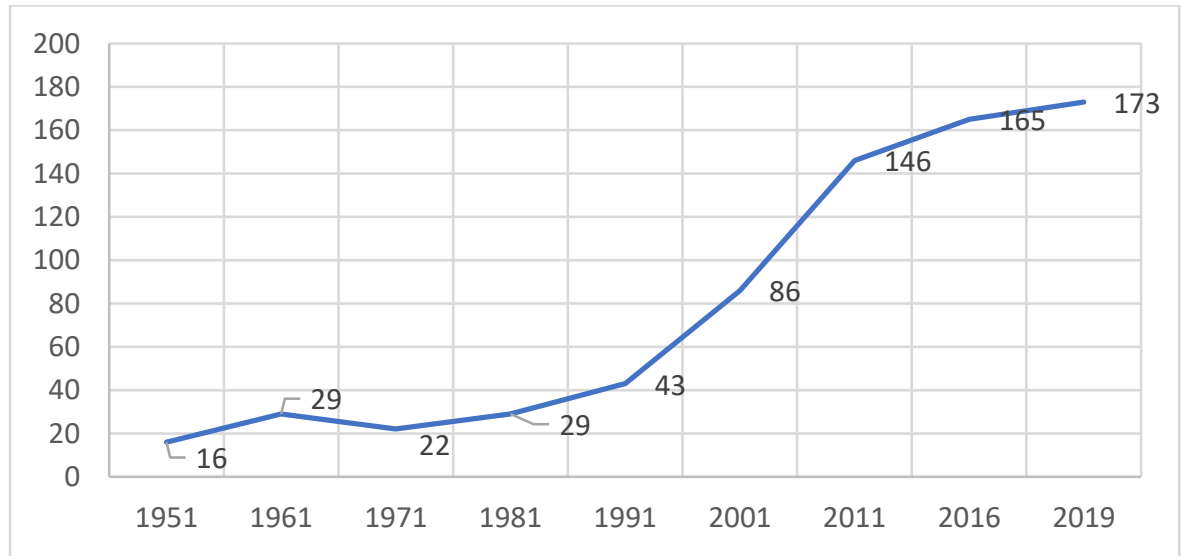

Source: 1951-2011 (Ducasse-Rogier, 2001); 2011: (IOM, 2012a); 2019: IOM (2019) 
Initially intended to provide a temporary solution for governments in Europe who feared the 'economic stagnation and the social unrest that could be generated by a pool of "surplus population"' (Karatani 2005, p.520), PICMME had an initial lifespan of 12 months. However, the question of the ongoing need for PICMME services became quickly evident to its member governments. From 13 to 21 October 1952, 20 member governments met in Geneva for the fourth session of PICMME. On the agenda at the meeting was a discussion about the future of the committee, including an appraisal of 'whether the experimental plan of attack on Europe's chronic surplus population problem during the previous year should be broadened or abandoned' (ICEM 1953, p.169). UNHCR had already asked PICMME to expand its transportation services beyond Europe to support in the transportation of European refugees (mainly White Russians who had fled to China during the First World War) from China. Discussions regarding the possible involvement of PICMME in land resettlement programmes in Latin America were also underway. Therefore, the Committee concluded that PICMME continued to be relevant and so PICMME became the Intergovernmental Committee for European Migration (ICEM 1953; Elie 2010).

In 1953 the ICEM Constitution was adopted, coming into force in November 1954 (Ducasse-Rogier, 2001). The Constitution authorized ICEM to organize the transport of migrants from European countries and to promote migration from Europe. ICEM was also tasked with the provision of services relating to the processing, placement, and settlement of migrants upon the request of states (Ducasse-Rogier, 2001). At this stage, it was anticipated that the organization would have a lifespan of a further three to five years with 1953 designated as a 'trial period for ICEM...because member governments wished to have further evidence that such a body as ICEM could make an effective contribution to the problems of population in Europe and overseas before acceding to the establishment of ICEM as a permanent agency; and second, because the Committee had to demonstrate its worth in a climate of receding migration and increasing obstacles to the development of organized migration' (ICEM 1955, p.317).

Over the next decade, ICEM facilitated the movement of over one million people, the majority of whom were European (Table 7.1). By the end of January 1957, ICEM had transported more than half a million $(545,000)$ migrants and refugees from Europe. The main countries of destination were Australia (29.7\%), the US (22.9\%), Canada (15.2\%), Argentina (11.7\%), Brazil 
$(9.9 \%)$, and Venezuela $(3.9 \%)^{2}$. The main countries of origin were Italy $(32.3 \%)$, the Federal Republic of Germany (31.6\%), Austria (9.5\%), Greece (7.9\%), and the Netherlands $(7.2 \%)^{3}$ (ICEM 1957, p.406). The 'one millionth migrant' was a 10-year-old Latvian boy called Andrejs Suritis, who arrived in the US on 11 May 1960 (United States Department of State 1960, p.395). While transportation continued to be its primary function, ICEM was also providing a range of different services to countries related to the sustainability of the movement. For example, ICEM was involved in establishing a vocational training centre for prospective migrants in Italy and a training course for government officials in countries of destination (ICEM, 1959).

Table 7.1 Movements facilitated by ICEM, 1952-1961

\begin{tabular}{|c|c|c|c|}
\hline Date & $\begin{array}{l}\text { Transported } \\
\text { since } 1 \text { Feb } \\
1952\end{array}$ & Data descriptor & Source \\
\hline 21 December 1952 & 77,626 & 'from Europe' & ICEM (1953) \\
\hline $\begin{array}{ll}30 & \text { September } \\
1953 & \end{array}$ & 138,628 & 'from Europe' & ICEM (1954) \\
\hline 31 July 1954 & 237,956 & 'total movements' & ICEM (1955) \\
\hline 31 December 1955 & 406,867 & 'number of Europeans' & ICEM (1956) \\
\hline 31 January 1957 & 545,000 & 'total' & ICEM (1957) \\
\hline 31 August 1957 & 717,918 & $\begin{array}{l}\text { 'total number of } \\
\text { individuals' }\end{array}$ & ICEM (1958a) \\
\hline 31 December 1957 & 775,000 & 'migrants and refugees' & ICEM (1958b) \\
\hline 11 May 1960 & $1,000,000$ & 'one millionth migrant.' & $\begin{array}{l}\text { ICEM (1960), } \\
\text { United States } \\
\text { Department of } \\
\text { State }(1960)\end{array}$ \\
\hline 11 May 1961 & $1,091,099$ & $\begin{array}{l}\text { 'European refugees and } \\
\text { nationals' }\end{array}$ & ICEM (1961) \\
\hline
\end{tabular}

Notes: The data was collated from summary texts prepared for International Organization between 1953 and 1961. The data descriptor is included to signify whom the number presented in the adjacent column includes.

\footnotetext{
${ }^{2}$ Since these calculations are based on numbers presented textually in ICEM (1957) it is assumed that the remaining $6.6 \%$ were either transported to other destinations or are the result of a rounding issue.

${ }^{3}$ As for countries of destination, it is assumed that the remaining $11.6 \%$ were either transported from other countries or are the result of a rounding issue.
} 
In the early 1960s, the fledgling organization faced new challenges. Compounding already existent budgetary challenges (ICEM, 1956), the cost of transportation had increased, and the availability of vessels for transportation decreased (ICEM, 1958a). The demand for ICEM services within Europe declined. Between 1955 and 1963, the number of refugees in camps in Europe dropped from 85,000 to 3,450 (ICEM 1964: 669). Despite the declining need for ICEM's services in Europe, however, the UNHCR still called upon ICEM for assistance with refugee populations in other parts of the world 'particularly in North Africa, Togo, the Congo, and Tanganyika ${ }^{4}$ ' (ICEM 1962: 665). The US also thought that ICEM should evolve in light of the changing international situation and, 'since the European refugee problem was considerably less critical and there was no longer a need for ICEM to "siphon-off" western Europe's surplus population, the new task for the Committee should be to supply manpower to underdeveloped countries' (ICEM 1961 p.532). Thus, even in its early days it is possible to see how external factors influenced the organization.

The politics of the Cold War also impacted the organization. In the postSecond World War period, the Soviet Union accused governments such as the US, the UK, Australia and France of treating individuals residing in camps in Europe as a source of cheap labour, with the International Refugee Organization (IRO) acting as a recruitment agent supporting the capitalist agendas of potential destination countries (Long, 2013). Having replaced the operational functions of IRO, and with a membership that explicitly excluded communist countries, ICEM was not immune to these criticisms. In the early 1960s, then Director-General, Wouter Havemaan accused the Soviet Union of spreading the term 'economic refugee' in a 'campaign aimed at weakening the Western sense of responsibility for refugees' (ICEM 1963: 828). Accordingly, from the early 1960s, special attention was given to providing resettlement to migrants with disabilities (ICEM, 1961; Long, 2013). However, while the number of individuals with a disability able to migrate had increased from one per cent in 1953 to seven per cent by 1961 (ICEM, 1961), UNHCR reported that, of the 15,000 European refugees still wishing to relocate in 1962, half required special assistance because of disabilities (ICEM, 1962). Perhaps as a result of these challenges, the survival of the organization seemed to be in question. Between 1962 and 1980 several countries left the organization including Canada (1962), France (1962), Sweden (1962) New

${ }^{4}$ Now mainland Tanzania 
Zealand (1967), the UK (1968), Australia (1973), Spain (1977), and Brazil (1980) based mainly on the view that the organization was no longer required (Ducasse-Rogier, 2001; ICEM, 1961, 1963).

The 1980s saw the consolidation and expansion of ICEM from an organization at the brink of extinction into what was to become IOM. In 1979, James L. Carlin was appointed as Director-General, tasked with turning the organization around. One of his early accomplishments, as director, was the removal of the geographical restriction from the name of the organization to reflect the expansion of ICEM's work into other parts of the world (Carlin, 1989). From 1980, the organization was renamed the Intergovernmental Committee for Migration (ICM). Beyond the elimination of the geographical limitation, this also led to changes in the type of work that the organization performed: 'in the early years, transport was the priority, but increasingly, more complex and sophisticated migration services (for example, recruitment, selection, labour reinsertion, and integration) took precedence' (Perruchoud 1989, p.507). In 1985, when Australia re-joined the organization (having left in 1973), the organization had representation from all continents (except Antarctica) within its membership for the first time (Ducasse-Rogier, 1991). Accordingly, the ICM constitution was amended in 1987 and, two years later, the organization became the International Organization for Migration (IOM) (Ashutosh \& Mountz, 2011; Carlin, 1989).

The early history of the organization continued to affect IOM, first in its struggle to survive (Section 7.3), in establishing itself as a leading international migration agency (Section 7.4), and finally, as the 'UN migration agency' (Section 7.5). Even as the organization evolved, it continued to be dismissed as either 'basically a reisburo, service de voyage for migrants' (INTIO-005), or as an 'American Front organization' (INT-IO-019). The fact that, until the appointment of António Vitorino (Portugal) in 2018, the DirectorGeneral of IOM was, except for Bastiaan Wouter Haveman of the Netherlands between 1961 and 1969, always a US appointee, has further reinforced IOM's reputation as a US-driven organization. 


\subsection{The Nineties: IOM Moves Closer to the UN}

The end of the Cold War was significant for the evolution of the multilateral system. As discussed in Chapter 4, the early 1990s saw revived interest in multilateralism (Hulme, 2009). The Uruguay Round of Trade Talks in 1994 led to the Agreement on Trade in Services (GATS) and the establishment of the WTO in 1995. In this context, the notion of an equivalent global body for migration started to gain traction (Ghosh, 2000; Straubhaar, 1993) and, at the International Conference on Population and Development in Cairo in 1994, UN Member States started to consider the idea of holding a conference on international migration. However, tainted by its legacy in the politics of the Cold War, the newly renamed IOM was struggling to find its place. Despite having grown during the past decade, the organization was still far from being universal. Between 1981 and 1991 the number of IOM Member States grew from 29 to 43 (Ducasse-Rogier 2001; Figure 7.2). Equipped with a broader mandate but with reduced need for resettlement services after the collapse of the Soviet Union and facing the closure of the Vietnam programme, James N. Purcell Jr. who became the Director-General of IOM in 1988, recognized that the organization needed to prove its relevance to Member States, as otherwise it would very quickly lose steam. An accident of history, in the form of the first Gulf War, arguably helped IOM to survive:

'You had a moment where the organization was wondering, "well, what are we doing now?" And then Saddam Hussein invaded Kuwait and hundreds of thousands of migrant workers, not refugees, people who had a job one day and a country to go home to, fled into Jordan. And the organization started to operate out of Jordan... we managed to build this air bridge for more than 200,000 and fly them home to countries like Bangladesh, India, Sri Lanka, the Philippines. Countries that had not even heard of the organization... And these countries suddenly became beneficiaries because IOM raised something like 120 million dollars at the time for the operation. The organization got better known, and we suddenly had a large number of new members coming in, as all of these countries realized that this might be a useful organization. And IOM suddenly had 
new things to do, emergencies, then the Yugoslav war started and so on. (INT-IO-019).

Thus, the first Gulf War was arguably what IOM needed to prove that it was an organization capable of acting swiftly in an emergency. IOM's engagement in the relocation of migrant workers from Kuwait showcased the capacity of the organization, not only to the UN but also to a new set of potential Member States. As one interview respondent observed: 'those efforts helped us tie back into the multilateral fabric' (INT-IO-022).

From 1991, IOM's growth accelerated with the number of Member States doubling between 1991 and 2001 from 43 to 86 (Figure 7.2). The organization also moved closer to the UN. Following IOM's intervention in the Gulf War, three significant advances occurred in IOM-UN relations. The first was that on 19 December 1991, IOM received a standing invitation to the Inter-Agency Standing Committee in paragraph 38 of the annex to the General Assembly Resolution ${ }^{5}$, which led to the establishment of the UN Office for the Coordination of Humanitarian Affairs (OCHA). The Resolution also stipulated that the Emergency Relief Coordinator should work closely with, among other organizations, the IOM (para. 36). The following year, on 16 October 1992, IOM was officially invited to become an observer at the UN General Assembly ${ }^{6}$. Thus, while IOM had not joined the UN, its role as an important international actor in the area of migration was consolidated:

'We were as close to UN membership as you could get without actually being a member. We were an observer' (INT-IO-022).

Three years later, after Council Agreement at its 407th meeting on 29 November 1995, IOM intensified cooperation with the UN. Director-General Purcell was invited 'to strengthen and, as appropriate, formalize cooperation with the UN system and other relevant organizations, having regard to the need to improve complementarity and avoid duplication, while ensuring mutual respect of the individual competences of the organizations

\footnotetext{
${ }^{5}$ Strengthening of the Coordination of Humanitarian Emergency Assistance of the United Nations, UNGAOR, $46^{\text {th }}$ Session, UN Doc. A/RES/46/182 (19 December 1991)

${ }^{6}$ Observer Status for the International Organization for Migration in the General Assembly, UNGAOR, $47^{\text {th }}$ Session, UN Doc. A/RES/47/4 (16 October 1992)
} 
concerned $^{7 \prime}$ (para 6). The result of his actions was a Cooperation Agreement between the UN and the IOM, which was signed by then UN SecretaryGeneral Boutros Boutros-Ghali and Mr Purcell on 25 June 1996. Building on this agreement, a further Resolution ${ }^{8}$ at the 84th Plenary Meeting of the General Assembly on 13 December 1996 established that the General Assembly should be informed about cooperation between IOM and the UN under its regular agenda item on 'International Migration and Development ${ }^{\prime}$.

While the Gulf War had provided a lifeline to the organization and allowed it to establish itself as a relevant player, there was also a recognition within the IOM administration that, without a clear strategy, IOM would continue to face challenges to its existence. Having brought the organization closer to the UN, the next significant change that was implemented by Mr Purcell was a process of decentralization. In his management review, which took place between 1996 and 1997, the 'primary responsibility for initiating and executing IOM service delivery to its Member States' (2003b, p.2) was delegated from Headquarters to the field. Accompanying the process of decentralization, was the initiation of a process, known as 'projectization' or 'the practice of allocating staff and office costs to the operational activities/projects to which they relate' (IOM, 2002a, p.vi). The change in funding structure marked a significant turning point for the organization and is arguably what allowed it to grow from a small organization into one that has seen exponential growth in both budget and membership. However, the projectized nature of IOM has also been the root of the criticism that IOM is an organization that will do 'anything for money' (INT-GOV-035) and is often described in the literature as a 'quasi-European' (Caillault, 2012, p.134) or 'quasi-governmental' (Geiger, 2010, p.151) organization.

This view is relevant to mention because the projectized nature of the organization allowed it to be cost-effective and responsive to Member States, which was one of the primary arguments levied by Member States against why IOM should become a UN entity in the discussions that took place

\footnotetext{
${ }^{7}$ Future Activities of IOM, IOM Council Res. No. 923 (LXXI), 71 st Session. IOM Doc RES No. 923 (LXXI (29 November 1995).

${ }^{8}$ Cooperation between the United Nations and the International Organization for Migration, UNGAOR, 51st Session, UN Doc. A/RES/51/148 (4 February 1997)

${ }^{9}$ International Migration and Development, UNGAOR, 50 ${ }^{\text {th }}$ Session, UN Doc. A/RES/50/123 (23 February 1996)
} 
between 2002 and 2007 (Section 5.4). However, it is also what allowed the organization to evolve in close relationship with its Member States:

'I think the states really feel like they do not own the UN enough, and they cannot control it enough, and so, it is a weird ambiguous relationship, and I guess they feel a little bit more like the IOM is just doing what they want without having its own agenda' (INT-IO-006).

The significance of IOM's close relationship with its Member States would bear fruit several decades later when the Member States lobbied the UN for IOM's entry as a related agency (Section 7.6).

\subsection{IOM-UN Relations as 'Migration' receives more attention}

In the early 2000s, IOM's non-UN status was again subject to discussion. Director-General Brunson McKinley attributed this to heightened awareness within the UN that migration was a subject that merited international attention, evidenced by its inclusion in the Secretary-General's Report to the General Assembly on 9 September $2002^{10}$. In his address to the IOM Council on 2 December 2002, McKinley stated:

'The UN is conscious of a gap in coverage and is looking for ways to fill the gap. What are the options? Creating a new $\mathrm{UN}$ agency for migration is problematic and would doubtlessly be strongly resisted by existing agencies and many governments. UN coordination mechanisms have serious limitations as well. That leads back to $\mathrm{IOM}^{\prime}$ (IOM, 2002b, para. 27).

In the remainder of his speech, he made it clear that the Administration of IOM did not have a specific position on whether the IOM should join the UN but did highlight some positive and negative implications of such a move.

\footnotetext{
${ }^{10}$ Report of the Secretary-General: Strengthening of the United Nations: an Agenda for Further Change, UNGAOR, 57 th Session, UN Doc A/57/387 (9 December 2002)
} 
On the negative side of the ledger, questions surrounding whether IOM would be able to retain many of the characteristics that its Member States valued, such as its flexibility, light bureaucracy, and ability to act when the UN was unable to do so. However, he also pointed to the disadvantages of outsider status, such as the inability to contribute to discussions within the $\mathrm{UN}$ and a harder time gaining acceptance and recognition for its work. Additionally, it was plausible that outsider status would eventually restrict the resources available to the organization. Already at this stage, the suggestion of becoming a 'related' as opposed to a 'specialized' agency was tabled, as an alternative, more loosely defined status. In the General Debate that followed, 22 Member States offered their views on UN-IOM relations, converging on the view that further discussion and analysis was needed before making any further decisions (IOM, 2003a). Accordingly, $\mathrm{Mr}$ McKinley announced in his closing remarks that a Working Group on Institutional Arrangements would be established under the chairmanship of Ambassador Amina Mohammed (IOM, 2002b).

As was discussed in Chapter 4, it was shortly after the IOM Council General Debate of 2002 that Michael Doyle submitted his report to Kofi Annan on migration. In particular, Doyle's consideration of the possibility of an agency within the UN for migration, although dismissed at that stage for feasibility reasons, was enough to exert pressure on the IOM Administration to take action to preserve its role in the international landscape:

'Of course, we were not too happy to read about it, but it gave some kind of stimulus to try and get closer to the UN because when you smell competition, you have sort of an incentive' (INT-IO-019).

With the knowledge that the UN was actively evaluating its role on migration and preparing to launch the Global Commission on International Migration (GCIM), the first report of the Working Group on Institutional Arrangements was issued on 7 April 2003. The report outlined the advantages and disadvantages of two options: 1) keeping IOM outside the UN system (the 'status quo'; or 2) bringing it into the UN as a 'specialized' or 'related' agency (Table 7.2). 
Table 7.2 Pros and Cons of IOM Joining the UN Legal status for staff

\begin{tabular}{|c|c|c|}
\hline & Status Quo & Specialized Agency \\
\hline Pros & $\begin{array}{l}\text { Under the present configuration, } \\
\text { IOM has already been able to } \\
\text { contribute to global debates. } \\
\text { Current UN coordination costs are a } \\
\text { fraction of the cost for existing } \\
\text { specialized agencies. }\end{array}$ & $\begin{array}{l}\text { De jure status preferable to de facto } \\
\text { status, i.e., while IOM participates } \\
\text { in UN Country Teams, this is by } \\
\text { indulgence and is not a right. } \\
\text { Access to the Chief Executive Board } \\
\text { of the UN and its subsidiary bodies } \\
\text { Ability to call on Residence } \\
\text { Coordinator in countries where } \\
\text { IOM is not present. } \\
\text { Higher profile. } \\
\text { Possible additional funding } \\
\text { sources. } \\
\text { Clarity for interlocuters. } \\
\text { Legal status for staff. }\end{array}$ \\
\hline Cons & $\begin{array}{l}\text { No authoritative UN voice on } \\
\text { migration. } \\
\text { Risk of UN creating its own UN } \\
\text { Migration Organization creating } \\
\text { duplication or competition. } \\
\text { IOM has no access to decision- } \\
\text { making processes. } \\
\text { UN status could make it easier to } \\
\text { secure funding rather than having } \\
\text { to justify its role constantly. }\end{array}$ & $\begin{array}{l}\text { Timing is not right - economic, } \\
\text { social, and political circumstances. } \\
\text { Membership not large enough. } \\
\text { Staff apprehension to change } \\
\text { Increase cost and time. } \\
\text { The potential loss of independence, } \\
\text { efficiency, flexibility, and } \\
\text { responsiveness. }\end{array}$ \\
\hline
\end{tabular}

Source: Summarized from United Nations Archives 2003a

When the Working Group met with IOM Member States on 15 May 2003 to discuss the preliminary report, the main conclusion as communicated by letter to Kofi Annan on 28 May 2003, was that:

'The majority of the members who spoke said that they were not convinced that the advantages of a move to seek specialized agency status outweighed the disadvantages, and were thus in favour of retaining IOM's current status outside the UN system' (IOM, 2003a, p.35). 
Despite Member State resistance, the Working Group continued its work and an addendum to the 7 April report was prepared and circulated on 22 September 2003 ahead of their next meeting on 17 October 2003. This report paid more attention to the cost implications of specialized agency status and ways in which the current arrangements could be further enhanced through amendments to the existing cooperation agreement, as a sort of 'enhanced status quo'. Interestingly, given that IOM would later become a related agency, this option was dismissed out of hand given that "'related agency status" is not a realistic option insofar as it is granted only to agencies whose mandate does not fall within the terms of reference of ECOSOC (the Economic and Social Council)' (IOM, 2003b, para. 25).

As these discussions were ongoing, Brunson McKinley and the High Commissioner for Refugees, Ruud Lubbers, exchanged a series of letters between 6 August 2003 and 8 October 2003. On 20 October 2003, these letters were shared with IOM Member and Observer states via a Note Verbale and with Kofi Annan by the UN office in Geneva (UNOG) on 23 October 2003 (United Nations Archives, 2003b). These letters offer a window of insight into some of the underlying tensions between the organizations, particularly with regards to their division of labour concerning Internally Displaced Persons (IDPs) in Iraq. At a time when Brunson McKinley was trying to establish the IOM as a key player in the area of migration, these letters, copied to several high ranking officials, including Kofi Annan, downplayed IOM as a serious actor, primarily due to its non-normative and projectized nature. This challenge was further compounded because, at the same time, IOM was the subject of a critical campaign spearheaded by the No Border Network who accused IOM of being a 'Janus-faced organization' (Ashutosh and Mountz 2011, p.28) supporting the agenda of its main donors at the expense of migrant rights (Georgi, 2010). The European No Border Network organized protests against IOM in 2002 in Berlin, Vienna, and Helsinki and in 2003 in Geneva and Bonn. During the G8 Summit in 2003, more than 2,000 people marched to IOM's Headquarters in Geneva (Georgi \& Schatral, 2012).

When Member States met on 17 October 2003, views were mixed, with 'a very small number' in favour of specialized agency status, and 'a very small number' opposed and calling for the debate to be closed (IOM, 2003b, para. 9). The remaining Member States did not dismiss the idea of specialized agency status; however, either reserved judgement or expressed feelings that the timing was not right. In a letter dated 28 January 2004, this position was communicated to Kofi Annan: 
'IOM Member States were largely not in favour of IOM moving towards specialized agency status at this time. Nevertheless, they recognized both that current practical arrangements could be improved and that the broader issue should remain under advisement' (United Nations Archives 2004, p.1).

As later recorded in a note on IOM-UN relations at IOM's 92nd Council Session in November 2006, an informal decision was taken following these letters to table the discussion until after the GCIM had concluded its deliberations (IOM, 2006).

The next communication between Brunson McKinley and Kofi Annan recorded in the archives relating to the IOM-UN relationship appeared some two years later and came in response to the Secretary-General's report in the lead up to the first High-Level Dialogue ${ }^{11}$ on 18 May 2006. In his letter dated 30 June 2006, Brunson McKinley expressed concerns to Kofi Annan regarding the 'omission of any serious reference to IOM' (United Nations Archives 2006c, p.4). In his letter, Brunson McKinley called for a 'new, objective look at UN-IOM relations' (United Nations Archives 2006c, p.4) and advises that it will be the focus of further discussion at the IOM Council meeting in November 2006. The letter suggested that the news of the establishment of a Global Forum on Migration and Development (Chapter 5), was the driver of this renewed focus on IOM-UN relations. Accordingly, Mr McKinley called for the further strengthening of IOM-UN relations in one of two ways. First, through the development of a new agreement that would preserve IOM as a non-UN entity but better integrate it into the various interagency management systems including UN Country Teams. Or second, that a relationship agreement in line with what the UN had in place with the World Trade Organization (WTO) (related agency) would be adopted. The outcome of this exchange of letters was a round of technical discussions, coordinated by the UN Department of Economic and Social Affairs (DESA) in September 2006 (IOM, 2006, para. 6). The broad conclusions of these discussions were that without UN membership IOM could not regularly participate in the UN's Chief Executive Board for Coordination (CEB) and that 'related agency' status was not an option. Thus, if the IOM wanted to join the UN, it would

${ }^{11}$ Report of the Secretary-General: International Migration and Development, UNGAOR, $60^{\text {th }}$ Session, UN Doc. A/60/871 (18 May 2006) 
have to do so as a 'specialized agency' which would cost the organization approximately USD 210,000 per year (IOM, 2006, para. 10).

At IOM's 92nd Council meeting in 2006, this report was opened to a discussion (IOM, 2007b). Despite the communications with the UN, Brunson McKinley noted in his introductory remarks that he was not convinced that specialized agency status or maintaining the status quo were the only options available. He argued that, with membership growth, IOM was approaching the numbers used by WTO to negotiate its related agency status. The ensuing discussion echoed that of three years before: the majority felt that the time was not right to enter the UN with one unnamed delegate vehemently opposing UN membership:

'One delegate did not support the Administration's action in reopening the issue in 2006, and considered that a clear position had been established in 2003 which it was inappropriate to change without putting forward very good reasons' (IOM, 2007b, para. 225).

There was a call for further review, particularly to establish a cost-benefit analysis of joining the UN, but a general preference for the status quo was evident. As one close observer of the process noted:

'I went to some Member States and said, "look, this issue is just swirling around, and I do not think you are particularly wise to leave so much uncertainty around it." The answer I got was very clear. They said, "look, that was a very deliberate stance. We said no because we did not think that it would be appropriate for IOM to get into the UN now, but we did not say no, because we do not know how things are going to evolve, and we would like to leave that option open"' (INT-IO-015).

Seemingly unphased by previous discussions, Brunson McKinley on 10 July 2007 wrote to Ban Ki-moon requesting two things: that IOM would be formally invited to the UN Development Group (UNDG) and to the CEB of the UN. Both requests were declined in a letter dated 8 October 2007 unless IOM became a specialized agency. However, a concession was made allowing IOM to receive invitations to the High-Level Committee for Programme (HLCP), which was a subsidiary body of the CEB, when issues 
of relevance were to be discussed. On 9 November 2007, an updated document on IOM-UN relations was released (IOM, 2007a) in preparation for a discussion at the $96^{\text {th }}$ Session of the IOM Council. This document explored four possible ways forward, albeit dismissing one of these outright. These were: 1) the fuller implementation of the existing cooperation agreement; 2) related agency status; 3) IOM as a UN programme or fund (dismissed outright), and 4) specialized agency status. At the $96^{\text {th }}$ Session of the Council, the Member States decided to deepen the IOM-UN relationship without any changes to the legal relationship (IOM, 2008).

An examination of the debates regarding IOM-UN relations between 2002 and 2007 indicates that a degree of action-reaction to the developments occurring within the UN at that time existed. Each new development within the UN brought new energy to the discussion of the IOM-UN relationship. While several interview participants noted that Brunson McKinley was not interested in seeing IOM join the UN, and 'toed the line of the US administration' (INT-OTHER-030), the evidence suggests that he actively sought to continue the conversation on IOM-UN relations. For example, in a letter from Brunson McKinley to Kofi Annan sent not long after submission of the Doyle report, and as preparations were underway to launch the GCIM, he made a comment about Amina Mohammed (then President of IOM Council) being 'best positioned to follow up with counterparts in the UN system and to influence the evolution of IOM Member State views' (United Nations Archives, 2003c). It is also arguably the case that McKinley's efforts to expand the organization, an effort that was remarked upon by multiple interviewees, was part of a strategy to ensure that, in the long term, IOM would be able to secure its position as a, if not the key actor on migration at the global level. The picture painted of Brunson McKinley by several interviewees was that of an 'entrepreneur' (INT-IO-008; INT-IO-010; INT-IO011) who 'aggressively expanded' (INT-IO-011) the organization and was 'very jealous of anybody else's engagement' (INT-IO-008) on migrationrelated matters. Indeed, while Brunson McKinley was Director-General of IOM, its membership numbers doubled, from 43 to 86 members (Figure 7.2). Thus, while the discussions that took place between 2002 and 2007 did not result in IOM becoming a UN agency, they did plant a seed in the minds of its Member States that becoming part of the UN might be something that would be necessary for the future. 


\subsection{The Road to 2016: The Fear of Being Left Behind}

The next time that IOM-UN relations were subject to formal discussion at the IOM Council was in 2012 as the UN was preparing to hold the second HighLevel Dialogue on International Migration and Development and as discussions regarding the post-2015 development agenda were underway. Director-General William Lacy Swing proposed in his report to the $101^{\text {st }}$ Session of the IOM Council that 'Member States may find it in their interest once again to consider conducting a formal review of IOM's relationship with the $\mathrm{UN}^{\prime}$ (IOM, 2012b, para. 99). While exhibiting sensitivity to the political nature of the topic and emphasizing his neutrality, Director-General Swing drew attention to the importance of ensuring that IOM retained its position as 'the leading international migration' agency/organization on multiple occasions (IOM, 2012b).

While IOM had grown as an organization in the decade since the start of the last round of discussions on IOM-UN relations, the global landscape related to migration had also changed considerably, and the UN had made strides in its efforts to bring migration more clearly under its mandate. Although organized outside of the UN, the GFMD by 2012 had already met five times, with preparations underway for its sixth meeting in Mauritius. Sutherland continued to act as the link between the GFMD and the UN, and, within the UN, plans for the second UN High-Level Dialogue on Migration and Development in 2013 were in place. The GMG had also grown from six members in 2002 to 20 members in 2012. These developments signified a maturation in the way the international community discussed migration. However, as new actors joined the field, IOM's place in the global governance landscape became less secure:
'As more actors appear on the migration stage - many of them with a somewhat limited interest in migration and often lacking a global footprint - IOM is increasingly challenged to ensure that its own universal mandate and global reach are recognized...' (IOM, 2012b, para. 69).

A review of the archival records during this time uncovers two specific occurrences that point to the possibility that IOM may have faced exclusion as the $\mathrm{UN}$ formalized its role in the area of migration. These occurrences may 
have prompted IOM's Member States to reopen the discussion regarding IOM-UN relations. The first was the omission of IOM from an initial draft of the Secretary-General's report on International Migration. As noted by Director-General Swing in a letter addressed to Deputy Secretary-General Jan Eliasson on 24 July 2013:

'the draft report of the Secretary-General, prepared by DESA does not adequately reflect IOM's leadership on migration globally or in HLD preparations' (United Nations Archives 2013b, p.1).

Director-General Swing called for a speaking role for the GMG, which IOM was chairing, at the second HLD and the addition of a sentence to the Secretary-General's report which acknowledged 'the expansion of IOM's membership, activities and reach since the first HLD in 2006 and its evercloser partnership with the UN across the board, as an indication of improved attention to global migration governance' (United Nations Archives 2013b, p.2). There was a swift response to this letter, as, the very next day, the Executive Office of the Secretary-General sent a revised copy of the report to Jan Eliasson in which two additional references to IOM were made in the introductory ${ }^{12}$ and concluding ${ }^{13}$ paragraphs of the report which were in line with the suggestions made by Director-General Swing (United Nations Archives, 2013c).

The second occurrence was in August 2013 and took the form of the report submitted to the $68^{\text {th }}$ session of the General Assembly by the Special Rapporteur on the Human Rights of Migrants, François Crépeau. In his report ${ }^{14}$, Professor Crépeau highlighted some concerns regarding the organization:

'The fact that the mandate of IOM is not supportive of human rights is of concern for the whole United Nations

\footnotetext{
12 'Since the first High-Level Dialogue. (IOM) has seen an expansion of its membership, activities and reach and an ever closer partnership with the United Nations entities dealing with migration.' (United Nations Archives 2013b, p.29).

13 'Cooperation and dialogue on migration within the United Nations, IOM and regional economic communities should be strengthened' (United Nations Archives 2013, p.52).

${ }^{14}$ UNGA, Report of the Special Rapporteur on the Human Rights of Migrants: Human Rights of Migrants, UNGAOR, 68th Session, UN Doc. A/68/283 (7 August 2013)
} 
system, as IOM is part of the Global Migration Group and the United Nations Country Teams in many countries and is often mistakenly believed, including by migrants themselves, to be a United Nations agency' (para. 61, p.12).

Many civil society organizations and UN agencies believed that IOM should amend its constitution and receive a normative mandate if it were to join the $\mathrm{UN}$. It is unsurprising to see this view amplified at a time when both the UN and the IOM were reflecting on their positions in the global migration governance landscape. It is also reflective of a schism in the global migration governance landscape between those promoting a rights-based approach to human mobility, and those focused on the management of migration. IOM may have viewed these critiques as an attempt to undermine the credibility of IOM at a time when the organization was trying to secure its position, at the behest of its Member States, as the lead international agency for migration.

As in 2002, when Kofi Annan announced his concern that the UN should more comprehensively tackle the issue of migration, the possibility that the UN would seek to create its own migration agency emerged in 2013. Two key documents were prepared that reviewed IOM-UN relations in September of that year, which led to the establishment of a Working Group on IOM-UN relations and the IOM Strategy:

'The documents entitled IOM-UN relations (SCPF/106) and Review of the IOM Strategy (SCPF/105) highlighted that, although IOM had worked as closely as possible with the United Nations within the current framework and had succeeded in making significant progress, it continued to be excluded from important processes because of its status as a non-United Nations organization. The Standing Committee had therefore agreed to establish a working group to consider IOMUN relations and the IOM Strategy' (IOM, 2014b, para. $54)$.

After the first meeting of this Working Group, which took place on 13 February 2014, and upon the request of the group, William Lacy Swing wrote to Ban Ki-moon to request information 'on the different modalities of 
association that currently exist in the common system for agencies, specialized organizations and other intergovernmental organizations to have any form of association with the UN' (United Nations Archives 2014a, p.7).

The fear of IOM's exclusion from the UN's work on migration was compounded in 2014. With discussions already underway, 'the issue was brought into sharper and more urgent focus because of the discussions of the draft Second Committee Resolution on Migration and Development, and the potential implications of that for both the relationship and for IOM's role and work on the global stage in general' (United Nations Archives, 2014b, p.1). The Second Committee Resolution on Migration and Development ${ }^{15}$ gave credence to the idea that the UN was bracing itself to take on migration, and by implication that the matter of a UN body for migration may again be put on the table. In his response to the Chairperson's Report on the Working Group on IOM-UN Relations and the IOM Strategy, Director-General Swing noted that 'the resolution, as currently drafted, risks the marginalization of IOM and the creation of new, additional and duplicative arrangements within the UN' (United Nations Archives 2014b, p.4). He noted that IOM may have to, 'as a matter of self-defence...consider the possibility of a more formal association with the UN system' (United Nations Archives, 2014b, pp.3-4).

In late 2014, documents issued by the UN Development Operations Coordination Office (DOCO) solidified these fears. On 11 December 2014, DOCO issued a document outlining new 'Functioning and Working Arrangements' effective as per 1 January 2015. On 3 March 2015, a second document, 'Briefing Note: New UNDG Functioning and Working Arrangements and IOM', was released, offering further clarifications on the original document. In short, these documents meant that IOM, as a non-UN entity, would no longer be allowed to sign UN Development Assistance Frameworks (UNDAFs), take a role in UN Country Teams beyond that of an ad hoc participant, or be the beneficiary of specific funding opportunities. The DOCO documents arguably triggered the IOM Member States to conclude that, if IOM did not join the UN, then it was at risk of becoming irrelevant, and critically, cut off from resources. By this stage, IOM was well integrated into almost all UN Country Teams (UNCTs) around the world and was a signatory to UNDAFs in 66 countries (United Nations Archives, 2015). On 5 March 2015, Director-General Swing wrote to Deputy Secretary-General

\footnotetext{
15 Second Committee Draft Resolution: International migration and development, 69 $9^{\text {th }}$ Session, UN Doc. A/C.2/69/L.32 (30 October 2014)
} 
Jan Eliasson to express his concern about the implications of the document for IOM-UN relations.

\begin{abstract}
'As you are aware, IOM has, on a practical basis, for some time enjoyed inclusion in and access to various UN processes and mechanisms such as UNCTs and UNDAFs. I believed that the UN, as much as IOM, had been benefitting from this. We have, however, been taken by surprise that suddenly, and without any prior discussion or consultation, this practical approach is no longer to be followed as of 1 January 2015.

\section{$[\ldots]$}

I am now obliged to bring to the attention of IOM Member States the likely impact this will have on IOM's work, as it significantly changes the facts about the IOMUN relationship that we have presently shared with them' (United Nations Archives 2015a, pp.1-2).
\end{abstract}

There appears to be a direct correlation between the UN Development Operations Coordination Office documents and the decision of Member States to move IOM into the UN. As one interviewee argued:
'That was what woke up the Member States to a realization that it was not just that we kept whinging and whining, but that not being formally in the UN system was a problem. They began to see that there really was an issue' (INT-IO-040).

By October 2015, the Working Group on IOM-UN Relations and the IOM Strategy had concluded that it was time for the organization to formalize its relationship with the UN and presented its report to the Standing Committee on Programmes and Finance on 28-29 October 2015 (IOM, 2015). The Standing Committee recommended that the Council adopt the draft resolution, which was done on 24 November 2015. Council Resolution No. 
$1309^{16}$ requested the Director-General to pursue a better legal relationship with the UN. From this point onward, IOM's transition into a related agency was a swift one:

'On 25 July 2016, following the endorsement of the draft Agreement concerning the Relationship between the United Nations and the International Organization for Migration by the IOM Council on 30 June 2016, the General Assembly passed a resolution approving the draft Agreement. This Agreement, which came into force on 19 September, not only brought IOM into the United Nations system, it also resulted in IOM becoming the 'UN Migration Agency' (IOM, 2017, para. 8).

\subsection{IOM joins the UN: The "Perfect Storm ${ }^{17 " ?}$}

Previous attempts to bring IOM into the UN system have shown that it is ultimately the Member States of the organization that determined its fate. Without the endorsement of its Members States, the IOM Administration could not have pursued a relationship agreement with the UN. The question then becomes, what had changed by 2016 that resulted in the Member States of IOM agreeing for the organization to join the UN, having resisted this option for more than 20 years? Coupled with this, what led the UN to agree to IOM's entry as a 'related agency', an option that had been categorically taken off the table just 15 years earlier? Perhaps the single most compelling argument relates to the fear of exclusion and the negative implication that exclusion could have for the organization's access to resources and for its long term survival. On each occasion, sensing a certain level of threat to the organization's existence, the management of IOM responded by seeking counsel on the matter of IOM-UN relations with its Member States. In the early 1990s, this threat was an existential one, whereby the organization was facing the genuine possibility that its lifespan was coming to an end. In 2002, this threat was represented by the Secretary-General's report in which he

\footnotetext{
16 IOM-UN Relations, IOM Council Res. No. 1309, 106th Session, IOM Doc. C/106/RES/1309 (4 December 2015)

17 INT-IO-040
} 
expressed his intention for the UN to engage more comprehensively with the topic of migration.

However, while an external threat to IOM's existence seems to have been the trigger to discuss the organization's relationship with the UN on each occasion, it does not seem to be sufficient to explain IOM's entry into the UN system. One of the reasons cited for why IOM's Member States decided not to join the UN in the early 2000s was the fear that the organization would become more expensive and bureaucratic should it join the UN. However, at that stage, the likelihood of migration being institutionalized within the UN did not seem to be plausible. Hence, there was not sufficient pressure to convince the IOM Member States that UN membership was required. By 2012 when the matter was reopened for discussion, the migration governance landscape had evolved significantly, and it looked increasingly likely that migration would be included in the post-2015 development agenda and accordingly, institutionalized into the UN system. Several developments, most notably the UNOG clarifying the position of IOM with regards to the UNCTs, meant that IOM Member States faced the genuine possibility that IOM may be replaced by a new UN entity with a migration mandate:

'Because migration had been becoming more important, all the UN agencies had been trying to polish their credentials on migration issues. The UN was going to be exclusionary because that is how it functions. Money is tighter and tighter because there is less and less core funding, and more and more project and earmarked funding, and as migration is a sexy issue, everyone is trying to get a part of that cake. They were trying to make sure that the UN got the whole of the cake and that IOM was not going to have any part of it. So, eventually, the members, well, there were some holdouts, including the UK and the US. However, eventually, they saw that there was no way of guaranteeing IOM's continuing role if it was not within the UN system' (INT-IO-040).

While the fear of IOM's exclusion may have tipped the scales in favour of UN membership from the perspective of its Member States, this was not the only relevant factor at play. Just as the first Gulf War had allowed IOM to establish itself as a relevant player, the migration crises of 2015 also created a window of opportunity: 
'Of course, the Syrian crisis was out of control. We had the host countries such as Jordan, Lebanon, and Turkey at breaking point, and still have that, in terms of numbers of refugees. Then we had the Myanmar situation, which later exploded into a mass outflow of Rohingyas to Bangladesh. Again, the increasing number of refugees, the protracted nature of the refugee situation, with no solutions in sight, and a very high burden on least developed countries, hosting large numbers of refugees. There was a clear feeling that something needed to happen. I think that this combination of factors helped the IOM Council to request the Director-General to look into cooperation agreements with the UN with the proviso that the IOM constitution or the IOM mandate should change as little as possible, or not at all. We did not want to change IOM, but we did want to have a link of some kind with the UN system, which is what, in the end, materialized' (INT-IO029).

Thus ultimately, after the discussion had been simmering away for the best part of two decades, the decision to bring IOM into the UN happened relatively quickly, to the great surprise of many actors involved:

'I am very surprised that the IOM deal went through so quickly, I was amazed by it. I think many people were actually' (INT-IO-001).

The speed at which the decision for IOM to join the UN was taken points to the importance of context-related factors that caused the relevant actors to move so swiftly. Having described IOM's entry to the UN as a 'perfect storm', one observer noted:

'I remember the sense of urgency that was coming from the $38^{\text {th }}$ floor, this sense of if we do not do it now, however imperfectly, we will never get the chance again to bring IOM into the system. For all of these actors, Sutherland, Ban Ki-moon, Eliasson, Bill Swing, this 
became an urgent priority, a personally urgent priority' (INT-IO-040).

Next to the notion of a 'perfect storm', several of the respondents interviewed employed similar metaphors to describe IOM's entry into the UN system (INT-IO-028; INT-IO-015; INT-IO-016; INT-IO-040; INT-GOV-031). The most commonly used metaphor was that of 'moons', 'planets' or 'stars' aligning. Both metaphors imply that IOM joining the UN was something that only occurred because multiple factors converged and that the right people were in the right positions at the right time:

'All of these things: the SDGs containing migration, the Global Compact starting its momentum before IOM became a member, the growing number of migration crises, and the fact that IOM had been part of UN Country Teams across the board without being a member, all of that, the stars were aligned somehow' (INT-IO-028).

\subsection{Conclusion}

This chapter has demonstrated that IOM, as theory would lead us to expect from an IO, is sensitive to changes in its environment and reacts to external events that present both opportunities and threats to its existence. Having traced IOM's journey from 1951 to 2016 with a focus on IOM-UN relations, this chapter has also provided empirical evidence in support of the argument that resources, as argued in Chapter 2, are a central factor influencing the evolution of global migration governance.

An examination of IOM's development trajectory as an organization shows that access to resources has played a determining role in how the organization has evolved. IOM's very existence was the result of a decision by the US to exercise its monetary power to ensure that its preference for keeping migration out of the UN was achieved. Beyond its creation story, however, resources have continued to play an important role in IOM's evolution as an organization. The management reforms initiated by James $\mathrm{N}$. 
Purcell Jr. in the 1980s, which led to the decentralization and projectization of the organization, contributed to its transition from an organization with a small and declining membership, to one that has seen exponential growth in both budget and membership and has become the lead UN agency for migration.

One of the main reasons cited for why many IOM Member States wished to keep IOM outside of the UN until 2016 was that its organizational structure allowed for the cost-efficient delegation of migration management tasks, such as return, to an organization less encumbered by bureaucracy than the UN and, perhaps more importantly, one without a normative mandate. While the internal funding structure of IOM has allowed it to cut costs and increase efficiency, IOM's dependence on the finances of wealthier states for its survival has meant that the organization is often viewed with suspicion by other actors. Given the support of wealthier states for the migration management frame with its associated focus on pragmatic solutions as opposed to the focus on norms among adherents of the migrant rights frame, this suspicion is particularly prominent among adherents of the migrant rights frame.

While the IOM Administration may have sought to steer Member States towards the UN in the interest of ensuring that the organization remained viable, its Member States, especially the US as its main sponsor, have retained control over the organization. It was not until states accepted migration as a $\mathrm{UN}$ issue through the inclusion of migration in the SDGs that the necessity of having a UN body to coordinate its work on migration became apparent. Faced with the choice between the creation of a new UN agency for migration (or appointment of an existing UN agency) or to accept the entry of IOM to the UN system, its Member States chose for the latter with the provision that IOM could become a 'related agency' and enter with minimal changes to how the organization functioned.

Hence this dissertation argues that it is a range of factors that led its Member States to acknowledge the necessity of IOM becoming part of the UN system in 2016. These factors included the migration crises of 2015 which propelled migration into the political limelight; the reframing of migration as a development issue (Chapter 5) and subsequent inclusion of migration in the Sustainable Development Goals (Chapter 6); coupled with the threat of IOM's exclusion and the threat of the creation or appointment of a new lead agency for migration within the UN. However, while the migration crises of 2015 
created the necessary 'window of opportunity' to bring IOM into the UN, they also provided a fertile environment for advocates of the migrant rights frame to revive their struggle for universal norms to govern international migration (Chapter 8). 


\title{
8. Responding to Crisis? The Global \\ Compacts
}

\subsection{Introduction}

\begin{abstract}
'In Europe today, I believe we may be confronted with a crisis. On one hand, the structure for the protection of refugees, so painstakingly built up over decades and emulated all over the world, is in serious danger. On the other hand, we have the opportunity at these Consultations to show that this structure is as valid and precious as ever and that the international community has the will and capacity to defend it and to strengthen it' (Hartling, 1985).
\end{abstract}

The words of former UN High Commissioner for Refugees, Poul Hartling in his opening address to the Consultations on the Arrival of Asylum-seekers and Refugees in Europe on 28 May 1985, could easily have been written for the High-Level Summit to Address the Large Movements of Refugees and Migrants in September 2016. As discussed in Chapter 4, the circumstances leading to each of these meetings bear a resemblance to one another. The events leading up to the meeting in 1985 started in the mid-1970s when several European countries closed programmes for guest workers as the effects of the 1973 oil crisis slowed down the pace of development. A mismatch between labour demand and the opportunities to migrate led to an increase in irregular migration (Castles 1986; Freeman 1992). Following the conference, Europe sought intergovernmental solutions informally within the context of the Intergovernmental Consultations on Migration and Asylum (IGC) (Section 4.4). Thirty years later, Europe was again in 'crisis' (Section 4.8).

In 2015 almost a million people arrived in Europe, many of them seeking asylum (Ferris \& Martin, 2019). With growing media attention, the political saliency of migration increased, and states again looked to intergovernmental cooperation for the solution. Accordingly, in December 2015, states called upon the UN to organize the High-Level Summit to Address the Large Movements of Refugees and Migrants. The Summit led to the adoption of the 
New York Declaration (NYD), which in turn laid out a roadmap for the negotiation of two Global Compacts, one on Refugees and one for Migration. On 17 December 2018, 181 states voted in favour of adopting the Global Compact on Refugees (GCR) at the UN General Assembly. Two days later, after being adopted by 164 Member States at an Intergovernmental Conference in Marrakesh, Morocco on Monday 10 December 2018, the Global Compact for Safe, Orderly and Regular Migration (GCM) was endorsed by 153 Member States at the General Assembly on 19 December 2018.

The notion that crisis can lead to policy change is well established in the literature (cf. Alink et al., 2001; Balch \& Geddes, 2011; Rinscheid, 2015). However, the fact that not all crises lead to policy change poses an interesting empirical puzzle, which has led researchers to consider what mediating factors play a role in determining the impact of crises on policy. Employing advocacy coalition theory, Rinscheid (2015) suggests that 'the type of policy subsystem that is hit (by crises) is the decisive moderating factor' (p.35) in determining whether policy change occurs as a result of a crisis. Weible (2008) describes three types of policy subsystems: unitary, collaborative, and adversarial. The evidence presented in Chapters 5 and 6 suggests that, as migration has evolved as a global policy issue, the migration policy subsystem has transitioned from being adversarial, characterized by fragmentation, low levels of coordination, and seemingly incompatible ways of framing migration as a global policy issue, towards a more collaborative subsystem. According to Weible (2008), a collaborative subsystem is still characterized by fragmentation but with an emphasis on 'win-win' policy design and more interaction between adherents of different advocacy coalitions (p.622).

However, in responding to the 'migration crises' of 2015, the fault lines between different coalitions of actors appear to have resurfaced. There is evidence that the migration policy subsystem may be transitioning back to a more adversarial model, as members of different advocacy coalitions make use of the 'migration crises' to reorient the discussions regarding migration. Furthermore, another fault line that has long characterized migration governance came to the fore: the separation between migrants and refugees. As Chapter 4 discussed, the refugee regime is far more unitary than the migration regime. Rinschied (2015) argues that policy change is more likely to result from a crisis in adversarial subsystems as compared to unitary subsystems because different advocacy coalitions will be more likely to have arguments ready to employ when an opportunity for policy change presents 
itself. Accordingly, one would expect to see more policy changes arising from the 'migration crisis' within the migration subsystem as opposed to the refugee subsystem. Furthermore, Rinschied (2015) also argued that 'a policyproximate crisis is likely to trigger a temporary increase in subsystem polarization' (p.39). I extend this argument by suggesting that the 2015 crisis also led to inter-subsystem polarization.

While the Global Compacts have only relatively recently been adopted, a considerable body of literature has already emerged, providing commentary on the compacts ${ }^{1}$. Thus far, the literature on the Global Compacts, often written by close observers and participants in the process, can be grouped into three broad categories. The first to a body of literature focused on the process leading up to the adoption of the Global Compacts (c.f. Ferris and Donato, 2019; Newland, 2019; Klein Solomon and Sheldon, 2019; Ferris and Martin, 2019; Guild, 2018; Vitorino, 2019; McAdam, 2019; Rother and Steinhilper, 2019; Wouters and Wauters, 2019). The second to assessments of the content of the Compacts from different thematic perspectives such as human rights (Gest et al., 2019; Guild et al., 2019; Hujo, 2019; Delgado Wise, 2018b); the facilitation of mobility (Costello, 2019; Crépeau, 2019); detention (Majcher, 2019); forced migration (Jubilut \& Casagrande, 2019); labour markets (Martin and Ruhs 2019); travel security (Koslowski, 2019); climate (Warner, 2018) and gender (Hennebry \& Petrozziello, 2019). The third category captures literature that reflects on the (potential) impact of the Compacts from a geographical perspective (c.f. Khadria et al., 2019; Maiyegun, 2019; Kale \& Erdoğan, 2019; Goodwin-Gill, 2019; Martín Díaz \& Aris Escarcena, 2019; Akram, 2019). This chapter contributes to this growing literature on the Global Compacts by examining the process that led to the adoption of the Global Compacts in 2018, with specific attention given to inter-subsystem (refugees versus migrants) and intra-subsystem (human rights versus management) polarization. The chapter addresses the following research question:

How did the 'migration crises' of 2015 affect how migration was framed as a global policy issue?

\footnotetext{
${ }^{1}$ The majority of this literature can be found in two special issues on the Global Compacts, one in the International Journal of Refugee Law (2018) and one in International Migration (2019).
} 
In keeping with the process-tracing approach, the chapter follows the emergence of the Compacts in a chronological way (Figure 8.1). As such, the remainder of the chapter is structured as follows. Section 8.2 discusses the origin of the Global Compacts from the original conceptualization as a global compact on responsibility-sharing for refugees in 2015 to two separate compacts, one for refugees and one for migrants. It explores the first example of polarization accentuated by the crisis: the distinction between migrants and refugees. Section 8.3 focuses on the High-Level Summit with attention to the drafting and adoption of the New York Declaration, which provided the blueprints for the subsequent Global Compact negotiations. Here it is already possible to identify evidence that the migration crises exacerbated intrasubsystem tensions and provided a platform upon which to discuss migration within a protection framework making a rights-based approach more palatable. Section 8.4 examines the evolving context within which the Global Compacts were negotiated before Section 8.5 compares the negotiations and reception of each Compact. Section 8.6 concludes the chapter. 

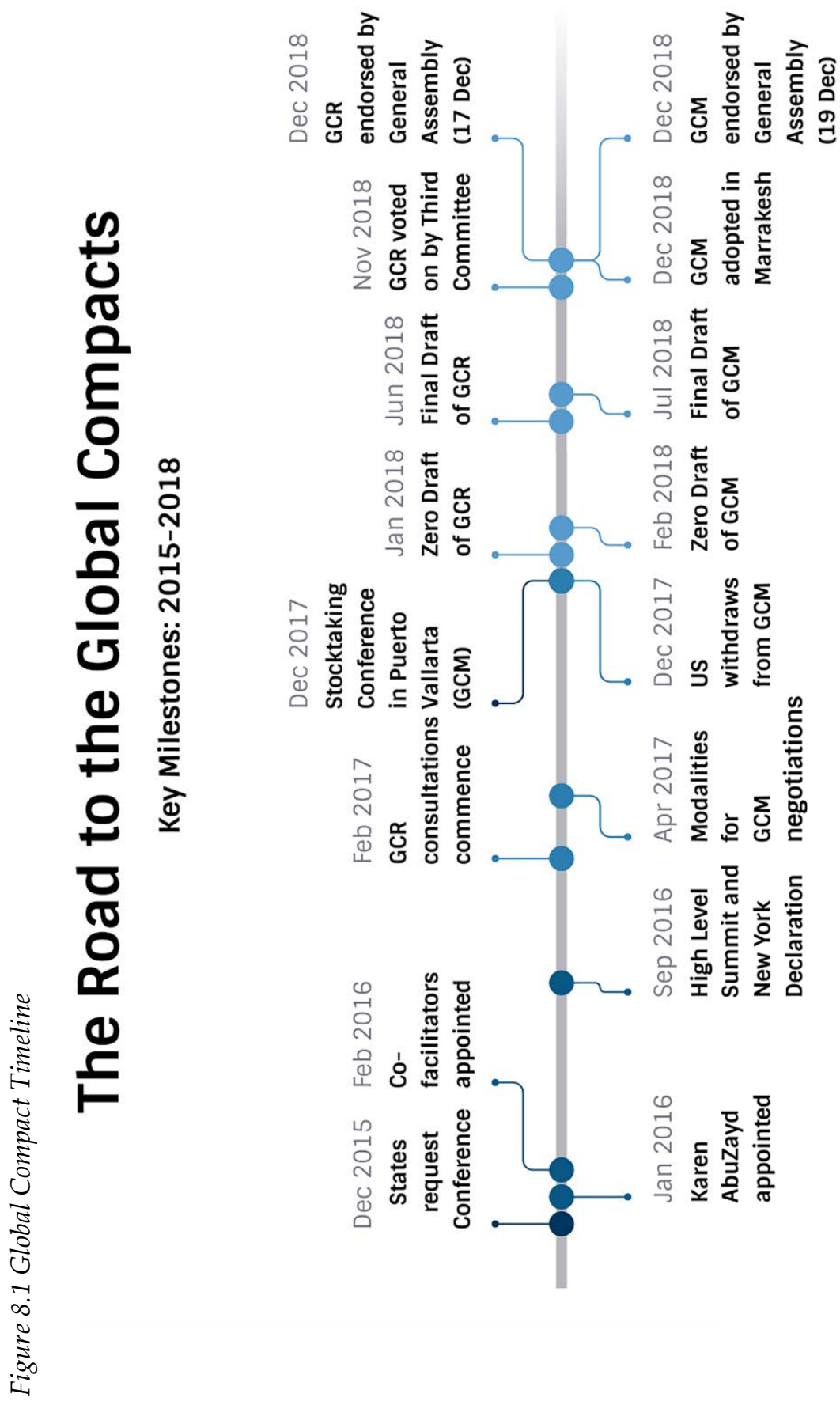


\subsection{The Genesis of an Idea: One Compact becomes Two}

From January to April 2015, nearly 2,000 people are known to have lost their lives in the Mediterranean Sea (IOM, 2020b). On one day, 19 April 2015, more than 600 people died when their boat capsized near the island of Lampedusa (Spindler, 2015). It is widely accepted that the Global Compact process was triggered by the increase in the number of people arriving in Europe (c.f. Betts, 2018; Guild, 2018; Klein Solomon and Sheldon, 2019; Newland, 2019; Arnold-Fernández, 2019; Hujo, 2019; and Maiyegun, 2019):

'If you had asked me when the crunch point came, I could identify one fairly clearly, and that was the 2015 mass inflow of people into Europe. To me, that was the tipping point' (INT-IO-015).

One of the earliest references to a Global Compact in the UN archives is in a letter sent by Ban Ki-moon to the leaders of the G20 on 4 November 2015:

'It is time that we agree on a new Global Compact on burden and responsibility sharing in this area. We need a new spirit of solidarity, and a renewed commitment to our obligations and responsibilities' (United Nations Archives 2015b, p.4).

Initial discussions focused on holding a conference likened to the conference that led to the Comprehensive Plan of Action (CPA), which was formulated for Indochinese refugees in 1989 (Klein Solomon \& Sheldon, 2019). However, particularly given that arrivals in Europe represented but a fraction of the world's displaced population, an international conference to solve a problem that many actors felt Europe should be able to address on its own, did not receive much support:

'We first tried to create a summit of European, African Union, and Middle Eastern leaders in June of 2015 to deal with the Mediterranean crisis. We pushed hard for the idea of a comprehensive approach, an action plan for the Mediterranean. Ban (Ki-moon) was simply not able to do that' (INT-IO-037). 
In the context of preparations for the eighth GFMD meeting in Istanbul in October 2015, however, the idea of a conference took on a more international flavour as countries beyond Europe highlighted their displacement-related challenges (Ferris and Martin, 2019). As Sutherland wrote to Ban Ki-moon on 21 July 2015:

'Last week, I spoke at an excellent (preparatory) GFMD meeting in Brussels that focused on the international dimensions of the Mediterranean crisis; the session attracted dozens of states and agencies, as well as civil society, and was the first such conference to bring a truly international dimension to what has been framed principally as a European crisis' (United Nations Archives, 2015a, p.4).

After several informal meetings about a conference, at the UN General Assembly, in December 2015, Member States called on Ban Ki-moon to organize a High-Level Summit on Addressing Large Movements of Refugees and Migrants to be held on 19 September 2016². To this end, in January 2016, Ban Ki-moon appointed Karen AbuZayd to be his Special Adviser to assist in the preparation of the Summit and to prepare a report as input. The resulting report, released on 21 April 2016, 'In Safety and Dignity: Addressing Large Movements of Refugees and Migrants ${ }^{3}$, proposes two Global Compacts: one on responsibility-sharing for refugees; and one on safe and orderly migration. A striking aspect of the report is its reinforcement of the separation between migrants and refugees:

'It is important to bear in mind the significant distinction between migrants on the one hand and refugees on the other' (para 12).

The report refers to 'refugees and migrants' on 71 occasions. The reverse formulation, 'migrants and refugees', appears nine times. Alternative formulations, such as 'migrants, including refugees', which definitionally

\footnotetext{
${ }^{2}$ High-Level plenary meeting on addressing large movements of refugees and migrants, UNGAOR, UN Doc. A/70/L.34 (15 December 2015)

${ }^{3}$ Report of the Secretary-General: In Safety and Dignity: Addressing Large Movements of Refugees and Migrants, UNGAOR, 70 $0^{\text {th }}$ Session, UN Doc A/70/59 (21 April 2016)
} 
recognize refugees as a subcategory of migrants, do not appear in the report. The report does, however, acknowledge that 'certain vulnerable migrants who are not refugees' (para 93) also need international protection and, as such, established the three-pillar structure that was also reflected in the New York Declaration.

This points to our first schism. While the dissertation has predominantly focused on the frame conflict between a human rights and a management approach to migration, another longstanding area of friction relates to the separation of the migration regime and the refugee regime (cf. Karatani, 2005; Betts, 2011; Long, 2013). Refugees have long been institutionalized within the UN, represented by an institution (UNHCR) and norms (the 1951 Refugee Convention and its 1967 Protocol).

However, the categories used to define mobile populations are highly political, and it has been long acknowledged that distinguishing between migrants and refugees is not straightforward (cf. Scalettaris, 2010; Crawley \& Skleparis, 2018; Carling, n.d.). Carling (n.d.) distinguishes between residualist and inclusive definitions of a migrant. A residualist definition would be that a migrant is anyone who is not a refugee. In contrast, an inclusive definition would view refugees, like international students or labour migrants, as a category of migrant. As argued by Rasmussen (2011), 'classifying issues into categories that link them to or separate them from other policy issues requires "framing" by political actors' (p.934). One of the most prominent actors behind the framing of refugees as a distinct category of individuals separate from migrants is UNHCR.

'UNHCR has taken on this stance that refugees are not migrants. They are not a sub-class of migrants. They have nothing to do with migrants. It is a completely different thing, and they are scrupulously going through every document that comes their way to make sure that they say "refugees and migrants"' (INT-OTHER-034).

While this is by no means a new concern, it appears to have become more pertinent in the context of the 2015 crises:

'Before UNHCR's creation, it was considered quite normal to talk about refugee movements and labour migration as two sides of the same coin. From the 50s, 
60s and 70s onwards there became a complete separation where UNHCR insisted on a strict distinction between refugees and migrants culminating in an article written by Eleanor Feller, a senior UNHCR staff member, with the title "Refugees are not Migrants" (Feller, 2005). From that point onwards, UNHCR actually moved away from the "refugees are not migrants" position, however, over the last two years, UNHCR is reversing to a more traditional perspective where refugees and migrants are strictly distinguished, and I think that is mainly because of the so-called refugee crisis particularly in Europe' (INT-IO-08).

Feller (2005) argues that UNHCR has 'good reasons' (p.28) to uphold the clear distinction between refugees and migrants because, in the context of the internationally agreed-upon framework, the Refugee Convention and its Protocol, refugees are clearly defined. Referring to refugees as migrants, particularly in a climate where 'migrants' are viewed pejoratively, may undermine public sympathy towards refugees. In the context of the 2015 'crisis' in Europe, Crawley and Skleparis (2018) argued along a similar line: 'the use of different categories to describe those on the move has become deeply politicised in the context of Europe's "migration crisis" (p.49). By casting those arriving in Europe as 'migrants' rather than 'refugees', the legitimacy of their claims for international protection was no longer taken for granted. However, Feller (2005) also acknowledges that:

'Definitions can become quite artificial, even dangerous, if they lead to some being helped and others ignored, regardless of need' (Feller, 2005, p.34).

While there is an argument to be made for preserving the refugee definition, there is also a clear rationale to address the challenges faced by migrants who are not refugees:

'I think we probably do need to preserve the legal distinction, but I also think we need to be very aware that it is not an absolute distinction. An awful lot of people who want to move from one country to another have a mixture of motives and may or may not qualify 
as refugees. At the same time, even if they do not qualify as refugees, this does not mean that their movement is entirely voluntary' (INT-IO-038).

Over the years, and particularly in times of 'crisis' there have been moves made by members of both the migration regime and the refugee regime to more clearly define the grey area that exists between the migration and refugee regimes, sometimes referred to as the 'migration-asylum nexus' (Castles, 2007, p.39). Different concepts have been used to describe individuals who 'fall in between this ideal type of refugee on the one hand and migrant on the other' (INT-IO-040) such as the concept of migrants in vulnerable situations, or mixed migration.

According to Scalettaris (2010), since 2001, UNHCR has 'strived to introduce the distinction between forced and voluntary migration' (p.263). Distinguishing between forced and voluntary migration would give credence to the argument that individuals who do not qualify as refugees under the 1951 Refugee Convention but are nevertheless in refugee-like situations such as Internally Displaced Persons (IDPs) or individuals displaced by factors such as climate or natural disasters, should fall under an expanded UNHCR mandate. Particularly under the leadership of António Guterres, who was the UN High Commissioner for Refugees between 2005 and 2015, and who is often described as an 'expansionist' (INT-IO-08), UNHCR sought to move the discussion beyond the refugees and migrant dichotomy.

In 2007, the High Commissioner's Dialogue on Protection Challenges focused on the question of how to address what is often referred to as mixed migration flows. Ahead of the meeting, Guterres published an op-ed in the Guardian with the title 'People on the Move' in which he points to the challenges associated with the increasingly complex patterns of mobility, and the need to 'provide more opportunities for people to move in a safe and legal manner' in order to, one the one hand, ensure that the asylum systems are not overwhelmed, and, implicitly, to maximize the development benefits of migration (Guterres, 2007). As one observer noted, 'it was a fairly calculated strategy to get beyond the traditional dichotomy of refugees and migrants' (INT-IO-08). However, there has been general resistance to UNHCR expanding its mandate:

'You had the major donor states, particularly the US, saying "stick to your refugee mandate, this is too big for 
UNHCR to take on", and, "if you move in this direction, we are not going to fund you to do it". At the same time, you had refugee-hosting countries in the developing world saying "we are very concerned that if UNHCR moves into climate change and natural disasters, you are going to have less money for refugee programmes in our countries"' (INT-IO-08).

States have, on the other hand, viewed IOM as an organization that can assist in emergency situations, and, perhaps more importantly, does not have a normative mandate. After IOM's intervention during the first Gulf War to repatriate migrant workers from Kuwait (Section 7.4), IOM has attracted significant funds for its work with populations that have been displaced, including refugees but also other migrants. In McGregor (2019), I draw on project descriptions for all voluntary earmarked contributions made by Member States and the European Union (until 2005) and the European Commission (from 2006) $(n=13,306)$ in order to review the patterns of contributions made to IOM between 2000 to 2016. For the top 10 donors plus the European Commission, which accounted for 86.6 per cent of all voluntary contributions from Member States across the period under review, projects related to refugees accounted for over one fifth $(21.2 \%)$ of IOM's revenue from these donors. Furthermore, 13.5 per cent of IOM's projects related to work in emergency settings, 6.6 per cent for work with internally displaced persons, and 4.7 per cent related to natural disasters. IOM are also actively involved in projects related to return $(18.0 \%)$, post-crisis reconstruction $(11.8 \%)$, and irregular migration $(3.6 \%)^{4}$. These numbers highlight the important operational role that IOM plays, not only for migrants who qualify for refugee status but also for vulnerable migrants who do not.

The fact that IOM and UNHCR both see a role for themselves in addressing the challenges faced by vulnerable migrants who fall outside of the refugee definition has led to tensions between IOM and UNHCR. As the example of Iraq (Section 7.4) demonstrated, 'there are very significant turf problems

\footnotetext{
${ }^{4}$ The percentages do not add up to 100 per cent because projects were categorized based on the identification of keywords. Some projects were therefore coded into multiple categories. Furthermore, the percentage is calculated based on the total value of each project as opposed to a count of projects with the specified keywords included in the short project description provided (McGregor, 2019).
} 
going on between UNHCR and IOM (INT-OTHER-0345). These tensions were, as predicted by Rinscheid (2015), accentuated by the 'migration crisis' and were arguably the reasons why states ultimately decided to negotiate two Global Compacts in relative isolation from one another.

\subsection{The High-Level Summit and the New York Declaration}

In February 2016, the President of the General Assembly (PGA) appointed Ambassador Dina Kawar of Jordan, and Ambassador David Donoghue of Ireland to co-facilitate the High-Level Summit, and to prepare an outcome document for the meeting, which would become the New York Declaration (NYD) ${ }^{6}$. During the negotiations, a two-year process was envisaged for both Compacts. However, for some states, this was not acceptable, and they tried to push for quicker results:

'During the negotiations, the idea that the Summit
would launch a process of negotiations leading to the
adoption of two Global Compacts was subject to some
controversy. There was concern that an agreement
needed to be reached, particularly with respect to the
ongoing crisis in Syria, as soon as possible. Shortly
before the High-Level Summit, therefore, it was agreed
that a Comprehensive Refugee Response Framework
would be annexed to the NYD as a 'down payment, a
first draft of what would become the Global Compact on
refugees' (INT-GOV-027).

The US also wanted to see quicker results and, the day after the High-Level Summit was due to be held, Barack Obama hosted a Leaders' Summit for Refugees to secure commitments for refugees. Despite some controversy in the lead up to the High-Level Summit on 19 September, however, the NYD was unanimously adopted on 19 September 2016. Mirroring the structure of

\footnotetext{
${ }^{5} \mathrm{~A}$ similar argument was also presented in INT-IO-015

${ }^{6}$ New York Declaration for Refugees and Migrants, UNGAOR. 71 ${ }^{\text {st }}$ Session, UN Doc. A/RES/71/1 (3 October 2016)
} 
Karen AbuZayd's report, the NYD was structured around three sets of commitments: commitments for migrants, commitments for refugees, and commitments for migrants and refugees.

The NYD received a mixed reception. On the one hand, some viewed the NYD positively for its clear and consistent references to human rights:

'We were very, very happy with the New York Declaration, and we think that it is a human rights-based document' (INT-IO-040).

The human rights nature of the document has also been noted in the academic literature on the NYD (cf. Gest et al., 2019; Guild et al., 2019). Guild et al. (2019), for example, point to the fact that there are more than 30 references to human rights in the NYD. An arguable by-product of the inter-subsystem tensions between the migration and refugee subsystems, which ultimately led to the decision to develop two distinct compacts, was that it also allowed the humans-rights advocacy coalition to frame the discussion on migration in a protection framework:
'Almost by accident, migrants became integrated into a protection discussion. Because both migrants and refugees were included in the New York Declaration, it became inconceivable to speak about migrants different from refugees from a human rights perspective. This then prompted the migration compact to become more and more of a human rights instrument' (INT-IO-040).

However, others have been more critical. As Doyle (2018) noted: 'the New York Declaration was long on principles but short on specific commitments' (p.618). There was a concern that the New York Declaration, and subsequently, the Global Compacts represented acceptance of a new more informal system of global governance, at the expense of legally binding global norms:

'The New York Declaration has behind it, an interest by some of its proponents to set a non-binding framework that can be put out there as a model for policy and governance that will substitute for an obligation, or a 
sense of obligation to adhere to the much higher normative standards that are embodied in, particularly, the International Convention on the Protection of the Rights of all Migrant Workers and Members of their Families and the two complementary ILO Conventions' (INT-IO-012).

The argument embedded here is that the global compact process essentially legitimized a migration management approach to migration. Although the GCM is framed in terms of human rights, it is underpinned by another agenda (Jubilut and Casagrande, 2019; Delgado Wise, 2018b). The main argument is that the GCM represents the interests of proponents of the migration management frame to 'depoliticise migration, obfuscate the existence of divergent interests, asymmetries of power or conflicts, avoid obligations imposed by international law and promote the idea that managing migration can be beneficial for all stakeholders: countries of destination, countries of origin, migrants themselves and their families' (Delgado Wise 2018b, p.1-2). The main fear is that the non-binding nature of the Compacts allows states to retract from existing commitments and thus weakens normative instruments and ushers in a new form of international organization which reflects the interests of the world's most powerful states (Gammeltoft-Hansen, 2019; Ferris and Donato, 2019; Gest, Kysel, and Wong, 2019; Gilbert, 2019; Majcher, 2019). As Gammeltoft-Hansen (2019) noted, 'the compact as a choice of instrument tends to place emphasis on political and practical cooperation as opposed to legal commitments' (p.606).

While largely united during the process leading up to the adoption of the SDGs (Chapter 6), therefore, the 'migration crises' arguably brought underlying frame conflicts back to the surface. However, other changes also had implications for the international landscape.

\subsection{The Changing of the Guards}

Chapter 7 discussed the 'perfect storm' that resulted in IOM's admission into the UN system as a 'related agency.' Shortly after IOM joined the UN, however, several other changes occurred which had implications for the negotiations of the Global Compacts. The first significant change was that 
Peter Sutherland, who, as discussed in the pages of this dissertation, had spent more than a decade advocating for the UN to take on a more visible and concrete role on migration, became gravely ill and was unable to continue in his role as the SRSG:

\begin{abstract}
'Peter Sutherland's illness prevented him from participating in the UN Summit on Migration and Refugees in September 2016. This global meeting was very much the product of his active promoting of a more active UN role in these issues. IOM's closer association was one of the outcomes. I am not sure that he would have liked some other aspects of it...(such as) the two "separated, distinct and independent" global compacts, for refugees and for migrants. For my part, I consider it disastrous...My long experience with refugees has taught me how thin and variable can be the distinction between a refugee and a migrant' (INT-IO-026).
\end{abstract}

Peter Sutherland's tasks were temporarily taken over by Karen AbuZayd, who, as noted, became Ban Ki-moon's Special Adviser on the Summit on Addressing Large Movements of Refugees and Migrants. Later, when it became clear that Sutherland would not be able to resume his post (United Nations Archives, 2016), Louise Arbour was appointed as the Special Representative of the Secretary-General on International Migration in March 2017. Her title is the first indication of a shift in the way migration was framed:

'What is interesting, for example, is that when Louise Arbour replaced Peter Sutherland, her title was Special Representative of the Secretary-General on International Migration. Development was eliminated from the title because now states consider that migration is a $\mathrm{UN}$ topic' (INT-IO-013).

With the appointment of Louise Arbour, Sutherland's team was effectively disbanded (INT-IO-002; INT-IO-006; INT-IO-016). Her appointment was welcomed, particularly by advocates of a rights-based approach to migration: 
'At least Louise Arbour was earlier a Human Rights
Commissioner...so she has a much clearer idea about
migration and the rights-based approach' (INT-IO-011).

One significant difference between the team supporting Sutherland and the team supporting Arbour is that the latter was institutionalized within the UN. Where Sutherland had operated at the margins of the UN, the establishment of Louise Arbour's team provides further evidence of the institutionalization of migration into the UN:

'Peter did not have a physical office. The people who were working with him all had contracts with different organizations, so there was not one kind of institutional home: it was all a bit of a patchwork, a virtual office arrangement. Whereas it is much more institutionalized and formalized now, and Louise has formalized responsibilities' (INT-IO-006).

In addition to supporting the Global Compact negotiations, one of the responsibilities of Louise Arbour's office was to manage the entry of IOM into the UN and to mediate the sensitivities that surrounded its membership. With states recognizing IOM as the global lead agency on migration in the $\mathrm{NYD}^{7}$, some concern among existing members of the UN system could be observed:

'UNDESA saw itself as being the central, leading, coordinating agency, but the dynamics shifted significantly when IOM entered the system. Louise Arbour's office was set up to address that dynamic... But then agencies like ILO and OHCHR continue to have reservations, and a lot of that boils down to IOM's status as a non-normative organization which, for those organizations which have normative mandates

\footnotetext{
7 Paragraph 49 of the New York Declaration states: 'We commit to strengthening global governance of migration. We therefore warmly support and welcome the agreement to bring the International Organization for Migration, an organization regarded by its Member States as the global lead agency on migration, into a closer legal and working relationship with the United Nations as a related organization' (A/RES/71/1).
} 
themselves, is seen as being quite troublesome' (INT-IO016).

This arguably fed into the concern that, although the NYD had promoted a rights-based approach to migration, the negotiations of the GCM would reflect a continuation of the existing informal and non-binding approach to migration governance from a migration management perspective.

IOM's integration into the UN also took place during a period of UN reform. On 1 January 2017, former UN High Commissioner for Refugees, António Guterres, replaced Ban Ki-moon as Secretary-General of the UN. Shortly after becoming Secretary-General, Guterres initiated a management review and subsequently announced plans to reform the UN. The main goal of his reform was to make the UN 'less fragmented and reactive ${ }^{8}$ ' (para. 16, p.7). A key part of his reform agenda was the restructuring of the UN Development System ${ }^{9}$. This includes steps to improve the efficiency of UN Country Teams by, among other reforms, delegating more authority to Resident Coordinators, encouraging organizations to share premises and back offices (at least 50 per cent by 2021), charging a one per cent coordination levy on all earmarked contributions and advocating for an increase in voluntary funding. Another was a shift in the 'management paradigm' based on three principles: simplification, decentralization, and delegation ${ }^{10}$. Accordingly, 'the UN that we (IOM) joined in 2016 was a very different animal from what it is now' (INT-IO-041).

External to the UN, change was also afoot that challenged the multilateral project. On 23 June 2016, the British public voted in a Referendum on their membership in the EU. The resulting vote, marginally in favour of leaving the EU, triggered several years of negotiations, which ultimately resulted in the UK leaving the EU on 31 January 2020. As one interviewee mused:

\footnotetext{
${ }^{8}$ Report of the Secretary-General on the work of the Organization, UNGAOR, $72^{\text {nd }}$ Session, UN Doc. A/72/1 (28 July 2017)

${ }^{9}$ Report of the Secretary-General on the work of the Organization, UNGAOR, $73^{\text {rd }}$ Session, UN Doc. A/73/1 (13 August 2018) and Operational Activities for Development of the United Nations System, UNGAOR, 72 ${ }^{\text {nd }}$ Session, UN Doc. A/RES/72/236 (20 December 2017)

${ }^{10}$ Report of the Secretary-General: Shifting the Management Paradigm in the United Nations: Comparative Assessment of Human Resources Structures, UNGAOR, 73 ${ }^{\text {rd }}$ Session, UN Doc. A/73/366 (5 September 2018)
} 


\begin{abstract}
'After Brexit, has there ever been a worse time to try to get to a global understanding and common agreement on migration management? I think there has never been a worse time to start discussing it, and it became worse after Trump won' (INT-IO-003).
\end{abstract}

Furthermore, shortly after the adoption of the NYD, on 9 November 2016, Donald Trump was elected the $45^{\text {th }}$ president of the US, marking the start of an era of American isolationism. His election platform was centred around the idea of 'America First' and, in his years in office, thus far, he has pulled the US out of several multilateral agreements. One such withdrawal was his decision in December 2017 to remove the US from the negotiations of the GCM citing incompatibility between the provisions of the NYD and US immigration policy:

'The global approach in the New York Declaration is simply not compatible with U.S. sovereignty' (U.S. Mission to the United Nations, 2017).

Despite the apparent crisis of multilateralism, the negotiations continued, and, against all the odds, a GCM emerged alongside the GCR. One factor that may have contributed to the perceived ease of the GCM negotiations (Section 8.5) was Trump's withdrawal from the negotiation process. Trump's withdrawal from the GCM is arguably also why, after being a US-led organization for the best part of its history, the new head of IOM, António Vitorino of Portugal, was elected over the US' candidate Ken Isaacs to become the new Director-General of IOM on 29 June $2018^{11}$. As one interviewee noted: 'it was a gift from Trump' (INT-OTHER-039). However, as argued earlier in the chapter, the way the Compacts emerged, and their reception, may also have been a product of the historical differences between the migration and refugee policy subsystems.

${ }^{11}$ He took office on 1 October 2018. 


\subsection{Negotiating the Global Compacts}

While the NYD envisaged three sets of commitments, for migrants, for refugees, and for 'migrants and refugees', this third set of commitments mostly fell through the cracks because the GCM and GCR negotiations took place in relative isolation from one another:

'If you read the New York Declaration, it is quite different from the development of the Global Compacts. The New York Declaration makes commitments for refugees and migrants and then for refugees separately and migrants separately, three types of commitments. But if you look at the development of the two Global Compacts, you can see that there is no mechanism, legislated by the General Assembly, to ensure that there are commitments for both refugees and migrants' (INTIO-029).

As shown in Figure 8.1, from the same origin point, the 'migration crises', the GCM and GCR were negotiated in parallel but separate negotiations. However, as theorized in the introduction and as the further examination of the negotiations (Section 8.51. and 8.5.2) demonstrates, their outcomes were perceived very differently (summarized in Table 8.3). As GammeltoftHansen (2018) argued: 'while the migration compact may potentially come to fulfil such a role (as soft law filling gaps in treaty law) with regard to the more fragmented and rudimentary area of international migration law, the Refugee Compact enters a far more well-established normative terrain' (p.607). This supports the notion that the impact of crises on unitary policy subsystems will be less pronounced than for collaborative or adversarial subsystems 
Table 8.3 Comparing the Negotiations of the GCR and GCM

\begin{tabular}{|c|c|c|}
\hline & GCR & GCM \\
\hline $\begin{array}{l}\text { Subsystem } \\
\text { Characteristics }\end{array}$ & Unitary & Collaborative/Adversarial \\
\hline Negotiations & UNHCR led & State-led \\
\hline In Favour of Compact & $\begin{array}{l}181 \text { in favour, } \\
\text { Three abstentions }\end{array}$ & $\begin{array}{l}152 \text { in favour } \\
12 \text { abstentions }\end{array}$ \\
\hline $\begin{array}{l}\text { Not in Favour of } \\
\text { Compact }\end{array}$ & Two: Hungary and US & $\begin{array}{l}\text { Five: Czech Republic, } \\
\text { Hungary, Israel, Poland, US }\end{array}$ \\
\hline Main Controversies & $\begin{array}{l}\text { Inclusion } \\
\text { commitments }\end{array}$ & $\begin{array}{l}\text { US withdrawal in November } \\
\text { 2017; the challenge to state } \\
\text { sovereignty, non-binding } \\
\text { nature, references to refugees }\end{array}$ \\
\hline Views on the Compact & $\begin{array}{l}\text { Negative to neutral. } \\
\text { Lack of ambition, } \\
\text { preserves the existing } \\
\text { system but has the } \\
\text { potential to bring more } \\
\text { money into the } \\
\text { humanitarian system. }\end{array}$ & $\begin{array}{l}\text { Both positive and negative } \\
\text { with the potential for the } \\
\text { GCM to become soft law } \\
\text { furthering a rights-based } \\
\text { approach to migration touted } \\
\text { as its main contribution. }\end{array}$ \\
\hline
\end{tabular}

\subsubsection{The Global Compact on Refugees}

In Annex 1 of the New York Declaration, the High Commissioner for Refugees was invited to submit a proposal for a Global Compact on Refugees with his 2018 annual report to the General Assembly (para 19). Since the Comprehensive Refugee Response Framework (CRFF) had already been agreed upon in the New York Declaration, the central area of work for UNHCR was the application of the CRRF and the preparation of a programme of action. For the first task, UNHCR created a Task Team on Comprehensive Responses. UNHCR then organized a series of thematic sessions in Geneva in 2017 covering a range of topics. At the thematic sessions, inputs were gathered from Member States and other experts. Like the GCM process, these sessions were followed up by a stocktaking phase. After the stocktaking phase, UNHCR prepared the draft compact, which was presented to Member States and other stakeholders in a series of consultations held between February and July 2018 (UNHCR, 2017). 
Unlike the GCM (Section 8.5.2), UNHCR led the process of developing the Global Compact on Refugees (GCR) and not states.

'UNHCR wrote it. The GCR is based on their
Comprehensive Refugee Relief Framework. The
governments influenced the consultations, but it was
ultimately what UNHCR wanted to put out. UNHCR
was afraid that if they went too far, the governments
would say no and not sign off on it. They were quite
conservative in what they chose to put in the Compact'
(INT-OTHER-034).

The drafted GCR was first put to the vote by the Third Committee of the General Assembly ${ }^{12}$ on 13 November 2018 and received 176 votes in its favour with only the US opposing the resolution ${ }^{13}$. While a vote on a resolution related to the work of UNHCR was unprecedented in the Third Committee, Türk (2019) argued that it 'showed how seriously States take the responsibilities set out in the Compact and the importance they attribute to it, as well as how such a non-binding text could nonetheless influence State behaviour' (p.580).

However, the literature on the GCR thus far has been mostly critical (c.f. (Aleinikoff, 2019; Betts, 2018a; Chimni, 2019; Costello, 2019; Hathaway, 2019). The main criticisms levied towards the GCR are that it: 1 ) fails to provide any concrete solutions to the question of 'responsibility sharing' (Chimni, 2018, Hathaway, 2018); 2) does not adequately address the 'root causes' of displacement; and 3) dilutes existing commitments (Chimni, 2018). Aleinikoff (2019) suggested that 'it would be better to think of the Refugee Compact as a ratchet - preventing backward slippage and creating opportunities for forward movement' (2019, p.612). Betts (2018) suggested that 'its basic aim, though, is to get more resources into the system rather than to change the system' (p.625).

The GCR also reinforced the refugee-migrant dichotomy by failing to address the situation for vulnerable migrants in refugee-like situations meaningfully. Evidence suggests that, throughout the negotiations, references that implied

\footnotetext{
12 The Third Committee of the General Assembly addresses matters relating to social, humanitarian, and cultural issues.

${ }_{13}$ Thirteen countries were not present.
} 
any kind of commitment to protecting those who did not fulfil the criteria established in the 1951 Refuge Convention were toned down (Aleinikoff, 2018). A byproduct of state pressure on UNHCR to limit the scope of the GCR, however, was that many of these issues ended up in the GCM (Aleinikoff, 2018). As one observer noted:

'I think the refugee compact is a weaker document because the US was in the room. And not because the US would have said anything, but because the assumption was that the US would not go along with it if certain issues were raised. It is self-censorship on the part of UNHCR and some of the other governments' (INTOTHER-034).

Ultimately, when put to the vote at the UN General Assembly on 17 December 2018, 181 Member States voted in favour of the GCR. Despite participating in the negotiations, when it came to the vote, the US, along with Hungary, voted against the GCR.

\subsubsection{The Global Compact for Safe Orderly and Regular Migration}

After laying out an initial roadmap in Annex II of the New York Declaration, the General Assembly adopted a resolution on the negotiation modalities on 6 April 201714. The President of the General Assembly appointed the Permanent Representatives of Mexico and Switzerland to facilitate the negotiations. The process included three phases: 1) preparatory, 2) stocktaking and 3) negotiations. During the preparatory phase, thematic and regional consultations were organized with a range of different stakeholders, which were fed into a stocktaking conference organized in Puerto Vallarta, Mexico, in December 2017. After the Stocktaking conference, the SecretaryGeneral released a summary report entitled 'Making Migration Work for All', following which the co-facilitators prepared a draft compact, which was then discussed in six rounds of negotiation between February and July 2018.

\footnotetext{
${ }^{14}$ Modalities for the Intergovernmental Negotiations of the Global Compact for Safe, Orderly and Regular Migration, UNGAOR, 71st session, UN Doc. A/RES/71/280 (6 April 2017)
} 
Accordingly, between 5 February 2018 and 13 July 2018, seven drafts of the GCM were released. An examination of how the key objectives of the GCM evolved during the negotiations highlights a minimum of controversy (Annex 8.1), although, as Newland (2019) noted, the co-facilitators kept a 'tight grip on the text' (p.657). Of the initial 22 objectives in the Zero draft, 13 appeared unaltered in the final draft. Of the remaining objectives, most of the revisions can be described as relatively minor. For example, instead of providing 'adequate' information, Objective 3 specifies that the information should be 'accurate', which is essentially a condition of its adequacy. In some cases, the revision makes the objective more ambitious. For example, Objective 10 expanded its goal to include the eradication of trafficking. Objective 12 was the most controversial. In its first formulation, Objective 12 referred to status determination, a process firmly under the mandate of UNHCR, and therefore, from the perspective of those wishing to keep the refugee and migration regimes separate, an issue that was better placed in the GCR.

After a relatively uneventful negotiation, and as the 'Intergovernmental Conference to Adopt the Global Compact for Safe, Orderly and Regular Migration' in Marrakech on 10 and 11 December 2018 approached, states, particularly in Europe, became anxious about the implications of the GCM (Guild et al., 2019). As Becker (2020) observed: 'a global network of nationalist, far-right activists fuelled a surge in social media activity by framing "compact" as a threat to national sovereignty thereby putting a spotlight on the negotiations' (p.1). Three days before the meeting, and despite repeated assurances from UN officials, the US fuelled the fire by releasing a new statement on 7 December:

'We believe the Compact and the process that led to its adoption, including the New York Declaration, represent an effort by the United Nations to advance global governance at the expense of the sovereign right of States to manage their immigration systems in accordance with their national laws, policies and interests' (United States Mission to the United Nations, 2018 in Guild et al. 2019, p.44).

Perhaps the most extreme example of how the GCM affected national politics is the case of Belgium, where the Flemish nationalist party, Nieuw-Vlaamse 
Alliantie ${ }^{15}$ withdrew from the governing coalition over their disagreement with the Prime Minister's decision to endorse the GCM (Birnbaum, 2018; Schultheis \& Calamur, 2018).

Duncan (2019) refers to the GCM as 'one of the most important acts of policymaking in the migration field' (p.4). The very fact that the GCM exists has been hailed as 'the beginning for the global regulation of migration' (McAdam 2019, p.5736). Despite being non-binding, the GCM holds the potential to have legal effects as it builds on existing human rights and other obligations (Costello, 2019; Guild et al., 2019). Particularly given the context in which the Compacts were negotiated, with rising nationalism and a disdain for multilateralism, it is an achievement that they even came into being (Ferris and Donato 2019). However, as discussed, this is also the reason why several UN Member States withdrew from or voted against, the GCM.

Despite the last-minute controversy, the GCM was officially adopted at the intergovernmental conference on international migration in Marrakesh on 11 December 2018, with 164 Member States in attendance. At the General Assembly on 19 December 2018, the Global Compact for Safe Orderly and Regular Migration (GCM) was endorsed by the General Assembly. A total of 152 Member States voted in favour of endorsing the GCM. Five Member States voted against it (Czech Republic, Hungary, Israel, Poland, US), and 12 Member States abstained ${ }^{17}$. Twenty-four States did not vote (Ferris and Martin 2019). Among the countries in favour of the Compact, the Philippines hailed its endorsement as 'a triumph of multilateralism', a sentiment shared by many other Member States including Comoros, Morocco, and Namibia, who spoke on behalf of the Africa Group (United Nations, 2018b). The recurring theme of their statements was that a vote in favour of the GCM was a vote in favour of multilateralism, particularly given that the GCM was the product of two years of multilateral negotiations. Many Member States, including Belgium, Croatia, Denmark, Estonia, Finland, France, Georgia, Iceland, Lithuania, Malta, the Netherlands, Turkey, Peru, and the UK, while endorsing the Compact, did, however, emphasize its non-binding nature and the fact that it did not affect state sovereignty in matters related to migration.

\footnotetext{
15 The New Flemish Alliance

${ }^{16}$ A similar observation is made by Klein Solomon and Sheldon (2019).

${ }^{17}$ For a full list of the votes see United Nations (2018b)
} 
Among opposing states, the US reiterated its position of the incompatibility of the Compact with its sovereignty. Poland signalled a similar position. Hungary described it as an 'unbalanced, biased, and pro-migration document' and considered its endorsement a mistake (United Nations, $2018 b)$. The biggest concern of the Czech Republic, who had opted not to attend the meeting in Marrakech the week before the General Assembly, was the failure to make a clear distinction between 'legal' and 'illegal' migration. Libya shared this view and abstained from the vote.

Several European countries were among those abstaining from the vote. Romania abstained because, despite recognizing that the GCM was not legally binding and represented a 'menu of policy actions', wished to take a balanced position ahead of taking over the Presidency of the European Union Council (United Nations, 2018b). Several of the countries that abstained from the vote, such as Singapore and Bulgaria, acknowledged several positive aspects of the Compact but chose to abstain because they were 'not in a position to adhere fully to certain commitments' (United Nations, 2018b). In other cases, the necessary parliamentary agreement had not been reached to allow a vote to be made. Interestingly, Switzerland, while the co-facilitator of the GCM, did not attend the meeting in Marrakesh and abstained from the General Assembly vote for this reason.

\subsection{Conclusion}

The case of the Global Compacts provides empirical support to the argument that policy change as a result of crises is less likely in a unitary subsystem as compared to adversarial or collaborative subsystems. The different configurations of the refugee and migration regimes, coupled with the US withdrawal from the GCM and participation in the GCR, seem to have made it easier for the discussion on migrants in refugee-like situations to take place within the context of the GCM process. Rather than bring more coherence to the global landscape concerning human mobility, the Global Compact process has arguably merely served to reinforce and perhaps exacerbate existing schisms.

For many of the individuals involved with discussions regarding migration at the global policy level, the GCM, while imperfect, represents the 
culmination of several decades of work. Gaining the agreement of states on the wording of a broad range of commitments on migration was likely facilitated by the fact that many of the same conversations had already occurred in the context of the GFMD (Chapter 5), the HLDs, and during the SDG negotiations (Chapter 6). Through the crafting of the SDGs, states developed and agreed upon common language, much of which is reflected in the text of the NYD and the GCM.

As Ferris and Donato (2019) eloquently word it: the adoption of the Global Compacts is 'both a symptom and a cause of fundamental changes in the global order' (p.3). The migration crises also brought frame conflicts back out into the open. Many countries, notably the US, share a concern that the GCM represents more than a non-binding agreement on migration. From the perspective of the US, the GCM represents an attempt by the UN to deepen its role. From the perspective of some human rights advocates, it is an attempt to further deepen the neoliberal project by advocating a technocratic and depoliticized approach to migration. For others, it offers the potential for developing soft law that can improve the way the international community responds to migration-related issues. How the GCM will impact migration governance at the regional and national levels remains an empirical question for the future. 


\section{Conclusion: International Organizations and Global Migration Governance}

\subsection{Introduction}

This dissertation has examined the role played by IOs in the evolution of global migration governance. Accordingly, global governance was defined as both the process and product of the interactions of resource-dependent actors operating in networks around different policy issues of international relevance. At its core, the dissertation was about power: the power of IOs to establish norms and rules to govern the behaviour of states regarding specific global policy problems Two core theoretical principles were central to its approach.

First, states delegate authority to IOs to address challenges where intergovernmental cooperation is deemed more efficient than unilateral efforts, often to achieve broader collaborative goals, such as global economic development or world peace. However, theory suggests that states will be unlikely to cede authority on matters that lead to the establishment of a new global order in which IOs, rather than states, become the main building block of the global system. The relationship between states and 'their' IOs is therefore theorized as one in which a careful balancing act exists between states delegating enough authority for IOs to be effective, but not too much that it would challenge state sovereignty. Migration has been challenging because the control of borders is at the heart of state sovereignty. While, like trade, the free mobility of people is central to neoliberal ideas about the virtues of a free global market economy, it questions one of the most central aspects of state sovereignty, the control of one's territorial borders. The idea of IOs having a key role in the governance of migration also cuts to the core of an ideological discussion regarding the role of the state in society. From a (neo)liberal perspective, states should intervene when markets fail. From a Marxist perspective, free mobility supplies the global market with a 'reserve army of labour', exerting downward pressure on wages and increasing profits. As the dissertation has shown, these deeply embedded ideological differences continue to characterize the discussion of migration at the global level. 
The second core theoretical principle was that IOs are able to exercise influence over states not only through the creation and enforcement of legal norms but also by shaping how policy problems are defined. Given the trend toward informal forms of multilateralism over the agreement of binding norms, this dissertation argues that this latter form of influence is increasingly important to understand the role of IOs in society. Reality construction is essentially about framing and framing how people think about an issue can influence how they think about solutions. In the current literature on IOs, a shift towards an ideational approach has focused attention on how IOs exercise autonomy through their power to frame: constitutive or symbolic power (Barnett and Finnemore, 2004). The focus of this scholarship has generally been on how individual organizations employ constitutive power to frame issues in a manner that justifies their existence. By situating the relationship between states and IOs within the context of the migration policy subsystem, and testing the potential of framing analysis as a methodological tool allowing for the implementation of interpretive process tracing, the dissertation has considered how different factors have influenced the way that migration has been framed as a global policy issue in order to explain how global migration governance has evolved.

Three dominant approaches to the framing of migration as a global policy issue were identified: the rights-based approach, migration management, and migration and development. Framing migration as an issue of rights has a long tradition, particularly within the UN. The driving force behind the development of norms in the area of migration was an interest, particularly among countries of origin, to protect the rights of migrant workers in countries of destination (Section 4.3). The argument of many of the actors framing migration in terms of rights is that, if the rights of migrants are upheld, then many of the problems associated with migration will be solved. In this context, migrant rights are human rights. The frame pursued through many of the regional consultative processes (Section 4.4) and amplified through IOM's International Migration Dialogues (IMD) and the State-led Berne Initiative (Section 4.6) was 'migration management'. Discussions focused on logistical aspects of human mobility that states could theoretically address more efficiently in cooperation with one another, often on topics such as irregular migration, border management, smuggling, and trafficking. The central premise of the 'migration and development' frame is that migration can be both positive and negative for development. Through policies targeting remittances, migrants can contribute towards development in their countries of origin. Next to being a frame in its own right, however, the 
'migration and development' frame can also be viewed as a unifying frame within which advocates of rights-based and management approaches can find common ground. The central thesis presented in this dissertation is that the UN employed the 'migration and development' frame in an attempt to overcome the polarization that had thwarted previous efforts to further international cooperation on migration within the UN.

Accordingly, the central research question guiding the study was:

How have international organizations influenced global migration governance?

As opposed to taking IOs as the unit of analysis, this dissertation took migration, as a global policy issue, as its unit of analysis in line with Advocacy Coalition Framework. Drawing on interviews with 43 key informants and archival analysis, and employing process tracing and framing analysis, the dissertation has traced how migration has evolved as a global policy issue over the past century with a specific focus on how IOs have affected and been affected by, these developments. The remainder of this concluding chapter is structured as follows. Section 9.2 summarizes the main findings of the research. Section 9.3 discusses the contribution of the dissertation to the academic literature. Section 9.4 considers the policy recommendations that arise from the findings of the study. Section 9.5 closes with some reflections on the limitations of the study and avenues for future research.

\subsection{Summary of the Dissertation}

Historical accounts of the evolution of global migration governance are often presented linearly. Yet it is evident that a degree of cyclicity exists in how global migration governance has evolved. Events, such as the 1973 Oil Crisis, the end of the Cold War, 9/11, and the 'migration crises' of 2015, have elevated the position of migration in the public consciousness, creating the momentum required to seek international solutions to specific migration-relevant challenges. Accordingly, the way migration has been framed as an international policy issue has evolved, driven by external factors such as decolonization, economic crises, and conflict, which have shaped both the 
patterns and governability of population movements. Furthermore, as the multilateral system has evolved, the environment within which migration is discussed at the global level has also been altered as the power hierarchy has shifted from a bipolar to a multipolar system. The changing composition of the UN's membership made it increasingly difficult to accommodate the diversity of views, which resulted in many contentious matters, such as migration, being addressed in other more informal multilateral settings. Accordingly, the journey of migration as a global policy issue can be viewed as a commentary of the multilateral project.

Chapter 4 established the context for the dissertation by analysing the evolution of the global migration governance landscape from 1919 to 2018 . The majority of the IOs with a mandated role in global migration governance today were established by 1951. Between 1939 and 1990, various attempts were made to develop binding norms to govern population movements. However, these attempts generally failed to gain the support of, primarily countries in the Global North, which arguably pushed the issue of migration outside the UN and arguably fuelled the proliferation of Regional Consultative Processes (RCPs) starting from the Intergovernmental Consultations on Migration and Asylum (IGC) in 1985. After the fall of the Berlin Wall in 1991, renewed optimism for international cooperation saw the UN hosting a flurry of conferences on a range of different issues, although attempts in the area of migration did not garner much support. By the turn of the century, interest in migration had increased, and then UN SecretaryGeneral Kofi Annan signalled his desire to see migration more comprehensively addressed by the UN. The launch of the GFMD in 2007 after the first-ever High-Level Dialogue on International Migration and Development (HLD) in 2006, renewed hopes for global cooperation in the area of migration. The GFMD represented an attempt to build on the trend of informal intergovernmental cooperation embodied in the proliferation of $\mathrm{RCPs}$, with a view to continuing involvement of the UN in the discussions while moving the conversation away from the matter of norm-setting and rights.

In 2006, Kofi Annan appointed Peter Sutherland to assist in his preparations for the first HLD. While Kofi Annan and Peter Sutherland likely had different motivations for wanting to see migration included more clearly as part of the UN's mandate, they were united in the goal of seeing international cooperation move beyond the impasse that had characterized the Cold War. Accordingly, as Chapter 5 demonstrated, framing migration as a 
development issue was at the centre of the UN's efforts to convince states to deal with migration within the context of the UN. The 'migration and development' frame was strategically invoked to calm the fears of some Member States wary of the idea that the GFMD would lead to the creation of a World Migration Organization. By focusing on migration and development, as opposed to the human rights of migrants, or managementrelated issues, space was created for actors with different frames of reference to come together, to build trust, to further international cooperation on migration. Chapter 5 highlighted the strategic relocation of international dialogue on migration to a non-UN venue alongside the deliberate omission of human rights to progress the discussion without the alienation of certain powerful states, most notably, the US. The ongoing existence of the GFMD provides evidence of the resonance of the 'migration and development' frame.

The success of the GFMD in creating shared narratives around migration from a development perspective facilitated the inclusion of several migration-related references in the Sustainable Development Goals (SDGs) in 2015. As the diversity of references to migration in the SDGs discussed in Chapter 6 demonstrated, the 'migration and development' frame has assumed, if not resolved, frame conflicts. From a framing perspective, the comparison of the arguments made for the GFMD, with the calculated omission of human rights, with the arguments made for the inclusion of migration in the SDGs, which captured human rights within a broader migration and development perspective, shows that frames are not static and evolve. However, the conflict between adherents to the human rights and management frames remained unresolved. For some Member States, such as Ecuador, Mexico, and Switzerland, bringing migration into the post-2015 development agenda was a way of furthering the institutionalization of migration within the UN. With the acceptance of migration as a UN issue, not only in connection with development, the necessity of having a UN body to coordinate its work on migration emerged, and, faced with the choice between the creation of a new UN agency for migration or accepting the entry of IOM to the UN system, its Member States chose for the latter (Chapter 7). For some, the inclusion of migration in the SDGs was the step required to bring IOM into the UN, lending weight to the migration management frame. For others, it was an opportunity to renew past efforts to develop universal norms and to re-establish a place for migration under the UN's human rights instruments. Ultimately framing migration as a development issue has been a vehicle for bringing migration into the $\mathrm{UN}$. 
However, the migration crises of 2015 brought further attention to global migration governance and revealed the limits of the existing international architecture. As Chapter 8 demonstrated, the migration crises led to increased polarization both within the migration subsystem, but also with the refugee subsystem. Rather than bring more coherence to the global landscape concerning human mobility, the Global Compact process, which has its origin in the migration crises of 2015, has arguably merely served to reinforce existing schisms. The US withdrawal from the Compact negotiations owing to its perceived incompatibility with the sovereign right of states to control their borders, brings us back to the starting point of our discussion. Global migration governance has been challenging because it is not only about migration; it is also about how the process of international organization should function. Ultimately, the discussion on whether migration should be in the UN comes down to fundamental beliefs about the role of the UN and its organizations in the world. As an IO, the UN has become what its Member States want it to become. However, not all Member States are equal. However, as the balance of power in the global system evolved, with the end of the Cold War and the rise of a multipolar world, the nature of multilateralism has also changed. Whereas in the post-Second World War, the decision of the US to withdraw from a process almost inevitably led to its failure, in a multipolar world, this is no longer valid.

Hence the dissertation argues that it is a range of factors including the migration crises of 2015 which propelled migration into the political limelight; the reframing of migration as a development issue (Chapter 5) and the subsequent inclusion of migration in the Sustainable Development Goals (Chapter 6); coupled with the threat of IOM's exclusion and the creation or appointment of a new lead agency for migration within the UN, that led its Member States to acknowledge the necessity of IOM becoming part of the UN system in 2016 (Chapter 7). However, while the migration crises of 2015 created the necessary 'window of opportunity' to bring IOM into the UN, it also provided a fertile environment for advocates of the migrant rights frame to revive their struggle for universal norms to govern international migration (Chapter 8). The global migration governance continues to be characterised by frame conflicts. 


\subsection{Contribution to the Literature}

This section outlines the most relevant methodological and theoretical contributions that the dissertations add to the literature.

The dissertation offers a methodological contribution to the literature on IOs. Often the study of IOs takes a specific organization as unit of analysis, whereas this dissertation offers an approach that takes the policy issue as its main unit of analysis. By employing process tracing informed by the Advocacy Coalition Framework, the dissertation has traced the evolution of migration as a global policy issue. A similar approach may be applied to the evolution of other intractable policy challenges, such as climate change. The dissertation also fills a gap in the IR literature in the sense that migration is not often taken as a case study.

This dissertation has demonstrated that an examination of how migration has evolved as a global policy issue provides empirical evidence that supports much of the theoretical literature in IR on how multilateralism has evolved. As the world has evolved, so too have the concepts used to describe it. Cohen (2018) argues that multilateralism has a life cycle and that the success of early multilateral efforts in shifting the balance of power in the international system towards a multipolar model based on the principle of universality, has in fact made it increasingly difficult to reach agreement in a multilateral setting, an argument evident in the realist writings of the early 1990s (Kahler, 1992). Hence, multilateralism, as a 'problem solving strategy or organizing principle' (Cohen, 2018, p.4), has evolved and matured over time (Kahler, 1992; Weber, 1992; Van Langenhove, 2010) which has led to the emergence of concepts such as Multilateralism 2.0 (Van Langenhove, 2010), and 'new multilateralism' (Villanueva Ulfgard \& Alejo Jaime, 2014) to describe the range of alternative approaches to multilateral cooperation that have proliferated, particularly since the end of the Cold War. The account of migration's journey as a global policy issue presented in this dissertation can be viewed as a commentary on the evolution of multilateralism in the $20^{\text {th }}$ and $21^{\text {st }}$ centuries.

The dissertation also contributes evidence to the body of literature on discursive institutionalism. Schmidt (2010) calls on researchers to focus on showing, by empirical means, 'how, when, where and why ideas and discourse matter for institutional change, and when they do not' (Schmidt, 
2010, p.21). The case of migration has illustrated how the UN, through the work of Peter Sutherland and his team, have employed discursive tactics to further international cooperation. The empirical findings of the dissertation show how the 'migration and development' frame was instrumentalized for the purpose of furthering international cooperation on migration. While it is clear that institutional change cannot be solely attributed to the role of individual 'entrepreneurs' or 'reframers', they play a role in creating the necessary space for dialogue and the development of common language. The relative banality of the GCM negotiations demonstrates the strategic relevance of reframing an issue in order to move beyond an impasse, a tactic that may be applied to other intractable policy problems

Finally, the dissertation also offers a contribution to the growing literature on the behaviour of IOs. Chapter 7 provides evidence that IOM, as theory would lead us to expect from an $\mathrm{IO}$, is sensitive to changes in its environment responding to external events that present both opportunities and threats to its existence. However, the same can also be observed for other organizations, such as ILO in the 1950s, UNHCR from the 1980s, and DESA since the IOM joined the UN.

\subsection{Policy Implications}

The primary policy-relevant suggestions arising from this dissertation relate to the importance of being aware that global problems are defined through the struggles of different actors, not limited to IOs, to achieve certain goals. Strategically framing an issue in a specific way, with the underlying motivation to achieve an unstated goal, may lead to unintended consequences. For example, it may allow funding to be diverted towards issues that serve unilateral interests. The focus on migrants as development actors may dilute the responsibility of states to provide development opportunities to their populations. Rein and Schon (1996) make the argument for a frame-reflexive approach to public policy and, in particular, to developing educational programmes that prepare future policymakers to be critically aware of how problem-framing influences policy. Students should be encouraged to ask questions such as: how is the problem being framed? What solutions does a particular problem formulation imply? Moreover, whose interests do they serve? 
Another framing related suggestion relates to being aware of how linking two issues together can be used in a strategic way to achieve particular goals. Therefore, when people start linking different topics to migration, one might wish to critically question the underlying reasoning. One of the initial hurdles that proponents of the 'migration and development' frame claimed to have overcome when they wanted to see migration included in the post-2015 development agenda was the use of migration as a 'scare tactic' to compel action on climate change. Migration is an issue that cuts across all aspects of society. Migration touches on issues of identity and is politically emotive. Actors using migration as a way of elevating other issues up the international agenda should be conscious that the consequences of doing so may lead to the reinforcement of xenophobia and, ultimately, worse outcomes for migrants and societies in general. Brexit is perhaps the best contemporary example of how this can play out in practice.

The reverse may also be true. The outcry against the GCM as a challenge to sovereignty reflects more deep-seated fears that a new political system that transcends the state is slowly being built by advocates of a new global order. This may lead those interested in maintaining their sovereignty to find alternative ways of asserting their authority and redefining multilateralism. Although a rapidly evolving issue, a contemporary example of this can be found in the response of many states, including the US, to the COVID-19 pandemic. At the time of writing, the US had frozen its contributions to the World Health Organization and was also threatening to withdraw from the organization over concerns regarding its handling of the pandemic.

\subsection{Limitations and Avenues for Future research}

The focus of this dissertation has been on how IOs exercise constitutive power in order to shape the decisions made by states with regards to how migration is governed at the global level. Through framing the research project in this way, several avenues of investigation inevitably remain unexplored. Thus, in closing the dissertation, this section reviews some potential areas for future research that also respond to its inherent limitations.

The first avenue for future research is the application of the same methodology to a different policy area. A testable proposition would be that 
a similar trajectory would be identified when tracing the evolution of governance in other intractable policy issues. Applying the methodological approach to a different policy area would serve to add robustness to the argument that the evolution of global migration governance provides insights into the evolution of multilateralism more broadly. Another means of increasing the robustness of the findings would be to test its results through the inclusion of more voices from the Global South.

Another area for future research would be to investigate the impact of changes in the way migration has been framed at the global level on what has happened at the regional and national levels, and vice versa. The dissertation has focused on what happened at the global level, but governance happens at different levels, from the household to the global. To a certain extent, this is one of its main limitations. While I can say with relative certainty that IOs seek to influence the actions of states through the creation and maintenance of frames that shape the way states think about the necessity for international cooperation on migration-related issues, I cannot make any conclusive remarks regarding the effects that this has on the level of national policymaking. While the inclusion of migration in the SDGs, IOM's entry into the UN system as a 'related agency' and the adoption of two Global Compacts, provides evidence that states have deemed migration to be an issue that merits the attention of the UN, the fact that all these commitments are non-binding, and make use of constructive ambiguity in their framing, means that their actual impact on what happens on the ground remains to be seen. Particularly given the pertinence of sovereignty and state emphasis on the non-binding nature of the GCM, one might anticipate the impacts to be modest. One way of investigating the impact of the 'migration and development' frame on the behaviour of states would be an examination of how migration policies have evolved. Building on the policy diffusion and policy transfer literature, this avenue of research could seek to investigate the impact of the global discourse on national policymaking. Some initial support for the diffusion of the 'migration and development' frame can be seen in the proliferation of diaspora institutions across the world (Gamlen, 2014).

Another relevant area for further research would be an examination of how states use IOs to influence other states. One way of investigating this would be to 'follow the money.' The influence of earmarked funding has been alluded to in the dissertation. States have increasingly used earmarked funding to pursue areas of international cooperation that are neither suitable nor politically feasible to address at the global level. A growing body of 
literature exists that examines the relationship between earmarked funding and governance and to which I have already contributed (cf. Graham, 2015; 2017a; 2017b; Bayram and Graham, 2017; Gray, 2014; Seitz and Martens, 2017; McGregor, 2019). In the context of UN reforms (Section 8.4) where, on the one hand, the Secretary-General is promoting a process of decentralization and on the other encouraging less earmarked funds, there is, at least rhetorically, a desire to return to a purer form of multilateralism within the UN. How these reforms play out will be an area of relevance for future empirical work.

A notable characteristic of contemporary multilateralism is the relevance of non-state actors to global governance. While this dissertation has focused on a narrow subset of IOs, it is clear that another relevant line of inquiry is the role of other forms of IOS, including regionally-oriented intergovernmental organizations as well as non-state actors in supporting or opposing particular frames. The role of civil society in challenging the 'migration and development' frame as a way of depoliticizing migration and furthering the technocratic migration management approach to its governance has been alluded to in the pages of the dissertation and is the subject of an emerging body of literature (cf. Jaeger, 2007; Piper and Rother, 2012; Rother, 2013; Piper, 2015; Delgado Wise, 2018b; Wee, Vanyoro, and Jinnah, 2018; Rother, 2018; Rother and Steinhilper, 2019; Schierup et al., 2018). Another relevant group of non-state actors is the private sector, and, as the GFMD has evolved, it has already granted access to a broader group of such actors. The GFMD Business Mechanism is an example of how the international community is seeking to engage the private sector in the discussion of migration governance. Between states, an increase in the number of dialogues between municipal actors through fora such as the Global Mayoral Forum on Human Mobility, Migration and Development is also evident. After the US withdrew from the GCM negotiations, more than 130 mayors, including 18 from the US, signed a position paper that lobbied for cities to have a seat at the negotiation table.

It is evident that the adoption of the GCM does not mark the end of the journey for global migration governance. Faced with a new crisis, such as the COVID-19 pandemic, one might reasonably expect that the frame conflicts that characterize the migration policy subsystem become even more pronounced. Advocates of the human rights frame may use the pandemic crisis to extract further commitments from states regarding the protection of different categories of migrants who in many cases are being recognized as 'key workers' providing essential services in, among others, the health care sector, the agriculture and food sector; and the transportation and logistics 
sector. However, the pandemic also lends credence to the necessity of improving the management of human mobility from a virus containment perspective. The next chapter in the evolution of global migration governance will be a further test of how states cooperate multilaterally on matters that transcend state borders. Advocates of a more formal system of global governance for migration may seize the opportunity presented by the current crisis, to push forward further policy change. Time will tell. 


\section{Bibliography}

Abolafia, M. Y. (2004). Framing Moves: Interpretive Politics at the Federal Reserve. Journal of Public Administration Research and Theory, 14(3), 349-370. https://doi.org/10.1093/jopart/muh023

Abrams, A. (2019). U.S. Avoids Postal "Brexit" as Universal Postal Union Reaches a Deal. Time. https://time.com/5687134/trump-universal-postal-union-deal/

Akram, S. M. (2019). Assessing the Impact of the Global Compacts on Refugees and Migration in the Middle East. International Journal of Refugee Law, 30(4), 691695. https://doi.org/10.1093/ijrl/eey071

Albrectsen, A.-B. (2013, June 19). Sustainable Development and Population Dynamics: Placing People at the Centre. Statement by Anne-Birgitte Albrectsen, UNFPA's Deputy Executive Director of Managment, at the Open Working Group on Sustainable Development Goals. /press/sustainable-development-andpopulation-dynamics-placing-people-centre

Aleinikoff, T. A. (2019). The Unfinished Work of the Global Compact on Refugees. International Journal of Refugee Law, 30(4), 611-617. https://doi.org/10.1093/ijrl/eey057

Alink, F., Boin, A., \& T'Hart, P. (2001). Institutional crises and reforms in policy sectors: The case of asylum policy in Europe. Journal of European Public Policy, 8(2), 286-306. https://doi.org/10.1080/13501760151146487

Amaya-Castro, J. M. (2012). Migration and the World of Work: Discursive Constructions of the Global in ILO Narratives about Migration. The New Politics of International Mobility: Migration Management and Its Discontent, 3349.

Andreev, A. (2007). To What Extent are International Organizations (IOs) Autonomous Actors in World Politics? Opticon1826, 2. https://doi.org/10.5334/opt.020705

Andrew, J., \& Eden, D. (2011). Offshoring and outsourcing the 'unauthorised': The annual reports of an anxious state. Policy and Society, 30(3), 221-234. https://doi.org/10.1016/j.polsoc.2011.07.006

Andrijasevic, R., \& Walters, W. (2010). The International Organization for Migration and the International Government of Borders. Environment and Planning D: Society and Space, 28(6), 977-999. https://doi.org/10.1068/d1509

Annan, K. (2006). The Secretary General Address to the High Level Dialogue of the General Assembly on International Migration and Development. International Migration Review, 40(4), 963-965. 
Armstrong, J. D. (1982). The rise of the international organisation: A short history. Macmillan International Higher Education.

Arnold-Fernández, E. E. (2019). National Governance Frameworks in the Global Compact on Refugees: Dangers and Opportunities. International Migration, 57(6), 188-207. https://doi.org/10.1111/imig.12643

Ashutosh, I., \& Mountz, A. (2011). Migration management for the benefit of whom? Interrogating the work of the International Organization for Migration. Citizenship Studies, 15(1), 21-38. https://doi.org/10.1080/13621025.2011.534914

Ba, A. D. (2019). Multilateralism and East Asian transitions: The English School, diplomacy, and a networking regional order. International Politics, 1-19.

Bache, I., \& Flinders, M. V. (Eds.). (2004). Multi-level governance. Oxford University Press.

Bakewell, O. (2008). 'Keeping Them in Their Place': The ambivalent relationship between development and migration in Africa. Third World Quarterly, 29(7), 1341-1358. https://doi.org/10.1080/01436590802386492

Balabanova, E., \& Balch, A. (2010). Sending and receiving: The ethical framing of intraEU migration in the European press. European Journal of Communication, 25(4), 382-397. https://doi.org/10.1177/0267323110381005

Balch, A., \& Geddes, A. (2011). Opportunity from Crisis? Organisational Responses to Human Trafficking in the UK. The British Journal of Politics and International Relations, 13(1), 26-41. https://doi.org/10.1111/j.1467-856X.2010.00437.x

Ban, Ki-moon. (2013). Secretary-General's remarks to High-Level Dialogue on International Migration and Development. United Nations Secretary-General. https://www.un.org/sg/en/content/sg/statement/2013-10-03/secretarygenerals-remarks-high-level-dialogue-international

Ban, Ki-moon. (2007). Address to Inaugural Global Forum on Migration and Development. https://www.gfmd.org/speech-mr-he-mr-ban-ki-moon

Bardsley, D. K., \& Hugo, G. J. (2010). Migration and climate change: Examining thresholds of change to guide effective adaptation decision-making. Population and Environment, 32(2-3), 238-262. https://doi.org/10.1007/s11111010-0126-9

Barnett, M., \& Finnemore, M. (2004). Rules for the world: International organizations in global politics. Cornell University Press.

Barnett, M. N., \& Finnemore, M. (1999). The Politics, Power, and Pathologies of International Organizations. International Organization, 53(04), 699-732. https://doi.org/10.1162/002081899551048

Basok, T., \& Piper, N. (2012). Management Versus Rights: Women's Migration and Global Governance in Latin America and the Caribbean. Feminist Economics, 18(2), 35-61. https://doi.org/10.1080/13545701.2012.690525

Bauloz, C. (2017). A Comparative Thematic Mapping of Global Migration Initiatives: Lessons learned towards a Global Compact for safe, orderly and regular migration. International Organization for Migration. 
Bayram, A. B., \& Graham, E. R. (2017). Financing the United Nations: Explaining variation in how donors provide funding to the UN. The Review of International Organizations, 12(3), 421-459. https://doi.org/10.1007/s11558016-9261-0

Becker, J. (2020). Refugees, migration and global governance: Negotiating the global compacts: by Elizabeth G. Ferris and Katharine M. Donato, New York, Routledge, 2020, \$38.25 (paperback), ISBN: 978-0-8153-8801-2. Journal of Borderlands Studies, 1-2. https://doi.org/10.1080/08865655.2020.1723127

Benford, R. D. (1997). An Insider's Critique of the Social Movement Framing Perspective. Sociological Inquiry, 67(4), 409-430. https://doi.org/10.1111/j.1475-682X.1997.tb00445.x

Bennett, A., \& Checkel, J. T. (Eds.). (2015). Process tracing: From metaphor to analytic tool. Cambridge University Press.

Berent-Braun, M. M., \& Uhlaner, L. M. (2012). Family governance practices and teambuilding: Paradox of the enterprising family. Small Business Economics, 38(1), 103-119. https://doi.org/10.1007/s11187-010-9269-4

Berne Initiative (Ed.). (2005). International Agenda for Migration Management. Federal Office for Migration ; International Organization for Migration.

Bernstein, S. (2005). The changing discourse on population and development: Toward a new political demography. Studies in Family Planning, 36(2), 127-132.

Betts, A., \& Durieux, J.-F. (2007). Convention Plus as a Norm-Setting Exercise. Journal of Refugee Studies, 20(3), 509-535. https://doi.org/10.1093/jrs/fem010

Betts, A. (Ed.). (2011). Global migration governance. Oxford University Press.

Betts, A. (2018). The Global Compact on Refugees: Towards a Theory of Change? International Journal of Refugee Law, 30(4), 623-626. https://doi.org/10.1093/ijrl/eey056

Betts, A. \& Collier, P. (2017). Refuge: Transforming a broken refugee system. Penguin UK.

Betts, A. \& Kainz, L. (2017). The history of global migration governance. Refugee Studies Centre Working Paper Series, 122(122), 22.

Bhagwati, J. (1998). A Stream of Windows. MIT press, Cambridge, Massachusetts

Bhagwati, J. (2003). Borders Beyond Control. Foreign Affairs, January/February 2003, 98 104.

Birnbaum, M. (2018, 12). Belgium's ruling coalition collapses over U.N. pact on migration. Washington Post. https://www.washingtonpost.com/world/europe/belgiums-ruling-coalitioncollapses-over-un-pact-on-migration/2018/12/09/e9740cc2-fbc9-11e8-a17e162b712e8fc2_story.html

Bisong, A. (2018). Trans-regional institutional cooperation as multilevel governance: ECOWAS migration policy and the EU. Journal of Ethnic and Migration Studies, 1-16. https://doi.org/10.1080/1369183X.2018.1441607

Bleich, E. (2011). Social Research and 'Race' Policy Framing in Britain and France. The British Journal of Politics and International Relations, 13(1), 59-74. https://doi.org/10.1111/j.1467-856X.2010.00439.x 
Böhning, R. (1991). The ILO and the New UN Convention on Migrant Workers: The Past and Future. International Migration Review, 25(4), 698. https://doi.org/10.2307/2546841

Böhning, R. (2004). The Challenge of Population and Migration. Copenhagen Consensus. Copenhagen Consensus, Copenhagen

Böhning, W. R., \& Schloeter-Paredes, M.-L. (1994). Aid in place of migration?: Selected contributions to an ILO-UNHCR meeting. International Labour Organization.

Boswell, C. (2007). Migration Control in Europe After 9/11: Explaining the Absence of Securitization. JCMS: Journal of Common Market Studies, 45(3), 589-610. https://doi.org/10.1111/j.1468-5965.2007.00722.x

Boswell, C., Geddes, A., \& Scholten, P. (2011). The Role of Narratives in Migration Policy-Making: A Research Framework. The British Journal of Politics and International Relations, 13(1), 1-11. https://doi.org/10.1111/j.1467856X.2010.00435.x

Bourdieu, P. (1991). Language and symbolic power. Harvard University Press.

Brachet, J. (2016). Policing the Desert: The IOM in Libya Beyond War and Peace: Policing the Desert. Antipode, 48(2), 272-292. https://doi.org/10.1111/anti.12176

Bradley, M. (2017). The International Organization for Migration (IOM): Gaining Power in the Forced Migration Regime. Refuge, 33(1), 10.

Brønden, B. M. (2012). Migration and development: The flavour of the 2000s. International Migration, 50(3), 2-7.

Broome, A., \& Seabrooke, L. (2012). Seeing like an International Organisation. New Political Economy, 17(1), 1-16. https://doi.org/10.1080/13563467.2011.569019

Brouwer, J., van der Woude, M., \& van der Leun, J. (2017). Framing migration and the process of crimmigration: A systematic analysis of the media representation of unauthorized immigrants in the Netherlands. European Journal of Criminology, 14(1), 100-119. https://doi.org/10.1177/1477370816640136

Browne, S. (2017). Vertical Funds: New Forms of Multilateralism. Global Policy, 8, 3645. https://doi.org/10.1111/1758-5899.12456

Browne, S., \& Weiss, T. G. (2014). Introduction: The UN we want for the world we want. In Post-2015 UN Development (pp.1-14). Routledge.

Caillault, C. (2012). The Implementation of Coherent Migration Management Through IOM Programs in Morocco. The New Politics of International Mobility. Migration Management and Its Discontents, IMIS, Osnabrück.

Caponio, T., \& Jones-Correa, M. (2018). Theorising migration policy in multilevel states: The multilevel governance perspective. Journal of Ethnic and Migration Studies, 44(12), 1995-2010. https://doi.org/10.1080/1369183X.2017.1341705

Carbone, M. (2013). Policy coherence and EU development policy. Routledge.

Carlin, J. A. (1989). Refugee Connection: Lifetime of Running a Lifeline. Springer.

Carling, J. (n.d.). Explaining the meaning of migrants and refugees. Retrieved May 15, 2020, from https://meaningofmigrants.org/

Carragee, K. M., \& Roefs, W. (2004). The Neglect of Power in Recent Framing Research. Journal of Communication, 20. 
Carrera, S., \& Hernanz, N. (2015). Re-Framing Mobility and Identity Controls: The Next Generation of the EU Migration Management Toolkit. Journal of Borderlands Studies, 30(1), 69-84. https://doi.org/10.1080/08865655.2015.1012737

Castles, S. (1986). The guest-worker in Western Europe-An obituary. International Migration Review, 20(4), 761-778.

Castles, S. (2007). The migration-asylum nexus and regional approaches. In New Regionalism and Asylum Seekers: Challenges Ahead (pp.25-42). Berghahn Books Oxford.

Chamie, J., \& Mirkin, B. (2013, January 29). Dodging International Migration at the United Nations. PassBlue. https://www.passblue.com/2013/01/29/dodginginternational-migration-at-the-united-nations/

Checkel, J. T. (2014). Mechanisms, process, and the study of international institutions. In A. Bennett \& J. T. Checkel (Eds.), Process Tracing (pp.74-97). Cambridge University Press. https://doi.org/10.1017/CBO9781139858472.006

Cheng, L., Igartua, J. J., Palacios, E., Acosta, T., \& Palito, S. (2011). Framing Immigration News in Spanish Regional Press: Framing immigration news. International Migration, no-no. https://doi.org/10.1111/j.14682435.2010.00647.x

Chetail, V. (2019). International migration law. Oxford University Press.

Chimni, B. S. (2019). Global Compact on Refugees: One Step Forward, Two Steps Back. International Journal of Refugee Law, 30(4), 630-634. https://doi.org/10.1093/ijrl/eey067

Cholewinski, R., \& Taran, P. (2009). Migration, Governance and Human Rights: Contemporary Dilemmas in the Era of Globalization. Refugee Survey Quarterly, 28(4), 1-33. https://doi.org/10.1093/rsq/hdq019

Claude, I. L. (1958). Multilateralism-Diplomatic and Otherwise. International Organization, 12(1), 43-52.

Claude, I. L. (1964). Swords Into Plowshares: The problems and progress of international organization. Random House.

Cohen, H. G. (2018). Multilateralism's Life Cycle. American Journal of International Law, 112(1), 47-66. https://doi.org/10.1017/ajil.2018.11

Collier, D. (2011). Understanding Process Tracing. PS: Political Science E Politics, 44(04), 823-830. https://doi.org/10.1017/S1049096511001429

Collier, P., \& Gunning, J. W. (1999). The IMF'S Role in Structural Adjustment. The Economic Journal, 109(459), 634-651. https://doi.org/10.1111/1468-0297.00475

Collyer, M. (2012). Deportation and the Micropolitics of Exclusion: The Rise of Removals from the UK to Sri Lanka. Geopolitics, 17(2), 276-292. https://doi.org/10.1080/14650045.2011.562940

Cook, M. L. (2010). The Advocate's Dilemma: Framing Migrant Rights in National Settings. Studies in Social Justice, 4(1), 145. https://doi.org/10.26522/ssj.v4i2.999 
Costello, C. (2019). Refugees and (Other) Migrants: Will the Global Compacts Ensure Safe Flight and Onward Mobility for Refugees? International Journal of Refugee Law, 30(4), 643-649. https://doi.org/10.1093/ijrl/eey060

Crawley, H., \& Skleparis, D. (2018). Refugees, migrants, neither, both: Categorical fetishism and the politics of bounding in Europe's 'migration crisis.' Journal of Ethnic and Migration Studies, 44(1), 48-64. https://doi.org/10.1080/1369183X.2017.1348224

Crépeau, F. (2019). Towards a Mobile and Diverse World: 'Facilitating Mobility' as a Central Objective of the Global Compact on Migration. International Journal of Refugee Law, 30(4), 650-656. https://doi.org/10.1093/ijrl/eey054

Crush, J. (2013). Between North and South: The EU-ACP Migration Relationship. CIGI Papers, No. 16, 20.

Cruz, S. O. (2015). Alternative futures of global governance: Scenarios and perspectives from the Global South. Foresight, 17(2), 125-142. https://doi.org/10.1108/FS-05-2014-0030

Dedman, M. (2006). The origins and development of the European Union 1945-1995: A history of European integration. Routledge.

de Haas, H. (2010). Migration and Development: A Theoretical Perspective <sup/>. International Migration Review, 44(1), 227-264. https://doi.org/10.1111/j.17477379.2009.00804.x

de Haas, H. (2012). The Migration and Development Pendulum: A Critical View on Research and Policy: The migration and development pendulum. International Migration, 50(3), 8-25. https://doi.org/10.1111/j.14682435.2012.00755.x

de Haas, H., Natter, K., \& Vezzoli, S. (2018). Growing Restrictiveness or Changing Selection? The Nature and Evolution of Migration Policies ${ }^{1}$. International Migration Review, imre.12288. https://doi.org/10.1111/imre.12288

de Senarclens, P. (1998). Governance and the crisis in the international mechanisms of regulation. International Social Science Journal, 50(155), 91-104. https://doi.org/10.1111/1468-2451.00112

de Wenden, C. W. (2012). Globalization and International Migration Governance. IMIS Beitraage, 75-88.

Dehm, S. (2015). Framing international migration. London Review of International Law, 3(1), 133-168. https://doi.org/10.1093/lril/lrv004

Delgado Wise, R., Márquez Covarrubias, H., \& Puentes, R. (2013). Reframing the debate on migration, development and human rights. Population, Space and Place, 19(4), 430-443.

Delgado Wise, R. (2018a). Is there a space for counterhegemonic participation? Civil society in the global governance of migration. Globalizations, 15(6), 746-761. https://doi.org/10.1080/14747731.2018.1484204

Delgado Wise, R. (2018b). The global compact in relation to the migrationdevelopment nexus debate. Global Social Policy, 18(3), 328-331. https://doi.org/10.1177/1468018118799007 
Dian, M., \& Meijer, H. (2019). Networking hegemony: Alliance dynamics in East Asia. International Politics, 1-19.

DiMaggio, P. J., \& Powell, W. W. (1983). The Iron Cage Revisited: Institutional Isomorphism and Collective Rationality in Organizational Fields. American Sociological Review, 48(2), 147-160.

Dingwerth, K., \& Pattberg, P. (2009). Actors, arenas, and issues in global governance. In Palgrave advances in global governance (pp.41-65). Springer.

Dini, S. (2018). Migration management, capacity building and the sovereignty of an African State: International Organization for Migration in Djibouti. Journal of Ethnic and Migration Studies, 44(10), 1691-1705. https://doi.org/10.1080/1369183X.2017.1354058

Dobbins, M., Knill, C., \& Vögtle, E. M. (2011). An analytical framework for the crosscountry comparison of higher education governance. Higher Education, 62(5), 665-683. https://doi.org/10.1007/s10734-011-9412-4

Dodds, F., Donoghue, D., \& Leiva Roesch, J. L. (2017). Negotiating the sustainable development goals: A transformational agenda for an insecure world. Routledge.

Doyle, M. W. (2004). The Challenge of Worldwide Migration. Journal of International Affairs, 57(2), 1-5.

Doyle, M. W. (2018). Responsibility Sharing: From Principle to Policy. International Journal of Refugee Law, 30(4), 618-622.

Ducasse-Rogier, M. (2001). The International Organization for Migration 1951-2001. International Organization for Migration.

Duncan, H. (2019). Editorial. International Migration, 57(6), 3-4. https://doi.org/10.1111/imig.12673

Dyer, C. (2010). Education and social (in)justice for mobile groups: Re-framing rights and educational inclusion for Indian pastoralist children. Educational Review, 62(3), 301-313. https://doi.org/10.1080/00131911.2010.503601

Eckersley, R. (2012). Moving Forward in the Climate Negotiations: Multilateralism or Minilateralism? Global Environmental Politics, 12(2), 24-42. https://doi.org/10.1162/GLEP_a_00107

Ege, J., \& Bauer, M. W. (2017). How Financial Resources Affect the Autonomy of International Public Administrations. Global Policy, 8, 75-84. https://doi.org/10.1111/1758-5899.12451

Elie, J. (2010). The Historical Roots of Cooperation Between the UN High Commissioner for Refugees and the International Organization for Migration. Global Governance, 16, 345-360.

Engelbrekt, K. (2015). Minilateralism matters more? Exploring opportunities to end climate negotiations gridlock. Global Affairs, 1(4-5), 399-410. https://doi.org/10.1080/23340460.2015.1077607

Entman, R. M. (1993). Framing: Toward Clarification of a Fractured Paradigm. Journal of Communication, 43(4), 51-58. https://doi.org/10.1111/j.14602466.1993.tb01304.x

Evans, P., \& Finnemore, M. (2001). Organizational Reform and the Expansion of the South's Voice at the Fund. G-24 Discussion Paper Series, 15. 
Faassen, M. van. (2014). Polder en emigratie: Het Nederlandse emigratiebestel in internationaal perspectief, 1945 - 1967. Huygens.

Feldblum, M. (1999). Passage-Making and Service Creation in International Migration. International Actors in Immigration Policy-Making: Contributions to the Sovereignty Debate in International Relations, 25.

Feller, E. (2005). Refugees are not Migrants. Refugee Survey Quarterly, 24(4), 27-35. https://doi.org/10.1093/rsq/hdi077

Ferreira, S. (2019). Towards Migration Governance. In Human Security and Migration in Europe's Southern Borders (pp.9-29). Springer.

Ferris, E. E., \& Martin, S. F. (2019). The Global Compacts on Refugees and for Safe, Orderly and Regular Migration: Introduction to the Special Issue. International Migration, 57(6), 5-18. https://doi.org/10.1111/imig.12668

Ferris, E. G., \& Donato, K. M. (2019). Refugees, Migration and Global Governance: Negotiating the Global Compacts. Routledge.

Finkelstein, L. S. (1995). What Is Global Governance? Global Governance, 1, 367-372.

Finnemore, M. (2014). Dynamics of Global Governance: Building on What We Know. International Studies Quarterly, 58(1), 221-224. https://doi.org/10.1111/isqu.12095

Finnemore, M., \& Sikkink, K. (2001). Taking Stock: The Constructivist Research Program in International Relations and Comparative Politics. Annual Review of Political Science, 4(1), 391-416. https://doi.org/10.1146/annurev.polisci.4.1.391

Fligstein, N. (2001). Institutional entrepreneurs and cultural frames-The case of the European Union's Single Market Program. European Societies, 3(3), 261-287.

Food and Agriculture Organization of the United Nations, (FAO). (2014a). Food Security and the Right to Food (FAO17; FAO and the Post-2015 Development Agenda Issue Papers). SDG Grey Literature Corpus. www.fao.org/post2015-mdg/

Food and Agriculture Organization of the United Nations, (FAO). (2014b). Poverty Eradication (FAO04; FAO and the Post-2015 Development Agenda Issue Papers). SDG Grey Literature Corpus. www.fao.org/post-2015-mdg/

Food and Agriculture Organization of the United Nations, (FAO). (2015). The DirectorGeneral's Medium Term Plan 2014-17 (reviewed) and Programme of Work and Budget 2016-17 (FAO09; C 2015/3). SDG Grey Literature Corpus.

Freeman, G. P. (1992). Migration Policy and Politics in the Receiving States. The International Migration Review, 26(4), 1144-1167.

Friedman, T. L. (2000). The Lexus and the olive tree (1st Anchor Books ed). Anchor Books.

Friedrichs, J. (2009). Global governance as liberal hegemony. In Palgrave Advances in Global Governance (pp.105-122). Springer.

Frowd, P. M. (2014). The field of border control in Mauritania. Security Dialogue, 45(3), 226-241. https://doi.org/10.1177/0967010614525001

Gabriel, C., \& Macdonald, L. (2018). After the International Organization for Migration: Recruitment of Guatemalan temporary agricultural workers to 
Canada. Journal of Ethnic and Migration Studies, 44(10), 1706-1724. https://doi.org/10.1080/1369183X.2017.1354062

Gamlen, A. (2010). The New Migration and Development Optimism: A Review of the 2009. Global Governance, 16, 415-422.

Gamlen, A. (2014). Diaspora Institutions and Diaspora Governance. International Migration Review, 48(1_suppl), 180-217. https://doi.org/10.1111/imre.12136

Gammeltoft-Hansen, T. (2019). The Normative Impact of the Global Compact on Refugees. International Journal of Refugee Law, 30(4), 605-610. https://doi.org/10.1093/ijrl/eey061

Geddes, A. (2018). The governance of migration in Europe: Towards fragmentation? In Handbook of Migration and Globalisation (p.125). Edward Elgar.

Geiger, M. (2010). Mobility, development, protection, EU-integration! The IOM's national migration strategy for Albania. In The politics of international migration management (pp.141-159). Springer.

Geiger, M., \& Pécoud, A. (2012). The new politics of international mobility: Migration management and its discontents. In The new politics of international mobility: Migration management and its discontents (pp.11-24). Institut für Migrationsforschung und Interkulturelle Studien (IMIS)

Geiger, M., \& Pécoud, A. (2014). International Organisations and the Politics of Migration. Journal of Ethnic and Migration Studies, 40(6), 865-887. https://doi.org/10.1080/1369183X.2013.855071

George, V., \& Wilding, P. (1994). Welfare and Ideology. Prentice Hall Europe.

Georgi, F. (2010). For the benefit of some: The international organization for migration and its global migration management. In The politics of international migration management (pp.45-72). Springer.

Georgi, F., \& Schatral, S. (2012). Towards a critical theory of migration control: The case of the International Organization for Migration (IOM). Geiger, Martin $\mathcal{E}$ Pécoud, Antoine. The New Politics of International Mobility. Migration Management and Its Discontents, 193-221.

Georgiou, M., \& Zaborowski, R. (2017). Media coverage of the "refugee crisis": A crossEuropean perspective. Council of Europe.

Gest, J., Kysel, I. M., \& Wong, T. K. (2019). Protecting and Benchmarking Migrants' Rights: An Analysis of the Global Compact for Safe, Orderly and Regular Migration. International Migration, 57(6), 60-79. https://doi.org/10.1111/imig.12635

Global Forum on Migration and Development (GFMD). (2014). Report of the Swedish Chairmanship of the Global Forum on Migration and Development 2013-2014. https://www.gfmd.org/files/documents/gfmd_sweden20132014_report_of_proceedings.pdf

GFMD Civil Society. (2014). Civil Society "Stockholm Agenda" on Migrant and Migrationrelated Goals and Targets in post-2015 Global and National Development Agendas. http://madenetwork.org/sites/default/files/PDF/Civil\%20Society\%20Migrati on\%20Stockholm\%20Agenda\%20-\%20June\%202014.pdf

Ghosh, B. (2000). Managing migration: Time for a new international regime? OUP Oxford. 
Ghosh, B. (2005). Managing Migration: Interstate Cooperation at the Global Level: Is the Emergence of a New Paradigm of Partnership around the Corner? ? In Interstate Cooperation and Migration (p.20).

Gilbert, G. (2019). Not Bound but Committed: Operationalizing the Global Compact on Refugees. International Migration, 57(6), 27-42. https://doi.org/10.1111/imig.12632

Global Migration Group (GMG). (2013). Integrating migration in the post-2015 UN Development Agenda: Position Paper. https:/globalmigrationgroup.org/system/files/uploads/news/GMGposition-paper-Migration-and-post-2015-Development-Agenda.pdf

Goffman, E. (1974). Frame analysis: An essay on the organization of experience. Harvard University Press.

Goodwin-Gill, G. S. (2019). The Global Compacts and the Future of Refugee and Migrant Protection in the Asia Pacific Region. International Journal of Refugee Law, 30(4), 674-683. https://doi.org/10.1093/ijrl/eey064

Graham, E. R. (2015). Money and multilateralism: How funding rules constitute IO governance. International Theory, 7(01), 162-194. https://doi.org/10.1017/S1752971914000414

Graham, E. R. (2017a). The institutional design of funding rules at international organizations: Explaining the transformation in financing the United Nations. European Journal of International Relations, 23(2), 365-390. https://doi.org/10.1177/1354066116648755

Graham, E. R. (2017b). Follow the Money: How Trends in Financing Are Changing Governance at International Organizations. Global Policy, 8, 15-25. https://doi.org/10.1111/1758-5899.12450

Gray, J. (2014). Donor funding and institutional expansions in international organizations: Failures of legitimacy and efficiency. Unpublished Manuscript, University of Pennsylvania.

Greussing, E., \& Boomgaarden, H. G. (2017). Shifting the refugee narrative? An automated frame analysis of Europe's 2015 refugee crisis. Journal of Ethnic and Migration Studies, 43(11), 1749-1774. https://doi.org/10.1080/1369183X.2017.1282813

Guild, E. (2018). The global compact as a milestone in global governance of migration. Global Social Policy, 18(3), 325-327. https://doi.org/10.1177/1468018118799418

Guild, E., Basaran, T., \& Allinson, K. (2019). From Zero to Hero? An analysis of the human rights protections within the Global Compact for Safe, Orderly and Regular Migration (GCM). International Migration, 57(6), 43-59. https://doi.org/10.1111/imig.12609

Guild, E., Grant, S., \& Groenendijk, K. (2017). IOM and the UN: Unfinished Business. Queen Mary University of London, School of Law Legal Studies Research Paper No. 255/2017, 255, 24.

Guterres, A. (2007, December 11). People on the move. The Guardian. https://www.theguardian.com/commentisfree/2007/dec/11/peopleonthemo ve 
Habermas, J. (1993). Justification and application: Remarks on discourse ethics (C. Cronin, Trans.). The MIT Press.

Hall, N. (2013). Moving Beyond its Mandate? UNHCR and Climate Change Displacement. Journal of International Organizations, 4(1), 91-108.

Hall, N. (2015). Money or Mandate? Why International Organizations Engage with the Climate Change Regime. Global Environmental Politics, 15(2), 79-97. https://doi.org/10.1162/GLEP_a_00299

Hall, N. (2016). Displacement, development, and climate change: International organizations moving beyond their mandates. Routledge.

Hart, O. (1995). Corporate Governance: Some Theory and Implications. The Economic Journal, 105(430), 678. https://doi.org/10.2307/2235027

Hartigan, K. (1992). Matching Humanitarian Norms with Cold, Hard Interests: The Making of Refugee Policies in Mexico and Honduras, 1980-89. International Organization, 46(3), 709-730.

Hartling, P. (1985). Opening Statement by Mr. Poul Hartling, United Nations High Commissioner for Refugees, at the Consultations on the Arrivals of Asylum-seekers and Refugees in Europe, Geneva, 28 May 1985. UNHCR. https://www.unhcr.org/admin/hcspeeches/3ae68fd028/opening-statementmr-poul-hartling-united-nations-high-commissioner-refugees.html

Hathaway, J. C. (2019). The Global Cop-Out on Refugees. International Journal of Refugee Law, 30(4), 591-604. https://doi.org/10.1093/ijrl/eey062

Helbling, M. (2014). Framing Immigration in Western Europe. Journal of Ethnic and Migration Studies, 40(1), 21-41. https://doi.org/10.1080/1369183X.2013.830888

Heldt, E., \& Schmidtke, H. (2017). Measuring the Empowerment of International Organizations: The Evolution of Financial and Staff Capabilities. Global Policy, 8, 51-61. https://doi.org/10.1111/1758-5899.12449

Helton, A. C. (2003). People movement: The need for a World Migration Organisation. Open Democracy. https://www.opendemocracy.net/en/people-movementneed-for-world-migration-organisation/

Hennebry, J. L., \& Petrozziello, A. J. (2019). Closing the Gap? Gender and the Global Compacts for Migration and Refugees. International Migration, 57(6), 115-138. https://doi.org/10.1111/imig.12640

Henökl, T., \& Stemberger, A. (2016). EU Policies in the Arab World: Update and Critical Assessment. European Foreign Affairs Review, 21(2), 227-250.

Henökl, T., \& Webersik, C. (2016). Power Politics or Transnational Public Policy? European and Chinese Development Cooperation with Sri Lanka and Myanmar. Asia-Pacific Journal of EU Studies, 14(1), 1-23.

Hess, S. (2010). 'We are Facilitating States!' An Ethnographic Analysis of the ICMPD. In The politics of international migration management (pp.96-118). Springer.

Hewitt de Alcántara, C. (1998). Uses and abuses of the concept of governance. International Social Science Journal, 50(155), 105-113. https://doi.org/10.1111/1468-2451.00113

High-Level Panel of Eminent Persons. (2013). A New Global Partnership: Eradicate Poverty and Transform Economies through Sustainable Development. 
Hoffmann, S. (2016). International Humanitarian Agencies and Iraqi Migration in Preconflict Syria. International Journal of Middle East Studies, 48(02), 339-355. https://doi.org/10.1017/S0020743816000076

Hood, C. (1995). The "new public management" in the 1980s: Variations on a theme. Accounting, Organizations and Society, 20(2-3), 93-109. https://doi.org/10.1016/0361-3682(93)E0001-W

Hujo, K. (2019). A global social contract: New steps towards a rights-based approach to migration governance? Global Social Policy, 19(1-2), 25-28. https://doi.org/10.1177/1468018119849232

Hulme, D. (2009). The Millennium Development Goals (MDGs): A Short History of the World's Biggest Promise. SSRN Electronic Journal. https://doi.org/10.2139/ssrn.1544271

Huntington, S. P. (1973). Transnational Organizations in World Politics. World Politics, 25(03), 334-368. https://doi.org/10.2307/2010115

Hurrell, A. (2017). Can the study of global governance be decentred? Global Governance from Regional Perspectives. A Critical View, 25-44.

ICEM. (1953). Intergovernmental Committee for European Migration. International Organization, 7(1), 169-170.

ICEM. (1954). Intergovernmental Committee for European Migration. International Organization, 8(3), 418-421.

ICEM. (1955). Intergovernmental Committee for European Migration. International Organization, 9(2), 316-318.

ICEM. (1956). Intergovernmental Committee for European Migration. International Organization, 10(2), 347-350.

ICEM. (1957). Intergovernmental Committee for European Migration. International Organization, 11(2), 404-406.

ICEM. (1958a). Intergovernmental Committee for European Migration. International Organization, 12(2), 264-265.

ICEM. (1958b). Intergovernmental Committee for European Migration. International Organization, 12(3), 418-419.

ICEM. (1959). Intergovernmental Committee for European Migration. International Organization, 13(2), 355-356.

ICEM. (1960). Intergovernmental Committee for European Migration. International Organization, 14(3), 491.

ICEM. (1961). Intergovernmental Committee for European Migration. International Organization, 15(3), 532-533.

ICEM. (1962). Intergovernmental Committee for European Migration. International Organization, 16(3), 663-665.

ICEM. (1963). Intergovernmental Committee for European Migration. International Organization, 17(3), 828-829.

ICEM. (1964). Intergovernmental Committee for European Migration. International Organization, 18(3), 669-670.

International Labour Organization. (2004). Conclusions on a fair deal for migrant workers in a global economy. Ninety-second Session, Geneva, 2004. 
International Labour Organization. (2006). ILO multilateral framework on labour migration: Non-binding principles and guidelines for a rights-based approach to labour migration. International Labour Office.

International Labour Organization. (2013). Integrating Labour Migration into the 2013 UN High-level Dialogue on International Migration and Development, and the Post-2015 UN Development Agenda (ILO09; International Labour Organization Position Paper). SDG Grey Literature Corpus. https://www.ilo.org/wcmsp5/groups/public/---ed_protect/---protrav/--migrant/documents/briefingnote/wcms_222913.pdf

International Labour Organization. (2014). Fair migration: Setting an ILO agenda : report of the Director-General: International Labour Conference, 103rd Session, 2014 (ILO13; ILC.103/DG/IB). International Labour Office; SDG Grey Literature Corpus. $\quad$ https://www.ilo.org/wcmsp5/groups/public/---ed_norm/--relconf/documents/meetingdocument/wcms_242879.pdf

International Labour Organization. (2019). NORMLEX - Information System on International Labour Standards. International Labour Organization. https://www.ilo.org/dyn/normlex/en/f?p=NORMLEXPUB:1:0::NO:::

International Organization for Migration, (IOM). (n.d.a). Health in the Post-2015 Development Agenda: The importance of migrants' health for sustainable and equitable development (IOM17; Migration and Health Position Paper Series, p.4). SDG Grey Literature Corpus. https://www.iom.int/files/live/sites/iom/files/What-We-Do/docs/Health-inthe-Post-2015-Development-Agenda.pdf

International Organization for Migration, (IOM). (n.d.b). IOM position on the post-2015 United Nations development agenda (IOM02). SDG Grey Literature Corpus. https://www.iom.int/files/live/sites/iom/files/What-We-Do/docs/IOM-

Position-Paper-on-Post-2015.pdf

International Organization for Migration, (IOM). (2002a). Programme and Budget for 2003 (MC/2083).

International Organization for Migration, (IOM). (2002b). Statement by the Director General at the Eighty-fourth Session of the Council (MICEM/7/2002).

International Organization for Migration, (IOM). (2003a). Summary Record of the Four Hundred and Forty-Fourth Meeting of the Council (MC/C/SR/444).

International Organization for Migration, (IOM). (2003b). IOM-UN Relationship: Summary Report of the Working Group on Institutional Arrangements (MC/INF/263).

International Organization for Migration, (IOM). (2006). IOM-UN Relationship (MC/INF/285).

International Organization for Migration, (IOM). (2007a). Options for the IOM-UN Relationship: Additional Analysis of Costs and Benefits (MC/INF/290).

International Organization for Migration, (IOM). (2007b). Report of the Ninety Second Session of the Council (MC/2210/Rev.1).

International Organization for Migration, (IOM). (2008). Draft Report on the NinetyFourth Session of the Council (MC/2239). 
International Organization for Migration, (IOM). (2012a). Financial Report for the year ended 31 December 2011 (MC/2345).

International Organization for Migration, (IOM). (2012b). Director General's Report to the 101st Session of the Council: 101 ${ }^{\text {st }}$ Session of the Council: Milestones, stumbling stones and stepping stones (MICEM/3/2012).

International Organization for Migration, (IOM). (2013). Migration and the United Nations post-2015 development agenda (F. Laczko \& L. J. Lönnback, Eds.; IOM01). IOM; SDG Grey Literature Corpus. https://publications.iom.int/system/files/pdf/migration_and_the_un_post20 15_agenda.pdf

International Organization for Migration, (IOM). (2014a). Migration in the post-2015 process: Analyzing key trends (IOM20). SDG Grey Literature Corpus. https://unofficeny.iom.int/sites/default/files/post2015/website\%20draft\%20\%20analyzing\%20trends\%20in\%20p2015\%20final.pdf

International Organization for Migration, (IOM). (2014b). Report on the 103rd Session of the Council (MC/2398/Rev.1).

International Organization for Migration, (IOM). (2015). Report of the Standing Committee on Programmes and Finance on the Seventeenth Session (S/17/14).

International Organization for Migration, (IOM) (2016). Key Migration Terms. International Organization for Migration. https://www.iom.int/keymigration-terms

International Organization for Migration, (IOM). (2017). Annual Report for 2016 (C/108/4).

International Organization for Migration, (IOM). (2019). Member States. International Organization for Migration. https://www.iom.int/member-states

International Organization for Migration, (IOM). (2020a). Migration Governance Indicators | IOM's Global Migration Data Analysis Centre. https:/gmdac.iom.int/migration-governance-indicators

International Organization for Migration, (IOM). (2020b). Missing Migrants Project. Missing Migrants Project. https://missingmigrants.iom.int/region/mediterranean

Jacobs, A. M. (2015). Process tracing the effects of ideas. Process Tracing: From Metaphor to Analytic Tool, 41-73.

Jaeger, H.-M. (2007). "Global Civil Society" and the Political Depoliticization of Global Governance. International Political Sociology, 1(3), 257-277. https://doi.org/10.1111/j.1749-5687.2007.00017.x

Jessop, B. (1998). The rise of governance and the risks of failure: The case of economic development. International Social Science Journal, 50(155), 29-45. https://doi.org/10.1111/1468-2451.00107

Jobert, B. (1989). The normative frameworks of public policy. Political Studies, 37(3), 376-386.

Jordan, A. D. (2002). Human rights or wrongs? The struggle for a rights-based response to trafficking in human beings. Gender \& Development, 10(1), 28-37. https://doi.org/10.1080/13552070215891 
Jubilut, L. L., \& Casagrande, M. M. (2019). Shortcomings and/or Missed Opportunities of the Global Compacts for the Protection of Forced Migrants. International Migration, 57(6), 139-157. https://doi.org/10.1111/imig.12663

Kahler, M. (1992). Multilateralism with Small and Large Numbers. International Organization, 46(3), 681-708.

Kahneman, D., \& Tversky, A. (1984). Choices, Values, and Frames. American Psychological Association, 39(4), 341-350.

Kale, B., \& Erdoğan, M. (2019). The Impact of GCR on Local Governments and Syrian Refugees in Turkey. International Migration, 57(6), 224-242. https://doi.org/10.1111/imig.12658

Kamau, M., Chasek, P., \& O'Connor, D. (2018). Transforming multilateral diplomacy: The inside story of the sustainable development goals. Routledge.

Karatani, R. (2005). How History Separated Refugee and Migrant Regimes: In Search of Their Institutional Origins. International Journal of Refugee Law, 17(3), 517541. https://doi.org/10.1093/ijrl/eei019

Keohane, R. O. (1990). Multilateralism: An Agenda for Research. International Journal, 45(4), 731. https://doi.org/10.2307/40202705

Keohane, R. O., \& Nye, J. S. (1974). Transgovernmental Relations and International Organizations. World Politics, 27(01), 39-62. https://doi.org/10.2307/2009925

Kerry, K. (2003). Higher Education Governance as a Key Policy Issue in the 21st Century. Educational Research for Policy and Practice, 2, 55-70.

Khadria, B., Thakur, N., Nicolas, I., Lee, T., Yang, J., \& Jang, Y. (2019). The Global Compact for Safe, Orderly and Regular Migration: Its Impact on Asia. International Migration, 57(6), 286-302. https://doi.org/10.1111/imig.12654

Kingdon, J. W. (1995). The policy window, and joining the streams. Agendas, Alternatives, and Public Policies, 172-189.

Kjær, A. M. (2004). Governance. Polity Press.

Klein Solomon, M. (2005). International Migration Management through Inter-State Consultation Mechanisms. United Nations Expert Group Meeting on International Migration and Development. United Nations Expert Group Meeting on International Migration and Development, New York.

Klein Solomon, M., \& Sheldon, S. (2019). The Global Compact for Migration: From the Sustainable Development Goals to a Comprehensive Agreement on Safe, Orderly and Regular Migration. International Journal of Refugee Law, 30(4), 584-590. https://doi.org/10.1093/ijrl/eey065

Knight, W. A. (2009). Global governance as a summative phenomenon. In Palgrave Advances in Global Governance (pp.160-188). Springer.

Koch, A. (2014). The Politics and Discourse of Migrant Return: The Role of UNHCR and IOM in the Governance of Return. Journal of Ethnic and Migration Studies, 40(6), 905-923. https://doi.org/10.1080/1369183X.2013.855073

Korneev, O. (2013). EU Migration Governance in Central Asia: Everybody's Business - Nobody's Business? European Journal of Migration and Law, 15(3), 301-318. https://doi.org/10.1163/15718166-00002038 
Korneev, O. (2014). Exchanging Knowledge, Enhancing Capacities, Developing Mechanisms: IOM's Role in the Implementation of the EU-Russia Readmission Agreement. Journal of Ethnic and Migration Studies, 40(6), 888904. https://doi.org/10.1080/1369183X.2013.855072

Korneev, O., \& Kluczewska, K. (2018). The globalised third sector in the migration policy field. In Handbook of Migration and Globalisation (p.54).

Koser, K. (2010). Introduction: International migration and global governance. Global Governance: A Review of Multilateralism and International Organizations, 16(3), 301-315.

Koslowski, R. (2019). International Travel Security and the Global Compacts on Refugees and Migration. International Migration, 57(6), 158-172. https://doi.org/10.1111/imig.12639

Krahmann, E. (2003). Conceptualizing Security Governance. Cooperation and Conflict, 38(1), 5-26.

Kunz, R., Lavenex, S., \& Panizzon, M. (2011). Multilayered migration governance: The promise of partnership (Vol. 89). Taylor \& Francis.

Lavenex, S. (2016). Multilevelling EU external governance: The role of international organizations in the diffusion of EU migration policies. Journal of Ethnic and Migration Studies, 42(4), 554-570. https://doi.org/10.1080/1369183X.2015.1102047

Lavenex, S. (2018). Regional migration governance - building block of global initiatives? Journal of Ethnic and Migration Studies, 1-19. https://doi.org/10.1080/1369183X.2018.1441606

Lavenex, S., Jurje, F., Givens, T. E., \& Buchanan, R. (2016). Regional Migration Governance. In The Oxford Handbook of Comparative Regionalism (pp. 457-485). Oxford University Press.

Lawlor, A. (2017). Deciding Who's Legitimate: News Media Framing of Immigrants and Refugees. 25.

Linder, S. H. (1999). Coming to Terms with the Public-Private Partnership: A Grammar of Multiple Meanings. American Behavioral Scientist, 43(1), 35-51.

Loescher, G. (2001). The UNHCR and World Politics: State Interests vs. Institutional Autonomy. International Migration Review, 35(1), 33-56. https://doi.org/10.1111/j.1747-7379.2001.tb00003.x

Long, K. (2013). When refugees stopped being migrants: Movement, labour and humanitarian protection. Migration Studies, 1(1), 4-26. https://doi.org/10.1093/migration/mns001

Lukes, S. (1974). 1974 Power: A radical view. London: Macmillan.

Maiyegun, O. (2019). Role of Regional Consultative Processes in the lead up to the Negotiations of Global Compact on Migration: The Case of Africa. International Migration, 57(6), 258-272. https://doi.org/10.1111/imig.12604

Majcher, I. (2019). Immigration Detention under the Global Compacts in the Light of Refugee and Human Rights Law Standards. International Migration, 57(6), 91-114. https://doi.org/10.1111/imig.12641 
Marchi, S. (2010). Global Governance: Migration's Next Frontier. Global Governance, $16,323-329$.

Marti, G. (2018). The effects of multilevel governance on the rights of migrant domestic workers in Singapore. Journal of Ethnic and Migration Studies, 1-16. https://doi.org/10.1080/1369183X.2018.1441614

Martín Díaz, E., \& Aris Escarcena, J. P. (2019). The European Union and the Background of the Global Compacts. International Migration, 57(6), 273-285. https://doi.org/10.1111/imig.12665

Martin, P. (2012). Labour Migration and Development Indicators in the Post-2015 Global Development Framework. Working Paper Prepared for IOM's 2013 World Migration Report (WMR). https://unofficeny.iom.int/sites/default/files/World_Migration_Report_2013 _-_Working_Paper_-_IOM.pdf

Martin, P., Martin, S., \& Cross, S. (2007). High-level Dialogue on Migration and Development. International Migration, 45(1), 7-25. https://doi.org/10.1111/j.1468-2435.2007.00394.x

Martin, P., \& Ruhs, M. (2019). Labour Market Realism and the Global Compacts on Migration and Refugees. International Migration, 57(6), 80-90. https://doi.org/10.1111/imig.12626

Martin, S. (2014). International migration: Evolving trends from the early twentieth century to the present. Cambridge University Press.

Martin, S. F. (2015). International Migration and Global Governance. Global Summitry, 1(1), 64-83. https://doi.org/10.1093/global/guv001

McAdam, J. (2019). The Global Compacts on Refugees and Migration: A New Era for International Protection? International Journal of Refugee Law, 30(4), 571-574. https://doi.org/10.1093/ijrl/eez004

McGee, J. S. (2011). Exclusive Minilateralism: An Emerging Discourse within International Climate Change Governance? PORTAL Journal of Multidisciplinary International Studies, 8(3). https://doi.org/10.5130/portal.v8i3.1873

McGregor, E. (2019). The Role of Funding in Migration Governance. IMIn Working Paper Series, 149, 37.

McGregor, E. (2020). Migration, the MDGs, and SDGs: Context and Complexity. In T. Bastia \& R. Skeldon, Routledge Handbook of Migration and Development.

McGregor, E. (2017). Intergovernmental Organizations, Migration and the Sustainable Development Goals. Migrating out of Poverty Conference: 'From Evidence to Policy,' 348. http://www.migratingoutofpoverty.org/documents/mcgregorintergovernmental-organizations-migration-and-sustainable-developmentgoals.pdf

Mearsheimer, J. J. (1995). The False Promise of International Institutions. International Security, 19(3), 5-49.

Menz, G. (2015). Framing the matter differently: The political dynamics of European Union labour migration policymaking. Cambridge Review of International Affairs, 28(4), 554-570. https://doi.org/10.1080/09557571.2015.1008400 
Merlingen, M. (2003). Governmentality: Towards a Foucauldian Framework for the Study of IGOs. Cooperation and Conflict, 38(4), 361-384. https://doi.org/10.1177/0010836703384002

Miller, D., \& Le Breton-Miller, I. (2006). Family Governance and Firm Performance: Agency, Stewardship, and Capabilities. Family Business Review, 19(1), 73-87. https://doi.org/10.1111/j.1741-6248.2006.00063.x

Miller, M. J. (2000). International migration in post-cold war international relations. Managing Migration: Time for a New International Regime, 27-47.

Millner, N. (2011). From "refugee" to "migrant" in Calais solidarity activism: Restaging undocumented migration for a future politics of asylum. Political Geography, 30(6), 320-328. https://doi.org/10.1016/j.polgeo.2011.07.005

Morris, T. (2005). IOM: trespassing on others' humanitarian space? Forced Migration Review, 22(1), 43.

Naím, M. (2009). Minilateralism: The Magic Number to get Real International Action. Foreign Policy, Jul/Aug 2009, 136-137.

Natorski, M. (2018). EU Mediation Practices in Ukraine during Revolutions: What Authority as a Peacemaker? International Negotiation, 23(2), 278-298. https://doi.org/10.1163/15718069-23021159

Nay, O. (2011). What Drives Reforms in International Organizations? External Pressure and Bureaucratic Entrepreneurs in the UN Response to Aids: What Drives Reforms in International Organizations? Governance, 24(4), 689-712. https://doi.org/10.1111/j.1468-0491.2011.01545.x

Newland, K. (2010). The Governance of International Migration: Mechanisms, Processes, and Institutions. Global Governance, 16, 331-343.

Newland, K. (2012). The GFMD and the governance of international migration. In Global perspectives on migration and development (pp.227-240). Springer.

Newland, K. (2019). The Global Compact for Safe, Orderly and Regular Migration: An Unlikely Achievement. International Journal of Refugee Law, 30(4), 657-660. https://doi.org/10.1093/ijrl/eey058

Nielson, J., \& Taglioni, D. (2003). A Quick Guide to the GATS and Mode 4. A Background Paper Prepared for Session I, November, 12.

Nieuwenhuys, C., \& Pécoud, A. (2007). Human Trafficking, Information Campaigns, and Strategies of Migration Control. American Behavioral Scientist, 50(12), 1674-1695. https://doi.org/10.1177/0002764207302474

Oelgemöller, C. (2011). Informal Plurilateralism: The Impossibility of Multilateralism in the Steering of Migration. The British Journal of Politics and International Relations, 13(1), 110-126. https://doi.org/10.1111/j.1467-856X.2010.00442.x

Office of the United Nations High Commissioner for Human Rights, (OHCHR). (2012). Towards freedom from fear and want: Human rights in the post- 2015 agenda (OHCHR19; UN System Task Team on the Post-2015 UN Development Agenda Thematic Think Pieces). SDG Grey Literature Corpus. https://www.un.org/millenniumgoals/pdf/Think\%20Pieces/9_human_right s.pdf 
Office of the United Nations High Commissioner for Human Rights, (OHCHR). (2013). Migration: Protecting human rights in the context of migration. In OHCHR Report 2013 (OHCHR04; pp.62-70). SDG Grey Literature Corpus. https://www2.ohchr.org/english/OHCHRReport2013/WEB_version/allegati /downloads/1_The_whole_Report_2013.pdf

Office of the United Nations High Commissioner for Human Rights, (OHCHR). (2014). Metadata Ratification Status. http://indicators.ohchr.org/Stock/Documents/MetadataRatificationStatus_D ashboard.pdf

Olson, M. (1965). The Logic of Collective Action. Harvard University Press.

Pagden, A. (1998). The genesis of "governance" and Enlightenment conceptions of the cosmopolitan world order. International Social Science Journal, 50(155), 7-15. https://doi.org/10.1111/1468-2451.00105

Pajnik, M. (2010). Media Framing of Trafficking. International Feminist Journal of Politics, 12(1), 45-64. https://doi.org/10.1080/14616740903429114

Panizzon, M. (2011). Franco-African pacts on migration: Billaterealism Revisisted in Multilayered Migration Governance. In Multilayered Migration Governance: The Promise of Partnership (Vol. 89, pp.207-248).

Panizzon, M., \& van Riemsdijk, M. (2018). Introduction to Special issue: 'Migration governance in an era of large movements: a multi-level approach.' Journal of Ethnic and Migration Studies, 1-17. https://doi.org/10.1080/1369183X.2018.1441600

Paoletti, E., \& Pastore, F. (2010). Sharing the dirty job on the southern front? IMI Working Paper Series, Paper 29.

Papadememetriou, D. G. (2011). The Governance of International Migration. Defining the Potential for Reform in the Next Decade. Council Statement from the 6th Plenary Meeting of the Transatlantic Council on Migration. Council statement from the 6th plenary meeting of the Transatlantic Council on Migration, Washington, D.C.

Pécoud, A. (2010). Informing migrants to manage migration? An analysis of IOM's information campaigns. In The politics of international migration management (pp.184-201). Springer.

Pécoud, A. (2015). Depoliticising migration. Palgrave Macmillan.

Pécoud, A. (2017). The Politics of the UN Convention on Migrant Workers' Rights. Groningen Journal of International Law, 5(1), 57-72. https://doi.org/10.21827/59db6983b848b

Pécoud, A. (2018). What do we know about the International Organization for Migration? Journal of Ethnic and Migration Studies, 44(10), 1621-1638. https://doi.org/10.1080/1369183X.2017.1354028

Pécoud, A., \& de Guchteneire, P. (2007). Between Global Governance and Human Rights. Georgetown Journal of International Affairs, Summer/Fall 2007, 115-123.

Perruchoud, R. (1989). From the Intergovernmental Committee for European Migration to the International Organization for Migration. International Journal of Refugee Law, 1(4), 501-517. https://doi.org/10.1093/ijrl/1.4.501 
Pian, A. (2010). The discursive framework for development. From discourses and concrete political actions to the range of actions by deportee associations. IMI Working Paper, 25, 18.

Pierce, J. J., Peterson, H. L., Jones, M. D., Garrard, S. P., \& Vu, T. (2017). There and Back Again: A Tale of the Advocacy Coalition Framework: Review of the Advocacy Coalition Framework. Policy Studies Journal, 45(S1), S13-S46. https://doi.org/10.1111/psj.12197

Piper, N. (2015). Democratising Migration from the Bottom Up: The Rise of the Global Migrant Rights Movement. Globalizations, 12(5), 788-802. https://doi.org/10.1080/14747731.2015.1024454

Piper, N. (2017). Migration and the SDGs. Global Social Policy, 17(2), 231-238.

Piper, N., \& Rother, S. (2012). Let's Argue about Migration: Advancing a right(s) discourse via communicative opportunities. Third World Quarterly, 33(9), 1735-1750. https://doi.org/10.1080/01436597.2012.721271

Pollitt, C. (2003). Joined-up Government: A Survey. Political Studies Review, 1(1), 34 49. https://doi.org/10.1111/1478-9299.00004

Porter, T. (2009). Global governance as configurations of state/non-state activity. In Palgrave advances in global governance (pp.87-104). Springer.

Poutignat, P., \& Streiff-Fénart, J. (2010). Migration policy development in Mauritania: Process, issues and actors. In The politics of international migration management (pp.202-219). Springer.

Raghuram, P. (2009). Which migration, what development? Unsettling the edifice of migration and development. Population, Space and Place, 15(2), 103-117. https://doi.org/10.1002/psp.536

Ransan-Cooper, H., Farbotko, C., McNamara, K. E., Thornton, F., \& Chevalier, E. (2015). Being(s) framed: The means and ends of framing environmental migrants. Global Environmental Change, 35, 106-115. https://doi.org/10.1016/j.gloenvcha.2015.07.013

Rasmussen, A. C. (2011). Contraception as Health? The Framing of Issue Categories in Contemporary Policy Making. Administration \& Society, 43(8), 930-953. https://doi.org/10.1177/0095399711413878

Ravenstein, E. G. (1885). The Laws of Migration. Journal of the Statistical Society of London, 48(2), 167-235.

Rein, M., \& Schön, D. (1996). Frame-critical policy analysis and frame-reflective policy practice. Knowledge and Policy, 9(1), 85-104. https://doi.org/10.1007/BF02832235

Rhodes, R. A. (1994). The hollowing out of the state: The changing nature of the public service in Britain. The Political Quarterly, 65(2), 138-151.

Rhodes, R. A. (1997). Understanding governance: Policy networks, governance, reflexivity and accountability. Open University.

Rhodes, R. A. W. (2007). Understanding Governance: Ten Years On. Organization Studies, 28(8), 1243-1264. https://doi.org/10.1177/0170840607076586

Richards, 2010, 
Rinscheid, A. (2015). Crisis, Policy Discourse, and Major Policy Change: Exploring the Role of Subsystem Polarization in Nuclear Energy Policymaking. European Policy Analysis, 1(2). https://doi.org/10.18278/epa.1.2.3

Robinson, C. (2017). Tracing and explaining securitization: Social mechanisms, process tracing and the securitization of irregular migration. Security Dialogue, 48(6), 505-523. https://doi.org/10.1177/0967010617721872

Roggeband, C., \& Verloo, M. (2007). Dutch Women are Liberated, Migrant Women are a Problem: The Evolution of Policy Frames on Gender and Migration in the Netherlands, 1995?2005. Social Policy \& Administration, 41(3), 271-288. https://doi.org/10.1111/j.1467-9515.2007.00552.x

Roldan, B., \& Gasper, D. (2010). The Global Forum on Migration and Development: "All Talk and No Action" or "A Chance to Frame the Issues in a Way that Allows you to Move Forward Together." The Institute of Social Studies Working Paper Series, 497.

Roper, S. D., \& Barria, L. A. (2010). Burden Sharing in the Funding of the UNHCR: Refugee Protection as an Impure Public Good. Journal of Conflict Resolution, 54(4), 616-637. https://doi.org/10.1177/0022002710364131

Rosenau, J. N. (1995). Governance in the Twenty-first Century. Global Governance, 1, 13-43.

Rother, S. (2013). Global migration governance without migrants? The nation-state bias in the emerging policies and literature on global migration governance. Migration Studies, 1(3), 363-371. https://doi.org/10.1093/migration/mnt019

Rother, S.. (2018). Angry birds of passage - migrant rights networks and counterhegemonic resistance to global migration discourses. Globalizations, 15(6), 854-869. https://doi.org/10.1080/14747731.2018.1472860

Rother, S., \& Steinhilper, E. (2019). Tokens or Stakeholders in Global Migration Governance? The Role of Affected Communities and Civil Society in the Global Compacts on Migration and Refugees. International Migration, 57(6), 243-257. https://doi.org/10.1111/imig.12646

Ruggie, J. G. (1992). Multilateralism: The Anatomy of an Institution. International Organization, 46(3), 561-598.

Sabatier, P. A. (1988). An advocacy coalition framework of policy change and the role of policy-oriented learning therein. Policy Sciences, 21(2-3), 129-168. https://doi.org/10.1007/BF00136406

Sabatier, P. A. (1998). The advocacy coalition framework: Revisions and relevance for Europe. Journal of European Public Policy, 5(1), 98-130. https://doi.org/10.1080/13501768880000051

Sabatier, P. A., \& Jenkins-Smith, H. (1988). Special issue: Policy change and policyoriented learning: Exploring an advocacy coalition framework. Policy Sciences, 21(2), 123-277.

Sabatier, P. A., \& Weible, C. M. (2007). The advocacy coalition framework. Theories of the Policy Process, 2, 189-220. 
Scalettaris, G. (2010). Refugees or Migrants? The UNHCR's Comprehensive Approach to Afghan Mobility into Iran and Pakistan. In The Politics of International Migration Management (pp.252-270). Springer.

Schatral, S. (2011). Categorisation and Instruction: IOM's Role in Preventing Human Trafficking in the Russian Federation.

Scheel, S., \& Ratfisch, P. (2014). Refugee Protection Meets Migration Management: UNHCR as a Global Police of Populations. Journal of Ethnic and Migration Studies, 40(6), 924-941. https://doi.org/10.1080/1369183X.2013.855074

Schierup, C.-U., Likić-Brborić, B., Wise, R. D., \& Toksöz, G. (2018). Migration, civil society and global governance: An introduction to the special issue. Globalizations, 15(6), 733-745. https://doi.org/10.1080/14747731.2018.1503840

Schiller, N. G. (2009). A Global Perspective on Migration and Development. Social Analysis, 53(3). https://doi.org/10.3167/sa.2009.530302

Schmidt, V. A. (2008). Discursive Institutionalism: The Explanatory Power of Ideas and Discourse. Annual Review of Political Science, 11(1), 303-326. https://doi.org/10.1146/annurev.polisci.11.060606.135342

Schmidt, V. A. (2010). Taking ideas and discourse seriously: Explaining change through discursive institutionalism as the fourth 'new institutionalism.' European Political Science Review, 2(01), 1. https://doi.org/10.1017/S175577390999021X

Scholten, P. (2011). Constructing Dutch Immigrant Policy: Research-Policy Relations and Immigrant Integration Policy-Making in the Netherlands. The British Journal of Politics and International Relations, 13(1), 75-92. https://doi.org/10.1111/j.1467-856X.2010.00440.x

Scholten, P., Engbersen, G., Ostaijen, M. van, \& Snel, E. (2018). Multilevel governance from below: How Dutch cities respond to intra-EU mobility. Journal of Ethnic and Migration Studies, 44(12), 2011-2033. https://doi.org/10.1080/1369183X.2017.1341707

Schultheis, E., \& Calamur, K. (2018, December 11). A Nonbinding Migration Pact Is Roiling Politics in Europe. The Atlantic. https://www.theatlantic.com/international/archive/2018/12/un-globalmigration-compact-germany-europe/577840/

Scott, D. A. (2013). Multipolarity, Multilateralism and Beyond ...? EU- China Understandings of the International System. International Relations, 27(1), 3051. https://doi.org/10.1177/0047117812463153

Seitz, K., \& Martens, J. (2017). Philanthrolateralism: Private Funding and Corporate Influence in the United Nations. Global Policy, 8, 46-50. https://doi.org/10.1111/1758-5899.12448

Siegel, M., McGregor, E., van der Vorst, V., \& Frouws, B. (2013). Independent Thematic Evaluation of the ILO's work on International Labour Migration. https://www.ilo.org/global/docs/WCMS_421232/lang--en/index.htm

Sjursen, H. (2002). Why Expand?: The Question of Legitimacy and Justification in the EU's Enlargement Policy. JCMS: Journal of Common Market Studies, 40(3), 491513. https://doi.org/10.1111/1468-5965.00366 
Skelcher, C. (2000). Changing images of the State: Overloaded, hollowed-out, congested. Public Policy and Administration, 15(3), 3-19. https://doi.org/10.1177/095207670001500302

Skeldon, R. (1997). Migration and development: A global perspective. Longman.

Skeldon, R. (2008). International Migration as a Tool in Development Policy: A Passing Phase? Population and Development Review, 34(1), 1-18. https://doi.org/10.1111/j.1728-4457.2008.00203.x

Skeldon, R. (2013). Bringing migration into the post-2015 agenda: Notes, reflections and policy directions (MERIT Working Papers No. 065). United Nations University - Maastricht Economic and Social Research Institute on Innovation and Technology (MERIT). https://ideas.repec.org/p/unm/unumer/2013065.html

Snow, D. A., \& Benford, R. D. (1992). Master Frames and Cycles of Protest,[in:] Morris AD and Mueller, CM (eds.), Frontiers in Social Movement Theory. 133-155. New Haven CT: Yale University Press.

Snow, D. A., Benford, R. D., McCammon, H. J., Hewitt, L., \& Fitzgerald, S. (2014). The Emergence, Development, and Future of the Framing Perspective: 25+ YEARS SINCE "FRAME ALIGNMENT". Mobilization: An International Quarterly, 19(1), 23-45.

Snow, D. A., Benford, R. D., \& others. (1988). Ideology, frame resonance, and participant mobilization. International Social Movement Research, 1(1), 197217.

Snow, D. A., Rochford, E. B., Worden, S. K., \& Benford, R. D. (1986). Frame Alignment Processes, Micromobilization, and Movement Participation. American Sociological Review, 51(4), 464. https://doi.org/10.2307/2095581

Sommer, D., \& Ruhrmann, G. (2010). Oughts and ideals: Framing people with migration background in TV news. 9(2), 15.

Spencer, M. E. (1970). Weber on Legitimate Norms and Authority. The British Journal of Sociology, 21(2), 123. https://doi.org/10.2307/588403

Spindler, W. (2015). 2015: The year of Europe's refugee crisis. UNHCR. https://www.unhcr.org/news/stories/2015/12/56ec1ebde/2015-year-europesrefugee-crisis.html

Sridhar, D., \& Woods, N. (2013). Trojan Multilateralism: Global Cooperation in Health. Global Policy, 4(4), 325-335. https://doi.org/10.1111/1758-5899.12066

Steets, J. (2009). Global governance as public policy networks and partnerships. In Palgrave Advances in Global Governance (pp.123-138). Springer.

Straubhaar, T. (1993). Migration Pressure. International Migration, 31(1), 5-41. https://doi.org/10.1111/j.1468-2435.1993.tb00717.x

Straubhaar, T. (2010). Why Do We Need a General Agreement on Movements of People. HWWA Discussion Paper, 94, 38.

Suess, J. (2014). Family governance - Literature review and the development of a conceptual model. Journal of Family Business Strategy, 5(2), 138-155. https://doi.org/10.1016/j.jfbs.2014.02.001

Sustainable Development Solutions Network, (SDSN). (2013). An Action Agenda for Sustainable Development. 
Sustainable Development Solutions Network, (SDSN). (2015). Indicators and a Monitoring Framework for the Sustainable Development Goals: Launching a Data Revolution.

Sutherland, P. D. (2013a). Migration 2.0: A time for action at the UN Summit on Migration and Development. Migration Policy Practice, 3(3), 3-7.

Sutherland, P. D. (2013b). Migration is development: How migration matters to the post-2015 debate. Migration and Development, 2(2), 151-156.

The United Nations Office on Drugs and Crime, (UNODC). (2012). Inputs by Member States for the post-2015 development agenda (UNODC01; E/CN.7/2012/CRP.11E/CN.15/2012/CRP.9). SDG Grey Literature Corpus. https://www.unodc.org/documents/commissions/CND/CND_Sessions/CN D_55Reconvened/E-CN7-2012-CRP11_V1257818_E.pdf

Thouez, C. (2018). Strengthening migration governance: The UN as 'wingman.' Journal of Ethnic and Migration Studies, 1-16. https://doi.org/10.1080/1369183X.2018.1441604

Thouez, C., \& Channac, F. (2005). Convergence and divergence in migration policy: The role of regional consultative processes. Global Migration Perspectives, 20, 14.

Türk, V. (2019). The Promise and Potential of the Global Compact on Refugees. International Journal of Refugee Law, 30(4), 575-583. https://doi.org/10.1093/ijrl/eey068

UN System Task Team on the Post-2015 UN Development Agenda, (UNTT). (2012). Realizing the Future We Want for All: Report to the Secretary General [Data set]. Koninklijke Brill NV. https://doi.org/10.1163/2210-7975_HRD-9823-0056

UN System Task Team on the Post-2015 UN Development Agenda, (UNTT). (2013). A Renewed Global Partnership for Development.

Union of International Associations. (2013). Historical overview of number of international organizations by type. https://uia.org/sites/uia.org/files/misc_pdfs/stats/Historical_overview_of_n umber_of_international_organizations_by_type_1909-2013.pdf

United Nations. (1945). Charter of the United Nations and the Statute of the International Court of Justice. United Nations. https://treaties.un.org/doc/publication/ctc/uncharter.pdf

United Nations. (2006). Secretary-General Appoints Peter Sutherland as Special Representative for Migration. United Nations. https://www.un.org/press/en/2006/sga976.doc.htm

United Nations. (2018a). Agency Revenue by Revenue Type. United Nations System Chief Executives Board for Coordination. https://www.unsystem.org/content/FS-A00-01

United Nations. (2018b). General Assembly Endorses First-Ever Global Compact on Migration, Urging Cooperation among Member States in Protecting Migrants I Meetings Coverage and Press Releases. United Nations Website. https://www.un.org/press/en/2018/ga12113.doc.htm 
United Nations. (2018c). Global Compact for Safe, Orderly and Regular Migration: Voting Records. http://digitallibrary.un.org/record/1656414

United Nations. (2019a). International Convention on the Protection of the Rights of All Migrant Workers and Members of their Families. United Nations Treaty Collection.

https://treaties.un.org/Pages/ViewDetails.aspx?src=IND\&mtdsg_no=IV$13 \&$ chapter $=4$

United Nations. (2019, September 5). UN establishes pioneering trust fund for cooperation on safe, orderly and regular migration. United Nations Website. https://www.un.org/development/desa/en/news/population/trust-fund-formigration.html

United Nations. (2019c). Member States | United Nations. https://www.un.org/en/member-states/

United Nations Archives, (UNA). (2003a, April 7). Letter exchange between Brunson McKinley and Louise Frechette regarding the preliminary report of the IOM Working Group on Institutional Arrangements (WG/IOM-UN/1) between 7 April 2003 and 10 June 2003 (S-1093-0048-11-00015). United Nations Archives.

United Nations Archives, (UNA). (2003b, August 6). Letters exchanged between Brunson McKinley and Ruud Lubbers between 6 August 2003 and 8 October 2003 (S-10930048-11-00026). United Nations Archives.

United Nations Archives, (UNA). (2003c, August 11). Letter from Brunson McKinley to Kofi Annan following up on a meeting in New York in August 2003 (S-1093-004811-00023). United Nations Archives.

United Nations Archives, (UNA). (2004, January 28). Letter from Janis Karklins to Kofi Annan regarding informal consultations on the IOM-UN relationship (S-10930035-11-00001). United Nations Archives.

United Nations Archives, (UNA). (2005, November 21). Letters addressed to Dr. Mamphela Ramphele and Mr. Jan O. Karlsson from Kofi Annan informing them of steps being taken to implement the proposals of the Global Commission on International Migration (S-1093-0022-10-00009). United Nations Archives.

United Nations Archives, (UNA). (2006a). Communications regarding the International Migration and Development Submission to the Policy Committee (2 versions of the document) (S-1092-0013-01-00009). United Nations Archives.

United Nations Archives, (UNA). (2006b, April 3). Letter from Peter Sutherland to Kofi Annan. S-1092-0005-01-00047.

United Nations Archives, (UNA). (2006c, April 3). Letter from Peter Sutherland to Kofi Annan regarding the Global Migration Forum (S-1100-0003-13-00013). United Nations Archives.

United Nations Archives, (UNA). (2006d, June 30). Letters exchanged between Mr. Brunson McKinley and Kofi Annan (reply by Mark Malloch Brown) between 30 June 2006 and 17 July 2006 (S-1093-0010-01-00002). United Nations Archives.

United Nations Archives, (UNA). (2006e, July 20). Letters between Mark Malloch Brown and Supachai Panitchpakdi regarding a Global Migration Forum (S-1092-0012-1000017). United Nations Archives. 
United Nations Archives, (UNA). (2006f). Note to the Secretary-General by Robert Orr: Consultative Forum for Migration (S-1092-0012-10-00014). United Nations Archives.

United Nations Archives, (UNA). (2006g). Note to the Secretary General by Jose Antonio Ocampo: Note on High-level Dialogue on Migration (S-1092-0012-10-00002). United Nations Archives.

United Nations Archives, (UNA). (2006h). Note to the Secretary General: Update on the Global Migration Forum (S-1093-0010-01-00003). United Nations Archives.

United Nations Archives, (UNA). (2006i). Note to the Secretary General by Jose Antonio Ocampo: High-level Dialogue on International Migration and Development (S1092-0012-09-00025). United Nations Archives.

United Nations Archives, (UNA). (2006j). Note to the Secretary General by Jose Antonio Ocampo: A Global Forum on International Migration and Development (S-10920012-09-00009). United Nations Archives.

United Nations Archives, (UNA). (2007). Note to the Secretary-General from Jose Antonio Ocampo: Global Forum on Migration and Development and the SRSG for International Migration and Development (1956-0025-0007-00014). United Nations Archives.

United Nations Archives, (UNA). (2008). Update on Migration and Development from Peter Sutherland to Ban Ki-Moon: September-December 2007 (S-1956-00560007-00006). United Nations Archives.

United Nations Archives, (UNA). (2013a, June 18). Letter from Peter Sutherland to Amina Mohammed enclosing the inputs from the informal working group (S-1959-01070001-00013). United Nations Archives.

United Nations Archives, (UNA). (2013b, July 24). Letter from William Lacy Swing to Jan Eliasson regarding preparations for the Second High Level Dialogue on International Migration and Development including remarks on the draft report of the Secretary-General (S-1959-0106-0006-00025). United Nations Archives.

United Nations Archives, (UNA). (2013c). Note to the Deputy Secretary-General from Lenni Montiel: Report of the Secretary-General on International Migration and Development (S-1959-0099-0003-00006). United Nations Archives.

United Nations Archives, (UNA). (2014a). Note from the Office of Legal Affairs (OLA) regarding a letter to the Secretary-General from the Director-General of IOM, requesting information on different modalities of association that currently exist between the United Nations and other international organizations in the UN system. (S-1959-0166-0010-00006). United Nations Archives.

United Nations Archives, (UNA). (2014b, December 8). Letter from William Lacy Swing to Jan Eliasson regarding IOM-UN relations with an enclosed copy of the Director General's Response to the Chairperson's Report on the Working Group on IOM-UN Relations and the IOM Strategy (C/105/CRP/48) (S-1959-0223-0006-00007). United Nations Archives.

United Nations Archives, (UNA). (2015). Letter from William Lacy Swing addresed to Jan Eliasson regarding a Briefing Note issued by the UN Development Group on New 
UNDG Functioning and Working Arrangements and IOM (2 March 2015) (S1959-0256-0008-00027) [Personal communication].

United Nations Archives, (UNA). (2015a, July 21). Update from Mr. Peter Sutherland, Special Representative of the Secretary-General for International Migration and Development (S-1959-0234-0004-00007). United Nations Archives.

United Nations Archives, (UNA). (2015b, November 4). Letter from Ban Ki-moon to the leaders of the G20 on 4 November 2015 ahead of their first meeting after the adoption of the 2030 Agenda for Sustainable Development (1959-0234-0009-00005). United Nations Archives.

United Nations Archives, (UNA). (2016, December 16). Secretary-General's letter to PGA on the appointment of SRSG for International Migration (S-1959-0311-000500006). United Nations Archives.

United Nations Children's Fund, (UNICEF). (2014). A Post-2015 World Fit for Children: An Agenda for \#Everychild 2015 (UNICEF09). SDG Grey Literature Corpus. https://www.unicef.org/media/files/2pager_everychild_FINAL_webFINAL. pdf

United Nations Department of Economic and Social Affairs (UNDESA). (2014). Twelfth Coordination Meeting on International Migration. Twelfth Coordination Meeting on International Migration. https://www.un.org/en/development/desa/population/migration/events/co ordination/12/documents/2014_CM_Report_Final.pdf

United Nations Department of Economic and Social Affairs, (UNDESA). (2015). Thirteenth Coordination Meeting on International Migration. https://www.un.org/en/development/desa/population/migration/events/co ordination/13/documents/2015_CM_Report_Final.pdf

United Nations Development Programme, (UNDP). (2013). Issues for a Global Human Development Agenda (UNDP07; Human Development Report Office Occasional Paper Series). SDG Grey Literature Corpus. http://hdr.undp.org/sites/default/files/issues_for_a_global_human_develop ment_agenda-hdro-feb_2013.pdf

United Nations Entity for Gender Equality and the Empowerment of Women, (UN Women). (2013a). Advancing Gender Equality: Promising Practices-Case Studies from the Millennium Development Goals Achievement Fund (UNWOMEN04). SDG Grey Literature Corpus. https://www.unwomen.org/mdgf/downloads/MDG-F_Case-Studies_SP.pdf

United Nations Entity for Gender Equality and the Empowerment of Women, (UN Women). (2013b). Hearts and Minds: Women of India Speak: Shaping the Post2015 Development Discourse and Agenda (UNWOMEN20). SDG Grey Literature Corpus. https://www.unwomen.org//media/headquarters/attachments/sections/library/publications/2014/hearts \%20and\%20minds\%208\%20august $\% 202013 \% 20$ final\%20pdf.pdf?la=en

United Nations High Commissioner for Refugees, (UNHCR). (2017, May 17). Towards a global compact on refugees: A roadmap. UNHCR. 
https://www.unhcr.org/events/conferences/58e625aa7/towards-globalcompact-refugees-roadmap.html

United Nations Population Fund, (UNFPA). (n.d.). The Future UNFPA Wants for AIl: Keys for the Post-2015 Development Agenda (UNFPA14). SDG Grey Literature Corpus.

United States Department of State. (1960). Press Releases. https://books.google.nl/books?id=n91IAQAAIAAJ\&pg=RA25PP15\&dq=Andrejs+Suritis\&hl=nl\&sa=X\&ved=0ahUKEwidzfKSqozlAhUKK 1AKHWv7CvoQ6AEIMDAB\# $\mathrm{v}=$ onepage\& $\mathrm{q}=$ Andrejs $\% 20$ Suritis\&f=false

U.S. Mission to the United Nations. (2017). United States Ends Participation in Global Compact on Migration I United States Mission to the United Nations. https://usun.usmission.gov/united-states-ends-participation-in-globalcompact-on-migration/

Valarezo, G. (2015). Offloading Migration Management: The Institutionalized Authority of Non-State Agencies over the Guatemalan Temporary Agricultural Worker to Canada Project. Journal of International Migration and Integration, 16(3), 661-677. https://doi.org/10.1007/s12134-014-0351-7

Vammen, I. M., \& Brønden, B. M. (2012). Donor-Country Responses to the MigrationDevelopment Buzz: From Ambiguous Concepts to Ambitious Policies? International Migration, 50(3), 26-42.

Van Gorp, B. (2005). Where is the Frame?: Victims and Intruders in the Belgian Press Coverage of the Asylum Issue. European Journal of Communication, 20(4), 484507. https://doi.org/10.1177/0267323105058253

van Hulst, M., \& Yanow, D. (2016). From Policy "Frames" to "Framing": Theorizing a More Dynamic, Political Approach. The American Review of Public Administration, 46(1), 92-112. https://doi.org/10.1177/0275074014533142

Van Langenhove, L. (2010). The Transformation of Multilateralism Mode 1.0 to Mode 2.0: Multilateralism 2.0. Global Policy, 1(3), 263-270. https://doi.org/10.1111/j.1758-5899.2010.00042.x

Villanueva Ulfgard, R., \& Alejo Jaime, A. (2014). New multilateralism and governmental mechanisms for including civil society during Mexico's presidency of the G20 in 2012. Third World Quarterly, 35(8), 1529-1546. https://doi.org/10.1080/01436597.2014.946662

Vitorino, A. (2019). The Global Compact for Safe, Orderly and Regular Migration: What's Next. International Migration, 57(6), 19-22. https://doi.org/10.1111/imig.12672

Vliegenthart, R., \& Roggeband, C. (2007). Framing Immigration and Integration: Relationships between Press and Parliament in the Netherlands. International Communication Gazette, 69(3), 295-319. https://doi.org/10.1177/1748048507076582

Vliegenthart, R., \& van Zoonen, L. (2011). Power to the frame: Bringing sociology back to frame analysis. European Journal of Communication, 26(2), 101-115. https://doi.org/10.1177/0267323111404838 
Vollmer, B. A. (2016). New Narratives from the EU External Border - Humane Refoulement? Geopolitics, 21(3), 717-741. https://doi.org/10.1080/14650045.2016.1154843

Von Koppenfels, A. K. (2001). Informal but Effective: Regional Consultative Processes as a Tool in Managing Migration. International Migration, 39(6), 61-84. https://doi.org/10.1111/1468-2435.00179

von Lucke, F. (2019). Principled Pragmatism in Climate Policy? The EU and Changing Practices of Climate Justice. The EU and Changing Practices of Climate Justice (July 12, 2019). GLOBUS Research Paper, 2.

Wall, P. (2018). In a Constructive Informal and Pragmatic Spirit. Intergovernmental Consultations on Migration, Asylum and Refugees (IGC).

Warner, K. (2018). Coordinated approaches to large-scale movements of people: Contributions of the Paris Agreement and the Global Compacts for migration and on refugees. Population and Environment, 39(4), 384-401. https://doi.org/10.1007/s11111-018-0299-1

Weber, S. (1992). Shaping the postwar balance of power: Multilateralism in NATO. International Organization, 46(3), 633-680. https://doi.org/10.1017/S0020818300027855

Wee, K., Vanyoro, K. P., \& Jinnah, Z. (2018). Repoliticizing international migration narratives? Critical reflections on the Civil Society Days of the Global Forum on Migration and Development. Globalizations, 15(6), 795-808. https://doi.org/10.1080/14747731.2018.1446600

Weible, C. M. (2008). Expert-Based Information and Policy Subsystems: A Review and Synthesis. Policy Studies Journal, 36(4), 615-635. https://doi.org/10.1111/j.1541-0072.2008.00287.x

Weible, C. M., Sabatier, P. A., Jenkins-Smith, H. C., Nohrstedt, D., Henry, A. D., \& deLeon, P. (2011). A Quarter Century of the Advocacy Coalition Framework: An Introduction to the Special Issue: Weible et al.: An Introduction to the Special Issue. Policy Studies Journal, 39(3), 349-360. https://doi.org/10.1111/j.1541-0072.2011.00412.x

Weible, C. M., Sabatier, P. A., \& McQueen, K. (2009). Themes and Variations: Taking Stock of the Advocacy Coalition Framework. Policy Studies Journal, 37(1), 121-140. https://doi.org/10.1111/j.1541-0072.2008.00299.x

Weiss, J. A. (1989). The powers of problem definition: The case of government paperwork. Policy Sciences, 22(2), 97-121. https://doi.org/10.1007/BF00141381

Weiss, T. G. (2000). Governance, good governance and global governance: Conceptual and actual challenges. Third World Quarterly, 21(5), 795-814. https://doi.org/10.1080/713701075

Weiss, T. G., \& Kamran, A. Z. (2009). Global governance as international organization. In Palgrave Advances in Global Governance (pp.66-86). Springer.

Whitman, J. (2009a). Global governance as sector-specific management. In Palgrave Advances in Global Governance (pp.139-159). Springer.

Whitman, J. (2009b). The fundamentals of global governance. Palgrave Macmillan. 
Widgren, J. (1990). International Migration and Regional Stability. International Affairs, 66(4), 749-766.

World Bank. (2014). Migration and Remittances: Recent Developments and Outlook (WB02; No. 22; Migration and Development Brief). The World Bank; SDG Grey Literature Corpus. https://doi.org/10.1596/1813-9450-5512

World Bank. (2015). Migration and Remittances: Recent Developments and Outlook Special Topic: Financing for Development (WB01; No. 24; Migration and Development Brief). SDG Grey Literature Corpus. http://pubdocs.worldbank.org/en/773611444756855376/MigrationandDevel opmentBrief24.pdf

World Trade Organization. (2020). Movement of natural persons. World Trade Organization.

https://www.wto.org/english/tratop_e/serv_e/mouvement_persons_e/mouv ement_persons_e.htm

Wouters, J., \& Wauters, E. (2019). The UN Global Compact for Safe, Orderl and Regular Migration: Some Reflections. Leuven Centre for Global Governance Studies Working Paper No. 210, 18.

Wunderlich, D. (2012). Europeanization through the Grapevine: Communication Gaps and the Role of International Organizations in Implementation Networks of EU External Migration Policy. Journal of European Integration, 34(5), 485-503. https://doi.org/10.1080/07036337.2011.611385

Zürn, M. (2018). A theory of global governance: Authority, legitimacy, and contestation. Oxford University Press. 


\title{
Annexes
}

\author{
Annex 3.1 Information Letter \\ Maastricht Graduate School of Governance I UNU-MERIT, Maastricht University \\ Boschstraat 24, $6211 \mathrm{AX}$, Maastricht \\ The Netherlands, T: +31 433884652
}

Title of Project: The Role of International Organizations in Migration Governance

Principal Investigator(s): Elaine McGregor - PhD Fellow at the Maastricht Graduate School of Governance, Maastricht University I UNU-MERIT (Supervision team: Ronald Skeldon, Michal Natorski and Melissa Siegel)

1. Purpose of the Study: The purpose of this research is to understand the role of international organizations in the evolution of the migration and development debate and to understand what impact, if any, this has had on migration governance. The interviews will contribute to this goal by investigating the relative importance of different factors in influencing migration narratives over time.

2. Procedures to be followed: You will be invited to take part in an interview that is anticipated to last approximately one hour. During the interview you will be asked questions about your engagement in migration issues throughout your career. With your permission, the interview will be recorded and later transcribed. The recording itself will be stored on a secure server only accessible to the researcher and her supervision team. It may be made available for the purpose of verifying the validity of the research findings. The interviews will only be used for the purpose of this study and not shared with any third parties.

3. Discomforts and Risks: There are no risks in participating in this research beyond those experienced in everyday life. Some of the questions may be politically sensitive. However, you are always able to decline to answer any question at any time.

4. Benefits: There are no direct benefits (e.g., compensation) to participating in this interview. However, you may feel satisfied knowing your participation helps to improve the knowledge about what drives debates on migration and development.

5. Duration/Time: The interview should not take longer than 1 hour to complete in its entirety.

6. Statement of Confidentiality: Your participation in this research is confidential. Even though the interview asks for certain identifying information, they will be 
anonymized with code numbers for all future purposes. Selected quotations may be used for illustrative purposes in future work; however, you will not be personally identified.

7. Right to Ask Questions: Please contact Elaine McGregor (e.mcgregor@maastrichtuniversity.nl) or her supervisor Ronald Skeldon (r.skeldon@sussex.ac.uk) with any questions, complaints, or concerns about this research.

8. Voluntary Participation: Your decision to participate in this research is voluntary. You can stop at any time. You do not have to answer any questions you do not want to answer. 


\section{Annex 3.2 Interview Guide}

\section{Interview Guide}

My name is Elaine McGregor, and I am currently a researcher at Maastricht University. My $\mathrm{PhD}$ research is focused on migration governance. As a professional working in the area of migration, I am thus interested in understanding your thoughts and experiences with regard to key events and people that have been influential in the field of migration at the global policy level. I would like to record the interview to ensure that I accurately recall the details of our discussion. However, all contributions will be completely anonymized. Do you agree to participate in the interview and give permission for the interview to be recorded?

\section{Introduction}

Please introduce yourself and explain your current role at <organization>.

Prompts: is migration part of your current work portfolio? In what ways?

How long have you worked on migration issues? In what capacity? For whom?

Prompts: have you worked for other IGOs? States? NGOs? Have you always worked on migration issues? Were there gaps? Why?

How long has your organization worked on migration issues? Constantly? Has it been more intense at specific points in time? Please explain.

What led you to work on migration? (i.e., personal motivation, career opportunity)

\section{Events}

Have any key events influenced your work on migration during your career? (e.g., economic, political, organizational) If so, in what ways?

\section{Individuals}

Are there specific individuals that you think are particularly noteworthy who have influenced the way migration is discussed at the global policy level a) within your organization b) externally?

Prompts: Who are they? In what way(s) have they influenced the discussion? Have you worked directly with these individuals? 


\section{Organizations}

Are there specific international organizations (IGO or NGO) that you think are particularly noteworthy who have influenced the way migration is discussed at the global policy level? In what way?

Prompts: What organizations? In what way(s) have they influenced the discussion? Have you worked directly with these organizations? In what way(s)?

\section{Governments}

Are there specific governments that you think are particularly noteworthy who have influenced the way migration is discussed at the global policy level? In what way?

Prompts: What governments? In what way(s) have they influenced the discussion? Have you worked directly with these governments? In what way(s)?

\section{Funders}

Are there specific funders that you think are particularly noteworthy who have influenced the way migration is discussed at the global policy level? In what way?

Prompts: What funders? In what way(s) have they influenced the discussion? Have you worked directly with these funders? In what way(s)?

\section{Publications}

Are there specific publications that you think are particularly noteworthy that have influenced the way migration is discussed at the global policy level? In what way?

Prompts: What publications? In what way(s) have they influenced the discussion? Were you involved in the preparation of this publication? In what way(s)?

\section{Other Influences}

Has anything else influenced the way migration is discussed at the global level? (e.g., specific processes?) 


\section{Specific Events}

\section{Sustainable Development Goals}

What do you think about the inclusion of migration in the SDGs?

Why do you think migration was included in the SDGs but not in the MDGs?

Were you involved in the run-up to the adoption of the MDGs? In what way? Were you supported or assisted by anyone if your efforts in this area (e.g., funders/States/collaboration with other IOs?)

Were you involved in the run-up to the adoption of the SDGs? In what way? Were you supported or assisted by anyone if your efforts in this area (e.g., funders/States/collaboration with other IOs?)

If applicable, how did the lead up to the MDGs and the SDGs differ?

Do you think any specific individuals or organizations influenced the inclusion of migration in the SDGs? In what way?

Has anything changed in the way your organization works on migration as a result of the inclusion of migration in the SDGs? If applicable, what has changed?

\section{Global Compact for Safe, Regular and Orderly Migration and a Comprehensive Refugee Response Framework}

Have you been involved in discussions surrounding the elaboration of a Global Compact for Safe, Regular and Orderly Migration and/or Comprehensive Refugee Response Framework? If yes, how? If no, skip to q23

Have you been supported or assisted by anyone if your efforts in this area thus far (e.g., funders/States/collaboration with other IGOS)?

What do you think of the process?

Do you think it will lead to a stronger multilateral framework for the global governance of migration? Why or why not? 
Who have been the most visible individuals/IGOs/states in the negotiations thus far? In what ways?

\section{IOM and the UN}

What do you think of IOM joining the UN system? Do you support IOM joining the UN? Do you have any hesitation?

What factors do you think led to IOM joining the UN system?

What changes, if any, do you think will happen as a result of IOM joining the UN system?

(If not IOM and changes are reported) Do you think these changes will affect your organization, if at all?

\section{Closing}

Thank you for your time. Is there anything we have not yet covered that you would like to add?

Is there anyone else that you would recommend that I speak to? 


\section{Annex 3.3 Code Book}

\begin{tabular}{|c|c|c|c|}
\hline Name & Description & Files & References \\
\hline Frames & $\begin{array}{l}\text { This node captures examples of how migration has } \\
\text { been framed in different ways. Broadly, there are } \\
\text { three child nodes (or frames), which are } 1 . \\
\text { development; 2. migration management; and } 3 . \\
\text { human rights, which correspond to the pillars of } \\
\text { the UN system. }\end{array}$ & 42 & 419 \\
\hline Development_Frame & $\begin{array}{l}\text { Captures examples of the migration and } \\
\text { development frame }\end{array}$ & 32 & 92 \\
\hline Human_Rights_Frame & $\begin{array}{l}\text { Captures examples of the 'human rights' } \\
\text { frame }\end{array}$ & 21 & 55 \\
\hline Management_Frame & $\begin{array}{l}\text { Captures examples of the 'migration } \\
\text { management' frame }\end{array}$ & 9 & 17 \\
\hline Frame_Shift & $\begin{array}{l}\text { Captures accounts of when a shift in framing } \\
\text { occurs }\end{array}$ & 23 & 45 \\
\hline Frame Conflicts & $\begin{array}{l}\text { Captures accounts of conflicts between } \\
\text { frames }\end{array}$ & 26 & 79 \\
\hline Categories & $\begin{array}{l}\text { Captures accounts of how the categorization } \\
\text { of different mobile populations affects } \\
\text { governance. This mostly relates to the } \\
\text { refugee vs migrant distinction }\end{array}$ & 24 & 63 \\
\hline Metaphors & $\begin{array}{l}\text { Captures any metaphors used to describe } \\
\text { either migration or the process of its } \\
\text { governance }\end{array}$ & 21 & 39 \\
\hline Narratives in General & $\begin{array}{l}\text { Captures accounts of how narratives are } \\
\text { constructed }\end{array}$ & 10 & 16 \\
\hline Global Initiatives & $\begin{array}{l}\text { This node captures all references to various } \\
\text { milestones in the evolution of migration as a } \\
\text { policy issue. }\end{array}$ & 41 & 464 \\
\hline 2004 ILO GB & $\begin{array}{l}\text { References to the } 2004 \text { Meeting of the ILO } \\
\text { Governing Body }\end{array}$ & 1 & 4 \\
\hline Berne & References to the Berne Initiative & 9 & 14 \\
\hline CAP - Vietnam & $\begin{array}{l}\text { References to the Comprehensive Plan of } \\
\text { Action for Indochinese Refugees in } 1989\end{array}$ & 2 & 3 \\
\hline Doha & $\begin{array}{l}\text { References to the Doha Round of Trade } \\
\text { Negotiations in } 2001\end{array}$ & 2 & 4 \\
\hline GCIM & $\begin{array}{l}\text { References to the Global Commission on } \\
\text { International Migration }\end{array}$ & 23 & 50 \\
\hline GFMD & $\begin{array}{l}\text { References to the Global Forum on Migration } \\
\text { and Development }\end{array}$ & 29 & 78 \\
\hline Global Compacts & References to the Global Compacts & 13 & 21 \\
\hline GCM & $\begin{array}{l}\text { References to the Global Compact for Safe, } \\
\text { Orderly and Regular Migration }\end{array}$ & 27 & 64 \\
\hline GCR & $\begin{array}{l}\text { References to the Global Compact on } \\
\text { Refugees }\end{array}$ & 4 & 7 \\
\hline
\end{tabular}




\begin{tabular}{|c|c|c|c|}
\hline Name & Description & Files & References \\
\hline GMG & References to the Global Migration Group & 17 & 27 \\
\hline HLD 2006 & $\begin{array}{l}\text { References to the first High-Level Dialogue } \\
\text { on International Migration and Development } \\
\text { in } 2006\end{array}$ & 21 & 34 \\
\hline HLD 2013 & $\begin{array}{l}\text { References to the second High-Level } \\
\text { Dialogue on International Migration and } \\
\text { Development in } 2013\end{array}$ & 12 & 20 \\
\hline ICPD & $\begin{array}{l}\text { References to the } 1994 \text { International } \\
\text { Conference on Population and Development } \\
\text { (ICPD) in Cairo }\end{array}$ & 15 & 23 \\
\hline IDM & $\begin{array}{l}\text { References to IOM's International Dialogue } \\
\text { on Migration (IDM) in } 2001\end{array}$ & 2 & 2 \\
\hline IGC + RCPS & $\begin{array}{l}\text { References to the Intergovernmental } \\
\text { Consultations on Migration, Asylum and } \\
\text { Refugees (IGC) and other Regional } \\
\text { Consultative Processes }\end{array}$ & 11 & 27 \\
\hline ILO C143 & $\begin{array}{l}\text { References to the Migrant Workers } \\
\text { (Supplementary Provisions) Convention } \\
1975 \text { (No. 143) }\end{array}$ & 6 & 8 \\
\hline ILO C97 & $\begin{array}{l}\text { References to the Migration for Employment } \\
\text { Convention (Revised), } 1949 \text { (No. 97) }\end{array}$ & 6 & 10 \\
\hline MICIC & $\begin{array}{l}\text { References to the Migrants in Countries in } \\
\text { Crisis Initiative }\end{array}$ & 1 & 2 \\
\hline MLF & $\begin{array}{l}\text { References to ILO's } 2006 \text { Multilateral } \\
\text { Framework on Labour Migration }\end{array}$ & 3 & 5 \\
\hline ICRMW & $\begin{array}{l}\text { References to the } 1990 \text { International } \\
\text { Convention on the Protection of the Rights of } \\
\text { All Migrant Workers and Members of Their } \\
\text { Families (ICRMW) }\end{array}$ & 9 & 14 \\
\hline NYD and Summit & $\begin{array}{l}\text { References to the New York Declaration and } \\
\text { the High-Level Summit to Address the Large } \\
\text { Movements of Refugees and Migrants in } \\
\text { September } 2016\end{array}$ & 19 & 31 \\
\hline Rio +20 & $\begin{array}{l}\text { References to the UN Conference on } \\
\text { Sustainable Development (Rio+20) }\end{array}$ & 4 & 5 \\
\hline SDGs & $\begin{array}{l}\text { References to the Sustainable Development } \\
\text { Goals }\end{array}$ & 27 & 81 \\
\hline Governance Drivers & $\begin{array}{l}\text { This node captures the factors that are drivers of } \\
\text { changes in the way migration has been discussed } \\
\text { at the international level. }\end{array}$ & 42 & 642 \\
\hline Conflict (end of) & $\begin{array}{l}\text { Capture accounts of how the period of } \\
\text { transformation after a conflict (e.g., World } \\
\text { War 2, the Cold War) provides momentum } \\
\text { for international dialogue }\end{array}$ & 9 & 18 \\
\hline Crisis & $\begin{array}{l}\text { Capture accounts of how crises provide } \\
\text { momentum for international dialogue }\end{array}$ & 29 & 56 \\
\hline
\end{tabular}




\begin{tabular}{|c|c|c|c|}
\hline Name & Description & Files & References \\
\hline Demography & $\begin{array}{l}\text { Captures accounts of the implications of } \\
\text { demographic change for global governance }\end{array}$ & 5 & 6 \\
\hline Economic & $\begin{array}{l}\text { Captures accounts of the implications of } \\
\text { economic factors on migration governance }\end{array}$ & 9 & 14 \\
\hline Events & $\begin{array}{l}\text { Captures specific occurrences that have } \\
\text { impacted global migration governance. } \\
\text { Examples include 9/11, Lampedusa, or Alan } \\
\text { Kurdi's death }\end{array}$ & 18 & 28 \\
\hline Governments & $\begin{array}{l}\text { Captures accounts of states influencing what } \\
\text { is possible in terms of international } \\
\text { cooperation }\end{array}$ & 40 & 202 \\
\hline Ideology & $\begin{array}{l}\text { Captures how ideological shifts have } \\
\text { influenced governance }\end{array}$ & 13 & 20 \\
\hline Media & $\begin{array}{l}\text { Captures how the media have influence } \\
\text { governance }\end{array}$ & 8 & 11 \\
\hline Money & $\begin{array}{l}\begin{array}{l}\text { Captures how money drives global } \\
\text { governance }\end{array} \\
\end{array}$ & 25 & 61 \\
\hline Organizations & $\begin{array}{l}\text { Captures the role of specific organizations in } \\
\text { driving global migration governance. }\end{array}$ & 31 & 78 \\
\hline People & $\begin{array}{l}\text { Captures the role of specific individuals in } \\
\text { driving global migration governance }\end{array}$ & 31 & 95 \\
\hline Technology & $\begin{array}{l}\text { Captures accounts of the implications of } \\
\text { technological change for global governance }\end{array}$ & 5 & 5 \\
\hline Time & $\begin{array}{l}\text { Captures accounts of global migration } \\
\text { governance as a temporal phenomenon }\end{array}$ & 13 & 18 \\
\hline Individuals & $\begin{array}{l}\text { This node captures ALL mentions of individuals } \\
\text { by interviewees }\end{array}$ & 40 & 643 \\
\hline Key & $\begin{array}{l}\text { Captures individuals who are considered by } \\
\text { the interviewee to have been key actors in } \\
\text { migration governance and is qualified in two } \\
\text { ways: } \\
\text { 1) the name is offered in answer to a direct } \\
\text { question about key individuals } \\
\text { 2) the interviewee describes the specific } \\
\text { individual's role in achieving something } \\
\text { specific, often using descriptive adjectives } \\
\text { such as 'influential' and 'key' }\end{array}$ & 25 & 121 \\
\hline Mentions & Captures all other individuals. & 40 & 506 \\
\hline$I O M$ & This node captures any mentions of IOM. & 39 & 428 \\
\hline Descriptions & $\begin{array}{l}\text { Captures the different ways that } \\
\text { interviewees describe and refer to IOM as an } \\
\text { organization }\end{array}$ & 33 & 173 \\
\hline IOM Journey to UN & $\begin{array}{l}\text { Captures accounts of IOM's journey in the } \\
\text { UN }\end{array}$ & 34 & 254 \\
\hline $\begin{array}{l}\text { Views on } \mathrm{UN} \\
\text { Membership }\end{array}$ & $\begin{array}{l}\text { Captures different views on IOM becoming a } \\
\text { related agency of the UN }\end{array}$ & 16 & 26 \\
\hline
\end{tabular}




\begin{tabular}{|c|c|c|c|}
\hline Name & Description & Files & References \\
\hline $\begin{array}{l}\text { Reasons for UN } \\
\text { Membership }\end{array}$ & $\begin{array}{l}\text { Captures the reasons why IOM became part } \\
\text { of the UN }\end{array}$ & 23 & 83 \\
\hline Specific Individuals & $\begin{array}{l}\text { Captures the role of specific individuals in } \\
\text { IOM becoming a UN agency }\end{array}$ & 19 & 34 \\
\hline Governments & $\begin{array}{l}\text { Captures the role of specific governments in } \\
\text { IOM becoming a UN Member }\end{array}$ & 19 & 43 \\
\hline Migration Journey & $\begin{array}{l}\text { Captures the argument that IOM joining the } \\
\text { UN was part of the strategy to bring } \\
\text { migration into the UN }\end{array}$ & 14 & 22 \\
\hline SDGs & $\begin{array}{l}\text { Captures the argument that the inclusion of } \\
\text { migration in the SDGs is the reason why IOM } \\
\text { joined the UN }\end{array}$ & 5 & 7 \\
\hline Fear of Exclusion & $\begin{array}{l}\text { Captures the argument that IOM feared } \\
\text { being excluded from work on migration if it } \\
\text { did not join the UN }\end{array}$ & 4 & 5 \\
\hline Crisis & $\begin{array}{l}\text { Captures the argument that the migration } \\
\text { crises of } 2015 \text { led IOM to join the UN }\end{array}$ & 4 & 6 \\
\hline Specific Individuals & $\begin{array}{l}\text { Based on an initial systematic coding of all } \\
\text { mentions of individuals (see 'individuals' node), } \\
\text { the most commonly recurring nodes were then } \\
\text { coded to capture accounts of how these } \\
\text { individuals were viewed in terms of the role in } \\
\text { migration governance. }\end{array}$ & 36 & 201 \\
\hline Peter Sutherland & Reference to Peter Sutherland & 30 & 97 \\
\hline Kofi Annan & References to Kofi Annan & 23 & 55 \\
\hline William Lacy Swing & References to William Lacy Swing & 21 & 49 \\
\hline
\end{tabular}




\section{Annex 3.4 UN Archives}

\begin{tabular}{|c|c|c|}
\hline Reference & Date & Broad Description \\
\hline S-1062-0022-0005-00001 & 23-12-1994 & Internally Displaced Persons \\
\hline S-1953-0078-0002-00005 & 02-07-1995 & Central Emergency Response Fund (CERF) \\
\hline S-1093-0086-04-00001 & 07-01-1997 & $\begin{array}{l}\text { Letter inviting Secretary-General to IOM } \\
\text { seminar }\end{array}$ \\
\hline S-1092-0138-01-00027 & 13-01-1997 & $\begin{array}{l}\text { Invitation to Inter-Agency Standing Committee } \\
\text { Meeting }\end{array}$ \\
\hline S-1093-0086-04-00002 & 09-05-1997 & $\begin{array}{l}\text { Summary of Meeting about demobilization in } \\
\text { Angola }\end{array}$ \\
\hline S-1093-0086-04-00003 & 16-05-1997 & Draft letter for UN PRs about Angola \\
\hline S-1092-0130-04-00034 & 29-05-1997 & $\begin{array}{l}\text { Letter to Peter Sutherland (highlights early } \\
\text { relationship) }\end{array}$ \\
\hline S-1093-0086-04-00004 & 03-06-1997 & $\begin{array}{l}\text { Summary of 73rd Special Session of the Council } \\
\text { of the IOM }\end{array}$ \\
\hline S-1093-0086-04-00005 & 04-06-1997 & $\begin{array}{l}\text { Submission of a report on IDPs to Secretary- } \\
\text { General }\end{array}$ \\
\hline S-1096-0344-01-00016 & 10-06-1997 & $\begin{array}{l}\text { Draft preface by the Secretary-General for } \\
\text { Masses in Flight }\end{array}$ \\
\hline S-1094-0027-02-00017 & $27-06-1997$ & Letter regarding IDPs (and IOM creeping in) \\
\hline S-1092-0137-07-00012 & 02-07-1997 & $\begin{array}{l}\text { Russian views on reform of the humanitarian } \\
\text { cluster. }\end{array}$ \\
\hline S-1093-0124-04-00034 & $19-07-1997$ & $\begin{array}{l}\text { Report on Regional Conference CIS and one on } \\
\text { UAM }\end{array}$ \\
\hline S-1093-0086-04-00006 & $16-09-1997$ & Angola \\
\hline S-1093-0086-04-00007 & 23-09-1997 & $\begin{array}{l}\text { Robert Paiva appointed as Permanent Observer } \\
\text { for IOM to UN }\end{array}$ \\
\hline S-1093-0086-04-00008 & 23-09-1997 & $\begin{array}{l}\text { Letter to Mr Purcell about the appointment of } \\
\text { Rover Paiva }\end{array}$ \\
\hline S-1093-0086-04-00009 & 07-10-1997 & Agenda for 74th session \\
\hline S-1093-0122-04-00020 & $10-10-1997$ & UN-OSCE Cooperation \\
\hline S-1093-0086-04-00010 & $30-10-1997$ & World Bank contribution for Angola \\
\hline S-1098-0151-07-00004 & 01-11-1997 & Brief 9: Refugees \\
\hline S-1093-0086-04-00011 & 30-01-1998 & $\begin{array}{l}\text { Executive Office of the Secretary-General } \\
\text { informing } \\
\text { recommendation for IOM post }\end{array}$ \\
\hline S-1094-0024-05-00053 & $10-02-1998$ & $\begin{array}{l}\text { Report of the Representative of the Secretary- } \\
\text { General on IDPs }\end{array}$ \\
\hline S-1093-0086-04-00012 & $17-02-1998$ & $\begin{array}{l}\text { Russian Permanent Representative writing } \\
\text { about refugees in CIS }\end{array}$ \\
\hline S-1093-0115-04-00042 & $17-02-1998$ & $\begin{array}{l}\text { Programme of Action of the Geneva Regional } \\
\text { Conference to Address the Problems of } \\
\text { Refugees, Displaced Persons, Other Forms of } \\
\text { Involuntary Displacement and Returnees in the } \\
\text { Countries of the Commonwealth of }\end{array}$ \\
\hline
\end{tabular}




\begin{tabular}{|c|c|c|}
\hline Reference & Date & Broad Description \\
\hline & & $\begin{array}{l}\text { Independent States and Relevant Neighbouring } \\
\text { States }\end{array}$ \\
\hline S-1097-0011-01-00026 & $20-03-1998$ & Press Briefing \\
\hline S-1093-0086-04-00013 & 02-06-1998 & 75th session of the IOM Council \\
\hline S-1096-0311-06-00007 & $10-07-1998$ & $\begin{array}{l}\text { Letter exchange with James Purcell about the } \\
\text { death of Special Representative in Angola }\end{array}$ \\
\hline S-1093-0115-03-00045 & 06-08-1998 & $\begin{array}{l}\text { Follow-up to the Regional Conference to } \\
\text { Address the Problems of Refugees, Displaced } \\
\text { Persons., Other Forms of Involuntary } \\
\text { Displacement and Returnees in the Countries of } \\
\text { the Commonwealth of Independent States and } \\
\text { Relevant Neighbouring States }\end{array}$ \\
\hline S-1093-0086-04-00014 & 01-10-1998 & $\begin{array}{l}\text { Notifying UNITAR and other UN agency } \\
\text { directors of his appointment as IOM Director- } \\
\text { General }\end{array}$ \\
\hline S-1093-0086-04-00015 & 03-11-1998 & Letter to Mr Purcell about IOM-UN relations \\
\hline S-1093-0112-04-00030 & 13-11-1998 & Cooperation between the UN and the OSCE \\
\hline S-1093-0086-04-00016 & $16-11-1998$ & $\begin{array}{l}\text { Letter to Brunson McKinley about his } \\
\text { appointment }\end{array}$ \\
\hline S-1093-0086-04-00017 & 03-12-1998 & $\begin{array}{l}\text { Fax from UNOG summarizing 76th Council } \\
\text { meeting }\end{array}$ \\
\hline S-1093-0106-07-00019 & $18-12-1998$ & $\begin{array}{l}\text { Regional Population Meeting Budapest. 7-9 } \\
\text { December } 1998\end{array}$ \\
\hline S-1094-0024-04-00003 & $18-12-1998$ & $\begin{array}{l}\text { The mandate of the Representative of the } \\
\text { Secretary-General on IDPs }\end{array}$ \\
\hline S-1093-0086-04-00018 & 04-05-1999 & $\begin{array}{l}\text { Brunson McKinley invited to meeting about } \\
\text { Balkan crisis }\end{array}$ \\
\hline S-1093-0086-04-00019 & 10-05-1999 & $\begin{array}{l}\text { Meeting on Balkan crisis referenced in S-1093- } \\
0086-04-00018\end{array}$ \\
\hline S-1096-0272-03-00053 & 10-05-1999 & $\begin{array}{l}\text { Thanking Mr Riza for inviting IOM to Balkan } \\
\text { meeting }\end{array}$ \\
\hline S-1093-0086-04-00020 & 18-05-1999 & Appointment of Martin Griffiths for Balkans \\
\hline S-1093-0086-04-00021 & 23-08-1999 & Resignation notification from Narcisa Escaler \\
\hline S-1093-0086-04-00023 & 23-08-1999 & $\begin{array}{l}\text { Letter to Louise Frechette notifying about } \\
\text { resignation }\end{array}$ \\
\hline S-1093-0086-04-00022 & 08-10-1999 & $\begin{array}{l}\text { Relates to the situation in Guatemala } \\
\text { (irregularities) }\end{array}$ \\
\hline S-1093-0086-04-00024 & $08-10-1999$ & Letter to Permanent Representative Guatemala \\
\hline S-1093-0106-07-00001 & 31-11-1999 & $\begin{array}{l}1999 \text { Review and Appraisal of the ICPD } \\
\text { Programme of Action }\end{array}$ \\
\hline S-1093-0090-02-00009 & $07-03-2000$ & On role of UNHCR and IDPs \\
\hline S-1093-0101-06-00040 & $29-06-2000$ & $\begin{array}{l}\text { Cooperation between the United Nations and } \\
\text { the Organization for Security and Cooperation } \\
\text { in Europe }\end{array}$ \\
\hline S-1093-0089-07-00023 & $31-08-2000$ & $\begin{array}{l}\text { Follow-up to the Regional Conference to } \\
\text { Address the Problems of Refugees, Displaced } \\
\text { Persons, Other Forms of Involuntary }\end{array}$ \\
\hline
\end{tabular}




\begin{tabular}{|c|c|c|}
\hline Reference & Date & Broad Description \\
\hline & & $\begin{array}{l}\text { Displacement and Returnees in the Countries of } \\
\text { the Commonwealth of Independent States and } \\
\text { Relevant Neighbouring States }\end{array}$ \\
\hline S-1093-0092-03-00018 & $13-12-2000$ & $\begin{array}{l}\text { Seminar for the Media on the Convention } \\
\text { against Transnational Organized Crime }\end{array}$ \\
\hline S-1096-0186-01-00007 & $16-05-2001$ & $\begin{array}{l}\text { The United Nations Family in Bosnia and } \\
\text { Herzegovina }\end{array}$ \\
\hline S-1093-0065-06-00001 & 21-05-2001 & Note to Secretary-General about IDPs \\
\hline S-1092-0094-07-00008 & 29-05-2001 & $\begin{array}{l}\text { Institutional Arrangements for the Internally } \\
\text { Displaced }\end{array}$ \\
\hline S-1093-0088-05-00004 & 19-06-2001 & $\begin{array}{l}\text { Cooperation between the United Nations and } \\
\text { the Organization for Security and Cooperation } \\
\text { in Europe }\end{array}$ \\
\hline S-1092-0094-03-00001 & $24-12-2001$ & Internal Displacement Unit \\
\hline S-1093-0051-03-00001 & $12-01-2002$ & Letter to Secretary-General about Afghan return \\
\hline S-1093-0056-05-00006 & 06-03-2002 & $\begin{array}{l}\text { International Migration Policy Programme } \\
\text { (IMP) }\end{array}$ \\
\hline S-1095-0030-01-00029 & $22-04-2002$ & Letter to Brunson McKinley about East Timor \\
\hline S-1093-0064-05-00018 & $16-07-2002$ & $\begin{array}{l}\text { Cooperation between the United Nations and } \\
\text { the Organization for Security and Cooperation } \\
\text { in Europe }\end{array}$ \\
\hline S-1100-0012-13-00014 & 05-09-2002 & Requesting a meeting with Kofi Annan \\
\hline S-1093-0086-04-00026 & 05-10-2002 & $\begin{array}{l}\text { Agenda Item 100: International Migration and } \\
\text { Development }\end{array}$ \\
\hline S-1093-0048-11-00001 & $15-10-2002$ & $\begin{array}{l}\text { Meeting between Brunson McKinley and } \\
\text { Secretary-General about IOM-UN relations }\end{array}$ \\
\hline S-1093-0048-11-00002 & $28-10-2002$ & Writes to Kofi Annan about IOM-UN discussion \\
\hline S-1093-0048-11-00004 & $25-11-2002$ & $\begin{array}{l}\text { Writes to Kofi Annan - includes the address to } \\
\text { IOM Council }\end{array}$ \\
\hline S-1093-0048-11-00006 & $04-12-2002$ & Summary of IOM's 64th Council Session \\
\hline S-1093-0051-02-00025 & $06-12-2002$ & $\begin{array}{l}\text { UNHCR Input for Secretary-General's meeting } \\
\text { with Brunson McKinley }\end{array}$ \\
\hline S-1093-0038-06-00011 & $14-02-2003$ & $\begin{array}{l}\text { Reply to Ruud Lubbers about UNHCR } 2004 \\
\text { Process }\end{array}$ \\
\hline S-1093-0048-11-00007 & $17-03-2003$ & $\begin{array}{l}\text { Letter from Executive Office of the Secretary- } \\
\text { General thanking DDG of IOM for a booklet } \\
\text { about Somalian Women and Conflict } \\
\text { Resolution }\end{array}$ \\
\hline S-1093-0038-06-00016 & $26-03-2003$ & $\begin{array}{l}\text { Reply to Ruud Lubbers regarding strengthening } \\
\text { New York office }\end{array}$ \\
\hline S-1093-0038-05-00001 & 27-03-2003 & Letter to Louise Frechette about IOM \\
\hline S-1093-0038-05-00006 & $10-04-2003$ & Letter to Secretary-General about Iraq \\
\hline S-1093-0038-05-00007 & 22-04-2003 & Reply to Ruud Lubbers about Iraq \\
\hline S-1093-0048-11-00011 & $07-05-2003$ & $\begin{array}{l}\text { Note to Secretary-General: Follow-up on } \\
\text { International Migration, including the } \\
\text { formation of a Global Commission }\end{array}$ \\
\hline
\end{tabular}




\begin{tabular}{|c|c|c|}
\hline Reference & Date & Broad Description \\
\hline S-1093-0048-11-00012 & $19-05-2003$ & $\begin{array}{l}\text { Letter to Brunson McKinley about the } \\
\text { appointment of Luca Dall'Oglio }\end{array}$ \\
\hline S-1093-0048-11-00013 & 03-06-2003 & Note to Secretary-General about GCIM \\
\hline S-1093-0045-09-00012 & 06-06-2003 & $\begin{array}{l}\text { Letter to Mr Riva regarding developments in } \\
\text { the area of migration }\end{array}$ \\
\hline S-1093-0038-05-00012 & $10-06-2003$ & Letter about UNHCR role in Iraq \\
\hline S-1093-0048-11-00015 & $10-06-2003$ & $\begin{array}{l}\text { Report of IOM Working Group on Institutional } \\
\text { Arrangements }\end{array}$ \\
\hline S-1093-0048-11-00016 & $18-06-2003$ & $\begin{array}{l}\text { Note to Secretary-General about including a } \\
\text { developing country in a meeting on migration }\end{array}$ \\
\hline S-1093-0048-11-00017 & $26-06-2003$ & $\begin{array}{l}\text { Letters to Brazil, Morocco, and the Philippines } \\
\text { about GCIM }\end{array}$ \\
\hline S-1096-0143-03-00013 & 01-07-2003 & Press Briefing \\
\hline S-1092-0059-01-00015 & 03-07-2003 & Press Release \\
\hline S-1098-0054-09-00007 & 07-07-2003 & $\begin{array}{l}\text { Secretary-General Activities including Berne } \\
\text { Initiative }\end{array}$ \\
\hline S-1093-0048-11-00018 & $08-07-2003$ & Note to Mr Tiza about Berne Initiative \\
\hline S-1093-0038-05-00017 & $15-07-2003$ & Letter to Secretary-General about UNHCR 2004 \\
\hline S-1093-0048-11-00019 & $20-07-2003$ & $\begin{array}{l}\text { Letter exchange with Brunson McKinley about } \\
\text { Iraq }\end{array}$ \\
\hline S-1093-0048-11-00020 & $23-07-2003$ & $\begin{array}{l}\text { Letter to Brunson McKinley about the loss of } \\
\text { staff member in Iraq }\end{array}$ \\
\hline S-1093-0048-11-00021 & $28-07-2003$ & $\begin{array}{l}\text { Letter to Kofi Annan thanking him for his letter } \\
\text { of condolence (S-1093-0048-11-00021) }\end{array}$ \\
\hline S-1093-0048-11-00022 & 04-08-2003 & $\begin{array}{l}\text { Seeking meeting between Director-General of } \\
\text { IOM and Secretary-General }\end{array}$ \\
\hline S-1093-0048-11-00023 & $11-08-2003$ & $\begin{array}{l}\text { A letter following up on August } 2003 \text { meeting } \\
\text { with Kofi Annan. }\end{array}$ \\
\hline S-1093-0038-04-00021 & $21-08-2003$ & $\begin{array}{l}\text { Letter to Kofi Annan about the report on } \\
\text { Strengthening UNHCR to carry out its mandate }\end{array}$ \\
\hline S-1093-0048-11-00024 & 03-09-2003 & $\begin{array}{l}\text { Letter to Ruud Lubbers about the division of } \\
\text { labour IOM-UNHCR }\end{array}$ \\
\hline S-1094-0009-02-00002 & $26-09-2003$ & $\begin{array}{l}\text { Protection of and assistance to internally } \\
\text { displaced persons }\end{array}$ \\
\hline S-1093-0048-11-00025 & $09-10-2003$ & Note to Mr Riza about GCIM \\
\hline S-1093-0048-11-00026 & $23-10-2003$ & $\begin{array}{l}\text { Letter exchanges Brunson McKinley and Ruud } \\
\text { Lubbers }\end{array}$ \\
\hline S-1096-0125-05-00001 & $19-12-2003$ & Emma Lazarus Lecture \\
\hline S-1093-0035-11-00001 & 28-01-2004 & $\begin{array}{l}\begin{array}{l}\text { Letter to Kofi Annan about } \\
\text { relationship }\end{array} \\
\end{array}$ \\
\hline S-1093-0035-11-00002 & 09-03-2004 & Meeting between IOM and the UN. \\
\hline S-1092-0050-01-00022 & 01-04-2004 & High-Level Humanitarian Forum \\
\hline S-1093-0035-11-00003 & $28-06-2004$ & $\begin{array}{l}\text { Writes to Kofi Annan about IOM relationship } \\
\text { with Cuba }\end{array}$ \\
\hline S-1093-0035-07-00013 & 01-09-2004 & $\begin{array}{l}\text { Cooperation between the United Nations and } \\
\text { regional and other organizations }\end{array}$ \\
\hline S-1096-0098-09-00005 & $16-09-2004$ & Criticizes IOM Practices in Darfur \\
\hline
\end{tabular}




\begin{tabular}{|c|c|c|}
\hline Reference & Date & Broad Description \\
\hline S-1093-0025-12-00015 & $14-10-2004$ & $\begin{array}{l}\text { Letter to Kofi Annan asking for permission to } \\
\text { take responsibility for IDPs in West Darfur }\end{array}$ \\
\hline S-1093-0028-05-00021 & $09-12-2004$ & $\begin{array}{l}\text { Summary of 88th Session of the Council of the } \\
\text { International Organization for Migration }\end{array}$ \\
\hline S-1093-0035-11-00004 & $10-12-2004$ & Note about the GCIM \\
\hline S-1093-0025-12-00022 & 21-12-2004 & $\begin{array}{l}\text { Review of Management and Administration in } \\
\text { the Office of the United Nations High } \\
\text { Commissioner for Refugees }\end{array}$ \\
\hline S-1100-0005-07-00011 & 04-05-2005 & $\begin{array}{l}\text { A letter exchange between Kofi Annan and } \\
\text { Peter Sutherland regarding him becoming High } \\
\text { Commissioner for Refugees }\end{array}$ \\
\hline S-1100-0005-07-00012 & 04-05-2005 & $\begin{array}{l}\text { Letter to Peter Sutherland about High } \\
\text { Commissioner for Refugees position }\end{array}$ \\
\hline S-1098-0020-09-00031 & 06-06-2005 & Secretary-General Appointments. \\
\hline S-1100-0005-07-00015 & $20-06-2005$ & Letters with Peter Sutherland about WTO \\
\hline S-1093-0022-10-00001 & 04-08-2005 & $\begin{array}{l}\text { Writes to Mark Malloch Brown about deficit } \\
\text { facing the Office of the Special Envoy (mentions } \\
\text { funding structure) }\end{array}$ \\
\hline S-1093-0022-05-00001 & 05-09-2005 & MDG contribution \\
\hline S-1093-0022-10-00002 & $22-09-2005$ & Invitation to presentation of GCIM report \\
\hline S-1092-0032-07-00013 & 29-09-2005 & $\begin{array}{l}\text { Proposal for an Upgraded Central Emergency } \\
\text { Response Fund (CERF): }\end{array}$ \\
\hline S-1093-0022-10-00003 & 04-10-2005 & $\begin{array}{l}\text { Note to Kofi Annan about the launch of GCIM } \\
\text { report }\end{array}$ \\
\hline S-1093-0022-10-00004 & $05-10-2005$ & Note to Kofi Annan about the GCIM \\
\hline S-1093-0022-10-00005 & $12-10-2005$ & Letter to Kofi Annan about the GCIM \\
\hline S-1092-0032-07-00004 & $14-10-2005$ & $\begin{array}{l}\text { Secretary-General Report on Central } \\
\text { Emergency Revolving Fund }\end{array}$ \\
\hline S-1093-0022-10-00006 & $19-10-2005$ & Note to Kofi Annan about GCIM \\
\hline S-1096-0062-01-00001 & $19-10-2005$ & Interparliamentary Union Resolution on M\&D \\
\hline S-1093-0022-10-00008 & $24-10-2005$ & Thank you letters to GCIM chairs \\
\hline S-1093-0048-11-00008 & $24-10-2005$ & $\begin{array}{l}\text { Note to Secretary-General about Migration } \\
\text { Report }\end{array}$ \\
\hline S-1093-0022-10-00009 & $17-11-2005$ & Letter: Kofi Annan-Ramphele \\
\hline S-1093-0048-11-00009 & $17-11-2005$ & $\begin{array}{l}\text { Note to Deputy Secretary-General about } \\
\text { meeting with Gene Dewey regarding the US } \\
\text { view towards international cooperation. }\end{array}$ \\
\hline S-1093-0048-11-00010 & $21-11-2005$ & Note to Kofi Annan about the GCIM \\
\hline S-1092-0019-08-00013 & 29-11-2005 & $\begin{array}{l}\text { Meeting between Peter Sutherland and Kofi } \\
\text { Annan }\end{array}$ \\
\hline S-1098-0020-07-00032 & $01-12-2005$ & Secretary-General Appointments \\
\hline S-1092-0005-04-00011 & $18-01-2006$ & $\begin{array}{l}\text { Memo about } 2006 \text { Treaty Event on Crossing } \\
\text { Borders }\end{array}$ \\
\hline S-1091-0001-03-00007 & $02-02-2006$ & $\begin{array}{l}\text { Deputy Secretary-General's monthly planning } \\
\text { meeting on economic, social and reform issues }\end{array}$ \\
\hline S-1098-0015-03-00001 & 02-02-2006 & $\begin{array}{l}\text { Secretary-General Activities in Switzerland, } 23 \text { - } \\
29 \text { January }\end{array}$ \\
\hline
\end{tabular}




\begin{tabular}{|c|c|c|}
\hline Reference & Date & Broad Description \\
\hline S-1092-0013-02-00006 & 06-02-2006 & $\begin{array}{l}\text { A proposal from the GMG on the enlargement } \\
\text { and enhancement of the inter-agency group on } \\
\text { migration }\end{array}$ \\
\hline S-1092-0013-06-00012 & 09-03-2006 & $\begin{array}{l}\text { Note to Secretary-General on Ministerial } \\
\text { Conference of the LDCs on Enhancing the } \\
\text { Development Impact of Remittances }\end{array}$ \\
\hline S-1100-0001-06-00003 & 13-03-2006 & $\begin{array}{l}\text { Secretary-General's telephone conversation } \\
\text { with Mr Oscar Berger regarding the death of } \\
\text { Guatemalan Peacekeepers: controversy } \\
\text { regarding IOM statement }\end{array}$ \\
\hline S-1092-0013-01-00009 & 23-03-2006 & $\begin{array}{l}\text { Draft Policy Committee Submission: Migration } \\
\text { including a discussion of changes }\end{array}$ \\
\hline S-1092-0013-01-00004 & $27-03-2006$ & $\begin{array}{l}\text { Note to the Secretary-General through the } \\
\text { Deputy Secretary-General (Policy Committee } \\
\text { Submission: Migration) }\end{array}$ \\
\hline S-1092-0009-04-00002 & $28-03-2006$ & $\begin{array}{l}\text { Letter about the visibility of EC contribution } \\
\text { managed by UN }\end{array}$ \\
\hline S-1092-0014-08-00001 & $31-03-2006$ & Accounts - CERF \\
\hline S-1092-0005-01-00047 & 03-04-2006 & $\begin{array}{l}\text { Letter from Peter Sutherland to Kofi Annan and } \\
\text { information about Treaty Event }\end{array}$ \\
\hline S-1100-0003-13-00013 & 03-04-2006 & $\begin{array}{l}\text { Letter from Peter Sutherland to Kofi Annan } \\
\text { about GMG/GFMD }\end{array}$ \\
\hline S-1092-0012-10-00032 & 04-05-2006 & $\begin{array}{l}\text { Letter from the Secretary-General to members } \\
\text { of the Global Migration Group }\end{array}$ \\
\hline S-1093-0011-01-00009 & $10-05-2006$ & Letter from EC to Kofi Annan about HLD \\
\hline S-1092-0017-02-00023 & $25-05-2006$ & $\begin{array}{l}\text { Draft of the Secretary-General's Report on } \\
\text { "Strengthening the Coordination of Emergency } \\
\text { Humanitarian Assistance of the United Nations }\end{array}$ \\
\hline S-1092-0016-05-00002 & 08-06-2006 & $\begin{array}{l}\text { Letter updating Secretary-General on work on } \\
\text { human security including eligibility of IOM }\end{array}$ \\
\hline S-1096-0030-02-00011 & 08-06-2006 & $\begin{array}{l}\text { A letter exchange between Trade Union } \\
\text { (ICFTU) regarding concerns about civil society } \\
\text { involvement in HLD. }\end{array}$ \\
\hline S-1092-0013-01-00002 & $10-06-2006$ & Letter from GCIM Chairs to Kofi Annan \\
\hline S-1096-0022-20-00002 & $12-06-2006$ & $\begin{array}{l}\text { The selection process for Secretary-General for } \\
\text { Humanitarian Affairs and Emergency Relief } \\
\text { Coordinator }\end{array}$ \\
\hline S-1092-0012-10-00022 & $26-06-2006$ & Letter from Michael Doyle to KA \\
\hline S-1093-0010-01-00002 & $17-07-2006$ & $\begin{array}{l}\text { Letter to Brunson McKinley about IOM-UN } \\
\text { relationship }\end{array}$ \\
\hline S-1092-0012-10-00017 & $20-07-2006$ & $\begin{array}{l}\text { Letter from UNCTAD to Mark Malloch Brown } \\
\text { and his reply }\end{array}$ \\
\hline S-1092-0012-10-00014 & $25-07-2006$ & $\begin{array}{l}\text { Note to the Secretary-General (Through Ms } \\
\text { Barcena) Consultative Forum for Migration } \\
\text { (from Bob Orr) }\end{array}$ \\
\hline S-1092-0017-01-00014 & $25-07-2006$ & $\begin{array}{l}\text { Draft of the Secretary-General's Report on } \\
\text { "Humanitarian Assistance And Rehabilitation }\end{array}$ \\
\hline
\end{tabular}




\begin{tabular}{|c|c|c|}
\hline Reference & Date & Broad Description \\
\hline & & $\begin{array}{ll}\text { For } & \text { Selected } \\
\text { Countries And Regions" } & \end{array}$ \\
\hline S-1093-0038-05-00018 & $25-07-2006$ & $\begin{array}{l}\text { Reply to Ruud Lubbers about Strengthening } \\
\text { UNHCR report }\end{array}$ \\
\hline S-1096-0029-02-00017 & $28-07-2006$ & $\begin{array}{l}\text { A letter exchange between Kofi Annan and Prof. } \\
\text { Sussmuth (part of GCIM) }\end{array}$ \\
\hline S-1092-0012-10-00006 & $21-08-2006$ & Letter responding to EU position at HLD \\
\hline S-1093-0010-13-00016 & $21-08-2006$ & Letter to Erkki Tuomioja (Finland) about HLD) \\
\hline S-1093-0010-01-00003 & $30-08-2006$ & Note: Orr: Kofi Annan \\
\hline S-1092-0012-10-00001 & 01-09-2006 & $\begin{array}{l}\text { Ref-. Speech to High-Level Dialogue on } \\
\text { Migration and Development }\end{array}$ \\
\hline S-1092-0012-10-00002 & 01-09-2006 & $\begin{array}{l}\text { Note on High-Level Dialogue on Migration } \\
\text { (from DESA with Secretary-General response) }\end{array}$ \\
\hline S-1093-0010-01-00004 & 01-09-2006 & $\begin{array}{l}\text { Letter to Chief of Cabinet (Alicia Barcena) } \\
\text { request meeting between Mr McKinley and } \\
\text { Secretary-General }\end{array}$ \\
\hline S-1092-0016-06-00019 & 08-09-2006 & $\begin{array}{l}\text { Draft of the Report of the Secretary-General on } \\
\text { the Central Emergency Response Fund (CERF) }\end{array}$ \\
\hline S-1098-0006-08-00006 & $12-09-2006$ & $\begin{array}{l}\text { Priority issues for the NAM Summit (Havana, } \\
11-16 \text { September) }\end{array}$ \\
\hline S-1092-0012-09-00025 & $18-09-2006$ & $\begin{array}{l}\text { Note to the Secretary-General High-Level } \\
\text { Dialogue on International Migration and } \\
\text { Development from DESA }\end{array}$ \\
\hline S-1093-0003-08-00016 & $25-09-2006$ & Letter to Kofi Annan from UNITAR post HLD \\
\hline S-1092-0012-09-00023 & $27-09-2006$ & $\begin{array}{l}\text { Note to the Secretary-General: a Global Forum } \\
\text { on International Migration and Development } \\
\text { from DESA }\end{array}$ \\
\hline S-1092-0001-03-00022 & 28-09-2006 & Letter to Mark Malloch Brown about CEDAW \\
\hline S-1092-0012-09-00009 & $13-10-2006$ & $\begin{array}{l}\text { Note to the Secretary-General: a Global Forum } \\
\text { on International Migration and Development } \\
\text { from DESA }\end{array}$ \\
\hline S-1093-0013-03-00004 & $16-10-2006$ & $\begin{array}{l}\text { Report of the High-Level Committee on } \\
\text { Programmes (HLCP) at its Twelfth Session }\end{array}$ \\
\hline S-1098-0006-05-00013 & $30-10-2006$ & $\begin{array}{l}\text { Global Forum on International Migration and } \\
\text { Development }\end{array}$ \\
\hline S-1098-0006-05-00012 & 03-11-2006 & $\begin{array}{lllll}\text { Secretary-General } & \text { Address } & \text { To } & \text { XVI } & \text { Ibero- } \\
\text { American Summit } & & & & \\
\end{array}$ \\
\hline S-1092-0001-01-00033 & $15-11-2006$ & $\begin{array}{l}\text { Pending Proposals, and invitations -November } \\
\text { and December }\end{array}$ \\
\hline S-1093-0003-08-00021 & $16-11-2006$ & $\begin{array}{l}\text { Meeting with Mr Boisard regarding 1UNITAR } \\
\text { becoming part of GMG }\end{array}$ \\
\hline S-1956-0025-0007-00016 & 19-01-2007 & $\begin{array}{l}\text { Letter to set up a meeting with Deputy } \\
\text { Secretary-General Asha Rose Migiro with } \\
\text { Ndiora Ndiaye }\end{array}$ \\
\hline S-1956-0030-0004-00017 & $15-02-2007$ & $\begin{array}{l}\text { A letter exchange between Jonathan Fanton } \\
\text { (MacArthur) and Ban Ki-moon }\end{array}$ \\
\hline S-1956-0025-0007-00014 & 19-03-2007 & Note: Orr-Ban Ki-moon \\
\hline
\end{tabular}




\begin{tabular}{|c|c|c|}
\hline Reference & Date & Broad Description \\
\hline S-1956-0025-0007-00015 & 19-03-2007 & Note: Ocampo-Ban Ki-moon \\
\hline S-1943-0031-0003-00002 & 21-03-2007 & Appointments of the Secretary-General \\
\hline S-1956-0025-0007-00013 & 13-04-2007 & $\begin{array}{l}\text { Letter to set up a meeting with Deputy } \\
\text { Secretary-General Asha Rose Migiro for } \\
\text { Brunson McKinley }\end{array}$ \\
\hline S-1956-0025-0007-00001 & 27-04-2007 & $\begin{array}{l}\text { Letter to Mr Yoon of Executive Office of the } \\
\text { Secretary-General to set up a meeting }\end{array}$ \\
\hline S-1956-0025-0007-00012 & 01-05-2007 & Letters: Sutherland-Ban Ki-moon \\
\hline S-1943-0019-0001-00011 & 07-05-2007 & Letter Ban Ki-moon to Peter Sutherland \\
\hline S-1956-0025-0007-00011 & 07-05-2007 & Letters: Sutherland-Ban Ki-moon \\
\hline S-1956-0025-0007-00010 & $11-05-2007$ & Note: Ocampo-Ban Ki-moon \\
\hline S-1953-0012-0002-00016 & 21-05-2007 & $\begin{array}{l}\text { Draft of the Secretary-General's Report on } \\
\text { "Strengthening the Coordination of Emergency } \\
\text { Humanitarian Assistance of the United } \\
\text { Nations" }\end{array}$ \\
\hline S-1956-0002-0006-00007 & 08-06-2007 & $\begin{array}{l}\text { Letter from Dutch Prime Minister to Ban Ki- } \\
\text { moon }\end{array}$ \\
\hline S-1953-0012-0002-00006 & 27-06-2007 & $\begin{array}{l}\text { Letter to PGA about Advisory Group of the } \\
\text { Central Emergency Response Fund }\end{array}$ \\
\hline S-1956-0025-0007-00008 & 06-07-2007 & Note: Orr-Ban Ki-moon \\
\hline S-1942-0041-0004-00003 & $10-07-2007$ & GFMD Belgium Programme \\
\hline 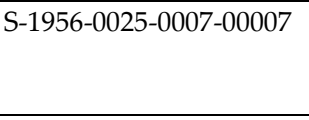 & 10-07-2007 & $\begin{array}{l}\text { Letter to Ban Ki-moon about IOM being in } \\
\text { UNDG and Chief Executive Board for } \\
\text { Coordination }\end{array}$ \\
\hline S-1956-0056-0008-00001 & $11-07-2007$ & Report of first GFMD \\
\hline S-1956-0025-0007-00006 & $23-07-2007$ & Note: Zukang-Ban Ki-moon \\
\hline S-1943-0017-0006-00019 & $30-08-2007$ & Letter Ban Ki-moon to Peter Sutherland \\
\hline S-1956-0025-0007-00002 & 25-09-2007 & Evaluation of first GFMD \\
\hline S-1956-0014-0011-00016 & $28-09-2007$ & $\begin{array}{l}\text { A letter from the President of the Philippines to } \\
\text { Ban Ki-moon }\end{array}$ \\
\hline S-1956-0025-0007-00005 & 08-10-2007 & $\begin{array}{l}\text { Letter from Ban Ki-moon to Brunson McKinley } \\
\text { about UNDG and Chief Executive Board for } \\
\text { Coordination }\end{array}$ \\
\hline S-1956-0025-0007-00004 & $25-10-2007$ & Letter: Navide-Ban Ki-moon \\
\hline S-1956-0031-0009-00011 & 09-11-2007 & $\begin{array}{l}\text { A letter exchange between Institut International } \\
\text { des Sciences Politiques and the Executive Office } \\
\text { of the Secretary-General }\end{array}$ \\
\hline S-1943-0054-0001-00003 & 23-11-2007 & $\begin{array}{l}\text { Secretary-General's meeting with Mr Esteban B. } \\
\text { Conejos, Under-Secretary for Migrant Workers' } \\
\text { Affairs, Department of Foreign Affairs, the } \\
\text { Philippines }\end{array}$ \\
\hline S-1956-0025-0007-00003 & $26-12-2007$ & $\begin{array}{l}\text { Letter to Mr Yoon to organize a meeting } \\
\text { between Brunson McKinley and Secretary- } \\
\text { General }\end{array}$ \\
\hline S-1956-0056-0007-00006 & 09-01-2008 & Letters: Sutherland-Ban Ki=moon \\
\hline
\end{tabular}




\begin{tabular}{|c|c|c|}
\hline Reference & Date & Broad Description \\
\hline S-1956-0056-0007-00005 & 04-02-2008 & $\begin{array}{l}\text { Letter to Deputy Secretary-General (Asha-Rose } \\
\text { Migito) thanking for participation in the } \\
\text { conference }\end{array}$ \\
\hline S-1953-0034-0003-00022 & 29-04-2008 & $\begin{array}{l}\text { Progress Report to the Advisory Board on } \\
\text { Human Security - IOM granted access to fund }\end{array}$ \\
\hline S-1953-0034-0003-00003 & $22-05-2008$ & $\begin{array}{l}\text { Draft Report of the Secretary-General on } \\
\text { Strengthening the Coordination of Emergency } \\
\text { Humanitarian Assistance of the United Nations } \\
\text { (Scores Out IOM) }\end{array}$ \\
\hline S-1957-0013-0006-00013 & 05-07-2008 & $\begin{array}{l}\text { Inviting Deputy Secretary-General to an event } \\
\text { on trafficking }\end{array}$ \\
\hline S-1956-0044-0007-00021 & $17-07-2008$ & $\begin{array}{l}\text { Letter from Mexico Secretary of Foreign Affairs } \\
\text { to Ban Ki-moon }\end{array}$ \\
\hline S-1956-0056-0007-00004 & $22-07-2008$ & Letters: Sutherland-Ban Ki-moon \\
\hline S-1943-0014-0001-00015 & 05-08-2008 & Letter Ban Ki-moon to Peter Sutherland \\
\hline S-1943-0014-0001-00014 & 08-08-2008 & Letter Ban Ki-moon to Peter Sutherland \\
\hline S-1956-0069-0009-00006 & $31 / 8 / 2008$ & Letter to Ban Ki-moon about Athens GFMD \\
\hline S-1953-0033-0005-00013 & $08-09-2008$ & $\begin{array}{l}\text { Draft report of the Secretary-General on the } \\
\text { Central Emergency Response Fund. }\end{array}$ \\
\hline S-1956-0056-0007-00003 & $16-09-2008$ & $\begin{array}{l}\text { Memo to PRs of UN and UN heads about } \\
\text { William Lacy Swing's appointment }\end{array}$ \\
\hline S-1956-0060-0003-00001 & 19-09-2008 & $\begin{array}{l}\text { Advisory Board on Human Security Seventh } \\
\text { annual meeting: Draft Agenda }\end{array}$ \\
\hline S-1956-0039-0007-00014 & $26-09-2008$ & $\begin{array}{l}\text { Letter Exchange between Greek (Mr John } \\
\text { Mourikis) inviting Ban Ki-moon to 3rd GFMD }\end{array}$ \\
\hline S-1956-0056-0007-00001 & $28-10-2008$ & $\begin{array}{l}\text { Letter to set up a meeting between William Lacy } \\
\text { Swing and Ban Ki-moon }\end{array}$ \\
\hline S-1953-0031-0001-00026 & $31-10-2008$ & DPI Weekly Press Review \\
\hline S-1956-0056-0007-00002 & 04-11-2008 & $\begin{array}{l}\text { Invitation to Secretary-General for 96th Council } \\
\text { meeting. }\end{array}$ \\
\hline S-1956-0087-0005-00032 & 13-01-2009 & $\begin{array}{l}\text { A letter exchange between Jonathan Fanton } \\
\text { (MacArthur) and Ban Ki-moon }\end{array}$ \\
\hline $\begin{array}{l}\text { S-1956-0115-0012-00011 } \\
\end{array}$ & $13 / 01 / 2009$ & $\begin{array}{l}\text { Letter to Ban Ki-moon thanking him for the first } \\
\text { meeting in his role as Director-General and } \\
\text { regarding the GFMD secretariat }\end{array}$ \\
\hline S-1953-0045-0003-00028 & 30-01-2009 & Re: Top Echelon and \$1 a Year Appointments \\
\hline S-1956-0115-0012-00010 & $02-02-2009$ & $\begin{array}{l}\text { Letter to } \mathrm{Mr} \text { Dall-Oglio and Joe Chamie } \\
\text { regarding a conference on migration and } \\
\text { development }\end{array}$ \\
\hline S-1956-0115-0012-00009 & 04-02-2009 & $\begin{array}{lllr}\text { Letter to } & \text { William } & \text { Lacy Swing } & \text { regarding } \\
\text { Tanzania } & \text { Regional } & \text { Immigration } & \text { Training } \\
\text { Academy } & & & \\
\end{array}$ \\
\hline S-1953-0045-0003-00024 & $25-02-2009$ & $\begin{array}{l}\text { Letters to the Top Echelon and WAE } \\
\text { Appointments (Ethics) }\end{array}$ \\
\hline S-1956-0073-0004-00026 & 02-03-2009 & $\begin{array}{l}\text { Report sent to Secretary-General post ABHS } \\
\text { meeting }\end{array}$ \\
\hline
\end{tabular}




\begin{tabular}{|c|c|c|}
\hline Reference & Date & Broad Description \\
\hline S-1956-0115-0012-00008 & 30-04-2009 & $\begin{array}{l}\text { Letter to Ban Ki-moon about UNITE to end } \\
\text { violence against women campaign. }\end{array}$ \\
\hline S-1953-0066-0005-00015 & 05-05-2009 & $\begin{array}{l}\text { Improving the coordination of efforts against } \\
\text { trafficking in persons }\end{array}$ \\
\hline S-1956-0083-0010-00010 & 19-05-2009 & $\begin{array}{l}\text { Italian Government concerns regarding } \\
\text { UNHCR statements on the handling of illegal } \\
\text { immigrants }\end{array}$ \\
\hline S-1956-0115-0012-00007 & $28-05-2009$ & Letters: Sutherland-Ban Ki-moon \\
\hline S-1956-0115-0012-00006 & $30-07-2009$ & Letters: Sutherland-Ban Ki-moon \\
\hline S-1953-0046-0006-00020 & 05-08-2009 & $\begin{array}{l}\text { An exchange between Executive Office of } \\
\text { Secretary-General regarding a meeting }\end{array}$ \\
\hline S-1956-0115-0012-00005 & 10-08-2009 & $\begin{array}{l}\text { Letter to Ndioro Ndiaye thanking her for words } \\
\text { reflecting on their collaboration }\end{array}$ \\
\hline S-1956-0115-0012-00004 & $25-08-2009$ & $\begin{array}{l}\text { Letter to Ndioro Ndiaye thanking for a letter } \\
\text { regarding his resignation }\end{array}$ \\
\hline S-1943-0009-0003-00055 & 14-09-2009 & Letter Ban Ki-moon to Peter Sutherland \\
\hline S-1956-0115-0012-00001 & 07-10-2009 & $\begin{array}{l}\text { Chef de Cabinet declining invitation for } \\
\text { Secretary-General to give opening remarks at a } \\
\text { conference on irregular migration }\end{array}$ \\
\hline S-1956-0115-0012-00003 & 23-10-2009 & Invites UNHCR to 98th Council session \\
\hline S-1956-0115-0012-00002 & $26-10-2009$ & $\begin{array}{l}\text { Letter thanking Ban Ki-moon for inviting him to } \\
\text { Heads of state and government luncheon at 64th } \\
\text { General Assembly }\end{array}$ \\
\hline S-1943-0008-0002-00070 & 05-01-2010 & Letter Ban Ki-moon to Peter Sutherland \\
\hline S-1953-0068-0004-00024 & 01-02-2010 & Note to Mr Sutherland from Ethics Office \\
\hline S-1956-0109-0003-00004 & 02-03-2010 & Interim Report on GFMD from Peter Sutherland \\
\hline S-1956-0109-0003-00001 & $15-03-2010$ & $\begin{array}{l}\text { Letter seeking a meeting between Ban Ki-moon } \\
\text { and William Lacy Swing }\end{array}$ \\
\hline S-1953-0079-0003-00030 & 24-03-2010 & $\begin{array}{l}\text { Letter to Secretary-General regarding Arab } \\
\text { Summit and problems regarding operations in } \\
\text { Libya }\end{array}$ \\
\hline S-1956-0109-0003-00005 & 07-04-2010 & $\begin{array}{l}\text { Letter to Ban Ki-moon congratulating him on } \\
\text { conferences related to Haiti }\end{array}$ \\
\hline S-1943-0007-0001-00023 & $22-04-2010$ & Letter Ban Ki-moon to Peter Sutherland \\
\hline S-1956-0112-0001-00003 & $26-04-2010$ & Letters to Mr Johan Ketelers (ICMC) \\
\hline S-1956-0095-0015-00002 & $14 / 7 / 2010$ & $\begin{array}{l}\text { Letter to Ban Ki-moon about a report of Athens } \\
\text { GFMD (not enclosed) }\end{array}$ \\
\hline S-1953-0079-0003-00015 & $19 / 7 / 2010$ & $\begin{array}{l}\text { Report of the Secretary-General on the } \\
\text { promotion and protection of human rights, } \\
\text { including ways and means to promote the } \\
\text { human rights of migrants }\end{array}$ \\
\hline S-1953-0078-0002-00008 & $20-07-2010$ & Expulsion of two IOM staff in Sudan \\
\hline S-1956-0110-0006-00013 & $21 / 07 / 2010$ & $\begin{array}{l}\text { Invitation to Ban Ki-moon to Chair Mexican } \\
\text { Civil Society Days }\end{array}$ \\
\hline S-1956-0110-0006-00004 & $26 / 08 / 2010$ & $\begin{array}{l}\text { Letter on behalf of Secretary-General declining } \\
\text { invite to Mexico GFMD }\end{array}$ \\
\hline S-1951-0003-0003-00013 & $23 / 9 / 2010$ & Letter exchange about GFMD in the Philippines \\
\hline
\end{tabular}




\begin{tabular}{|c|c|c|}
\hline Reference & Date & Broad Description \\
\hline S-1956-0109-0003-00003 & $12-10-2010$ & $\begin{array}{l}\text { Letter to Ban Ki-moon congratulating him on } \\
\text { meetings in September 2010, including review } \\
\text { of MDGs and thanking him for a meeting. } \\
\text { Michelle Klein Solomon appointed as a } \\
\text { Permanent Observer of the IOM to the UN. }\end{array}$ \\
\hline S-1956-0109-0003-00002 & $27-10-2010$ & $\begin{array}{l}\text { Letter to Ban Ki-moon about suicide attack in } \\
\text { Afghanistan }\end{array}$ \\
\hline S-1943-0109-0003-00020 & $01-12-2010$ & Update Note for the Secretary-General \\
\hline S-1953-0070-0004-00002 & $21-12-2010$ & $\begin{array}{l}\text { Meeting of the Advisory Group of the Central } \\
\text { Emergency Response Fund }\end{array}$ \\
\hline S-1943-0004-0004-00080 & $31-12-2010$ & Letter Ban Ki-moon to Peter Sutherland \\
\hline S-1943-0082-0006-00001 & $31-12-2010$ & Meeting Notes 2010 \\
\hline S-1959-0005-0001-00009 & 04-02-2011 & $\begin{array}{l}\text { Interim Report on GFMD ( } 2 \text { from Peter } \\
\text { Sutherland to Ban Ki-moon. }\end{array}$ \\
\hline S-1959-0004-0007-00019 & 05-05-2011 & $\begin{array}{l}\text { UN position on the } 2013 \text { High-Level Dialogue } \\
\text { on Migration and Development } \\
\text { - a Proposal }\end{array}$ \\
\hline S-1959-0022-0004-00010 & $13-05-2011$ & $\begin{array}{l}\text { Strengthening of the coordination of emergency } \\
\text { humanitarian assistance of the United Nations }\end{array}$ \\
\hline S-1943-0024-0004-00005 & $18-05-2011$ & Appointments of the Secretary-General \\
\hline S-1943-0024-0004-00004 & $19-05-2011$ & Appointments of the Secretary-General \\
\hline S-1959-0024-0004-00007 & 05-10-2011 & Draft Secretary-General Report on UNITAR \\
\hline S-1943-0075-0001-00025 & 01-01-2012 & Letter Ban Ki-moon to Peter Sutherland \\
\hline S-1943-0023-0003-00011 & 09-02-2012 & Appointments of the Secretary-General \\
\hline S-1943-0083-0001-00001 & 09-02-2012 & Meeting Notes 2012 \\
\hline S-1959-0050-0014-00008 & $23-02-2012$ & $\begin{array}{l}\text { A letter exchange between Ban Ki-moon and } \\
\text { Prime Minister of Mauritius regarding the } 2012 \\
\text { GFMD }\end{array}$ \\
\hline S-1959-0045-0008-00002 & 07-03-2012 & $\begin{array}{l}\text { Letter to UNHCR about the } 10 \text {-year report of } \\
\text { UNHCR }\end{array}$ \\
\hline S-1959-0050-0012-00022 & 04-06-2012 & $\begin{array}{l}\text { Report of the UN System Task Team on the } \\
\text { Post-2015 UN Development Agenda. }\end{array}$ \\
\hline S-1959-0095-0004-00027 & $18-07-2012$ & $\begin{array}{l}\text { Director-General of International commission } \\
\text { on Missing Persons writes about a partnership } \\
\text { with UN }\end{array}$ \\
\hline S-1959-0052-0001-00018 & $26-07-2012$ & $\begin{array}{l}\text { Implementation Matrix for the UN system on } \\
\text { the Rio+ } 20 \text { outcome document }\end{array}$ \\
\hline S-1959-0049-0002-00010 & $30-07-2012$ & $\begin{array}{l}\text { Explanatory Memorandum for the International } \\
\text { Conference } \\
\text { People's Empowerment and Development }\end{array}$ \\
\hline S-1959-0050-0015-00005 & 01-08-2012 & $\begin{array}{l}\text { Report of the Secretary-General on International } \\
\text { migration and development }\end{array}$ \\
\hline S-1959-0050-0015-00004 & 02-08-2012 & $\begin{array}{l}\text { Request for clearance of the report of the } \\
\text { Secretary-General on international migration } \\
\text { and development for the sixty-seventh session } \\
\text { of the General Assembly }\end{array}$ \\
\hline
\end{tabular}




\begin{tabular}{|c|c|c|}
\hline Reference & Date & Broad Description \\
\hline S-1959-0057-0005-00034 & $11-08-2012$ & $\begin{array}{l}\text { Letter to William Lacy Swing regarding his } \\
\text { letter of condolence }\end{array}$ \\
\hline S-1959-0090-0003-00005 & $22 / 08 / 2012$ & $\begin{array}{l}\text { A letter exchange between Deputy Secretary- } \\
\text { General and Jacque Chirac about an event that } \\
\text { conflicts with Mauritius GFMD }\end{array}$ \\
\hline S-1959-0051-0009-00002 & $28-08-2012$ & $\begin{array}{l}\text { Europe's Immigration Challenge By Peter D. } \\
\text { Sutherland and Cecilia Malmstrom }\end{array}$ \\
\hline S-1959-0066-0013-00004 & 07-09-2012 & $\begin{array}{l}\text { Secretary-General Report on Central } \\
\text { Emergency Response Plan }\end{array}$ \\
\hline S-1959-0046-0015-00003 & $18 / 09 / 2012$ & $\begin{array}{l}\text { UN Trust Fund for Human Security project } \\
\text { proposal }\end{array}$ \\
\hline S-1959-0050-0006-00003 & $28-09-2012$ & $\begin{array}{l}\text { Overview of the General Debate: } 27 \\
\text { September/Full day }\end{array}$ \\
\hline S-1943-0022-0002-00009 & $16-11-2012$ & Appointments of the Secretary-General \\
\hline S-1959-0088-0006-00007 & $16 / 11 / 2012$ & $\begin{array}{l}\text { Letter to Mauritius advising he cannot attend } \\
\text { GFMD due to tension in middle east }\end{array}$ \\
\hline S-1959-0050-0011-00009 & $20-11-2012$ & $\begin{array}{l}\text { United Nations System Chief Executives Board } \\
\text { for Coordination: Second Regular Session for } \\
\text { 2012: Issue Notes from High-Level Committee } \\
\text { on Programmes }\end{array}$ \\
\hline S-1943-0071-0006-00026 & 26-11-2012 & Letter Ban Ki-moon to William Lacy Swing \\
\hline S-1959-0050-0011-00007 & $26-11-2012$ & $\begin{array}{l}\text { Letter to Jan Eliasson about the Post-2015 } \\
\text { Development Agenda }\end{array}$ \\
\hline S-1959-0050-0014-00007 & $27 / 11 / 2012$ & Letter from UNODC Director (as Chair of GMG) \\
\hline S-1959-0088-0005-00011 & $27-11-2012$ & $\begin{array}{l}\text { Letter to William Lacy Swing saying he cannot } \\
\text { attend the 101st Council session but that Peter } \\
\text { Sutherland will address via video }\end{array}$ \\
\hline S-1959-0050-0011-00005 & $11-12-2012$ & $\begin{array}{l}\text { Secretary-General's Initial Input to the Open } \\
\text { Working Group on Sustainable Development } \\
\text { Goals }\end{array}$ \\
\hline S-1943-0089-0004-00024 & 09-01-2013 & Letter Ban Ki-moon to Peter Sutherland \\
\hline S-1951-0004-0006-00030 & 20-01-2013 & Letter to Mr Swing about the loss of life in Haiti \\
\hline S-1959-0126-0006-00013 & $29-01-2013$ & $\begin{array}{l}\text { Letter to William Lacy Swing - regarding Chief } \\
\text { Executive Board for Coordination/Policy } \\
\text { Committee }\end{array}$ \\
\hline S-1959-0099-0012-00002 & 02-02-2013 & $\begin{array}{l}\text { Official Visit of the Deputy Secretary-General to } \\
\text { Brussels and Geneva (27-28 November 2013) }\end{array}$ \\
\hline S-1959-0177-0010-00020 & $11-02-2013$ & $\begin{array}{l}\text { Letter to William Lacy Swing about Cholera in } \\
\text { Haiti }\end{array}$ \\
\hline S-1959-0151-0002-00016 & $26-02-2013$ & $\begin{array}{l}\text { Letter from International Planned Parenthood } \\
\text { Federation about post- } 2015 \text { agenda - mentions } \\
\text { migration as challenge }\end{array}$ \\
\hline S-1959-0104-0003-00007 & 04-03-2013 & $\begin{array}{l}\text { "Development for All" conference, which } \\
\text { recently took place in Dili, Timor Leste }\end{array}$ \\
\hline S-1959-0147-0004-00034 & $12-03-2013$ & $\begin{array}{l}\text { Invitation to } 2013 \text { IOM Council Meeting which } \\
\text { includes IOM position paper for HLD }\end{array}$ \\
\hline
\end{tabular}




\begin{tabular}{|c|c|c|}
\hline Reference & Date & Broad Description \\
\hline S-1959-0123-0002-00038 & $15-03-2013$ & $\begin{array}{l}\text { Secretary-General's } \text { Guidance Note on Racial } \\
\text { Discrimination and Protection of } \\
\text { Minorities }\end{array}$ \\
\hline S-1959-0150-0002-00030 & $28-03-2013$ & $\begin{array}{l}\text { invites Ban Ki-moon to Commission on } \\
\text { Population and Development }\end{array}$ \\
\hline S-1959-0106-0002-00016 & 03-04-2013 & $\begin{array}{l}\text { Report of the fourth meeting of HLP on the } \\
\text { P2015 Development agenda }\end{array}$ \\
\hline S-1959-0106-0002-00004 & 08-04-2013 & $\begin{array}{l}\text { Letter to Ivan Lewis (Shadow Secretary of State } \\
\text { for International Development of UK) about } \\
\text { Social Contract without borders (vision for post- } \\
\text { 2015) }\end{array}$ \\
\hline S-1959-0155-0008-00012 & 08-04-2013 & $\begin{array}{l}\text { Thanking Secretary-General for inviting him to } \\
\text { Chief Executive Board for Coordination } \\
\text { meeting on 05.04.2013 }\end{array}$ \\
\hline S-1959-0145-0022-00013 & 01-05-2013 & $\begin{array}{l}\text { Letter about meeting on } 24 \text { April } 2013 \text { (discusses } \\
\text { IOM-UN relation and SDGs) }\end{array}$ \\
\hline S-1959-0127-0002-00023 & 07-05-2013 & UNITAR- Report of the Secretary-General \\
\hline S-1959-0152-0005-00033 & 08-05-2013 & $\begin{array}{l}\text { Invitation from the Scalibrini International } \\
\text { Migration Network to Jan Eliasson to give } \\
\text { opening remarks at the IV International Forum } \\
\text { on Migration and Peace }\end{array}$ \\
\hline S-1959-0107-0001-00013 & $18-06-2013$ & $\begin{array}{l}\text { Letter from Peter Sutherland to Amina } \\
\text { Mohammed regarding SDGs }\end{array}$ \\
\hline S-1943-0021-0004-00004 & $25-06-2013$ & $\begin{array}{l}\text { Meeting between Peter Sutherland and Ban Ki- } \\
\text { moon }\end{array}$ \\
\hline S-1943-0087-0004-00022 & $25-06-2013$ & $\begin{array}{l}\text { Letter to William Lacy Swing regarding the } \\
\text { death of an IOM staff member in Kabul }\end{array}$ \\
\hline S-1959-0105-0008-00005 & $25-06-2013$ & $\begin{array}{l}\text { Letter to Secretary-General from Civil Society } \\
\text { Sexual and Reproductive Health and Rights } \\
\text { Platform - one mention of migration }\end{array}$ \\
\hline S-1959-0112-0002-00016 & $26-06-2013$ & $\begin{array}{l}\text { Declaration from the Fourth International } \\
\text { Forum on Migration And Peace (In New York } \\
\text { City) }\end{array}$ \\
\hline S-1959-0102-0002-00018 & 05-07-2013 & $\begin{array}{l}\text { Preparatory event for HLD including } \\
\text { roundtable on post-2015 }\end{array}$ \\
\hline S-1959-0105-0007-00040 & 05-07-2013 & $\begin{array}{l}\text { A letter exchange between Peter Sutherland and } \\
\text { Ban Ki-moon relating to the SDGs }\end{array}$ \\
\hline S-1959-0107-0001-00005 & 05-07-2013 & $\begin{array}{l}\text { A letter exchange between Peter Sutherland and } \\
\text { Ban Ki-moon relating to the SDGs }\end{array}$ \\
\hline S-1959-0148-0002-00004 & 05-07-2013 & Letter to PGA on behalf of Secretary-General \\
\hline S-1959-0105-0007-00034 & $12-07-2013$ & $\begin{array}{l}\text { Reply to letter from Bernd Nilles about his } \\
\text { report on MDGs and Post-2015 - includes one } \\
\text { mention of migration }\end{array}$ \\
\hline S-1943-0087-0002-00058 & $19-07-2013$ & $\begin{array}{l}\text { Preface to "International Migration and } \\
\text { Development: Contributions and } \\
\text { Recommendations of the International System", }\end{array}$ \\
\hline
\end{tabular}




\begin{tabular}{|c|c|c|}
\hline Reference & Date & Broad Description \\
\hline S-1959-0106-0006-00025 & $24-07-2013$ & $\begin{array}{l}\text { Letter to Jan Eliasson regarding dissatisfaction } \\
\text { with contents of Secretary-General report for } \\
\text { HLD }\end{array}$ \\
\hline S-1959-0099-0003-00006 & $25-07-2013$ & $\begin{array}{l}\text { Report of the Secretary-General on International } \\
\text { Migration and Development }\end{array}$ \\
\hline S-1959-0105-0006-00017 & 07-08-2013 & $\begin{array}{l}\text { Reply to letter from } \mathrm{Mr} \text { Adler Bynoe regarding } \\
\text { recommendations for the Secretary-General } \\
\text { report on the SDGs }\end{array}$ \\
\hline S-1959-0106-0005-00018 & 09-08-2013 & $\begin{array}{l}\text { Letter to Pope and post-2015 development } \\
\text { including Secretary-General report }\end{array}$ \\
\hline S-1959-0155-0003-00017 & $27-08-2013$ & $\begin{array}{l}\text { Letter scheduling meeting with Secretary- } \\
\text { General about, among other things M\&D and } \\
\text { the post- } 2015 \text { development agenda }\end{array}$ \\
\hline S-1959-0126-0009-00005 & 04-09-2013 & $\begin{array}{l}\text { Letter from William Lacy Swing to Francois } \\
\text { Crépeau }\end{array}$ \\
\hline S-1959-0101-0013-00025 & $17-09-2013$ & $\begin{array}{l}\text { Letter regarding IOM taking over as chair of } \\
\text { GMG and asking him to open side event }\end{array}$ \\
\hline S-1959-0122-0003-00012 & $17-09-2013$ & Ten year report of UNHCR \\
\hline S-1959-0147-0002-00011 & $17-09-2013$ & Letter from William Lacy Swing to Ban Ki-moon \\
\hline S-1959-0147-0002-00006 & 18-09-2013 & Letter from Peter Sutherland to Jan Eliasson \\
\hline S-1959-0106-0003-00019 & $26-09-2013$ & $\begin{array}{l}\text { Note to Secretary-General about the proposed } \\
\text { scenario for opening of } 2013 \text { HLD }\end{array}$ \\
\hline S-1959-0107-0006-00025 & $01-10-2013$ & $\begin{array}{l}\text { A letter exchange between Sweden and UN } \\
\text { Deputy Secretary-General }\end{array}$ \\
\hline S-1943-0049-0005-00017 & 03-10-2013 & $\begin{array}{l}\text { Remarks To High-Level Dialogue } \\
\text { International Migration And Development }\end{array}$ \\
\hline S-1959-0107-0004-00008 & 09-10-2013 & $\begin{array}{l}\text { Note on the High-Level Dialogue on } \\
\text { International Migration and Development }\end{array}$ \\
\hline S-1959-0127-0006-00010 & $09-10-2013$ & $\begin{array}{l}\text { Note on the United Nations Chronicle Issue on } \\
\text { Migration }\end{array}$ \\
\hline S-1959-0105-0003-00002 & $16-10-2013$ & Letter from Peter Sutherland to Jan Eliasson \\
\hline S-1959-0105-0004-00036 & $16-10-2013$ & $\begin{array}{l}\text { Report on the follow up to the ICPD Programme } \\
\text { of Action beyond } 2014\end{array}$ \\
\hline S-1959-0105-0004-00029 & $19-10-2013$ & $\begin{array}{l}\text { Gender-specific content of the general debate } \\
\text { and high-level meetings of the 68th session of } \\
\text { the General Assembly }\end{array}$ \\
\hline S-1959-0105-0004-00032 & $19-10-2013$ & $\begin{array}{l}\text { The } 2013 \text { ECOSOC Presidential Retreat - } \\
\text { migration as a global challenge that should be in } \\
\text { the post- } 2015\end{array}$ \\
\hline S-1959-0154-0001-00050 & $21-10-2013$ & $\begin{array}{l}\text { Letter about HLD follow up and GMG meeting } \\
\text { (IOM=chair) }\end{array}$ \\
\hline S-1959-0108-0005-00004 & 04-11-2013 & $\begin{array}{l}\text { Chair's Summary of the United Nations } \\
\text { Economic Commission for Europe's Regional } \\
\text { Conference on lCPD beyond 2014, "Enabling } \\
\text { Choices: Population Priorities for the 21st } \\
\text { Century." }\end{array}$ \\
\hline S-1943-0085-0005-00079 & $07-11-2013$ & Letter Ban Ki-moon to Peter Sutherland \\
\hline
\end{tabular}




\begin{tabular}{|c|c|c|}
\hline Reference & Date & Broad Description \\
\hline S-1959-0101-0011-00008 & 07-11-2013 & $\begin{array}{l}\text { Invites Secretary-General to 103rd Session of } \\
\text { IOM Council }\end{array}$ \\
\hline S-1943-0120-0003-00002 & $17-01-2014$ & $\begin{array}{l}\text { Remarks At Informal Meeting of the Plenary of } \\
\text { the General Assembly To Hear a Briefing on UN } \\
\text { Challenges }\end{array}$ \\
\hline S-1959-0166-0007-00013 & $20-01-2014$ & $\begin{array}{l}\text { Summary report of the Secretary-General on the } \\
\text { Operational Review of the ICPD }\end{array}$ \\
\hline S-1959-0157-0008-00005 & 04-02-2014 & $\begin{array}{l}\text { Draft Report of the Secretary-General on the } \\
\text { Activities of the Department of Public } \\
\text { Information - para on HLD }\end{array}$ \\
\hline S-1959-0222-0001-00002 & 05-02-2014 & $\begin{array}{l}\text { Invitation to Secretary-General to attend 25th } \\
\text { Conference of NGOs in Consultative } \\
\text { Relationship with the United Nations }\end{array}$ \\
\hline S-1943-0120-0002-00004 & $12-02-2014$ & $\begin{array}{l}\text { Remarks At Launch of International Conference } \\
\text { on Population And Development Global } \\
\text { Review Report }\end{array}$ \\
\hline S-1943-0090-0008-00007 & 21-02-2014 & Appointments of the Secretary-General \\
\hline S-1959-0164-0001-00004 & 07-03-2014 & $\begin{array}{l}\text { The ninth session of the Open Working Group } \\
\text { on SDGs }\end{array}$ \\
\hline S-1959-0185-0009-00011 & 13-03-2014 & $\begin{array}{l}\text { Twenty-fifth session of the Human Rights } \\
\text { Council (3-28 March 2014) }\end{array}$ \\
\hline S-1959-0166-0010-00007 & 14-03-2014 & $\begin{array}{l}\text { Note to the Deputy Secretary-General: Twelfth } \\
\text { coordination meeting on international } \\
\text { migration New York, 20-21 Feb }\end{array}$ \\
\hline S-1959-0218-0003-00001 & 18-03-2014 & Student event in Stockholm \\
\hline S-1959-0174-0006-00014 & 19-03-2014 & $\begin{array}{l}\text { Letter from Abi Williams (Hague Institute) to } \\
\text { Ban Ki-moon }\end{array}$ \\
\hline S-1959-0212-0004-00002 & 27-03-2014 & $\begin{array}{l}\text { Reports of Secretary-General drafts prepared by } \\
\text { UNODC }\end{array}$ \\
\hline S-1943-0118-0005-00003 & 02-04-2014 & $\begin{array}{l}\text { Remarks To Opening of the Fourth Eu-Africa } \\
\text { Summit }\end{array}$ \\
\hline S-1959-0160-0004-00013 & 09-04-2014 & $\begin{array}{l}\text { Letter to Dr Niblett regarding meeting about } \\
\text { post- } 2015 \text { development agenda - migration } \\
\text { mentioned }\end{array}$ \\
\hline S-1959-0166-0007-00010 & 14-04-2014 & $\begin{array}{l}\text { Letter to Secretary-General about 47th } \\
\text { Commission on Population and Development } \\
\text { Meeting }\end{array}$ \\
\hline S-1959-0166-0010-00006 & $15-04-2014$ & $\begin{array}{l}\text { Note from IOM requesting information about } \\
\text { different possibilities for UN-IOM relationship }\end{array}$ \\
\hline S-1959-0164-0004-00017 & 17-04-2014 & $\begin{array}{l}\text { The outcome of the Forty-Seventh Session of the } \\
\text { Commission on Population and Development }\end{array}$ \\
\hline S-1943-0090-0006-00003 & 28-04-2014 & Appointments of the Secretary-General \\
\hline S-1959-0167-0005-00002 & 05-05-2014 & $\begin{array}{l}\text { Draft report of the intergovernmental } \\
\text { committee of experts on Sustainable } \\
\text { Development Financing }\end{array}$ \\
\hline S-1959-0165-0002-00004 & 13-05-2014 & $\begin{array}{l}\text { Report of the Secretary-General: } \\
\text { Implementation of the Programme of Action for }\end{array}$ \\
\hline
\end{tabular}




\begin{tabular}{|c|c|c|}
\hline Reference & Date & Broad Description \\
\hline & & $\begin{array}{l}\text { he Least Developed Countries for the Decade } \\
\text { 2011-2020 }\end{array}$ \\
\hline S-1959-0166-0010-00003 & $19-06-2014$ & $\begin{array}{l}\text { Letter from Tobias Billstrom and Hillevi } \\
\text { Engstrom regarding the GFMD in Sweden }\end{array}$ \\
\hline S-1959-0185-0008-00014 & $20-06-2014$ & $\begin{array}{l}\text { Twenty-sixth session of the Human Rights } \\
\text { Council (10-27 June 2014) }\end{array}$ \\
\hline S-1943-0112-0001-00010 & 29-06-2014 & Letter to Princess of Sweden about GFMD/SDGs \\
\hline S-1959-0193-0005-00004 & 36-06-2014 & $\begin{array}{l}\text { Reports prepared by UNODC for the General } \\
\text { Assembly at its } 69 \text { th session }\end{array}$ \\
\hline S-1959-0186-0003-00014 & $07-07-2014$ & Secretary-General report on Globalization \\
\hline S-1959-0163-0004-00022 & $10-07-2014$ & $\begin{array}{l}\text { Letter to PGA about the thematic debate on } \\
\text { Human Security }\end{array}$ \\
\hline S-1959-0166-0010-00001 & $23-07-2014$ & $\begin{array}{l}\text { Report of the Secretary-General: International } \\
\text { Migration and Development }\end{array}$ \\
\hline S-1943-0114-0005-00002 & $30-07-2014$ & $\begin{array}{l}\text { Lecture At the Inter-American Court of Human } \\
\text { Rights }\end{array}$ \\
\hline S-1959-0188-0012-00005 & 01-08-2014 & $\begin{array}{l}\text { Draft Report of the Secretary-General on } \\
\text { International } \\
\text { Cooperation on Humanitarian Assistance In the } \\
\text { Field } \\
\text { Natural Disasters, From Relief To Development }\end{array}$ \\
\hline S-1959-0193-0005-00003 & 07-08-2014 & $\begin{array}{l}\text { Reports of Secretary-General drafts prepared by } \\
\text { UNODC }\end{array}$ \\
\hline S-1959-0161-0005-00028 & 14-08-2014 & $\begin{array}{l}\text { Letter from Director of Communications and } \\
\text { Speech Writing Department to Peter Sutherland }\end{array}$ \\
\hline S-1959-0186-0002-00005 & $20-08-2014$ & $\begin{array}{l}\text { Draft Secretary-General report on the assistance } \\
\text { to refugees, returnees, and displaced persons in } \\
\text { Africa. }\end{array}$ \\
\hline S-1959-0190-0005-00016 & $27-08-2014$ & Letter to Secretary-General about post-2015 \\
\hline S-1959-0193-0007-00006 & 02-09-2014 & $\begin{array}{l}\text { Report of the Secretary-General on Oceans and } \\
\text { the Law of the Sea }\end{array}$ \\
\hline S-1959-0191-0001-00004 & $12-09-2014$ & Letter to PGA about AoC report \\
\hline S-1959-0158-0009-00002 & $16-09-2014$ & $\begin{array}{l}\text { An email exchange about a non-relevant event } \\
\text { with one mention of Deputy Secretary-General } \\
\text { representing Secretary-General at GFMD in } \\
\text { Turkey }\end{array}$ \\
\hline S-1959-0220-0002-00035 & $18-09-2014$ & $\begin{array}{l}\text { The } 2014 \text { World Forum on the Diaspora } \\
\text { Economy }\end{array}$ \\
\hline S-1959-0169-0002-00004 & 21-09-2014 & $\begin{array}{l}\text { Letter from Transparency International } \\
\text { Bangladesh about climate change - including } \\
\text { migration }\end{array}$ \\
\hline S-1959-0165-0004-00006 & $02-10-2014$ & $\begin{array}{l}\text { A summary note on the United Nations General } \\
\text { Assembly Special Session on the follow-up to } \\
\text { the Programme of Action of the International } \\
\text { Conference on Population and Development } \\
\text { beyond 2014: }\end{array}$ \\
\hline
\end{tabular}




\begin{tabular}{|c|c|c|}
\hline Reference & Date & Broad Description \\
\hline S-1959-0158-0007-00004 & $20-10-2014$ & $\begin{array}{l}\text { Letter from Permanent Representative Italy and } \\
\text { China on World Cities Day }\end{array}$ \\
\hline S-1959-0163-0002-00009 & $26-11-2014$ & $\begin{array}{l}\text { Letter to Guy Ryder about GMG contributions } \\
\text { to post-2015 development agenda }\end{array}$ \\
\hline S-1959-0223-0006-00007 & 08-12-2014 & $\begin{array}{l}\text { Letter from William Lacy Swing to Ban Ki- } \\
\text { moon. }\end{array}$ \\
\hline S-1959-0187-0007-00002 & $18-12-2014$ & $\begin{array}{l}\text { Letter to International Maritime Organization } \\
\text { about the Mediterranean }\end{array}$ \\
\hline S-1959-0163-0001-00003 & $24-12-2014$ & $\begin{array}{l}\text { Letter to Peter Sutherland from Amina } \\
\text { Mohammed regarding Stockholm Agenda }\end{array}$ \\
\hline S-1959-0211-0005-00007 & $24-12-2014$ & $\begin{array}{l}\text { Letter regarding Michelle Klein Solomon } \\
\text { resignation }\end{array}$ \\
\hline S-1959-0256-0009-00014 & 05-01-2015 & $\begin{array}{l}\text { Letter to Jan Eliasson about a meeting about } \\
\text { UN-IOM relationship }\end{array}$ \\
\hline S-1959-0282-0002-00024 & 19-01-2015 & $\begin{array}{l}\text { Invitation to address the 13th coordination } \\
\text { meeting on international migration }\end{array}$ \\
\hline S-1959-0232-0008-00036 & 21-01-2015 & Invitation to Turkish GFMD \\
\hline S-1959-0280-0004-00016 & 21-01-2015 & $\begin{array}{l}\text { Invitation from Turkey to Ban Ki-moon for } \\
\text { Turkish GFMD }\end{array}$ \\
\hline S-1959-0234-0004-00012 & 23-01-2015 & $\begin{array}{l}\text { Letter about 13th coordination meeting and } \\
\text { organizing meeting for GFMD troika }\end{array}$ \\
\hline S-1959-0340-0005-00031 & 27-01-2015 & IOM IDM on implementation of SDGs \\
\hline S-1959-0256-0009-00011 & 02-02-2015 & $\begin{array}{l}\text { Draft report of the Secretary-General on the UN } \\
\text { Institute for Training and Research for } \\
\text { consideration by the Economic and Social } \\
\text { Council in April } 2015 \text {. }\end{array}$ \\
\hline S-1959-0256-0008-00027 & 05-03-2015 & $\begin{array}{l}\text { Letter to Jan Eliasson about UNDG's decision to } \\
\text { exclude IOM }\end{array}$ \\
\hline S-1943-0137-0003-00025 & 06-03-2015 & Letter Ban Ki-moon to Peter Sutherland \\
\hline S-1959-0234-0004-00011 & 13-03-2015 & 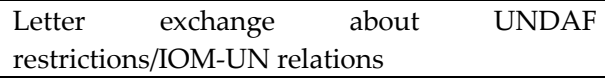 \\
\hline S-1943-0137-0003-00061 & $17-03-2015$ & Letter Ban Ki-moon to Peter Sutherland \\
\hline S-1959-0229-0005-00024 & $17-03-2015$ & $\begin{array}{l}\text { Invitation to Secretary-General (from Belgium) } \\
\text { to forty-eighth session of the Commission on } \\
\text { Population and Development }\end{array}$ \\
\hline S-1959-0283-0003-00042 & $17-03-2015$ & $\begin{array}{l}\text { A letter exchange between Ban Ki-moon and } \\
\text { Peter Sutherland about the Sutherland Report }\end{array}$ \\
\hline S-1959-0256-0008-00022 & $20-03-2015$ & $\begin{array}{l}\text { Letter to Secretary-General about the death of } \\
\text { two Dutch UN Peacekeepers }\end{array}$ \\
\hline S-1959-0233-0002-00008 & 26-03-2015 & $\begin{array}{l}\text { Draft report of the Secretary-General on } \\
\text { mainstreaming the three dimensions of } \\
\text { sustainable development to the United Nations } \\
\text { system }\end{array}$ \\
\hline S-1959-0256-0008-00018 & $13-04-2015$ & $\begin{array}{l}\text { Letter to Jan Eliasson about a meeting about } \\
\text { UN-IOM relationship }\end{array}$ \\
\hline S-1959-0311-0006-00004 & $20-04-2015$ & General Assembly decision 70/539 \\
\hline
\end{tabular}




\begin{tabular}{|c|c|c|}
\hline Reference & Date & Broad Description \\
\hline S-1959-0234-0004-00009 & $24-04-2015$ & $\begin{array}{l}\text { Letter about inviting Committee for ICRMW to } \\
\text { Istanbul }\end{array}$ \\
\hline S-1959-0227-0009-00030 & $22-05-2015$ & $\begin{array}{l}\text { DPI Press Review including several migration- } \\
\text { related paragraphs }\end{array}$ \\
\hline S-1959-0227-0009-00029 & 29-05-2015 & $\begin{array}{l}\text { DPI Press Review including several migration- } \\
\text { related paragraphs }\end{array}$ \\
\hline S-1959-0283-0003-00018 & $22-06-2015$ & $\begin{array}{l}\text { Writes to request meeting between Prime } \\
\text { Minister of Malta and BM to discuss, among } \\
\text { other things, migration }\end{array}$ \\
\hline S-1959-0266-0007-00013 & $24-06-2015$ & $\begin{array}{l}\text { Deputy Secretary-General report on visits to } \\
\text { Oslo, Stockholm, London, and Luxembourg }\end{array}$ \\
\hline S-1959-0346-0011-00001 & $09-07-2015$ & Declaration \\
\hline S-1959-0284-0008-00017 & $16-07-2015$ & $\begin{array}{l}\text { Letter to Martin Schulz discussing among other } \\
\text { things the European Agenda on Migration }\end{array}$ \\
\hline S-1959-0284-0008-00016 & $20-07-2015$ & $\begin{array}{l}\text { Letter to Frank Walter Steinmeier (Germany) - } \\
\text { mentions discussing migration }\end{array}$ \\
\hline S-1959-0234-0004-00007 & $21-07-2015$ & $\begin{array}{l}\text { Note to the Secretary-General: Update from } \mathrm{Mr} \\
\text { Peter Sutherland, Special Representative of the } \\
\text { Secretary-General for International Migration } \\
\text { and Development // Letter from Sutherland to } \\
\text { Ban Ki-moon including a summary by Paul } \\
\text { Akiwumi }\end{array}$ \\
\hline S-1959-0234-0004-00008 & $22-07-2015$ & Letter about European Migration Agenda \\
\hline S-1959-0234-0010-00006 & $27-07-2015$ & $\begin{array}{l}\text { The outcome of the Third International } \\
\text { Conference on Financing for Development }\end{array}$ \\
\hline S-1959-0259-0007-00004 & $30-07-2015$ & $\begin{array}{l}\text { Relationship between the United Nations and } \\
\text { the International Organization for Migration } \\
(\mathrm{IOM})\end{array}$ \\
\hline S-1959-0284-0008-00014 & $30-07-2015$ & $\begin{array}{l}\text { Letter to Federica Mogherini about the } \\
\text { partnership between the EU and the UN on } \\
\text { migration }\end{array}$ \\
\hline S-1959-0251-0005-00009 & 05-08-2015 & $\begin{array}{l}\text { Draft report on Activities of the United Nations } \\
\text { Voluntary Fund for Victims of Torture }\end{array}$ \\
\hline S-1959-0254-0001-00006 & $12-08-2015$ & $\begin{array}{l}\text { Draft Secretary-General report on international } \\
\text { cooperation on humanitarian assistance in the } \\
\text { field of natural disasters (ND). }\end{array}$ \\
\hline S-1959-0251-0004-00008 & $18-08-2015$ & $\begin{array}{l}\text { Draft Secretary-General report on Assistance to } \\
\text { refugees, returnees, and displaced persons in } \\
\text { Africa }\end{array}$ \\
\hline S-1959-0251-0004-00005 & 21-08-2015 & $\begin{array}{l}\text { Draft Secretary-General report on total } \\
\text { elimination of racism, racial discrimination, } \\
\text { xenophobia, and related intolerance. }\end{array}$ \\
\hline S-1959-0234-0004-00006 & $24-08-2015$ & Talking points on Migration Crisis \\
\hline S-1943-0139-0005-00036 & $28-08-2015$ & Letter Ban Ki-moon to Mevlut Cavusoglu \\
\hline S-1959-0227-0009-00018 & $28-08-2015$ & $\begin{array}{l}\text { DPI Press Review including several migration- } \\
\text { related paragraphs }\end{array}$ \\
\hline S-1959-0227-0009-00017 & 04-09-2015 & DPI Weekly Press Review \\
\hline
\end{tabular}




\begin{tabular}{|c|c|c|}
\hline Reference & Date & Broad Description \\
\hline S-1959-0232-0004-00018 & 08-09-2015 & $\begin{array}{l}\text { Address to UNICEF Executive Board about } \\
\text { SDGs }\end{array}$ \\
\hline S-1959-0227-0009-00016 & $11-09-2015$ & DPI Weekly Press Review \\
\hline S-1959-0281-0003-00002 & 28-09-2015 & $\begin{array}{l}\text { Letter from Turkey (Mehmet Samsar) to Jan } \\
\text { Eliasson regarding GFMD in Turkey }\end{array}$ \\
\hline S-1959-0227-0009-00014 & $02-10-2015$ & DPI Weekly Press Review \\
\hline S-1959-0234-0004-00005 & 02-10-2015 & $\begin{array}{l}\text { Address to side event: "Strengthening } \\
\text { cooperation on migration and refugee } \\
\text { movements under the new development } \\
\text { agenda," }\end{array}$ \\
\hline S-1959-0257-0004-00010 & 05-10-2015 & Letter from Peter Sutherland to Ban Ki-moon \\
\hline S-1943-0140-0002-00008 & 22-10-2015 & $\begin{array}{l}\text { Message To United Nations Association of New } \\
\text { York Humanitarian Awards Dinner }\end{array}$ \\
\hline S-1959-0234-0009-00005 & 04-11-2015 & $\begin{array}{l}\text { Letter to G20 leaders ahead of the first meeting } \\
\text { after the adoption of the SDGs. }\end{array}$ \\
\hline S-1959-0234-0004-00004 & 05-11-2015 & $\begin{array}{l}\text { Note to Deputy Secretary-General about Valetta } \\
\text { Summit }\end{array}$ \\
\hline S-1959-0234-0004-00001 & $10-11-2015$ & Situation report on Migrants \\
\hline S-1959-0227-0009-00008 & 13-11-2015 & $\begin{array}{l}\text { DPI Press Review including several migration- } \\
\text { related paragraphs }\end{array}$ \\
\hline S-1959-0232-0004-00004 & $17-11-2015$ & $\begin{array}{l}\text { Letter to International Maritime Organization } \\
\text { about people in distress at sea }\end{array}$ \\
\hline S-1943-0140-0005-00002 & $18-11-2015$ & $\begin{array}{l}\text { Communications with King and Prime Minister } \\
\text { of Spain about SDGs and migration crisis }\end{array}$ \\
\hline S-1959-0227-0009-00005 & $25-11-2015$ & $\begin{array}{l}\text { DPI Press Review including several migration- } \\
\text { related paragraphs }\end{array}$ \\
\hline S-1959-0251-0003-00008 & 07-12-2015 & $\begin{array}{l}\text { draft Secretary-General report on "Impact of the } \\
\text { arbitrary deprivation of nationality }\end{array}$ \\
\hline S-1959-0233-0007-00004 & $16-12-2015$ & $\begin{array}{l}\text { Letter to Secretary-General about data } \\
\text { disaggregation }\end{array}$ \\
\hline S-1959-0237-0001-00005 & $16-12-2015$ & 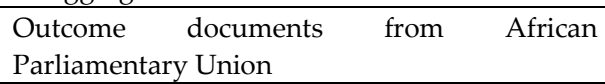 \\
\hline S-1959-0347-0016-00001 & $17-12-2015$ & $\begin{array}{l}\text { Letter from Advisory Board on Human Security } \\
\text { - concerning migration and SDGs }\end{array}$ \\
\hline S-1959-0234-0004-00003 & $31-12-2015$ & $\begin{array}{l}\text { Writes about developments in Denmark and } \\
\text { threats to reopen } 1951 \text { convention }\end{array}$ \\
\hline S-1959-0311-0007-00001 & $15-01-2016$ & $\begin{array}{l}\text { Writes to Mr Lars Løkke Rasmussen (Denmark) } \\
\text { about Danish response to refugees }\end{array}$ \\
\hline S-1959-0354-0003-00013 & $18-01-2016$ & $\begin{array}{l}\text { Invitation Secretary-General to give the opening } \\
\text { address at 108th session of the council }\end{array}$ \\
\hline S-1959-0311-0007-00014 & $20-01-2016$ & Eritrean Minister writes to Ban Ki-moon \\
\hline S-1959-0335-0001-00023 & $20-01-2016$ & $\begin{array}{l}\text { A letter exchange between Sheikh Hasina } \\
\text { (Bangladesh) and Ban Ki-moon regarding } \\
\text { GFMD }\end{array}$ \\
\hline S-1959-0311-0007-00013 & 21-01-2016 & $\begin{array}{l}\text { Writes to Minister for Foreign Affairs and } \\
\text { Emigrants (Lebanon) responding to letter } \\
\text { regarding the situation in Lebanon }\end{array}$ \\
\hline
\end{tabular}




\begin{tabular}{|c|c|c|}
\hline Reference & Date & Broad Description \\
\hline S-1959-0311-0007-00012 & $25-01-2016$ & $\begin{array}{l}\text { Prime Minister of Denmark replies to Ban Ki- } \\
\text { moon (S-1959-0311-0007-00001) }\end{array}$ \\
\hline S-1959-0342-0005-00021 & $25-01-2016$ & $\begin{array}{l}\text { Bangladesh writes to Secretary-General to seek } \\
\text { a meeting between Shahidul Haque and Ban Ki- } \\
\text { moon and Peter Sutherland }\end{array}$ \\
\hline S-1959-0340-0005-00028 & 29-01-2016 & $\begin{array}{l}\text { Invitation to Jan Eliasson from Bangladesh for a } \\
\text { special meeting on } 25 \text { February } 2016\end{array}$ \\
\hline S-1959-0311-0007-00011 & 03-02-2016 & $\begin{array}{l}\text { Club de Madrid (non-profit - members are } \\
\text { former world leaders) proposing to use } 2016 \\
\text { dialogue to discuss the refugee crisis }\end{array}$ \\
\hline S-1959-0317-0001-00016 & 05-02-2016 & $\begin{array}{l}\text { Letter to William Lacy Swing about IOM } \\
\text { relationship agreement }\end{array}$ \\
\hline S-1959-0311-0007-00010 & $12-02-2016$ & Letter from Canadian Bishop \\
\hline S-1959-0311-0007-00009 & $17-02-2016$ & $\begin{array}{l}\text { Writes to Ban Ki-moon about Syrian Donor } \\
\text { conference in London on } 4 \text { February } 2016\end{array}$ \\
\hline S-1959-0311-0007-00008 & $25-02-2016$ & $\begin{array}{l}\text { Writes to Prime Minister of Iraq copying in } \\
\text { Secretary-General about the situation in Iraq }\end{array}$ \\
\hline S-1959-0311-0007-00007 & $26-02-2016$ & $\begin{array}{l}\text { Views of refugee movements ahead of High- } \\
\text { Level Summit }\end{array}$ \\
\hline S-1959-0311-0007-00005 & $29-02-2016$ & $\begin{array}{l}\text { Views of refugee movements ahead of High- } \\
\text { Level Summit }\end{array}$ \\
\hline S-1959-0311-0007-00006 & 29-02-2016 & $\begin{array}{l}\text { Views of refugee movements ahead of High- } \\
\text { Level Summit }\end{array}$ \\
\hline S-1959-0311-0007-00003 & 01-03-2016 & $\begin{array}{l}\text { Views of refugee movements ahead of High- } \\
\text { Level Summit }\end{array}$ \\
\hline S-1959-0311-0007-00004 & 01-03-2016 & $\begin{array}{l}\text { Views of refugee movements ahead of High- } \\
\text { Level Summit }\end{array}$ \\
\hline S-1959-0311-0006-00013 & $02-03-2016$ & $\begin{array}{l}\text { Contributions from Bangladesh for UN High- } \\
\text { Level Plenary Meeting on addressing large } \\
\text { movements of refugees and migrants }\end{array}$ \\
\hline S-1959-0311-0006-00012 & 11-03-2016 & $\begin{array}{l}\text { Writes to Ban Ki-moon about the situation in } \\
\text { Europe }\end{array}$ \\
\hline S-1959-0311-0006-00011 & 13-03-2016 & $\begin{array}{l}\text { Writes to Ban Ki-moon about the situation in } \\
\text { Lebanon }\end{array}$ \\
\hline S-1959-0311-0006-00010 & $15-03-2016$ & French letter about refugees \\
\hline S-1959-0311-0006-00009 & 18-03-2016 & $\begin{array}{l}\text { Writes to Ban Ki-moon about the situation on } \\
\text { Lesvos }\end{array}$ \\
\hline S-1959-0311-0006-00008 & 23-03-2016 & $\begin{array}{l}\text { Head of Republic Forum - former president of } \\
\text { Lebanon writes to Ban Ki-moon about the } \\
\text { Syrian crisis }\end{array}$ \\
\hline S-1959-0311-0006-00007 & 24-03-2016 & $\begin{array}{l}\text { Letter to Jan Eliasson advising that Michele } \\
\text { Klein Solomon and Lea Matheson have been } \\
\text { seconded for the Summit preparations }\end{array}$ \\
\hline S-1959-0311-0006-00006 & 07-04-2016 & $\begin{array}{l}\text { Asking about grants for organizations helping } \\
\text { IDPs }\end{array}$ \\
\hline S-1959-0311-0006-00005 & 08-04-2016 & $\begin{array}{l}\text { Advisor to Prime Minister of Pakistan writes to } \\
\text { Ban Ki-moon regarding refugee crises }\end{array}$ \\
\hline
\end{tabular}




\begin{tabular}{|c|c|c|}
\hline Reference & Date & Broad Description \\
\hline S-1959-0293-0012-00015 & $13-04-2016$ & $\begin{array}{l}\text { Letter about High-Level Summit (NY Sep 2016) } \\
/ / \text { Refers to a concept note for GFMD and } \\
\text { suggested elements for a Global Compact which } \\
\text { is not attached }\end{array}$ \\
\hline S-1959-0295-0007-00016 & $19-04-2016$ & $\begin{array}{l}\text { Letter to Secretary-General regretting he cannot } \\
\text { attend the signing of Paris Agreement }\end{array}$ \\
\hline S-1959-0311-0006-00001 & 21-04-2016 & $\begin{array}{l}\text { Invitation to Jan Eliasson for the Regional } \\
\text { Forum on Syria Refugee Crisis: }\end{array}$ \\
\hline S-1959-0311-0006-00002 & $25-04-2016$ & $\begin{array}{l}\text { Three letters to and from Ban Ki-moon relating } \\
\text { to his visit to Lebanon }\end{array}$ \\
\hline S-1959-0311-0005-00024 & $27-04-2016$ & $\begin{array}{l}\text { Letter to Ban Ki-moon protesting the actions of } \\
\text { FYROM in closing borders }\end{array}$ \\
\hline S-1959-0311-0005-00025 & $27-04-2016$ & $\begin{array}{l}\text { Letter to Yale President (referred to in S-1959- } \\
\text { 0311-0005-00017) regarding scholarships for } \\
\text { Syrians }\end{array}$ \\
\hline S-1959-0340-0004-00004 & 06-05-2016 & $\begin{array}{l}\text { Invitation from the IIEA to Jan Eliasson for an } \\
\text { event on Migration and the } 2030 \text { Development } \\
\text { Agenda. }\end{array}$ \\
\hline S-1959-0311-0005-00023 & 09-05-2016 & $\begin{array}{l}\text { Letter to Ban Ki-moon reference in S-1959-0311- } \\
0005-00020\end{array}$ \\
\hline S-1959-0311-0005-00021 & $11-05-2016$ & Letter from Kenya about Dadaab \\
\hline S-1959-0287-0004-00003 & $13-05-2016$ & Press Review \\
\hline S-1959-0340-0003-00034 & $25-05-2016$ & $\begin{array}{l}\text { Thematic Workshop on Migration for Peace, } \\
\text { Stability, and Growth }\end{array}$ \\
\hline S-1959-0311-0005-00019 & 02-06-2016 & $\begin{array}{l}\text { Regards a situation where a refugee was } \\
\text { prevented from leaving Iraq }\end{array}$ \\
\hline S-1959-0311-0005-00020 & 02-06-2016 & Protection of women and girls in refugee crises. \\
\hline S-1959-0311-0005-00018 & 07-06-2016 & $\begin{array}{l}\text { Update on the preparations for the high-level } \\
\text { plenary meeting of the General Assembly to } \\
\text { address large movement of refugees and } \\
\text { migrants }\end{array}$ \\
\hline S-1959-0311-0005-00016 & $20-06-2016$ & $\begin{array}{l}\text { Civil society letter about the situation in } \\
\text { Cameroon. }\end{array}$ \\
\hline S-1959-0311-0005-00017 & $20-06-2016$ & $\begin{array}{l}\text { References a letter sent to the president of Yale } \\
\text { about Syrian Refugees }\end{array}$ \\
\hline S-1959-0311-0005-00015 & $28-06-2016$ & $\begin{array}{l}\text { Lithuania would like to become a Member State } \\
\text { of the Executive Committee of the High } \\
\text { Commissioner's } \\
\text { Programme. }\end{array}$ \\
\hline S-1959-0311-0005-00014 & 07-07-2016 & $\begin{array}{l}\text { Fiji would like to become a member of the } \\
\text { Executive Committee of the Programme of } \\
\text { UNHCR }\end{array}$ \\
\hline S-1959-0292-0007-00006 & $15-07-2016$ & $\begin{array}{l}\text { Draft Report of the Secretary-General on } \\
\text { International Migration and Development for } \\
\text { the seventy-first session of the General } \\
\text { Assembly }\end{array}$ \\
\hline
\end{tabular}




\begin{tabular}{|c|c|c|}
\hline Reference & Date & Broad Description \\
\hline S-1959-0293-0012-00007 & $26-07-2016$ & $\begin{array}{l}\text { Report of the Secretary-General on International } \\
\text { Migration and Development for the seventy- } \\
\text { first session of the General Assembly }\end{array}$ \\
\hline S-1959-0311-0005-00013 & $26-07-2016$ & Secretary-General visit to Lesvos \\
\hline S-1959-0317-0001-00008 & $28-07-2016$ & $\begin{array}{l}\text { Letter to William Lacy Swing about IOM } \\
\text { relationship agreement }\end{array}$ \\
\hline S-1959-0311-0005-00012 & 03-08-2016 & $\begin{array}{l}\text { Note to the Secretary-General: Outcome } \\
\text { document for } 19 \text { September Summit for } \\
\text { Refugees and Migrants }\end{array}$ \\
\hline S-1959-0313-0001-00006 & 04-08-2016 & Central Emergency Response Fund (CERF) \\
\hline S-1959-0335-0006-00009 & $19-08-2016$ & $\begin{array}{l}\text { Opening of the 108th Session of the IOM } \\
\text { Council }\end{array}$ \\
\hline S-1959-0309-0012-00015 & $22-08-2016$ & $\begin{array}{l}\text { Assistance to refugees, returnees, and displaced } \\
\text { persons in Africa }\end{array}$ \\
\hline S-1959-0311-0005-00011 & $22-08-2016$ & $\begin{array}{l}\text { Report of the Secretary-General: Assistance to } \\
\text { refugees, returnees, and displaced persons in } \\
\text { Africa }\end{array}$ \\
\hline S-1943-0147-0005-00017 & $30-08-2016$ & Letter Ban Ki-moon to Peter Sutherland \\
\hline S-1959-0309-0011-00004 & 23-09-2016 & Note after the NY Summit \\
\hline S-1959-0311-0005-00010 & $23-09-2016$ & $\begin{array}{l}\text { Memo on United Nations Summit for Refugees } \\
\text { and Migrants }\end{array}$ \\
\hline S-1959-0317-0001-00004 & 07-10-2016 & $\begin{array}{llll}\text { Agreement concerning the } & \text { UN-IOM } \\
\text { Relationship } & & & \\
\end{array}$ \\
\hline S-1959-0291-0009-00003 & $10-10-2016$ & $\begin{array}{l}\text { Synopsis of the general debate of the seventy- } \\
\text { first session of General Assembly }\end{array}$ \\
\hline S-1959-0311-0005-00009 & $12-10-16$ & $\begin{array}{l}\text { Letter from civil society actors outlining alarm } \\
\text { at how little states achieved at the summit. }\end{array}$ \\
\hline S-1959-0350-0011-00011 & $12-10-2016$ & $\begin{array}{l}\text { Letter to Secretary-General about meeting in } \\
\text { Cartagena }\end{array}$ \\
\hline S-1959-0354-0009-00001 & $12-10-16$ & About a petition \#WithRefugees \\
\hline S-1959-0340-0001-00017 & $14-10-2016$ & $\begin{array}{l}\text { Global Compact event on } 14 \text { November } 2016 \\
\text { including concept note }\end{array}$ \\
\hline S-1959-0340-0001-00012 & $31-10-2016$ & $\begin{array}{l}\text { Request for a video message from Jan Eliasson } \\
\text { for Global Compact event on } 14 \text { November }\end{array}$ \\
\hline S-1959-0311-0005-00008 & 04-11-2016 & Condemning attacks against Rohingya \\
\hline S-1959-0332-0011-00002 & 09-11-2016 & $\begin{array}{l}\text { Draft report on trafficking which references } \\
\text { GCM }\end{array}$ \\
\hline S-1959-0297-0003-00004 & 24-11-2016 & $\begin{array}{l}\text { Thanks Jan Eliasson for his efforts in migration } \\
\text { entering UN }\end{array}$ \\
\hline S-1959-0311-0005-00007 & $01-12-2016$ & Condemning attacks against Rohingya \\
\hline S-1959-0291-0009-00002 & $14-12-2016$ & $\begin{array}{l}\text { Summary of Second Committee Meeting of 71st } \\
\text { General Assembly (Dec 2016) }\end{array}$ \\
\hline S-1959-0293-0012-00005 & $16-12-2016$ & $\begin{array}{l}\text { Appointment of SRSG (only on international } \\
\text { migration) }\end{array}$ \\
\hline S-1959-0311-0005-00006 & $16-12-2016$ & $\begin{array}{l}\text { Secretary-General's letter to PGA on the } \\
\text { appointment of SRSG for International } \\
\text { Migration }\end{array}$ \\
\hline
\end{tabular}




\begin{tabular}{|l|l|l|}
\hline Reference & Date & Broad Description \\
\hline S-1959-0298-0004-00005 & $20-12-2016$ & $\begin{array}{l}\text { Letter congratulating Amina Mohammed on } \\
\text { appointment }\end{array}$ \\
\hline S-1943-0145-0005-00005 & $21-12-2016$ & Letter Bank Ki-moon to PGA \\
\hline S-1959-0298-0006-00010 & $29-12-2016$ & $\begin{array}{l}\text { Letter from Ban Ki-moon to Peter Sutherland - } \\
\text { thank you letters at end of tenure including to } \\
\text { Sutherland }\end{array}$ \\
\hline S-1959-0300-0001-00001 & 02-01-2017 & $\begin{array}{l}\text { Invitation to Guterres from the Scalibrini } \\
\text { International Migration Network to give } \\
\text { opening Remarks of the VI International Forum } \\
\text { on Migration and Peace }\end{array}$ \\
\hline
\end{tabular}




\section{Annex 3.5 List of GMG Documents}

\begin{tabular}{|c|c|c|c|}
\hline$\underline{\varrho}$ & 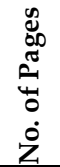 & 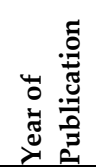 & 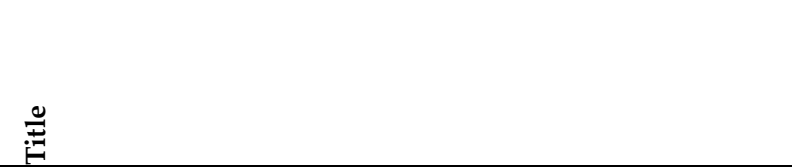 \\
\hline FAO & 12 & 2014 & $\begin{array}{l}\text { Targets and Indicators for the Post-2015 Development Agenda } \\
\text { and the Sustainable Development Goal }\end{array}$ \\
\hline FAO & 2 & 2014 & $\begin{array}{l}\text { FAO and the Post-2015 Development Agenda Issue Papers: } \\
\text { Poverty Eradication }\end{array}$ \\
\hline FAO & 134 & 2015 & $\begin{array}{l}\text { The Director-General's Medium Term Plan 2014-17 and } \\
\text { Programme of Work and Budget 2016-17 }\end{array}$ \\
\hline FAO & 28 & 2015 & $\begin{array}{l}\text { FAO and the Post- } 2015 \text { Development Agenda Issue Papers: } \\
\text { Food Security and the Right to Food }\end{array}$ \\
\hline FAO & 6 & 2015 & FAO's e-Bulletin on the Post-2015 Development Agenda. \\
\hline ILO & 1 & n.d. & The ILO and the Post-2015 Development Agenda \\
\hline ILO & 14 & n.d. & $\begin{array}{l}\text { Mainstreaming of Migration in Development Policy and } \\
\text { Integrating Migration in the Post- } 2015 \text { UN Development } \\
\text { Agenda }\end{array}$ \\
\hline ILO & 30 & 2013 & Labour Migration and Development: ILO Moving Forward \\
\hline ILO & 4 & n.d. & $\begin{array}{l}\text { Migration and Decent Work and the Post-2015 Development } \\
\text { Agenda }\end{array}$ \\
\hline ILO & 1 & 2014 & Fair Migration and the Post-2015 \\
\hline ILO & 14 & n.d. & $\begin{array}{l}\text { Integrating Labour Migration into the } 2013 \text { UN High-Level } \\
\text { Dialogue on International Migration and Development, and the } \\
\text { Post-2015 UN Development Agenda }\end{array}$ \\
\hline ILO & 11 & 2014 & $\begin{array}{l}\text { Promoting Effective Governance of Labour Migration from } \\
\text { South Asia }\end{array}$ \\
\hline ILO & 30 & 2014 & Report for ILC 2014 Fair Migration: Setting an ILO Agenda \\
\hline ILO & 13 & 2015 & Promoting Decent Work For Migrant Workers \\
\hline ILO & 12 & n.d. & PowerPoint Presentation by Michelle Leighton \\
\hline ILO & 5 & n.d. & Outcome 7 2014-2015 results \\
\hline ILO & 1 & 2014 & Michelle Leighton keynote to ICRMW Committee \\
\hline IOM & 144 & 2013 & $\begin{array}{l}\text { Migration and the United Nations Post-2015 Development } \\
\text { Agenda }\end{array}$ \\
\hline IOM & 8 & n.d. & $\begin{array}{l}\text { IOM Position on the Post-2015 United Nations Development } \\
\text { Agenda }\end{array}$ \\
\hline IOM & 392 & 2014 & Migration Initiatives 2015 Regional Strategies \\
\hline IOM & 1 & 2013 & Migration and the Post-2015 UN Development Agenda \\
\hline IOM & 12 & 2014 & $\begin{array}{l}\text { Integrating Migration into the Post-2015 United Nations } \\
\text { Development Agenda }\end{array}$ \\
\hline IOM & 4 & n.d. & $\begin{array}{l}\text { Health in the Post-2015 Development Agenda: The Importance } \\
\text { of Migrants' Health for Sustainable and Equitable Development }\end{array}$ \\
\hline IOM & 4 & 2014 & Migration in the Post-2015 process: Analysing Key Trends \\
\hline
\end{tabular}




\begin{tabular}{|c|c|c|c|}
\hline$\stackrel{0}{\underline{\theta}}$ & 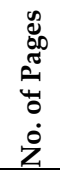 & 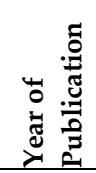 & 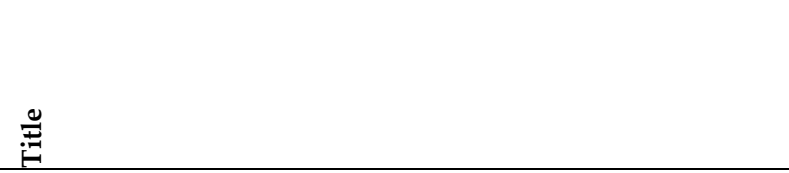 \\
\hline OHCHR & 48 & 2013 & $\begin{array}{l}\text { Migration and Human Rights: Improving Human Rights-Based } \\
\text { Governance of International Migration }\end{array}$ \\
\hline OHCHR & 10 & 2013 & $\begin{array}{l}\text { Protecting Human Rights in the Context of Migration (OHCHR } \\
\text { Report 2013) }\end{array}$ \\
\hline OHCHR & 8 & 2012 & $\begin{array}{l}\text { Protecting Human Rights in the Context of Migration (OHCHR } \\
\text { Report 2012) }\end{array}$ \\
\hline OHCHR & 128 & 2013 & OHCHR Management Plan 2014-2017 \\
\hline OHCHR & 11 & 2015 & $\begin{array}{l}\text { Twenty-Third Session of the Committee on the Protection of the } \\
\text { Rights of All Migrant Workers and Members of Their Families }\end{array}$ \\
\hline OHCHR & 12 & 2014 & $\begin{array}{l}\text { Twenty-First Session of the Committee on the Protection of the } \\
\text { Rights of All Migrant Workers and Members of Their Families }\end{array}$ \\
\hline OHCHR & 21 & 2014 & $\begin{array}{l}\text { Report of the Special Rapporteur on the Human Rights of } \\
\text { Migrants }\end{array}$ \\
\hline OHCHR & 7 & 2015 & $\begin{array}{l}\text { Twenty-Second Session of the Committee on the Protection of } \\
\text { the Rights of All Migrant Workers and Members of Their } \\
\text { Families }\end{array}$ \\
\hline OHCHR & 13 & 2012 & $\begin{array}{l}\text { Towards Freedom from Fear and Want: Human Rights in the } \\
\text { Post-2015 Agenda }\end{array}$ \\
\hline OHCHR & 26 & 2015 & $\begin{array}{l}\text { Report of the Special Rapporteur on the Human Rights of } \\
\text { Migrants }\end{array}$ \\
\hline UNCTAD & 14 & 2014 & $\begin{array}{l}\text { The Role Of International Trade in the Post-2015 Development } \\
\text { Agenda }\end{array}$ \\
\hline UNCTAD & 4 & 2015 & $\begin{array}{l}\text { Access To Financial Services as A Driver for the Post-2015 } \\
\text { Development Agenda }\end{array}$ \\
\hline UNCTAD & 14 & 2014 & $\begin{array}{l}\text { Tackling Inequality through Trade and Development in the } \\
\text { Post-2015 Development Agenda }\end{array}$ \\
\hline UNCTAD & 6 & 2013 & $\begin{array}{l}\text { Management Response to the External Evaluation of UNCTAD } \\
\text { Subprogramme } 3\end{array}$ \\
\hline UNCTAD & 42 & 2014 & Activity Report 2013 \\
\hline UNCTAD & 3 & 2013 & $\begin{array}{l}\text { Contribution to the Implementation of and Follow-up to the } \\
\text { Outcomes of Major United Nations Conferences and Summits } \\
\text { in the Economic and Social Fields }\end{array}$ \\
\hline UNDESA & 30 & 2012 & $\begin{array}{l}\text { The International Development Strategy Beyond 2015: Taking } \\
\text { Demographic Dynamics into Account }\end{array}$ \\
\hline UNDESA & 12 & 2015 & $\begin{array}{l}\text { Social Inclusion, Poverty Eradication \& Post-2015 Development } \\
\text { Agenda }\end{array}$ \\
\hline UNDESA & 56 & 2012 & Tenth Coordination Meeting on International Migration \\
\hline UNDESA & 10 & 2012 & $\begin{array}{l}\text { PowerPoint Presentation by Bela Hovy: Preparations for the } \\
2013 \text { High-Level Dialogue }\end{array}$ \\
\hline UNDP & 27 & 2013 & Post 2015 Discussions in Turkey \\
\hline UNDP & 106 & 2014 & Human Development Report Kosovo \\
\hline
\end{tabular}




\begin{tabular}{|c|c|c|c|}
\hline$\underline{0}$ & 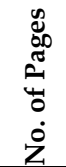 & 世. & 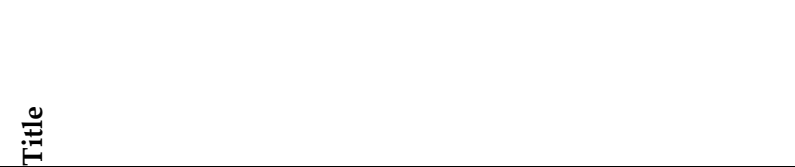 \\
\hline UNDP & 30 & 2013 & $\begin{array}{l}\text { Human Development Report Office Occasional Paper Series: } \\
\text { Issues for a Global Human Development Agenda }\end{array}$ \\
\hline UNDP & 52 & 2014 & $\begin{array}{l}\text { Building the Post-2015 Development Agenda: } 2014 \text { Annual } \\
\text { report }\end{array}$ \\
\hline UNDP & 15 & 2015 & 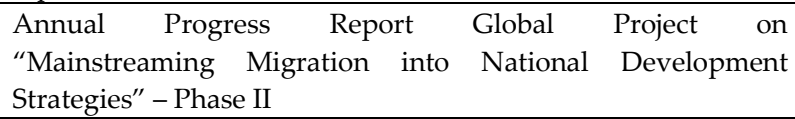 \\
\hline UNDP & 18 & 2015 & $\begin{array}{l}\text { China, the Millennium Development Goals, and the Post-2015 } \\
\text { Development Agenda }\end{array}$ \\
\hline UNDP & 239 & 2014 & Human Development Report 2014 \\
\hline UNDP & 14 & 2014 & $\begin{array}{l}\text { Discussion Paper: Governance for Sustainable Development } \\
\text { Integrating Governance in the Post-2015 Development } \\
\text { Framework }\end{array}$ \\
\hline UNDP & 65 & n.d. & $\begin{array}{l}\text { Building More Inclusive, Sustainable, and Prosperous Societies } \\
\text { in Europe and Central Asia: A Common United Nations Vision } \\
\text { for the Post-2015 Development Agenda }\end{array}$ \\
\hline UNESCO & 41 & 2015 & $\begin{array}{l}\text { UNESCO's Participation in the Preparations for a Post-2015 } \\
\text { Development Agenda }\end{array}$ \\
\hline UNESCO & 28 & 2015 & $\begin{array}{l}\text { Background Paper for Education for All Global Monitoring } \\
\text { Report } 2015\end{array}$ \\
\hline UNESCO & 13 & n.d. & Position Paper on Education Post-2015 \\
\hline UNESCO & 63 & 2014 & UNESCO Education Strategy 2014-2021 \\
\hline UNESCO & 40 & 2015 & $\begin{array}{l}\text { Background paper for the Education for All Global Monitoring } \\
\text { Report } 2015\end{array}$ \\
\hline UNESCO & 11 & 2013 & $\begin{array}{l}\text { UNESCO'S Participation in the Preparations for a Post-2015 } \\
\text { Development Agenda }\end{array}$ \\
\hline UNESCO & 8 & 2013 & Envisioning Education Post-2015 \\
\hline UNESCO & 24 & 2014 & $\begin{array}{l}\text { Sustainable Development begins with Education: How } \\
\text { Education can Contribute to The Proposed Post-2015 Goals }\end{array}$ \\
\hline UNESCO & 9 & 2014 & $\begin{array}{l}\text { UNESCO'S Participation in the Preparations for a Post-2015 } \\
\text { Development Agenda }\end{array}$ \\
\hline UNFPA & 23 & 2015 & $\begin{array}{l}\text { United Nations Population Fund Report of the Executive } \\
\text { Director }\end{array}$ \\
\hline UNFPA & 24 & 2013 & The UNFPA Strategic Plan, 2014-2017 \\
\hline UNFPA & 49 & 2013 & $\begin{array}{l}\text { Development Challenges and Population Dynamics in a } \\
\text { Changing Arab World }\end{array}$ \\
\hline UNFPA & 32 & 2012 & Population Matters for Sustainable Development \\
\hline UNFPA & 7 & n.d. & $\begin{array}{l}\text { The Future UNFPA Wants for All: Keys For The Post-2015 } \\
\text { Development Agenda }\end{array}$ \\
\hline UNFPA & 60 & 2014 & Realizing the Potential 2013: UNFPA Annual Report \\
\hline UNFPA & 19 & 2013 & UNFPA Strategic Plan, 2014-2017 Annex 2 \\
\hline
\end{tabular}




\begin{tabular}{|c|c|c|c|}
\hline$\underline{\varrho}$ & 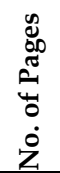 & 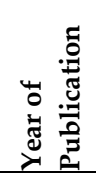 & $\stackrel{\Xi}{\Xi}$ \\
\hline UNFPA & 37 & 2013 & $\begin{array}{l}\text { UNFPA Global Interventions Action Plan, 2014-2017 Technical } \\
\text { Division }\end{array}$ \\
\hline UNHCR & 20 & 2014 & Trends Report \\
\hline UNHCR & 11 & 2014 & High Commissioner's Dialogue 2014 Background Paper \\
\hline UNHCR & 6 & 2014 & Global Appeal 2014-2015 \\
\hline UNHCR & 17 & 2015 & $\begin{array}{l}\text { 63rd Standing Committee Meeting: Note on international } \\
\text { protection }\end{array}$ \\
\hline UNHCR & 8 & 2015 & Global Appeal 2015 Update \\
\hline UNHCR & 8 & 2015 & $\begin{array}{l}\text { Report of the United Nations High Commissioner for Refugees } \\
\text { 2014-2015 }\end{array}$ \\
\hline UNHCR & 7 & 2014 & $\begin{array}{l}\text { High Commissioner's Dialogue on Protection at Sea (10-11 } \\
\text { December 2014) }\end{array}$ \\
\hline UNHCR & 7 & 2014 & 61st Standing Committee Meeting \\
\hline UNHCR & 19 & 2015 & 2015 Annual Consultation with CSOs \\
\hline UNHCR & 7 & 2015 & 62nd Standing Committee Meeting: \\
\hline UNHCR & 36 & 2014 & 2014-2024 Plan to End Statelessness \\
\hline UNHCR & 10 & 2014 & $\begin{array}{l}\text { 65th Session of the Executive Committee of the High } \\
\text { Commissioner's Programme }\end{array}$ \\
\hline UNICEF & 4 & 2013 & $\begin{array}{l}\text { UNICEF Population Dynamics: International Migration and } \\
\text { Generation } 2025\end{array}$ \\
\hline UNICEF & 2 & 2014 & $\begin{array}{l}\text { Early Childhood Development: The Foundation for Sustainable } \\
\text { Development }\end{array}$ \\
\hline UNICEF & 5 & 2013 & Key Asks on the Post-2015 Development Agenda \\
\hline UNICEF & 13 & 2013 & Key Messages On The Post-2015 Development Agenda \\
\hline UNICEF & 14 & 2014 & $\begin{array}{l}\text { A Post-2015 World Fit For Children - An Agenda For } \\
\text { \#Everychild } 2015\end{array}$ \\
\hline UNICEF & 41 & 2014 & Policy Advocacy and Partnerships for Children's Rights \\
\hline UNICEF & 62 & 2014 & Child Protection from Violence, Exploitation and Abuse \\
\hline UNITAR & 8 & 2014 & How Cities are already Leveraging a More Mobile World \\
\hline UNITAR & 3 & 2014 & Statement of Assistant Secretary-General \\
\hline UNITAR & 17 & 2013 & Report to the Secretary-General \\
\hline UNODC & 18 & 2012 & $\begin{array}{l}\text { Inputs by Member States for the Post-2015 Development } \\
\text { Agenda }\end{array}$ \\
\hline UNODC & 151 & 2013 & $\begin{array}{l}\text { Accounting for Security and Justice in the Post-2015 } \\
\text { Development Agenda }\end{array}$ \\
\hline UNODC & 19 & 2015 & Trafficking in Persons and Smuggling of Migrants \\
\hline UNODC & 133 & 2014 & UNODC Annual Report 2014 \\
\hline
\end{tabular}




\begin{tabular}{|c|c|c|c|}
\hline$\underline{0}$ & 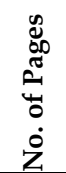 & 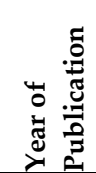 & $\stackrel{0}{\Xi}$ \\
\hline UNODC & 13 & 2015 & Draft Doha Declaration \\
\hline UNU & 6 & 2013 & Migration in the Post-2015 Development Agenda \\
\hline UNU & 17 & 2013 & $\begin{array}{l}\text { Bringing Migration into the Post-2015 Agenda: Notes, } \\
\text { Reflections and Policy Directions }\end{array}$ \\
\hline UNU & 1 & 2014 & MOSAICS 11 Newsletter \\
\hline UNU & 1 & 2015 & MOSAICS 23 Newsletter \\
\hline UNU & 1 & 2015 & MOSAICS 22 Newsletter \\
\hline UNU & 1 & 2014 & MOSAICS 10 Newsletter \\
\hline UNU & 97 & 2015 & $\begin{array}{l}\text { Independent Evaluation of Swiss Migration Partnerships: Final } \\
\text { Report }\end{array}$ \\
\hline UNU & 58 & 2013 & $\begin{array}{l}\text { Changing Climates, Moving People: Framing Migration, } \\
\text { Displacement and Planned Relocation }\end{array}$ \\
\hline UNU & 18 & 2015 & $\begin{array}{l}\text { Promoting Human Security and Minimizing Conflict associated } \\
\text { with Forced Migration in the Pacific region }\end{array}$ \\
\hline UNU & 28 & 2015 & GCM Annual Report 2014 \\
\hline UNWOMEN & 172 & 2013 & Advancing Gender Equality: Promising Practices \\
\hline UNWOMEN & 48 & 2013 & $\begin{array}{l}\text { A Transformative Stand-Alone Goal on Achieving Gender } \\
\text { Equality, Women's Rights and Women's Empowerment }\end{array}$ \\
\hline UNWOMEN & 10 & 2013 & Overview of Promising Practices \\
\hline UNWOMEN & 136 & 2013 & $\begin{array}{l}\text { Women of India Speak: Shaping the Post-2015 Development } \\
\text { Discourse and Agenda }\end{array}$ \\
\hline World Bank & 27 & 2015 & Migration and Development Brief 24 \\
\hline World Bank & 31 & 2014 & Migration and Development Brief 22 \\
\hline World Bank & 29 & 2013 & Migration and Development Brief 21 \\
\hline World Bank & 11 & 2013 & Migration and Development Brief 20 \\
\hline World Bank & 54 & 2013 & Financing for Development Post-2015 \\
\hline World Bank & 12 & 2015 & $\begin{array}{l}\text { The Role of Identification in the Post-2015 Development } \\
\text { Agenda }\end{array}$ \\
\hline World Bank & 30 & 2015 & The Global Effort in the Remittances Arena \\
\hline WHO & 2 & n.d. & TB Prevention and Care for Migrants \\
\hline WHO & 71 & 2013 & Health in the Post-2015 Development Agenda \\
\hline WHO & 21 & 2015 & $\begin{array}{l}\text { Towards a Monitoring Framework with Targets and Indicators } \\
\text { for the Health Goals of the Post-2015 Sustainable Development } \\
\text { Goals }\end{array}$ \\
\hline
\end{tabular}




\section{Annex 4.1 Timeline: The History of Global Migration Governance}

\begin{tabular}{|c|c|}
\hline Year & Event \\
\hline 1648 & Concept of State Sovereignty born in Westphalia \\
\hline 1919 & ILO Founded \\
\hline 1921 & $\begin{array}{l}\text { Fridjolt Nansen appointed as High Commissioner for (Russian) Refugees by the League } \\
\text { of Nations }\end{array}$ \\
\hline 1922 & Nansen Passport \\
\hline 1924 & Nansen's mandate extended to include Armenian refugees \\
\hline 1925 & ILO assumes operational responsibility for refugees (until 1929) / ILO Refugee Service \\
\hline 1927 & Nansen Stamp Fund (Refugees Revolving Fund) started (to run until 1930) \\
\hline 1927 & $\begin{array}{l}\text { League of Nations Conference exploring adoption of an international convention to } \\
\text { 'facilitate and regulate' the exchange of labour }\end{array}$ \\
\hline 1928 & Nansen's mandate extended to include Assyrian and Assyro-Chaldean refugees \\
\hline 1929 & $\begin{array}{l}\text { In 1929, the High Commission took back technical responsibilities } \\
\text { for refugee settlement and employment from the ILO.' (Long, 2013, p.11) }\end{array}$ \\
\hline 1933 & $\begin{array}{l}\text { League of Nations establishes a High Commissioner for Refugees (Jewish and Other) } \\
\text { Coming from Germany }\end{array}$ \\
\hline 1933 & Refugee Convention \\
\hline 1935 & Nanse \\
\hline 1938 & $\begin{array}{l}\text { ILO holds conference on international collaboration on migration establishing the } \\
\text { Permanent Migration Committee (PMC) }\end{array}$ \\
\hline 1938 & League of Nations Conference in Evian \\
\hline 1938 & $\begin{array}{l}\text { Creation of Intergovernmental Committee on Refugees (IGCR) outside of League of } \\
\text { Nations (but never became active) }\end{array}$ \\
\hline 1938 & Refugee Convention \\
\hline 1939 & ILO convenes a meeting to establish an 'international scheme for financing migration.' \\
\hline 1943 & US organizes a conference in Bermuda to 'revitalise the dormant IGCR' (p.527) \\
\hline 1943 & United Nations Relief and Rehabilitation Administration (UNRRA) established \\
\hline 1944 & Declaration of Philadelphia asserts ILO role in the transfer of labour \\
\hline 1946 & The first conference of ILO's PMC \\
\hline 1946 & $\begin{array}{l}\text { IRO founded, replaced UNRRA and IGCR (as non-permanent specialized agency } \\
\text { meaning not under the supervision of General Assembly) }\end{array}$ \\
\hline 1947 & $\begin{array}{l}\text { ILO-UN Plan on international coordination in the area of migration (mentions seven } \\
\text { organizations - ILO and the UN (as permanent) and IRO, UNSECO, FAO, WHO, } \\
\text { International Bank for Development and Reconstruction (as temporary) }\end{array}$ \\
\hline 1948 & ILO PMC Conference discussing Migration for Employment Convention \\
\hline 1948 & Universal Declaration of Human Rights \\
\hline 1948 & $\begin{array}{l}\text { Organization for European Economic Cooperation (OEEC) founded - now OECD - in } \\
\text { the context of Marshall Plan }\end{array}$ \\
\hline 1949 & $\begin{array}{l}\text { United Nations Relief and Works Agency for Palestine Refugees in the Near East } \\
\text { (UNRWA) }\end{array}$ \\
\hline 1949 & ILO 1949 Convention \\
\hline 1950 & ILO convenes the Preliminary Migration Conference \\
\hline
\end{tabular}




\begin{tabular}{|c|c|}
\hline Year & Event \\
\hline 1950 & United Nations High Commissioner for Refugees (UNHCR) \\
\hline 1951 & ILO convenes a conference in Naples \\
\hline 1951 & $\begin{array}{l}\text { Provisional Intergovernmental Committee for the Movement of Migrants from Europe } \\
\text { (PICMME) later to become ICM in } 1980 \text { and IOM in } 1989\end{array}$ \\
\hline 1951 & Refugee Convention \\
\hline 1953 & PICMME becomes ICEM \\
\hline 1967 & Refugee Protocol \\
\hline 1975 & ILO 1975 Convention \\
\hline 1978 & $\begin{array}{l}\text { UN Resolution "to explore with Member States, and in cooperation with the United } \\
\text { Nations agencies, and in particular the International Labour Organization, the } \\
\text { possibility of drawing up an international convention on the rights of migrant workers." }\end{array}$ \\
\hline 1979 & $\begin{array}{l}\text { Adoption at ICEM council that ICEM is relevant (for the foreseeable future) and to the } \\
\text { global community, not just Europe }\end{array}$ \\
\hline 1980 & PICMME becomes ICM \\
\hline 1980 & $\begin{array}{l}\text { The creation of an Open-ended Working Group of the General Assembly to develop a } \\
\text { new UN convention. }\end{array}$ \\
\hline 1980 & $\begin{array}{l}\text { West Germany makes a proposal at UN General Assembly which results in } \\
\text { 'International Cooperation to Avert New Flows of Refugees' as discussion point } \\
\text { (Widgren } 1990 \text { argues this resulted in little more than a data collection (bureaucracy) }\end{array}$ \\
\hline 1981 & The first draft of ICRMW presented (May) \\
\hline 1981 & $\begin{array}{l}\text { The decision to expand ICEM's transfer of qualified human resources programme from } \\
\text { LA to other regions. }\end{array}$ \\
\hline 1982 & The UN Commission on Human Rights releases 'Human Rights and Mass Exoduses.' \\
\hline 1984 & ICM Constitution updated to reflect global activities \\
\hline 1985 & Launch of the Intergovernmental Consultations on Migration, Asylum and Refugees \\
\hline 1986 & Single European Act \\
\hline 1987 & The decision to amend the ICEM Constitution \\
\hline 1989 & ICM becomes IOM and constitution changes accepted \\
\hline 1990 & Creation of the Central American Commission of Migration Directors \\
\hline 1990 & $\begin{array}{l}\text { International Convention on the Rights of All Migrant Workers and their Families } \\
\text { (ICRMW) }\end{array}$ \\
\hline 1991 & UNHCR Declares 'Year of Return' \\
\hline 1992 & ICMPD Founded \\
\hline 1992 & $\begin{array}{l}\text { Meeting in Bellagio resulting in statement 'Humanitarian Action in the post-Cold War } \\
\text { Era }\end{array}$ \\
\hline 1992 & $\begin{array}{l}\text { UNDP Human Development Report highlights economic gains of liberal immigration } \\
\text { policies }\end{array}$ \\
\hline 1993 & $\begin{array}{l}\text { Commission on Global Governance considered a paper (by Ghosh) on a new global } \\
\text { regime to better manage the movement of people. }\end{array}$ \\
\hline 1993 & $\begin{array}{l}\text { RES/48/113: Convening of a UN Conference for the Comprehensive consideration and } \\
\text { review of refugees, returnees, displaced persons, and migrants }\end{array}$ \\
\hline 1993 & Launch of the Budapest Process \\
\hline 1993 & Creation of the European Union \\
\hline 1994 & NAFTA \\
\hline 1994 & Uruguay Round of Trade Talks - General Agreement on Trade in Services (GATS) \\
\hline 1994 & Cairo International Conference on Population and Development \\
\hline 1995 & Survey of member state views on an international conference on international migration \\
\hline
\end{tabular}




\begin{tabular}{|c|c|}
\hline Year & Event \\
\hline 1995 & $\begin{array}{l}\text { Member States adopted an annual resolution on international migration and } \\
\text { development, which subsequently became a biennial resolution of the UN General } \\
\text { Assembly }\end{array}$ \\
\hline 1996 & Launch of the Regional Conference on Migration (Puebla Process) \\
\hline 1996 & $\begin{array}{l}\text { Launch of the Inter-Governmental Asia-Pacific Consultations on Refugees, Displaced } \\
\text { Persons and Migrants }\end{array}$ \\
\hline 1996 & International Metropolis Project founded \\
\hline 1996 & Launch of the Pacific Immigration Directors' Conference \\
\hline 1996 & Regional Conference on Migration in the Soviet Union \\
\hline 1996 & $\begin{array}{l}\text { Inclusion of Mode } 4 \text { commitments (on the movement of natural persons) under the } \\
\text { Third Protocol to the General Agreement on Trade in Services (GATS) }\end{array}$ \\
\hline 1996 & Launch of the Manila Process \\
\hline 1997 & New International Regime for Orderly Moven \\
\hline 1997 & Survey of member state views on an international conference on international migration \\
\hline 1997 & Human Rights Commission establishes a working group on migration \\
\hline 1998 & $\begin{array}{l}\text { ILO's Committee of Experts on the Application of Convention and Recommendations } \\
\text { (conclude conventions on migration written in a different context) }\end{array}$ \\
\hline 1998 & $\begin{array}{l}\text { International Labour Conference, ILO Declaration on Fundamental Principles and } \\
\text { Rights at Work, 86th Session of } 18 \text { June } 1998\end{array}$ \\
\hline 1998 & Launch of the International Migration Policy Programme \\
\hline 1999 & Survey of member state views on an international conference on international migration \\
\hline 1999 & $\begin{array}{l}\text { Appointment of a Special Rapporteur on the Human Rights of Migrants by the UN } \\
\text { Commission on Human Rights }\end{array}$ \\
\hline 2000 & $\begin{array}{l}\text { Publication of Replacement Migration: Is It a Solution to Declining and Ageing } \\
\text { Populations? }\end{array}$ \\
\hline 2000 & Launch of the Hague Process on Refugees and Migration \\
\hline 2000 & of the Migration Dialogue for Southern Africa \\
\hline 2000 & 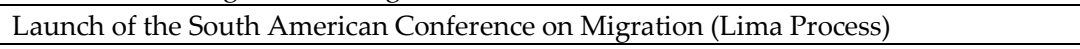 \\
\hline 2000 & Launc \\
\hline 2000 & $\begin{array}{l}\text { Adoption of the United Nations Millennium Declaration (Millennium Development } \\
\text { Goals) }\end{array}$ \\
\hline 2000 & UNHCR's Global Consultation Process \\
\hline 2000 & Trafficking/S \\
\hline 2000 & $\begin{array}{l}\text { West African Ministerial Conference on Migration, held in Dakar (the Programme of } \\
\text { Action mirrors recommendations of NIROMP project) }\end{array}$ \\
\hline 2001 & Creation of the Berne Initiative \\
\hline 2001 & Launch of the IOM International Dialogue on Migration (IDM) \\
\hline 2001 & Launch of the Cross-Border Cooperation Process (Söderköping Process) \\
\hline 2001 & Doha Round of Trade Negotiations \\
\hline 2001 & Launch of the Migration Dialogue for West Africa Process \\
\hline 2001 & $\begin{array}{l}\text { Debate NIROMP report (growing interest in multilateral regime to manage migration) } \\
+ \text { launch of the Commission on Human Security (2001-2003) }\end{array}$ \\
\hline 2002 & the Hague Declaration on the Future of Asylum and Migration Policy \\
\hline 2002 & $\begin{array}{l}\text { Launch of the Coordination Meeting on International Migration, United Nations } \\
\text { Population Division of the Department of Economic and Social Affairs }\end{array}$ \\
\hline 2002 & $\begin{array}{l}\text { Launch of the Regional Ministerial Conference on Migration in the Western } \\
\text { Mediterranean ( } 5+5 \text { Dialogue) }\end{array}$ \\
\hline
\end{tabular}




\begin{tabular}{|c|c|}
\hline Year & Event \\
\hline 2002 & $\begin{array}{l}\text { Launch of the Bali Process on People Smuggling, Trafficking in Persons and Related } \\
\text { Transnational Crime }\end{array}$ \\
\hline 2002 & $\begin{array}{l}\text { Adoption of the Migration Working Group's Report to the Secretary-General (Doyle } \\
\text { Report) }\end{array}$ \\
\hline 2002 & $\begin{array}{l}\text { UN Secretary-General Report: Strengthening of the United Nations: an agenda for } \\
\text { further change }\end{array}$ \\
\hline 2003 & $\begin{array}{l}\text { Conference on Migrant Remittances: Development Impact, Opportunities for the } \\
\text { Financial Sector and Future Prospects organized by DFID and the World Bank (but } \\
\text { more generally the point made (in Newland, 2010) is the role of the World Bank, Bretton } \\
\text { Woods, and other financial institutions on the realization that remittances exceeded } \\
\text { ODA }\end{array}$ \\
\hline 2003 & 1990 Migrant Workers Convention comes into force \\
\hline 2003 & $\begin{array}{l}\text { Launch of Convention Plus - the asylum-migration nexus is on the agenda (Newland, } \\
\text { 2010) }\end{array}$ \\
\hline 2003 & Survey of member state views on an international conference on international migration \\
\hline 2003 & Estab \\
\hline 2003 & \\
\hline 2003 & eneva Migration Group \\
\hline 2003 & tion Dialogue \\
\hline 2003 & $\begin{array}{l}\text { Launch of the Ministerial Consultation on Overseas Employment and Contractual } \\
\text { Labour for Countries of Origin in Asia (Colombo Process) }\end{array}$ \\
\hline 2003 & Launch of the Migration, Asylum, Refugees Regional Initiative \\
\hline 2003 & $\begin{array}{l}\text { General Assembly resolution 58/208 in December } 2003 \text { called for high-level dialogue on } \\
\text { international migration and development within the context of the } 2006 \text { General } \\
\text { Assembly. }\end{array}$ \\
\hline 2004 & $\begin{array}{l}\text { Adoption of the non-binding International Labour Organization (ILO) 'Report VII: } \\
\text { Towards a Fair Deal for Migrant Workers in the Global Economy, International Labour } \\
\text { Conference }\end{array}$ \\
\hline 2004 & $\begin{array}{l}\text { Adoption of the non-binding Berne Initiative, International Agenda for Migration } \\
\text { Management }\end{array}$ \\
\hline 2005 & \\
\hline 2005 & $\begin{array}{l}\text { New Special Rapporteur (OHCHR): Mr Jorge A. Bustamante (Mexico), August 2005- } \\
\text { July } 2011\end{array}$ \\
\hline 2005 & $\begin{array}{l}\text { Migration is the theme of its 10-year review at the Beijing World Conference on Women } \\
\text { and Development. }\end{array}$ \\
\hline 2005 & Europe's Global Approach to Mi \\
\hline 2005 & Secretary-General Resolution 60/227 on organization details of HLD \\
\hline 2006 & $\begin{array}{l}\text { Establishment of the Global Migration Group (GMG) (formerly the Geneva Migration } \\
\text { Group) }\end{array}$ \\
\hline 2006 & First High-Level Dialogue on International Migration and Development (2006 HLD) \\
\hline 2006 & $\begin{array}{l}\text { Appointment of a Special Representative of the Secretary-General for International } \\
\text { Migration and Development by the UN Secretary-General }\end{array}$ \\
\hline 2006 & Launch of the Euro-African Dialogue on Migration and Development (Rabat Process) \\
\hline 2006 & Adoption of the non-binding ILO Multilateral Framework on Labour Migration \\
\hline 2006 & f Human Rights Council by UN General Assembly \\
\hline 2007 & e Global Forum on Migration and Development (GFMD) \\
\hline
\end{tabular}




\begin{tabular}{|c|c|}
\hline Year & Event \\
\hline 2008 & $\begin{array}{l}\text { Launch of the Intergovernmental Authority on Development " Regional Consultative } \\
\text { Process on Migration }\end{array}$ \\
\hline 2008 & $\begin{array}{l}\text { Launch of the Ministerial Consultations on Overseas Employment and Contractual } \\
\text { Labour for Countries of Origin and Destination in Asia (Abu Dhabi Dialogue) }\end{array}$ \\
\hline 2008 & $\begin{array}{l}\text { The International Federation of Red Cross and Red Crescent Societies appoint a Special } \\
\text { Representative on International Migration }\end{array}$ \\
\hline 2010 & GMG Handbook on Mainstreaming Migration into Development Planning \\
\hline 2011 & Launch of the Global Diaspora Forum \\
\hline 2011 & $\begin{array}{l}\text { Launch of the Eastern Partnership Panel on Migration and Asylum (incorporating the } \\
\text { Söderköping Process) }\end{array}$ \\
\hline 2011 & $\begin{array}{l}\text { Adoption of the Istanbul Declaration and Programme of Action for the Least Developed } \\
\text { Countries }\end{array}$ \\
\hline 2011 & UN Conference of the Least Developed Countries \\
\hline 2011 & splacement in Oslo \\
\hline 2011 & $\begin{array}{l}\text { New Special Rapporteur (OHCHR): Mr François Crépeau (Canada), August } 2011 \text { - } \\
\text { present }\end{array}$ \\
\hline 2012 & UN Conference on Sustainable Development (Rio+20) \\
\hline 2012 & Launcl \\
\hline 2012 & \\
\hline 2012 & Adoption of the non-binding IOM Migration Crisis Operational Framework (MCOF) \\
\hline 2012 & UNDESA Launch UN Migration Strategy (received no traction - Thouez, 2018) \\
\hline 2013 & (2013 HLD) \\
\hline 2013 & Launch of the Almaty Process on Refugee Protection and International Migration \\
\hline 2013 & $\begin{array}{l}\text { Launch of the Common Market for Eastern and Southern Africa (COMESA) Regional } \\
\text { Consultative Process (Migration Dialogue for the COMESA Member States) }\end{array}$ \\
\hline 2013 & $\begin{array}{l}\text { Report to UN General Assembly by the Special Rapporteur on the human rights of } \\
\text { migrants, François Crépeau: Global migration governance (A/68/283) }\end{array}$ \\
\hline 2014 & Launch of the Migrants in Countries in Crisis (MICIC) Initiative \\
\hline 2014 & Lau \\
\hline 2014 & n of the non-binding report, 'Fair Migration: Setting an ILO Agenda' \\
\hline 2014 & \\
\hline 2014 & $\begin{array}{l}\text { Adoption of the non-binding Small Island Developing States Accelerated Modalities of } \\
\text { Action Pathway (SAMOA Pathway) }\end{array}$ \\
\hline 2015 & Launch of the Intra-Regional Forum on Migration in Africa (Pan-African Forum) \\
\hline 2015 & Launch of the Arab Regional Consultative Process \\
\hline 2015 & $\begin{array}{l}\text { Adoption of the } 2030 \text { Agenda for Sustainable Development by the UN General } \\
\text { Assembly }\end{array}$ \\
\hline 2015 & Adoption of the Migration Governance Framework by the IOM Council \\
\hline 2015 & Adoption of the Addis Ababa Action Agenda on Financing for Development \\
\hline 2015 & $\begin{array}{l}\text { Adoption of the Sendai Framework for Disaster Risk Reduction, Third UN World } \\
\text { Conference on Disaster Risk Reduction }\end{array}$ \\
\hline 2015 & Adoption of the Paris Agreement on Climate Change \\
\hline 2015 & $\begin{array}{l}\text { Adoption of the non-binding Nansen Initiative's Agenda for the Protection of Cross- } \\
\text { Border Displaced Persons in the Context of Disasters and Climate Change }\end{array}$ \\
\hline 2015 & $\begin{array}{l}\text { OHCHR's Recommended Principles and Guidelines on Human Rights at International } \\
\text { Borders }\end{array}$ \\
\hline
\end{tabular}




\begin{tabular}{|l|l|}
\hline Year & Event \\
\hline 2015 & $\begin{array}{l}\text { Formation of the 'ad hoc UN Quartet' including heads of agencies of IOM, UNHCR, } \\
\text { OHCHR, and the SRSG }\end{array}$ \\
\hline 2015 & EU Agenda on Migration \\
2016 & $\begin{array}{l}\text { In safety and dignity: addressing large movements of refugees } \\
\text { and migrants' Karen AbuZayd's report to Secretary-General ahead of the summit on } 21 \\
\text { April 2016 }\end{array}$ \\
\hline 2016 & World Humanitarian Summit and launch of the Grand Bargain \\
\hline 2016 & $\begin{array}{l}\text { Adoption of the New Urban Agenda, UN Conference on Housing and Sustainable } \\
\text { Development (Habitat III) }\end{array}$ \\
\hline 2016 & $\begin{array}{l}\text { Adoption of the non-binding MICIC Initiative's Guidelines to Protect Migrants in } \\
\text { Countries Experiencing Conflict or Natural Disasters }\end{array}$ \\
\hline 2016 & OHCHR-GMG Guidelines and Principles on Migrants in Vulnerable Situations \\
\hline 2016 & $\begin{array}{l}\text { Adoption of the New York Declaration for Refugees and Migrants at the UN Summit } \\
\text { for Refugees and Migrants }\end{array}$ \\
\hline 2016 & IOM incorporated in UN \\
\hline 2016 & Obama Leaders' Summit on Refugees \\
\hline 2017 & Sutherland Report \\
\hline 2017 & Appointment L. Arbour as Special Representative to UNSG on International Migration \\
\hline 2017 & SG Report Making migration work for all - 12 December 2017 \\
\hline 2017 & $\begin{array}{l}\text { UN MSs agreed to host a third HLD in the first half of 2019 and to reconvene every four } \\
\text { years after that }\end{array}$ \\
\hline 2017 & $\begin{array}{l}\text { PGA (President Miroslav Lajcàk) identifies migration as one of his six priorities on } 12 \\
\text { September 2017 }\end{array}$ \\
\hline 2018 & Global Compacts on refugees and migrants \\
\hline
\end{tabular}

Sources: Bauloz 2017; Betts and Kainz 2017; Martin 2014; 2015; Koser 2010; Chamie and Mirkin 2013; Newland 2010; Pécoud and de Guchteneire 2007; Thouez 2018; de Wenden 2012; Karatani 2005; Long 2013; Crush 2013; Ghosh 2005; Thouez and Channac 2005; Bohning 1991; Doyle 2004; Miller 2000; Martin, Martin, and Cross 2007; and Widgren 1990. 


\section{Annex 4.2 Comparing the Migration for Employment Convention, 1939 (No. 66) and the Migration for Employment Convention (Revised), 1949 (No. 97)}

\begin{tabular}{|c|c|c|}
\hline & C66 & $\mathrm{C} 97$ \\
\hline Article 1 & $\begin{array}{l}\text { Address propaganda and supervise } \\
\text { information distributed with regards } \\
\text { to migration. }\end{array}$ & $\begin{array}{l}\text { Requires ratifying states to provide } \\
\text { information on policies, provisions, } \\
\text { general agreements, and } \\
\text { arrangements to the ILO. }\end{array}$ \\
\hline Article 2 & $\begin{array}{l}\text { The government should ensure that } \\
\text { information is provided to } \\
\text { immigrants and emigrants. }\end{array}$ & $\begin{array}{l}\text { The government should ensure } \\
\text { migrants have access to assistance, } \\
\text { mainly information. }\end{array}$ \\
\hline Article 3 & Regards regulating recruitment. & Addresses propaganda. \\
\hline Article 4 & $\begin{array}{l}\text { Regards government supervision of } \\
\text { work contracts. }\end{array}$ & Measures to facilitate migration. \\
\hline Article 5 & $\begin{array}{l}\text { Provision for migrants for whom the } \\
\text { employment opportunity falls } \\
\text { through. }\end{array}$ & $\begin{array}{l}\text { Measures to ensure that migrants are } \\
\text { in good health before travel and to } \\
\text { ensure access to health care. }\end{array}$ \\
\hline Article 6 & $\begin{array}{l}\text { Equal conditions for foreign workers } \\
\text { (conditions of work including pay, } \\
\text { right to join trade unions, taxes, } \\
\text { contracts). }\end{array}$ & $\begin{array}{l}\text { Equal conditions without } \\
\text { discrimination, for foreign workers } \\
\text { (conditions of work including pay, } \\
\text { minimum age, working conditions, } \\
\text { right to join a trade union, } \\
\text { accommodation, social security, } \\
\text { taxes). }\end{array}$ \\
\hline Article 7 & $\begin{array}{l}\text { Exemption of personal effects from } \\
\text { customs duty. }\end{array}$ & $\begin{array}{l}\text { Cooperation between states on } \\
\text { matters related to employment; and } \\
\text { services provided to migrants should } \\
\text { be free. }\end{array}$ \\
\hline Article 8 & $\begin{array}{l}\text { Workers excluded from convention: } \\
\text { those moving within a territory, } \\
\text { frontier workers, seamen, and } \\
\text { indigenous workers. }\end{array}$ & $\begin{array}{l}\text { A provision relating to return if } \\
\text { migrant falls ill or is injured if they } \\
\text { have permanent status (which should } \\
\text { be given no more than five years after } \\
\text { arrival). }\end{array}$ \\
\hline Article 9 & Communication of ratification to ILO. & Remittances. \\
\hline Article 10 & $\begin{array}{l}\text { The Convention comes into effect } 12 \\
\text { months after ratification registered } \\
\text { (only two ratifications required for the } \\
\text { Convention to come into effect) }\end{array}$ & $\begin{array}{l}\text { Where a large number of migrants go } \\
\text { from one destination to another, states } \\
\text { can enter agreements relating to } \\
\text { common concerns. }\end{array}$ \\
\hline Article 11 & Relates to denouncing convention & $\begin{array}{l}\text { Workers excluded from the } \\
\text { convention: frontier workers; short } \\
\text { terms entry of liberal professions and } \\
\text { artistes; and seamen. }\end{array}$ \\
\hline Article 12 & $\begin{array}{l}\text { Relates to notifying members of } \\
\text { ratifications, denunciation }\end{array}$ & $\begin{array}{l}\text { Regards communication of ratification } \\
\text { to ILO }\end{array}$ \\
\hline
\end{tabular}




\begin{tabular}{|c|c|c|}
\hline & C66 & C97 \\
\hline Article 13 & $\begin{array}{l}\text { Relates to reporting on the } \\
\text { implementation of the convention, } \\
\text { including possible revisions. }\end{array}$ & $\begin{array}{l}\text { The Convention comes into effect } 12 \\
\text { months after ratification registered } \\
\text { (only two ratifications required for the } \\
\text { Convention to come into effect). }\end{array}$ \\
\hline Article 14 & $\begin{array}{l}\text { Relates to any future conventions that } \\
\text { may supersede this one. }\end{array}$ & $\begin{array}{l}\text { Relates to annexes and right to exclude } \\
\text { provisions. }\end{array}$ \\
\hline Article 15 & $\begin{array}{l}\text { Validates the English and French texts } \\
\text { of the Convention. }\end{array}$ & $\begin{array}{l}\text { Regards communicating declarations } \\
\text { to ILO. }\end{array}$ \\
\hline Article 16 & $\mathrm{n} / \mathrm{a}$ & $\begin{array}{l}\text { Regards to communicating which } \\
\text { parts of the convention apply. }\end{array}$ \\
\hline Article 17 & $\mathrm{n} / \mathrm{a}$ & Regards denunciation. \\
\hline Article 18 & $\mathrm{n} / \mathrm{a}$ & $\begin{array}{l}\text { Relates to notifying members of } \\
\text { ratifications, denunciation. }\end{array}$ \\
\hline Article 19 & $\mathrm{n} / \mathrm{a}$ & $\begin{array}{l}\text { Regards communicating ratifications, } \\
\text { declarations, and denunciations to the } \\
\text { UN Secretary-General }\end{array}$ \\
\hline Article 20 & $\mathrm{n} / \mathrm{a}$ & $\begin{array}{l}\text { Relates to reporting on the } \\
\text { implementation of the convention } \\
\text { including possible revisions. }\end{array}$ \\
\hline Article 21 & $\mathrm{n} / \mathrm{a}$ & $\begin{array}{l}\text { Relates to any future conventions that } \\
\text { may supersede this one. }\end{array}$ \\
\hline Article 22 & $\mathrm{n} / \mathrm{a}$ & Regards making revisions \\
\hline Article 23 & $\mathrm{n} / \mathrm{a}$ & $\begin{array}{l}\text { Validates the English and French texts } \\
\text { of the Convention }\end{array}$ \\
\hline Annex 1 & $\mathrm{n} / \mathrm{a}$ & $\begin{array}{l}\text { Recruitment and work conditions - } \\
\text { non-government sponsored }\end{array}$ \\
\hline Annex 2 & $\mathrm{n} / \mathrm{a}$ & $\begin{array}{l}\text { Recruitment and work conditions - } \\
\text { government-sponsored } \\
\text { transfers }\end{array}$ \\
\hline Annex 3 & $\mathrm{n} / \mathrm{a}$ & Import of personal effects \\
\hline
\end{tabular}




\section{Annex 4.3: Inter-State Consultation Mechanisms}

\begin{tabular}{|c|c|c|c|}
\hline Inter-State Consultation Mechanism & Region Covered & Founded & Status \\
\hline $\begin{array}{l}\text { The Intergovernmental Consultations on } \\
\text { Migration, Asylum and Refugees (IGC) }\end{array}$ & $\begin{array}{l}\text { Europe, Asia, and } \\
\text { Americas }\end{array}$ & 1985 & Active \\
\hline $\begin{array}{l}\text { Central American Commission of Migration } \\
\text { Directors (OCAM) }\end{array}$ & Americas & 1990 & Active \\
\hline The Budapest Process & Europe and Asia & 1993 & Active \\
\hline $\begin{array}{l}\text { Regional Conference on Migration (Puebla } \\
\text { Process) }\end{array}$ & $\begin{array}{l}\text { North and Central } \\
\text { America }\end{array}$ & 1996 & Active \\
\hline $\begin{array}{l}\text { Inter-Governmental } \\
\text { Consultations on Refugees, } \\
\text { Persons and Migrants (APC) }\end{array}$ & Asia-Pacific & 1996 & Inactive \\
\hline $\begin{array}{l}\text { The Pacific Immigration } \quad \text { Directors' } \\
\text { Conference (PIDC) }\end{array}$ & Pacific & 1996 & Active \\
\hline CIS Conference & CIS & 1996 & Inactive \\
\hline The Manila Process & Asia-Pacific & 1996 & Inactive \\
\hline $\begin{array}{l}\text { Migration Dialogue for Southern Africa } \\
\text { (MIDSA) }\end{array}$ & Africa & 2000 & Active \\
\hline $\begin{array}{lll}\text { South American Conference } & \text { on } \\
\text { Migration (Lima Process) } & & \\
\end{array}$ & South America & 2000 & Active \\
\hline $\begin{array}{l}\text { African, Caribbean and Pacific Group of } \\
\text { States (ACP) - European Union (EU) } \\
\text { Dialogue on Migration (ACP-EU) }\end{array}$ & $\begin{array}{l}\text { Africa, Asia, the } \\
\text { Americas, and } \\
\text { Europe }\end{array}$ & 2000 & Active \\
\hline $\begin{array}{l}\text { Launch of the Migration Dialogue for West } \\
\text { Africa Process (MIDWA) }\end{array}$ & West Africa & 2001 & Active \\
\hline $\begin{array}{ll}\text { Eastern Partnership } & \text { Panel on Migration, } \\
\text { Mobility, and } & \text { Integrated Border } \\
\text { Management } & \\
\end{array}$ & Europe & 2001 & Active \\
\hline $\begin{array}{l}\text { Launch of the Regional Ministerial } \\
\text { Conference on Migration in the Western } \\
\text { Mediterranean }\end{array}$ & Europe and Africa & 2002 & Active \\
\hline $\begin{array}{l}\text { Bali Process on People Smuggling, } \\
\text { Trafficking in Persons and Related } \\
\text { Transnational Crime }\end{array}$ & $\begin{array}{l}\text { Europe, Asia, the } \\
\text { Americas, Africa }\end{array}$ & 2002 & Active \\
\hline $\begin{array}{l}\text { The Asia - European Union Meetings } \\
\text { (ASEM) Conference of the Directors General } \\
\text { of Immigration and Management of } \\
\text { Migratory Flows }\end{array}$ & Asia and Europe & 2002 & Active \\
\hline $\begin{array}{l}\text { Launch of the Ministerial Consultation on } \\
\text { Overseas Employment and Contractual } \\
\text { Labour for Countries of Origin in Asia }\end{array}$ & Asia & 2003 & Active \\
\hline $\begin{array}{l}\text { Euro-African Dialogue on Migration and } \\
\text { Development }\end{array}$ & Africa and Europe & 2006 & Active \\
\hline $\begin{array}{l}\text { Launch of the Ministerial Consultations on } \\
\text { Overseas Employment and Contractual }\end{array}$ & $\begin{array}{l}\text { Asia and the Middle } \\
\text { East }\end{array}$ & 2008 & Active \\
\hline
\end{tabular}




\begin{tabular}{|c|c|c|c|}
\hline Inter-State Consultation Mechanism & Region Covered & Founded & Status \\
\hline \multicolumn{4}{|l|}{$\begin{array}{l}\text { Labour for Countries of Origin and } \\
\text { Destination in Asia }\end{array}$} \\
\hline $\begin{array}{l}\text { Intergovernmental Authority on } \\
\text { Development Regional Consultative Process } \\
\text { on Migration }\end{array}$ & Africa & 2008 & Active \\
\hline $\begin{array}{l}\text { Ibero-American Forum on Migration and } \\
\text { Development (FIBEMYD) }\end{array}$ & $\begin{array}{l}\text { South America, } \\
\text { Central America, the } \\
\text { Caribbean, and } \\
\text { Europe }\end{array}$ & 2008 & Active \\
\hline The Prague Process & Europe & 2009 & Active \\
\hline $\begin{array}{l}\text { European Union - Latin America and the } \\
\text { Caribbean Structured and Comprehensive } \\
\text { Bi-regional Dialogue on Migration (EU- } \\
\text { LAC) }\end{array}$ & $\begin{array}{l}\text { Europe, Latin } \\
\text { America, and the } \\
\text { Caribbean }\end{array}$ & 2009 & Active \\
\hline $\begin{array}{l}\text { Migration Dialogue for Central African } \\
\text { States (MIDCAS) }\end{array}$ & Central Africa & 2012 & Active \\
\hline $\begin{array}{l}\text { Ibero-American Network of Migration } \\
\text { Authorities (RIAM) }\end{array}$ & Americas and Europe & 2012 & Active \\
\hline $\begin{array}{l}\text { Almaty Process on Refugee Protection and } \\
\text { International Migration }\end{array}$ & Eurasia & 2013 & Active \\
\hline $\begin{array}{l}\text { Migration Dialogue from the Common } \\
\text { Market for Eastern and Southern Africa } \\
\text { Member States (MIDCOM) }\end{array}$ & Africa & 2013 & Active \\
\hline $\begin{array}{l}\text { EU-Horn of Africa Migration Route } \\
\text { Initiative (Khartoum Process) }\end{array}$ & $\begin{array}{l}\text { The Horn of Africa } \\
\text { and Europe }\end{array}$ & 2014 & Active \\
\hline $\begin{array}{l}\text { Arab Regional Consultative Process on } \\
\text { Migration and Refugees Affairs (ARCP) }\end{array}$ & $\begin{array}{l}\text { The Middle East and } \\
\text { Africa }\end{array}$ & 2015 & Active \\
\hline Pan-African Forum on Migration (PAFoM) & Africa (all regions) & 2015 & Active \\
\hline Caribbean Migration Consultations (CMC) & $\begin{array}{l}\text { Caribbean and } \\
\text { Central America }\end{array}$ & 2016 & Active \\
\hline
\end{tabular}




\section{Annex 6.1 Selected Migration References in the SDGs}

\begin{tabular}{|c|c|}
\hline SDG Target & $\begin{array}{l}\text { Relevance to } \\
\text { Migration }\end{array}$ \\
\hline $\begin{array}{l}\text { 1.1 By 2030, eradicate extreme poverty for all people everywhere, } \\
\text { currently measured as people living on less than } \$ 1.25 \text { a day. }\end{array}$ & $\begin{array}{l}\text { Inclusive } \\
\text { Language }\end{array}$ \\
\hline $\begin{array}{l}\text { 1.2 By 2030, reduce at least by half the proportion of men, women and } \\
\text { children of all ages living in poverty in all its dimensions according to } \\
\text { national definitions. }\end{array}$ & $\begin{array}{l}\text { Inclusive } \\
\text { Language }\end{array}$ \\
\hline $\begin{array}{l}\text { 1.3 Implement nationally appropriate social protection systems and } \\
\text { measures for all, including floors, and by } 2030 \text { achieve substantial } \\
\text { coverage of the poor and the vulnerable. }\end{array}$ & $\begin{array}{l}\text { Inclusive } \\
\text { Language }\end{array}$ \\
\hline $\begin{array}{l}1.4 \text { By 2030, ensure that all men and women, in particular the poor and } \\
\text { the vulnerable, have equal rights to economic resources, as well as } \\
\text { access to basic services, ownership and control over land and other } \\
\text { forms of property, inheritance, natural resources, appropriate new } \\
\text { technology and financial services, including microfinance. }\end{array}$ & $\begin{array}{l}\text { Inclusive } \\
\text { Language }\end{array}$ \\
\hline $\begin{array}{l}1.5 \text { By } 2030 \text {, build the resilience of the poor and those in vulnerable } \\
\text { situations and reduce their exposure and vulnerability to climate- } \\
\text { related extreme events and other economic, social, and environmental } \\
\text { shocks and disasters. }\end{array}$ & $\begin{array}{l}\text { Appears in all four } \\
\text { SDG review } \\
\text { publications (IOM, } \\
\text { ODI, JMDI, and } \\
\text { GMPA) }\end{array}$ \\
\hline $\begin{array}{l}2.1 \text { By 2030, end hunger and ensure access by all people, in particular } \\
\text { the poor and people in vulnerable situations, including infants, to safe, } \\
\text { nutritious, and sufficient food all year round. }\end{array}$ & $\begin{array}{l}\text { Inclusive } \\
\text { Language }\end{array}$ \\
\hline $\begin{array}{l}\text { 3.8 Achieve universal health coverage, including financial risk } \\
\text { protection, access to quality essential health-care services and access to } \\
\text { safe, effective, quality, and affordable essential medicines and vaccines } \\
\text { for all. }\end{array}$ & $\begin{array}{l}\text { Inclusive } \\
\text { Language, } \\
\text { Appears in all four } \\
\text { SDG review } \\
\text { publications (IOM, } \\
\text { ODI, JMDI, and } \\
\text { GMPA) }\end{array}$ \\
\hline $\begin{array}{l}\text { 3.b Support the research and development of vaccines and medicines } \\
\text { for the communicable and non-communicable diseases that primarily } \\
\text { affect developing countries, provide access to affordable essential } \\
\text { medicines and vaccines, in accordance with the Doha Declaration on } \\
\text { the TRIPS Agreement and Public Health, which affirms the right of } \\
\text { developing countries to use to the full the provisions in the Agreement } \\
\text { on Trade-Related Aspects of Intellectual Property Rights regarding } \\
\text { flexibilities to protect public health, and, in particular, provide access to } \\
\text { medicines for all. }\end{array}$ & $\begin{array}{l}\text { Inclusive } \\
\text { Language }\end{array}$ \\
\hline $\begin{array}{l}\text { 4.1 By 2030, ensure that all girls and boys complete free, equitable and } \\
\text { quality primary and secondary education leading to relevant and } \\
\text { effective learning outcomes. }\end{array}$ & $\begin{array}{l}\text { Inclusive } \\
\text { Language }\end{array}$ \\
\hline $\begin{array}{l}4.2 \text { By } 2030 \text {, ensure that all girls and boys have access to quality early } \\
\text { childhood development, care, and pre-primary education so that they } \\
\text { are ready for primary education. }\end{array}$ & $\begin{array}{l}\text { Inclusive } \\
\text { Language }\end{array}$ \\
\hline
\end{tabular}




\begin{tabular}{|c|c|}
\hline SDG Target & $\begin{array}{l}\text { Relevance } \\
\text { Migration }\end{array}$ \\
\hline $\begin{array}{l}\text { 4.3 By 2030, ensure equal access for all women and men to affordable } \\
\text { and quality technical, vocational, and tertiary education, including } \\
\text { university. }\end{array}$ & $\begin{array}{l}\text { Inclusive } \\
\text { Language }\end{array}$ \\
\hline $\begin{array}{l}\text { 4.4 By } 2030 \text {, substantially increase the number of youth and adults who } \\
\text { have relevant skills, including technical and vocational skills, for } \\
\text { employment, decent jobs, and entrepreneurship. }\end{array}$ & $\begin{array}{l}\text { Appears in all four } \\
\text { SDG review } \\
\text { publications (IOM, } \\
\text { ODI, JMDI, and } \\
\text { GMPA) }\end{array}$ \\
\hline $\begin{array}{l}\text { 4.6 By 2030, ensure that all youth and a substantial proportion of adults, } \\
\text { both men and women, achieve literacy and numeracy. }\end{array}$ & $\begin{array}{l}\text { Inclusive } \\
\text { Language }\end{array}$ \\
\hline $\begin{array}{l}\text { 4.7 By 2030, ensure that all learners acquire the knowledge and skills } \\
\text { needed to promote sustainable development, including, among others, } \\
\text { through education for sustainable development and sustainable } \\
\text { lifestyles, human rights, gender equality, promotion of a culture of } \\
\text { peace and non-violence, global citizenship and appreciation of cultural } \\
\text { diversity and of culture's contribution to sustainable development. }\end{array}$ & $\begin{array}{l}\text { Inclusive } \\
\text { Language }\end{array}$ \\
\hline $\begin{array}{l}\text { 4.a Build and upgrade education facilities that are child, disability and } \\
\text { gender sensitive and provide safe, non-violent, inclusive, and effective } \\
\text { learning environments for all. }\end{array}$ & $\begin{array}{l}\text { Inclusive } \\
\text { Language, } \\
\text { Appears in all four } \\
\text { SDG review } \\
\text { publications (IOM, } \\
\text { ODI, JMDI, and } \\
\text { GMPA) }\end{array}$ \\
\hline $\begin{array}{l}5.1 \text { End all forms of discrimination against all women and girls } \\
\text { everywhere }\end{array}$ & $\begin{array}{l}\text { Inclusive } \\
\text { Language }\end{array}$ \\
\hline $\begin{array}{l}5.2 \text { Eliminate all forms of violence against all women and girls in the } \\
\text { public and private spheres, including trafficking and sexual and other } \\
\text { types of exploitation. }\end{array}$ & $\begin{array}{l}\text { Inclusive } \\
\text { Language }\end{array}$ \\
\hline $\begin{array}{l}5.4 \text { Recognize and value unpaid care and domestic work through the } \\
\text { provision of public services, infrastructure and social protection } \\
\text { policies and the promotion of shared responsibility within the } \\
\text { household and the family as nationally appropriate. }\end{array}$ & $\begin{array}{l}\text { Appears in all four } \\
\text { SDG review } \\
\text { publications (IOM, } \\
\text { ODI, JMDI, and } \\
\text { GMPA) }\end{array}$ \\
\hline $\begin{array}{l}\text { 5.c Adopt and strengthen sound policies and enforceable legislation for } \\
\text { the promotion of gender equality and the empowerment of all women } \\
\text { and girls at all levels. }\end{array}$ & $\begin{array}{l}\text { Inclusive } \\
\text { Language }\end{array}$ \\
\hline $\begin{array}{l}\text { 6.1 By 2030, achieve universal and equitable access to safe and } \\
\text { affordable drinking water for all. }\end{array}$ & $\begin{array}{l}\text { Inclusive } \\
\text { Language }\end{array}$ \\
\hline $\begin{array}{l}6.2 \text { By 2030, achieve access to adequate and equitable sanitation and } \\
\text { hygiene for all and end open defecation, paying special attention to the } \\
\text { needs of women and girls and those in vulnerable situations. }\end{array}$ & $\begin{array}{l}\text { Inclusive } \\
\text { Language }\end{array}$ \\
\hline $\begin{array}{l}8.10 \text { Strengthen the capacity of domestic financial institutions to } \\
\text { encourage and expand access to banking, insurance, and financial } \\
\text { services for all. }\end{array}$ & $\begin{array}{l}\text { Inclusive } \\
\text { Language }\end{array}$ \\
\hline
\end{tabular}




\begin{tabular}{|c|c|}
\hline SDG Target & $\begin{array}{l}\text { Relevance to } \\
\text { Migration }\end{array}$ \\
\hline $\begin{array}{l}\text { 8.3 Promote development-oriented policies that support productive } \\
\text { activities, decent job creation, entrepreneurship, creativity, and } \\
\text { innovation, and encourage the formalization and growth of micro-, } \\
\text { small- and medium-sized enterprises, including through access to } \\
\text { financial services. }\end{array}$ & $\begin{array}{l}\text { Appears in all four } \\
\text { SDG review } \\
\text { publications (IOM, } \\
\text { ODI, JMDI, and } \\
\text { GMPA) }\end{array}$ \\
\hline $\begin{array}{l}8.5 \text { By 2030, achieve full and productive employment and decent work } \\
\text { for all women and men, including for young people and persons with } \\
\text { disabilities, and equal pay for work of equal value. }\end{array}$ & $\begin{array}{l}\text { Inclusive } \\
\text { Language }\end{array}$ \\
\hline $\begin{array}{l}8.7 \text { Take immediate and effective measures to eradicate forced labour, } \\
\text { end modern slavery and human trafficking and secure the prohibition } \\
\text { and elimination of the worst forms of child labour, including } \\
\text { recruitment and use of child soldiers, and by } 2025 \text { end child labour in } \\
\text { all its forms }\end{array}$ & $\begin{array}{l}\text { Appears in all four } \\
\text { SDG review } \\
\text { publications (IOM, } \\
\text { ODI, JMDI and } \\
\text { GMPA) }\end{array}$ \\
\hline $\begin{array}{l}\text { 8.8 Protect labour rights and promote safe and secure working } \\
\text { environments for all workers, including migrant workers, in particular } \\
\text { women migrants, and those in precarious employment. }\end{array}$ & $\begin{array}{l}\text { Explicit Reference, } \\
\text { Inclusive } \\
\text { Language, Appears } \\
\text { in all four SDG } \\
\text { review } \\
\text { publications (IOM, } \\
\text { ODI, JMDI, and } \\
\text { GMPA) }\end{array}$ \\
\hline $\begin{array}{l}\text { 9.1 Develop quality, reliable, sustainable, and resilient infrastructure, } \\
\text { including regional and trans-border infrastructure, to support } \\
\text { economic development and human well-being, with a focus on } \\
\text { affordable and equitable access for all. }\end{array}$ & $\begin{array}{l}\text { Inclusive } \\
\text { Language }\end{array}$ \\
\hline $\begin{array}{l}\text { 10.2 By 2030, empower and promote the social, economic, and political } \\
\text { inclusion of all, irrespective of age, sex, disability, race, ethnicity, origin, } \\
\text { religion or economic or other status. }\end{array}$ & $\begin{array}{l}\text { Inclusive } \\
\text { Language }\end{array}$ \\
\hline $\begin{array}{l}\text { 10.7 Facilitate orderly, safe, regular, and responsible migration and } \\
\text { mobility of people, including through the implementation of planned } \\
\text { and well-managed migration policies. }\end{array}$ & $\begin{array}{l}\text { Explicit Reference, } \\
\text { Appears in all four } \\
\text { SDG review } \\
\text { publications (IOM, } \\
\text { ODI, JMDI, and } \\
\text { GMPA) }\end{array}$ \\
\hline $\begin{array}{l}\text { 10.c By } 2030 \text {, reduce to less than } 3 \text { per cent the transaction costs of } \\
\text { migrant remittances and eliminate remittance corridors with costs } \\
\text { higher than } 5 \text { per cent. }\end{array}$ & $\begin{array}{l}\text { Explicit Reference, } \\
\text { Appears in all four } \\
\text { SDG review } \\
\text { publications (IOM, } \\
\text { ODI, JMDI, and } \\
\text { GMPA) }\end{array}$ \\
\hline $\begin{array}{l}11.1 \text { By 2030, ensure access for all to adequate, safe, and affordable } \\
\text { housing and basic services and upgrade slums }\end{array}$ & $\begin{array}{l}\text { Inclusive } \\
\text { Language }\end{array}$ \\
\hline $\begin{array}{l}11.2 \text { By 2030, provide access to safe, affordable, accessible, and } \\
\text { sustainable transport systems for all, improving road safety, notably by } \\
\text { expanding public transport, with special attention to the needs of those } \\
\text { in vulnerable situations, women, children, persons with disabilities and } \\
\text { older persons. }\end{array}$ & $\begin{array}{l}\text { Inclusive } \\
\text { Language }\end{array}$ \\
\hline
\end{tabular}




\begin{tabular}{|l|l|}
\hline SDG Target & $\begin{array}{l}\text { Relevance to } \\
\text { Migration }\end{array}$ \\
\hline $\begin{array}{l}\text { 13.1 Strengthen resilience and adaptive capacity to climate-related } \\
\text { hazards and natural disasters in all countries. }\end{array}$ & $\begin{array}{l}\text { Appears in all four } \\
\text { SDG review } \\
\text { publications (IOM, } \\
\text { ODI, JMDI, and } \\
\text { GMPA) }\end{array}$ \\
\hline $\begin{array}{l}\text { 13.b Promote mechanisms for raising capacity for effective climate } \\
\text { change-related planning and management in least developed countries } \\
\text { and small island developing States, including focusing on women, } \\
\text { youth, and local and marginalized communities. }\end{array}$ & $\begin{array}{l}\text { Appears in all four } \\
\text { SDG review } \\
\text { publications (IOM, } \\
\text { ODI, JMDI, and } \\
\text { GMPA) }\end{array}$ \\
\hline $\begin{array}{l}\text { 16.3 Promote the rule of law at the national and international levels and } \\
\text { ensure equal access to justice for all. }\end{array}$ & $\begin{array}{l}\text { Inclusive } \\
\text { Language, } \\
\text { Appears in all four } \\
\text { SDG review } \\
\text { publications (IOM, } \\
\text { ODI, JMDI, and } \\
\text { GMPA) }\end{array}$ \\
\hline $\begin{array}{l}\text { 16.9 By 2030, provide legal identity for all, including birth registration. } \\
\text { 17.18 By 2020, enhance capacity-building support to developing } \\
\text { countries, including for least developed countries and small island } \\
\text { developing states, to increase significantly the availability of high- } \\
\text { quality, timely and reliable data disaggregated by income, gender, age, } \\
\text { race, ethnicity, migratory status, disability, geographic location and } \\
\text { other characteristics relevant in national contexts. }\end{array}$ & $\begin{array}{l}\text { Language } \\
\text { Appears in all four } \\
\text { SDG review } \\
\text { publications (IOM, } \\
\text { ODI, JMDI, and } \\
\text { GMPA) }\end{array}$ \\
\hline
\end{tabular}




\section{Annex 6.2 Migration References in UNTT Thematic Think Pieces}

\begin{tabular}{|c|c|c|c|}
\hline $\begin{array}{l}\text { UNTT Thematic } \text { Think } \\
\text { Piece (May 2012) }\end{array}$ & Date & Author(s) & Migration Reference \\
\hline Countries with special needs & $\begin{array}{l}\text { May } \\
2012\end{array}$ & OHRLLS & $\begin{array}{l}\text { One reference }- \text { increased } \\
\text { migration as a challenge. }\end{array}$ \\
\hline $\begin{array}{l}\text { Culture: a driver and an } \\
\text { enabler of sustainable } \\
\text { development }\end{array}$ & $\begin{array}{l}\text { May } \\
2012\end{array}$ & UNESCO & No reference \\
\hline Disaster Risk and Resilience & $\begin{array}{l}\text { May } \\
2012\end{array}$ & UNISDR, WMO & No reference \\
\hline $\begin{array}{l}\text { Education and skills for } \\
\text { inclusive and sustainable } \\
\text { development beyond } 2015\end{array}$ & $\begin{array}{l}\text { May } \\
2012\end{array}$ & $\begin{array}{lr}\text { UNSECO with } \\
\text { contributions } \\
\text { DESA, ITU, and } \\
\text { UNITAR }\end{array}$ & No reference \\
\hline $\begin{array}{l}\text { Emerging development } \\
\text { challenges for the post-2015 } \\
\text { UN development agenda: } \\
\text { Employment }\end{array}$ & $\begin{array}{l}\text { May } \\
2012\end{array}$ & $\mathrm{ILO}^{1 *}$ & No reference \\
\hline $\begin{array}{l}\text { Imagining a world free from } \\
\text { hunger: Ending hunger and } \\
\text { malnutrition and ensuring } \\
\text { food and nutrition security }\end{array}$ & $\begin{array}{l}\text { May } \\
2012\end{array}$ & FAO, IFAD, WFP & No reference \\
\hline $\begin{array}{ll}\begin{array}{l}\text { Governance } \\
\text { development }\end{array} & \text { and } \\
\end{array}$ & $\begin{array}{l}\text { May } \\
2012\end{array}$ & $\begin{array}{l}\text { UNDESA, UNDP, } \\
\text { UNESCO }\end{array}$ & No reference \\
\hline $\begin{array}{l}\text { Health in the post-2015 UN } \\
\text { development agenda }\end{array}$ & $\begin{array}{l}\text { May } \\
2012\end{array}$ & $\begin{array}{l}\text { UNAIDS, UNICEF, } \\
\text { UNFPA, WHO }\end{array}$ & $\begin{array}{l}\text { One reference - migration as a } \\
\text { relevant factor for health }\end{array}$ \\
\hline $\begin{array}{l}\text { Towards freedom from fear } \\
\text { and want: Human rights in } \\
\text { the post } 2015 \text { agenda }\end{array}$ & $\begin{array}{l}\text { May } \\
2012\end{array}$ & $\mathrm{OHCHR}$ & $\begin{array}{l}\text { Several references - primarily } \\
\text { migrants as a group vulnerable } \\
\text { to exclusion or marginalization, } \\
\text { which denies them of their } \\
\text { human rights and limits their } \\
\text { potential development } \\
\text { contributions. }\end{array}$ \\
\hline $\begin{array}{l}\text { Addressing inequalities: The } \\
\text { heart of the post-2015 } \\
\text { agenda and the future we } \\
\text { want for all }\end{array}$ & $\begin{array}{l}\text { May } \\
2012\end{array}$ & $\begin{array}{l}\text { ECE, ESCAP, } \\
\text { UNDESA, } \\
\text { UNICEF, UNRISD, } \\
\text { UN Women }\end{array}$ & $\begin{array}{l}\text { One reference - migrants as a } \\
\text { vulnerable to exclusion } \\
\text { exacerbating inequality }\end{array}$ \\
\hline $\begin{array}{l}\text { Science, technology and } \\
\text { innovation and intellectual } \\
\text { property rights: The vision } \\
\text { for development }\end{array}$ & $\begin{array}{l}\text { May } \\
2012\end{array}$ & $\begin{array}{l}\text { IAEA, } \\
\text { UNESCO, } \\
\text { UNOOSA, WIPO }\end{array}$ & No reference \\
\hline
\end{tabular}

\footnotetext{
${ }^{1}$ ILO always makes the point that it is the view of senior officials and not ILO.
} 


\begin{tabular}{|c|c|c|c|}
\hline $\begin{array}{l}\text { Macroeconomic stability, } \\
\text { inclusive growth, and } \\
\text { employment }\end{array}$ & $\begin{array}{l}\text { May } \\
2012\end{array}$ & $\begin{array}{l}\text { ILO*, UNCTAD, } \\
\text { UNDESA, WTO }\end{array}$ & $\begin{array}{l}\text { One reference to migration as a } \\
\text { factor to be considered to avoid } \\
\text { unemployment. }\end{array}$ \\
\hline $\begin{array}{l}\text { Migration and human } \\
\text { mobility }\end{array}$ & $\begin{array}{l}\text { May } \\
2012\end{array}$ & IOM, UNDESA & $\begin{array}{l}\text { Migration is driven by } \\
\text { inequality (social, economic, } \\
\text { economic), which is affected by } \\
\text { population dynamics. Three } \\
\text { associations to development: } 1 \text { ) } \\
\text { underdevelopment as a root } \\
\text { cause; } 2 \text { ) underdevelopment as } \\
\text { a consequence (brain drain), } \\
\text { and 3) an enabler of } \\
\text { development if human rights } \\
\text { protected and migration is well } \\
\text { managed. Proposes that } \\
\text { migration is a cross-cutting } \\
\text { issue across the development } \\
\text { agenda. }\end{array}$ \\
\hline Peace and security & $\begin{array}{l}\text { May } \\
2012\end{array}$ & $\begin{array}{l}\text { Peace-Building } \\
\text { Support Office } \\
\text { (PBSO) }\end{array}$ & $\begin{array}{l}\text { One reference is made to } \\
\text { migration and human } \\
\text { trafficking as by-products of } \\
\text { development deficits. }\end{array}$ \\
\hline Population dynamics & $\begin{array}{l}\text { May } \\
2012\end{array}$ & UNDESA, UNFPA & $\begin{array}{l}\text { Several references are made to } \\
\text { migration as a demographic } \\
\text { phenomenon, often driven by } \\
\text { economic disparity. Migrants } \\
\text { are often vulnerable and yet } \\
\text { can contribute to development } \\
\text { when enabled to do so. }\end{array}$ \\
\hline $\begin{array}{l}\text { Social protection: A } \\
\text { development priority in the } \\
\text { post-2015 UN development } \\
\text { agenda }\end{array}$ & $\begin{array}{l}\text { May } \\
2012\end{array}$ & $\begin{array}{l}\text { ECA, ILO*, } \\
\text { UNCTAD, } \\
\text { UNDESA, UNICEF }\end{array}$ & $\begin{array}{l}\text { One reference to migrants as a } \\
\text { group vulnerable to exclusion } \\
\text { from social protection. }\end{array}$ \\
\hline $\begin{array}{l}\text { Building on the MDGs to } \\
\text { bring sustainable } \\
\text { development to the post- } \\
2015 \text { development agenda }\end{array}$ & $\begin{array}{l}\text { May } \\
2012\end{array}$ & $\begin{array}{lr}\text { ECE, } & \text { ESCAP, } \\
\text { UNDESA, } & \text { UNEP, } \\
\text { UNFCCC } & \end{array}$ & No reference \\
\hline Sustainable Urbanization & $\begin{array}{l}\text { May } \\
2012 \\
\end{array}$ & UN-Habitat & $\begin{array}{l}\text { One reference to immigration } \\
\text { as a social inclusion challenge }\end{array}$ \\
\hline $\begin{array}{l}\text { Assessment of MDG8 and } \\
\text { lessons learned }\end{array}$ & $\begin{array}{l}\text { Jan } \\
2013\end{array}$ & $\begin{array}{l}\text { ITU, OHCHR, } \\
\text { UNDESA }\end{array}$ & $\begin{array}{l}\text { One reference to tighter } \\
\text { immigration policies limiting } \\
\text { trade opportunities }\end{array}$ \\
\hline $\begin{array}{l}\text { Analysis and overview of } \\
\text { new actors and formats for } \\
\text { the global partnership for } \\
\text { development post- } 2015\end{array}$ & $\begin{array}{l}\text { Jan } \\
2013\end{array}$ & $\begin{array}{l}\text { IFAD, IOM, ITU, } \\
\text { OHCHR, OHRLLS, } \\
\text { UNCTAD, } \\
\text { UNDESA, UNEP, } \\
\text { UNFCCC, UNFPA, } \\
\text { UNIDO, WTO }\end{array}$ & $\begin{array}{l}\text { Two references to migration as } \\
\text { a global collective action } \\
\text { problem; and migration as an } \\
\text { enabler of development in both } \\
\text { monetary and non-monetary } \\
\text { ways }\end{array}$ \\
\hline
\end{tabular}




\begin{tabular}{|c|c|c|c|}
\hline $\begin{array}{l}\text { Financing for sustainable } \\
\text { development in the global } \\
\text { partnership beyond } 2015\end{array}$ & $\begin{array}{l}\text { Jan } \\
2013\end{array}$ & $\begin{array}{l}\text { OHCHR, OHRLLS, } \\
\text { IFAD, IOM, } \\
\text { UNCTAD, } \\
\text { UNDESA, UNDP, } \\
\text { UNEP, UNESCO, } \\
\text { UNFCCC, UNFPA }\end{array}$ & $\begin{array}{l}\text { Several references to the impact } \\
\text { of migrant remittances on how } \\
\text { development can be enhanced } \\
\text { by lowering transaction costs, } \\
\text { increasing migration } \\
\text { opportunities, and on financial } \\
\text { inclusion. }\end{array}$ \\
\hline $\begin{array}{l}\text { Trade and development and } \\
\text { the global partnership } \\
\text { beyond } 2015\end{array}$ & $\begin{array}{l}\text { Jan } \\
2013\end{array}$ & UNCTAD & No reference \\
\hline $\begin{array}{l}\text { Trade in the global } \\
\text { partnership for development } \\
\text { beyond } 2015\end{array}$ & $\begin{array}{l}\text { Jan } \\
2013\end{array}$ & $\begin{array}{l}\text { IOM, OHCHR, } \\
\text { OHRLLS, } \\
\text { UNCTAD, UNEP, } \\
\text { UNIDO, WTO }\end{array}$ & $\begin{array}{l}\text { One reference to interregional } \\
\text { mobility as a key factor for } \\
\text { labour market efficiency and a } \\
\text { source of remittances. }\end{array}$ \\
\hline $\begin{array}{l}\text { Global governance and } \\
\text { governance of the global } \\
\text { commons in the global } \\
\text { partnership for development } \\
\text { beyond } 2015\end{array}$ & $\begin{array}{l}\text { Jan } \\
2013\end{array}$ & $\begin{array}{l}\text { OHCHR, OHRLLS, } \\
\text { UNDESA, UNEP, } \\
\text { UNFPA }\end{array}$ & $\begin{array}{l}\text { Two references to migration as } \\
\text { contributing to the greater } \\
\text { interdependency between } \\
\text { countries yet simultaneously a } \\
\text { lack of adequate mechanisms } \\
\text { for the regulation of labour } \\
\text { migration, including protection } \\
\text { of the rights of migrants and } \\
\text { their access to services. }\end{array}$ \\
\hline $\begin{array}{l}\text { Partnerships for } \\
\text { development: Perspectives } \\
\text { from global health }\end{array}$ & $\begin{array}{l}\text { Jan } \\
2013\end{array}$ & $\begin{array}{l}\text { OHCHR, UNEP, } \\
\text { UNFPA, WHO }\end{array}$ & $\begin{array}{l}\text { One reference to the necessity } \\
\text { of ensuring that the recruitment } \\
\text { of health workers aligns with } \\
\text { an ethical code of practice. }\end{array}$ \\
\hline $\begin{array}{l}\text { Global partnerships in the } \\
\text { area of population and } \\
\text { migration }\end{array}$ & $\begin{array}{l}\text { Jan } \\
2013\end{array}$ & $\begin{array}{l}\text { IOM, UN DESA, } \\
\text { UNFPA }\end{array}$ & $\begin{array}{l}\text { Migration as a development } \\
\text { enabler for migrants; those left } \\
\text { behind (through remittances } \\
\text { and knowledge transfers) and } \\
\text { countries of reception } \\
\text { (innovation; easing labour } \\
\text { shortages). }\end{array}$ \\
\hline $\begin{array}{lr}\text { Building } & \text { Resilience to } \\
\text { Disasters } & \text { through } \\
\text { Partnerships } & \end{array}$ & $\begin{array}{l}\text { Jan } \\
2013\end{array}$ & $\begin{array}{l}\text { IOM, } \\
\text { OHCHR, } \\
\text { UNESCO, UNEP, } \\
\text { UNISDR, UNFPA, } \\
\text { WMO }\end{array}$ & $\begin{array}{l}\text { No direct references - } \\
\text { population growth in urban } \\
\text { areas as a challenge. }\end{array}$ \\
\hline $\begin{array}{l}\text { Science, technology, and } \\
\text { innovation for sustainable } \\
\text { development in the global } \\
\text { partnership for development } \\
\text { beyond } 2015\end{array}$ & $\begin{array}{l}\text { Jan } \\
2013\end{array}$ & $\begin{array}{l}\text { ITU, OHCHR, } \\
\text { UNCTAD, UNEP, } \\
\text { UNESCO, } \\
\text { UNFCCC, UNIDO, } \\
\text { WIPO, WMO }\end{array}$ & $\begin{array}{l}\text { One reference-labour mobility } \\
\text { as a source of innovation }\end{array}$ \\
\hline
\end{tabular}




\section{Annex 8.1 Comparing Objectives Across GCM Drafts}

\begin{tabular}{|c|c|c|}
\hline Objective & Text (Zero Draft) & Text (Final Draft) \\
\hline 3 & $\begin{array}{l}\text { Provide adequate and timely } \\
\text { information at all stages of migration }\end{array}$ & $\begin{array}{l}\text { Provide accurate and timely information } \\
\text { at all stages of migration }\end{array}$ \\
\hline 4 & $\begin{array}{l}\text { Provide all migrants with proof of legal } \\
\text { identity, proper identification and } \\
\text { documentation }\end{array}$ & $\begin{array}{l}\text { Ensure that all migrants have proof of } \\
\text { legal identity and adequate } \\
\text { documentation }\end{array}$ \\
\hline 10 & $\begin{array}{l}\text { Prevent and combat trafficking in } \\
\text { persons in the context of international } \\
\text { migration }\end{array}$ & $\begin{array}{l}\text { Prevent, combat and eradicate trafficking } \\
\text { in persons in the context of international } \\
\text { migration }\end{array}$ \\
\hline $12^{*}$ & $\begin{array}{l}\text { Strengthen procedures and } \\
\text { mechanisms for status determination }\end{array}$ & $\begin{array}{l}\text { Strengthen certainty and predictability } \\
\text { in migration procedures for appropriate } \\
\text { screening, assessment and referral }\end{array}$ \\
\hline 13 & $\begin{array}{l}\text { Use migration detention only as a last } \\
\text { resort and work towards alternatives }\end{array}$ & $\begin{array}{l}\text { Use migration detention only as a } \\
\text { measure of last resort and work towards } \\
\text { alternatives }\end{array}$ \\
\hline 15 & $\begin{array}{l}\text { Provide access to basic social services for } \\
\text { migrants }\end{array}$ & $\begin{array}{l}\text { Provide access to basic services for } \\
\text { migrants }\end{array}$ \\
\hline 17 & $\begin{array}{l}\text { Eliminate all forms of discrimination } \\
\text { and promote fact-based public } \\
\text { discourse to shape perceptions of } \\
\text { migration }\end{array}$ & $\begin{array}{l}\text { Eliminate all forms of discrimination } \\
\text { and promote evidence-based public } \\
\text { discourse to shape perceptions of } \\
\text { migration }\end{array}$ \\
\hline 18 & $\begin{array}{l}\text { Invest in skills development and } \\
\text { facilitate recognition of skills, } \\
\text { qualifications and competences }\end{array}$ & $\begin{array}{l}\text { Invest in skills development and } \\
\text { facilitate mutual recognition of skills, } \\
\text { qualifications and competences }\end{array}$ \\
\hline 21 & $\begin{array}{l}\text { Cooperate in facilitating dignified and } \\
\text { sustainable return, readmission and } \\
\text { reintegration }\end{array}$ & $\begin{array}{l}\text { Cooperate in facilitating safe and } \\
\text { dignified return and readmission, as } \\
\text { well as sustainable reintegration }\end{array}$ \\
\hline 23 & 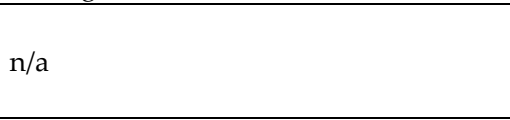 & $\begin{array}{l}\text { Strengthen international cooperation } \\
\text { and global partnerships for safe, orderly } \\
\text { and regular migration }\end{array}$ \\
\hline
\end{tabular}

* In the first round of revisions Objective 12 became 'Strengthen certainty and predictability in migration procedures' and then in the second round of revisions 'Strengthen certainty and predictability in migration procedures for appropriate determination and referral' 


\section{About the Author}

Elaine Lebon-McGregor (née McGregor) was born in 1985 in Glasgow in the United Kingdom. She completed her Bachelor's degree (2007) in Public Policy and a Master's degree in Urban Regeneration (2008) at the University of Glasgow. After moving to the Netherlands, she went on to gain a second Master's degree in Public Policy and Human Development (2012) from the United Nations University-MERIT and the Maastricht Graduate School of Governance (MGSoG).

From 2012, Elaine began work as a researcher within the Migration Group at UNU-MERIT/MGSoG, where she was involved in a range of different projects. She has fieldwork experience in Kosovo, Bosnia and Herzegovina, Serbia, Macedonia, Albania, Switzerland, the United Kingdom, Viet Nam, the Philippines, Pakistan and Nepal, and has worked with a range of IOs, NGOs, and National Governments including ILO, IOM, ICMPD, UNDP, UNIDO, OECD, World Bank, IDB, ICMC, the Swiss Government and the Dutch Government, and has been involved in the design, development, implementation and management of several key migration projects and evaluations during her time at Maastricht University.

She is currently a post-doctoral researcher at UNU-MERIT/MGSOG where she is contributing to the MIGNEX project and teaching on topics related to migration governance and policy coherence in various educational programmes. 


\section{Valorization}

From the 2015 'migration crises' in the Mediterranean, Central America, and the Andaman Sea, to the COVID-19 pandemic that has sent the world into an economic crisis, the rationale for international cooperation has become even more apparent in recent years. However, the international architecture established by states to respond more effectively to challenges that traverse state borders, most notably the UN and its agencies, has come under increasing scrutiny for its handling of global crises. The migration crises of 2015 demonstrated the inadequacy of existing intergovernmental responses to migration. Accordingly, states agreed to negotiate two global compacts, one for migrants and one for refugees in order to better respond to migration related issues at the international level. However, the non-binding nature of these agreements is characteristic of a broader trend in multilateralism, towards carefully crafted yet ambiguous agreements.

International organizations are limited in how they can respond to issues of global concern because they are the creations of states that impose limitations on how they can act. Sometimes these limitations are also self-imposed. For example, as was discussed in Chapter 8 of the thesis, UNCHR was deliberately conservative in what they chose to include in the negotiations of the Global Compact on Refugees for fear of states rejecting the Compact if deemed too radical by its key Member State funders. Blaming international organizations for failing to act ignores the role that the uneven distribution of power in the global system has played in creating the international system. However, blaming the uneven distribution of power between states also ignores the role that IOs play in shaping social reality and defining global problems.

Many people have devoted their careers to the furtherance of global migration governance. Sir Peter Sutherland, often referred to as 'the father of globalisation', devoted the last years of his illustrious career to the pursuit of a more significant role for the UN in global migration governance. The fact that the UN now has an agency for migration, the International Organization for Migration (IOM), which was considered impossible just 25 years ago, is testament to a significant change in how states view the role of the UN, and how the UN functions. The fact that the US' withdrawal from the Global Compact for Safe, Orderly and Regular Migration did not immediately result 
in its failure, as it did when the US rejected ILO's plans in the 1940s, supports the notion that the UN has evolved.

By examining the case of migration, the dissertation offers insights into how intergovernmental organizations operate and contributes to a growing body of literature on the role of international organizations in migration governance. Understanding the history of multilateralism has never been more relevant, but also more difficult to achieve. The dissertation provides a historical understanding of the emergence of global migration governance through a time of tumultuous change.

Accordingly, the materials in the dissertation have been integrated into the educational programme at UNU-MERIT and the Maastricht Graduate School of Governance. In the migration specialization of the MSc Public Policy and Human Development, students are introduced to the global dimension of migration governance in their fourth and final course. The materials in this dissertation have been used to develop a short course which provides students with a historical account of the emergence of global migration governance from 1919 to the present day. The teaching materials developed by the author have also been used by other teachers to implement similar courses in Ghana, Kenya and Kosovo. To promote the use of the dissertation in education, a revised version of chapter 4 is currently under review for publication as an International Migration Institute Network (IMIn) Working Paper to ensure its rapid dissemination through a well-respected channel. Many IMIn Working Papers have gone on to become well-cited articles in high impact journals. In the future, I plan to further develop and refine the monograph for submission to a relevant publisher. The envisioned manuscript is expected to be a useful resource for researchers and students interested in global migration governance, but also to practitioners who may be interested in understanding how and why global migration governance has evolved in the way that it has. I would also like to work on a paper that brings out the specific methodological contribution of the thesis in a nonmigration related journal. The potential for advocacy coalition framework theory to be more consistently applied to the study of the global policy process holds potential. The combination of analytical tools used to implement process tracing clearly and transparently also has the potential to be applied to other policy areas. Disseminating the methodological tools will serve to encourage research in this direction.

In addition to these broader plans, I had the opportunity to present various parts of my dissertation in different stages of development to diverse 
audiences, which has led to several publications. In March 2017, I presented an early draft of Chapter 6 at the Migrating out of Poverty "From Evidence to Policy" Conference at the School of Oriental and African Studies (SOAS). The conference was interesting in the sense that the audience was comprised not only of academics but also practitioners. Building on the feedback that I received at the conference, I further developed my research on the SDGs. A concrete outcome of this research was the contribution of a chapter entitled 'Migration, the MDGs, and SDGs: Context and Complexity" to the Routledge Handbook of Migration and Development edited by Tanja Bastia and Ronald Skeldon (London, 2020, pp.284-297).

Next to the opportunity to meet and discuss my initial ideas with a group of highly respected individuals, many of whom had long careers in the UN, the feedback received at the conference also inspired me to start a side project exploring the relationship between funding patterns and governance. This project attracted a great deal of attention. I published the initial research in an IMIn Working Paper entitled 'Money Matters: The Role of Funding in Migration Governance'. I presented the initial results of this research at a research seminar at the University of Amsterdam entitled "Show me the Money! Money Matters in Migration Policy and Practice". A chapter based on this work, further refined based on the research conducted for Chapter 7 has been contributed to an edited collection by Dr Tesseltje de Lange, Prof. Annette Schrauwen and Prof. Willem Maas which is currently under review with Cambridge University Press.

Based on this work, I was invited to join an Expert Workshop on the International Organization for Migration (IOM) on 2 Feb 2019 at the Refugee Studies Centre at the University of Oxford. The goal of this workshop was to bring together experts with interest in understanding the role of international organizations, especially IOM, in global migration governance. The meeting allowed me to share some of the preliminary findings of Chapter 7 and to engage in critical discussions with researchers from different disciplines which allowed me to disseminate its findings but also to refine and develop my research. A revised version of Chapter 7 has been accepted as a chapter in the forthcoming Edward Elgar Handbook on the Institutions of Global Migration Governance co-edited by Hélène Thiollet and Antoine Pécoud.

In the future, I would like to develop this line of research further. I am currently working on a collaboration with Dr Nicholas R. Micinski, the ISA James N. Rosenau Postdoctoral Fellow at the Center for the Study of Europe, Boston University on "Money, Multilateralism and Migration" to develop 
these ideas further. We plan to replicate the methodological approach that I used to examine IOM's earmarked contributions to other international organizations.

Furthermore, throughout the research process, I have engaged in several activities that have allowed me to engage in dialogue with policy-makers and other stakeholders. When I started working on the PhD as part of the GPAC2 dual-career programme in late 2015, I was working as a migration researcher at UNU-MERIT and the Maastricht Graduate School of Governance. While the research work conducted in this capacity was not always directly relevant to my $\mathrm{PhD}$, complementarities existed. My contract research work, as I explain in my methodology, helped me to gain an understanding of the global landscape, and access to respondents that I may not have otherwise been able to reach. However, my $\mathrm{PhD}$ research also helped me in the execution of much of my contract work.

I have been able to apply the knowledge gained in the context of writing my thesis in my consultancy work on several occasions. For example, I coauthored a report for the IOM Migration Research Series which looked at the relationship between migration and the Millennium Development Goals and discussed possible ways that migration could be included in the Post-2015 Development Agenda. Furthermore, in 2017, UNU-MERIT and the Maastricht Graduate School of Governance were asked by the United Nations Industrial Development Organization (UNIDO) to assist in the preparation of their Migration and Development Strategy. UNIDO had recently joined the Global Migration Group (GMG). In the discussions, I was able to use research conducted in the context of my dissertation work to brief staff on the landscape of organizations working on migration issues, the history of the GMG and to discuss some of the sensitivities of the field.

Additionally, I participated in three Global Forums on Migration and Development meetings (Civil Society Days and Common Space) in Turkey (2015), Bangladesh (2016), and Germany (2017), as well as several preparatory meetings. Ahead of the GFMD in Dhaka, Bangladesh, I prepared a report for the Migration and Development (MADE) network which looked at progress in achieving civil society's 5-year-8-point Plan of Action. The positive response to this report led to the elaboration of a second edition of the report in which I elaborated a methodology for measuring progress in global governance that aligned with the goals defined by global civil society networks. Additionally, I joined the International Steering Committee for the GFMD Civil Society Days. 
In recent months I have been working as a consultant for IOM. I have assisted the Government of the Republic of Armenia in the implementation of their first National Voluntary Review of the Global Compact for Safe, Orderly and Regular Migration which has provided a further opportunity to use the knowledge gained in the context of my $\mathrm{PhD}$ research but also to lay ground work for future research which will look beyond 2018. 



\section{UNU-MERIT/MGSoG Dissertation Series}

2020

\section{Janyl Moldalieva}

Playing the 'Game'of Transparency

and Accountability in Kyrgyzstan's

Resource Governance

UNU-MERIT/MGSoG

Dissertation Series № 246

\section{Kaleab Kebede Haile}

Essays on Rural Household Decision-

Making under Climate Risk

UNU-MERIT/MGSoG

Dissertation Series № 245

\section{Nora Jasmin Ragab}

Diaspora Mobilisation in a Conflict

Setting

UNU-MERIT/MGSoG

Dissertation Series № 244

\section{Mary Kaltenberg}

From Micro to Macro:

Essays on Technological Change and

Income Divergence

UNU-MERIT/MGSoG

Dissertation Series № 243

\section{Ayla E. Bonfiglio}

Student migrant, refugee or both?

Exploring Refugee Agency and

Mobility through Tertiary Education

in Kenya, South Africa and Uganda

UNU-MERIT/MGSoG

Dissertation Series № 242
Danilo Sartorello Spinola

Cycles, Economic Structures and

External Constraints.

A Structuralist study on the causes

of economic volatility in Latin

America

UNU-MERIT/MGSoG

Dissertation Series № 241

2019

\section{Jemal Adem}

Livelihood Vulnerability to Shocks,

Behaviour and Investment in

Education: Essays in Behavioural

Development Economics

UNU-MERIT/MGSoG

Dissertation Series № 240

\section{Davina Osei}

Corrupt or corrupted networks?

An empirical enquiry

UNU-MERIT/MGSoG

Dissertation Series № 239

\section{Patima Chongcharoentanawat}

Beyond Static Inequality

Public policies and economic mobility

in Thailand

UNU-MERIT/MGSoG

Dissertation Series № 238 


\section{Charlotte Guillard}

Rethinking economic growth

and structural change.

The role of boundaries and linkages

between industries

UNU-MERIT/MGSoG

Dissertation Series № 237

\section{Nicolas Echarti}

Employment Effects or Vocational

Rehabilitation in Germany:

A quantitative analysis

UNU-MERIT/MGSoG

Dissertation Series № 236

\section{Shellie E. Solomon}

Neighborhoods Matter:

Crime, collective efficacy and

foreclosures in Miami

UNU-MERIT/MGSoG

Dissertation Series № 235

\section{Michał Kazimierczak}

Regional Innovation and

Entrepreneurship

Patents, trade marks, entry and

entrants' growth in European

manufacturing industries

UNU-MERIT/MGSoG

Dissertation Series № 234

\section{Fernanda Soares}

The Influence of Within School and Across Schools' Collaborative

Practices on Student Learning and

Teaching Outcomes in West Africa

UNU-MERIT/MGSoG

Dissertation Series № 233

\section{Mira Bierbaum}

New Mindsets to Innovate

Activation

UNU-MERIT/MGSoG

Dissertation Series № 232

\section{Norman Dytianquin}

Technology in the Asian Miracle and Crisis Debates: Applications of and Insights from the Field of Influence Approach to Input-Output Analysis UNU-MERIT/MGSoG

Dissertation Series № 231

\section{Nga Le}

The implications of health insurance for the labour market and patient satisfaction with medical care in Vietnam

UNU-MERIT/MGSoG

Dissertation Series № 230

\section{Jinhyuck Park}

Intellectual Property right protection and cross-border RED investments

by multinational enterprises

UNU-MERIT/MGSoG

Dissertation Series № 229

\section{Richard de Groot}

Show me the Money:

Essays on the Impact of Cash

Transfers on Child Nutrition and the Role of Intra-Household Dynamics

UNU-MERIT/MGSoG

Dissertation Series № 228 


\section{Catie Lott}

Diamonds are a Women's Best

Friend

Broadening Measures of Women's

Access to Formal Political Decision-

Making

UNU-MERIT/MGSoG

Dissertation Series № 227

\section{Ana Cristina Calderon Ramirez}

Public Management Reforms

Three stories about public

procurement agencification in Latin

America

UNU-MERIT/MGSoG

Dissertation Series № 226

\section{Camilo Nicanor Carrillo Purin}

Teachers' in-service training and

student achievement:

The effect of in-service training of

Peruvian teachers on student

achievement

UNU-MERIT/MGSoG

Dissertation Series № 225

\section{Hugo Confraria}

Developing scientific capacity in the

Global South

UNU-MERIT/MGSoG

Dissertation

Series № 224

\section{Alison Cathles}

Educational Pathways and Skills:

Past, Present, and Future

UNU-MERIT/MGSoG

Dissertation Series № 223

\section{Ibrahima Sory Kaba}

Aggregate Fluctuations and

Development: Essays on

Macroeconomic Volatility and

Economic Growth

UNU-MERIT/MGSoG

Dissertation Series № 222

\section{Charlotte Keijser}

Firm Participation, Learning and

Innovation in Heterogenous Value

Chains of IT-enabled Services

UNU-MERIT/MGSoG

Dissertation Series № 221

\section{Salih Çevikarslan}

Innovation Strategies and Their

Implications for Technological

Change and Market Outcomes:

An Evolutionary Multi-Agent Based

Modelling Approach

UNU-MERIT/MGSoG

Dissertation Series № 220

\section{Wondimagegn Mesfin Tesfaye}

Essays on the Impacts of Climate-

Smart Agricultural Innovations on

Household Welfare

UNU-MERIT/MGSoG

Dissertation Series № 219

\section{Tatevik Poghosyan}

How Board Networks Affect Firm

Performance and Innovation

Incentives in Transition Economies:

The Case of Armenia

UNU-MERIT/MGSoG

Dissertation Series № 218 


\section{Arip Muttaqien}

Essays on Inequality and

Polarization:

Empirical Studies in Developing

Asia

UNU-MERIT/MGSoG

Dissertation Series № 217

2018

\section{Katrin Marchand}

Essays on Forced Migration and

Labour Market Participation in

Developing Countries

UNU-MERIT/MGSoG

Dissertation Series № 216

\section{Ortrun Merkle}

The Myth of Gender Neutral Power:

Corruption and Gender Norms

UNU-MERIT/MGSoG

Dissertation Series № 215

\section{Biljana Meshkovska}

Life after Trafficking:

(re)integration processes of women

that have been trafficked for the

purpose of sexual exploitation in

Europe

UNU-MERIT/MGSoG

Dissertation Series № 214

\section{Vincenzo Vinci}

The Relevance of Institutions and

People's Preferences for Social

Protection

UNU-MERIT/MGSoG

Dissertation Series № 213

\section{Silke Heuser}

The Effectiveness of Environmental

Policies on Reducing Deforestation in

the Brazilian Amazon

UNU-MERIT/MGSoG

Dissertation Series № 212

\section{Jennifer Waidler}

Social Assistance and Remittances

and Their Role in the Fight Against

Poverty

UNU-MERIT/MGSoG

Dissertation Series № 211

\section{Choolwe Muzyamba}

The role of community mobilization in the promotion of maternal health of women living with HIV in Zambia

UNU-MERIT/MGSoG

Dissertation Series № 210

Juan Carlos A. Castillo Sánchez

Assessing the Role of the Export

Sector in Mexican Economic

Development,1965-2014

UNU-MERIT/MGSoG

Dissertation

Series № 209

\section{Tareq Abuelhaj}

Food Security Policy Impact

Analysis: The Econometrics of Cash

and Food Assistance Cost

Effectiveness

UNU-MERIT/MGSoG

Dissertation

Series № 208 
Marta Férnandez de Arroyabe

Arranz

Essays on MEAS and Innovation

UNU-MERIT/MGSoG

Dissertation

Series № 207

\section{Clotilde Mahé}

Essays on Migration and

Occupational Choice

UNU-MERIT/MGSoG

Dissertation

Series № 206

\section{Simone Sasso}

Talent on the move. Essays on

Human Capital, Graduate Mobility

and Economic Development

UNU-MERIT/MGSoG

Dissertation

Series № 205

\section{Khaled Walid Rajab}

Strategic Planning under Fragility

UNU-MERIT/MGSoG

Dissertation

Series № 204

\section{Mutinta Hambayi Nseluke}

A Tall Order: Improving Child

Linear Growth

UNU-MERIT/MGSoG

Dissertation

Series № 203
Elvis Korku Avenyo

Innovations and Firm Performance

in sub-Saharan Africa: Empirical

Analyses

UNU-MERIT/MGSoG

Dissertation

Series № 202

\section{Ni Zhen}

Employment Dynamics, Firm

Performance and Innovation

Persistence in the Context of

Differentiated Innovation Types:

Evidence from Luxembourg

UNU-MERIT/MGSoG

Dissertation

Series № 201

\section{Caroline Wehner}

Too Scared to Achieve: The Relation

Between Neuroticism,

Conscientiousness

and Socioeconomic Outcomes

UNU-MERIT/MGSoG

Dissertation

Series № 200

\section{Stefania Innocenti}

On Institutional Persistence

UNU-MERIT/MGSoG

Dissertation Series № 199

Hassen Abda Wako

Economic Globalization, Institutions and Development: Essays on Aid, Foreign Direct Investment and Trade UNU-MERIT/MGSoG

Dissertation

Series № 198 
2017

Hans-Erik Edsand

Winds of Change

UNU-MERIT/MGSoG

Dissertation Series № 197

Ana Patricia Silva Vara

Redressing the Gender Gap

UNU-MERIT/MGSoG

Dissertation Series № 196

\section{Andrés Iván Mideros Mora}

Essays on the Economic Effects of

Non-contributory Social Protection

UNU-MERIT/MGSoG

Dissertation Series № 195

\section{Tobias Broich}

New Actors in the Global Economy

UNU-MERIT/MGSoG

Dissertation Series № 194

\section{Bernard Nikaj}

From No-government to E-

government

UNU-MERIT/MGSoG

Dissertation Series № 193

\section{Ali Safarnejad}

Prioritizing the HIV Response

UNU-MERIT/MGSoG

Dissertation Series № 192

\section{Clovis Freire}

Diversification and Structural

Economic Dynamics

UNU-MERIT/MGSoG

Dissertation Series № 191

\section{Michael Verba}

Innovation and Knowledge

Dynamics: Essays on the Knowledge

Economy

UNU-MERIT/MGSoG

Dissertation Series № 190

\section{Pui Hang Wong}

The Hearts and Minds in Conflict

and Peace: The Economics of

Counterinsurgency and the

Psychology of Reconstruction

UNU-MERIT/MGSoG

Dissertation Series № 189

\section{Brenda Yamba}

Schooling Despite All Odds:

Evidence from Lesotho on Female

Child Carers who Stayed in School

UNU-MERIT/MGSoG

Dissertation Series № 188

\section{Sheng Zhong}

Moving towards An Energy Efficient

Future: Essays on Energy Efficiency,

Technology and Development

UNU-MERIT/MGSoG

Dissertation Series № 187

\section{Julieta Marotta}

Access to Justice and Legal

Empowerment of Victims of

Domestic Violence through Legal

Organizations in the City of Buenos

Aires: A Qualitative Empirical Legal

Study

UNU-MERIT/MGSoG

Dissertation Series, № 186 


\author{
Andrea Franco-Correa \\ On the Measurement of \\ Multidimensional Poverty as a Policy \\ Tool: Empirical Applications to \\ Chile, Colombia, Ecuador and Peru \\ UNU-MERIT/MGSoG \\ Dissertation Series, № 185
}

2016

\section{Yesuf Awel}

Insurance for Growth: Empirical

Essays on Insurance Demand and

Impacts in Africa

UNU-MERIT Dissertation Series,

№ 108

\section{Tigist Mekonnen Melesse}

Grow More Food using Fewer

Resources: Agricultural Technology

Adoption and Innovation Practices

for Inclusive and Sustainable

Development

UNU-MERIT Dissertation Series, № 107

\section{Eleni Yitbarek}

Getting Ahead or left Behind? Essays

on Poverty Dynamics and Social

Mobility in Africa

UNU-MERIT Dissertation Series,

№ 106

\section{Thuy Dieu Nguyen}

Firm-Level Theory and Evidence of

Corruption

UNU-MERIT Dissertation Series,

№ 105

\section{Raquel Tsukada Lehman}

Essays on Household Production with Labor-Saving Technology

UNU-MERIT Dissertation Series,

№ 104

\section{Eva Barteková}

Multi-Problem Challenges for a

Renewable Future: Empirical Studies on Competitive Disadvantages from Electricity Price Differentials and Mineral Supply Risk in an Open Economy

UNU-MERIT Dissertation Series, № 103

\section{Jocelyn Olivari}

Entrepreneurial Traits and Innovation: Evidence from Chile UNU-MERIT Dissertation Series, № 102

\section{Muhammad Shafique}

Essays on the role of knowledge,

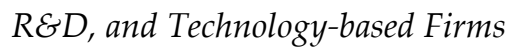
in the Evolution of Socio-technoeconomic System

UNU-MERIT Dissertation Series, № 101

\section{Serdar Türkeli}

Governance of Innovation Policy:

Empirical Studies on Applied

Political Economy by Multi-Methods Analysis

UNU-MERIT Dissertation Series, № 100 


\section{Ayokunu Adedokun}

Pathways to Sustainable Peace

building in Divided Societies:

Lessons and Experiences from

Mozambique

MGSoG Dissertation Series, № 75

\section{Luiz Rothier Bautzer}

Organizing Concurrent Engineering through ICT Platforms

Blueprinting Product Lifecycle

Management Platforms across

Disciplinary Agencies

MGSoG Dissertation Series, № 74

\section{Natalia Popova}

Migration in the Periphery of the

European Union:

Determinants of Successful and

Sustainable Labour Market

Integration of Return Migrants in

Albania, Egypt, Moldova and

Tunisia

MGSoG Dissertations Series, № 73

\section{Richard A. Martina}

Uncertainty and Resource Constraint in the Small Island Developing

States:

Essays in Entrepreneurial Cognition MGSoG Dissertations Series, № 72

\section{Cécile Cherrier}

The Expansion of Basic Social

Protection in Low-income Countries:

An Analysis of Foreign Aid Actors'

Role in the Emergence of Social

Transfers in Sub-Saharan Africa

MGSoG Dissertations series, № 71

\section{Paul Caldron}

The Tacit Bargain in Short-Term Medical Missions: Why U.S.

physicians go and what it costs

MGSoG Dissertation Series, № 70

\section{Mahmut Kobal}

Customs E Excellence: A

Comparative Approach on

Administrative and Regulatory

Compliance Perspectives of the EU-

Turkey Customs Union

MGSoG Dissertation Series, № 69

\section{Craig Loschmann}

Essays on Conflict-related Migration and Development in the Case of

Afghanistan

MGSoG Dissertations Series, № 68

\section{Andrea Milan}

Rural Livelihoods, Location and

Vulnerable Environments:

Approaches to Migration in

Mountain areas of Latin America

MGSoG Dissertation Series, № 67 


\section{Farida Lada}

On Guarding the Welfare of Clinical Trial Subjects While Promoting

Novel Drug Innovation

A Game Theoretical Approach

MGSoG Dissertation Series, № 66

2015

\section{Hibret Belete Maemir}

Dissecting Aggregate Productivity:

International Integration and

Growth with Heterogeneous Firms

UNU-MERIT Dissertation Series,

№ 96

\section{Giorgio Triulzi}

Looking for the Right Path:

Technology Dynamics, Inventive

Strategies and Catching-up in the

Semiconductor Industry

UNU-MERIT Dissertation Series, № 95

\section{Abdul Baseer Qazi}

Knowledge flows and networks in the

ICT sector: The case of Pakistan

UNU-MERIT Dissertation Series, № 94

\section{Ajay Thutupalli}

Technology Paradigm Shifts in

Agriculture: Drivers of

Sustainability and Catch up

UNU-MERIT Dissertation Series, № 93

\section{Eduardo Urias}

Improving access to HIV/AIDS

treatment in Brazil: When are

Compulsory Licenses effective in

Price Negotiations?

UNU-MERIT Dissertation Series,

№ 92

\section{Francesca Guadagno}

Why have so few Countries

Industrialised?

UNU-MERIT Dissertation Series, № 91

\section{Daniel Opolot}

The Evolution of Beliefs and Strategic Behaviour

UNU-MERIT Dissertation Series, № 90

\section{Alejandro Lavopa}

Structural Transformation and

Economic Development: Can

Development Traps be Avoided

UNU-MERIT Dissertation Series,

№ 89

\section{Jinjin Zhao}

Urban water management reform:

The Case of China

UNU-MERIT Dissertation Series, № 88

\section{Simona Vezzoli}

Borders, Independence and Postcolonial Ties: the Role of the State in Caribbean Migration

MGSoG Dissertation Series, № 65 


\section{Silvia Consuelo Gómez Soler}

Civil Conflict and Education: How

Does Exposure to Civil Conflict

Affect Human Capital

Accumulation? Evidence from

Standardized Exit Exams in

Colombia

MGSoG Dissertation Series, № 64

\section{Paula Nagler}

Occupational Choice in the

Developing World

MGSoG Dissertation Series, № 63

\section{Jasmin Kientzel}

Determinants of Professional

Commitment to Environmental

Sustainability

MGSoG Dissertation Series, № 62

\section{Mehmet Güney Celbiş}

Regional Policies: Convergence,

Trade, and the Allocation of Public

Capital

MGSoG Dissertation Series, № 61

\section{Florian Henning}

Living Up to Standard:

Interoperability Governance and

Standards Adoption in Government

Information Networks

MGSoG Dissertation Series, № 60

\section{Niels P. Groen}

The Never-Ending Project

Understanding E-Government

Project Escalation

MGSoG Dissertation Series, № 59

\section{Derek Copp}

Teacher-Based Reactivity to

Provincial Large-scale Assessment in

Canada

MGSoG Dissertation Series, № 58

\section{Michaella Vanore}

Family-Member Migration and the

Psychosocial Health Outcomes of

Children in Moldova and Georgia

MGSoG Dissertation Series, № 57

\section{Sonja Fransen}

The Economic and Social Effects of Remittances and Return Migration in Conflict-Affected Areas: The Case of Burundi

MGSoG Dissertation Series, № 56

\section{Ibrahim Khalil Conteh}

The Impact of Floods on Primary

School Education in Zambia

MGSoG Dissertation Series, № 55

\section{Richard Bluhm}

Growth Dynamics and Development Essays in Applied Econometrics and Political Economy

MGSoG Dissertation Series, № 54

\section{Nevena P. Zhelyazkova}

Work-Family Reconciliation and Use of Parental Leave in Luxembourg:

Empirical Analysis of Administrative Records

MGSoG Dissertation Series, № 53 
2014

\section{Dirk Crass}

The Impact of Brands on Innovation and Firm Performance: Empirical

Evidence from Germany

UNU-MERIT Dissertation Series, № 87

\section{Samyukta Bhupatiraju \\ The Geographic Dimensions of \\ Growth and Development}

UNU-MERIT Dissertation Series, № 86

\section{François Lafond}

The Evolution of Knowledge Systems UNU-MERIT Dissertation Series, № 85

\section{Annalisa Primi}

Promoting Innovation in Latin America: What Countries Have Learned (and What They Have Not) in Designing and Implementing Innovation and Intellectual Property Policies

UNU-MERIT Dissertation Series, № 84

\section{Fatoumata Lamarana Diallo}

Evaluation of Meal and Deworming Programs for Primary Schools in Rural Senegal

UNU-MERIT Dissertation Series, № 83
Sachin Kumar Badkas

Metachoice and Metadata:

Innovating with Environmental

Policy Analysis in Europe

MGSoG Dissertation Series, № 52

\section{Irina S. Burlacu}

An Evaluation of Tax-Benefit

Systems Impact on the Welfare of

Frontier Worker:

The Case of Luxembourg and

Belgium

MGSoG Dissertation Series, № 51

\section{Özge Bilgili}

Simultaneity in Transnational

Migration Research: Links Between

Migrants' Host and Home Country

Orientation

MGSoG Dissertation Series, № 50

\section{Yulia Privalova Krieger}

Reshaping the Big Agenda:

Transnational Politics and Domestic Resistance Financial crisis and social protection reform in Bosnia and

Herzegovina

MGSoG Dissertation Series, № 49

\section{Marieke van Houte}

Moving Back or Moving Forward?

Return migration after Conflict

MGSoG Dissertation Series, № 48

\section{Oxana Slobozhan}

Global Governance in the

Management of Natural Resources:

The Case of the Extractive Industries

Transparency Initiative (EITI)

MGSoG Dissertation Series, № 47 


\section{Luis Bernardo Mejia Guinand}

The Changing Role of the Central

Planning Offices in Latin America: A

Comparative Historical Analysis

Perspective (1950-2013)

MGSoG Dissertation Series, № 46

\section{Cheng Boon Ong}

Ethnic Segregation in Housing,

Schools and Neighbourhoods in the

Netherlands

MGSoG Dissertation Series, № 45

\section{Luciana V. Cingolani}

Bureaucracies for Development:

Oxymoron or Reality? Studies on

State Capacity in Challenging

Governance Contexts

MGSoG Dissertation Series, № 44

\section{Carlos Cadena Gaitán}

Green Politics in Latin American

Cities - Sustainable Transport

Agendas

MGSoG Dissertation Series, № 43

\section{Katie Kuschminder}

Female Return Migration and

Reintegration Strategies in Ethiopia

MGSoG Dissertation Series, № 42

\section{Metka Hercog}

Highly-Skilled Migration and New

Destination Countries

MGSoG Dissertation Series, № 41

\section{Margaret Agaba Rugadya}

Can Remittances Influence the

Tenure and Quality of Housing in

Uganda?

MGSoG Dissertation Series, № 40

\section{Ilire Agimi}

New Governance Under Limited

Statehood: The Case of Local

Government Reform in Kosovo

MGSoG Dissertation Series, № 39

2013

\begin{abstract}
Anant Kamath
Information Sharing through

Informal Interaction in Low-Tech

Clusters
\end{abstract}

UNU-MERIT Dissertation Series, № 82

\section{Flavia Pereira de Carvalho}

What we talk about when we talk about Brazilian Multinationals: An Investigation on Brazilian FDI, Economic Structure, Innovation and the Relationship between them UNU-MERIT Dissertation Series, № 81

\section{Jun Hou}

Complementarity in Innovation and Development: A Cross-country

Comparison

UNU-MERIT Dissertation Series, № 80 


\section{Rufin Baghana}

Impacts of Government Incentives to $R \mathcal{E}$, Innovation and Productivity: A Microeconometric Analysis of the Québec Case

UNU-MERIT Dissertation Series, № 79

\section{Lilia I. Stubrin}

High-Tech Activities in Emerging Countries: A Network perspective on the Argentinean Biotech Activity UNU-MERIT/MGSoG

Dissertation Series, № 78

\section{Kristine Farla}

Empirical Studies on Institutions, Policies and Economic Development MGSoG Dissertation Series, № 38

\section{Marina Petrovic}

Social Assistance and Activation in the Pursuit of Happiness: Shedding New Light on Old Policy Solutions to Social Exclusion

MGSoG Dissertation Series, № 37

\section{Laura Torvinen}

Assessing Governance Assessments:

The Case of Mozambique:

Governance Assessments in the

Context of Aid Effectiveness

Discourse

MGSoG Dissertation Series, № 36

\section{Biniam Egu Bedasso}

Institutional Change in the Long

Shadow of Elite: Essays on

Institutions, Human Capital and

Ethnicity in Developing Countries

MGSoG Dissertation Series, № 35

\section{Sepideh Yousefzadeh Faal}

\section{Deghati}

Childhoods Embargoed: Constructing and Reconstructing Multidimensional Child Poverty in Iran 1984-2009

MGSoG Dissertation Series, № 34

\section{Robert Bauchmüller}

Investing in Early Childhood Care and Education: The Impact of

Quality on Inequality

MGSoG Dissertation Series, № 33

\section{Martin Rehm}

Unified Yet Separated: Empirical

Study on the Impact of Hierarchical

Positions within Communities of

Learning

MGSoG Dissertation Series, № 32

2012
Abdul Waheed
Innovation Determinants and Innovation as a Determinant: Evidence from Developing Countries UNU-MERIT Dissertation Series, № 77 
Bilal Mirza

Energy Poverty and Rural Energy

Markets in Pakistan

UNU-MERIT Dissertation Series, № 76

\section{Benjamin Engelstätter}

Enterprise Software and Video

Games: An Empirical Analysis

UNU-MERIT Dissertation Series, № 75

\section{Fulvia Farinelli}

Natural Resources, Innovation and

Export Growth: The Wine Industry

in Chili and Argentina

UNU-MERIT Dissertation Series

\section{Rodolfo Lauterbach}

Innovation in Manufacturing: From

Product Variety and Labor

Productivity Growth to Economic

Development in Chile

UNU-MERIT Dissertation Series

\section{Kirsten Wiebe}

Quantitative Assessment of

Sustainable Development and

Growth in Sub-Saharan Africa

UNU-MERIT Dissertation Series, № 74

\section{Julio Miguel Rosa}

Organizational Strategies, Firms'

Performance and Spatial Spillovers:

The Canadian Case in Research and

Development.

UNU-MERIT Dissertation Series, № 73

\section{Johannes Wilhelmus Marie}

Boels

Joseph Schumpeter, Honderd Jaar

Economische Ontwikkeling: Een

Historisch-theoretische Beschouwing.

UNU-MERIT Dissertation Series

\section{Dorcas Mbuvi}

Utility Reforms and Performance of the Urban Water Sector in Africa

MGSoG Dissertation Series, № 31

\section{Lina Salanauskaite}

Distributional Impacts of Public

Policies: Essays in Ex-Ante and Ex-

Post Evaluation

MGSoG Dissertation Series, № 30

\section{Esther Schüring}

To Condition or not - is that the

Question?

An Analysis of the Effectiveness of

Ex-Ante and Ex-Post Conditionality

in Social Cash Transfer Programs

MGSoG Dissertation Series, № 29

\section{Joe Abah}

Strong Organisations in Weak

States: Atypical Public Sector

Performance in Dysfunctional

Environments

MGSoG Dissertation Series, № 28

\section{Zina Samih Nimeh}

Social Citizenship Rights: Inequality and Exclusion

MGSoG Dissertation Series, № 27 
2011

\section{Daniel Vertesy}

Interrupted Innovation: Emerging

Economies in the Structure of the

Global Aerospace Industry

UNU-MERIT Dissertation Series, № 72

\section{Tina Saebi}

Successfully Managing Alliance

Portfolios: An Alliance Capability

View

UNU-MERIT Dissertation Series, № 71

\section{Nora Engel}

Tuberculosis in India: A Case of

Innovation and Control

UNU-MERIT/MGSoG

Dissertation Series, № 70

\section{Evans Mupela}

Connectivity and growth in Sub-

Saharan Africa: The Role of

Communication Satellites

UNU-MERIT Dissertation Series, № 69

\section{Nantawan Kwanjai}

Cross Cultural Intelligence amid Intricate Cultural Webs: A Tale of the UnDutchables in the Land of 1002 Smiles

UNU-MERIT Dissertation Series, № 68

\section{Lina Sonne}

Innovation in Finance to Finance Innovation: Supporting Pro-poor Entrepreneur-based Innovation UNU-MERIT Dissertation Series, № 67

\section{Lenka Eisenhamerová}

Legitimacy of 'Humanitarian

Military Intervention'

MGSoG Dissertation Series, № 26

\section{Sonila Tomini}

Informal Payments for Health Care

Services in Albania

MGSoG Dissertation Series, № 25

\section{Jinjing Li}

Dynamic Microsimulation in Public Policy Evaluation

MGSoG Dissertation Series, № 24

\section{Aziz Atamanov}

Rural Nonfarm Employment and

International Migration as

Alternatives to Agricultural

Employment: The Case of

Kyrgyzstan

MGSoG Dissertation Series, № 23

\section{Frieda Vandeninden}

Poverty Alleviation: Aid and Social

Pensions

MGSoG Dissertation Series, № 22

Juliana Nyasha Tirivayi

The Welfare Effects of Integrating

AIDS Treatment with Food

Transfers: Evidence from Zambia

MGSoG Dissertation Series, № 21 


\section{Agnieska Ewa Sowa}

Who's Left Behind? Social

Dimensions of Health Transition and Utilization of Medical Care in Poland MGSoG Dissertation Series, № 20

\section{Emmanaouil Sfakianakis}

The Role of Private Actors in the

Provision of Public Goods with

Applications to Infrastructure and

Financial Stability

MGSoG Dissertation Series, № 19

\section{Siu Hing Lo}

White Collars Green Sleeves: An Inter-organizational Comparison of Determinants of Energy-Related Behaviors among Office Workers MGSoG Dissertation Series, № 18

\section{Treena Wu}

Constraints to Human Capital Investment in Developing Countries: Using the Asian Financial Crisis in Indonesia as a Natural Experiment MGSoG Dissertation Series, № 17

\section{Henry Espinoza Peña}

Impact Evaluation of a Job-Training

Programme for Disadvantaged

Youths:

The Case of Projoven

MGSoG Dissertation Series, № 16
2010

\section{Fernando Santiago}

Human Resources Management

Practices and Learning for

Innovation in Developing Countries:

Pharmaceutical Firms in Mexico

UNU-MERIT Dissertation Series,

№ 66

\section{Zakaria Babutsidze}

Essays on Economies with

Heterogeneous Interacting

Consumers

UNU-MERIT Dissertation Series, № 65

\section{Bertha Vallejo}

Learning and Innovation Under Changing Market Conditions: The Auto Parts Industry in Mexico UNU-MERIT Dissertation Series, № 64

\section{Donatus Ayitey}

Technical Change, Competitiveness and Poverty Reduction: A Study of the Ghanaian Apparel Industry UNU-MERIT Dissertation Series, № 63

\section{Sergey Filippov}

Multinational Subsidiary Evolution: Corporate Change in New EU Member States

UNU-MERIT Dissertation Series, № 62 


\section{Asel Doranova}

Technology Transfer and Learning under the Kyoto Regime: Exploring the Technological Impact of CDM Projects in Developing Countries UNU-MERIT Dissertation Series, № 61

\section{Florian Tomini}

Between Family and Friend:

Understanding the Interdependency of Private Transfers

MGSoG Dissertation Series, № 15

\section{Michał Polalowski}

The Institutional Transformation of Social Policy in East Central Europe: Poland and Hungary in Comparative and Historical Perspective MGSoG Dissertation Series, № 14

\section{Maha Ahmed}

Defining, Measuring and Addressing Vulnerability: The Case of Post

Conflict Environments

MGSoG Dissertation Series, № 13

\section{Pascal Beckers}

Local Space and Economic Success:

The Role of Spatial Segregation of Migrants in the Netherlands MGSoG Dissertation Series, № 12

\section{Victor Cebotari}

Conflicting Demands in Ethnically

Diverse Societies: Ethno political

Contention and Identity Values in

Europe

MGSoG Dissertation Series, № 11

\section{Dennis Gyllensporre}

Competing and Complementary Perspectives on the EU as a Crisis Management Actor:

An Examination of the Common Security and Defence Policy through the Lenses of Idealism and Realism MGSoG Dissertation Series, № 10

\section{Judit Vall Castello}

Business Cycle and Policy Effects on Labour Market Transitions of Older and Disabled Workers in Spain MGSoG Dissertation Series, № 9

\section{Keetie Roelen}

False Positives or Hidden

Dimensions: The Definition and

Measurement of Child Poverty

MGSoG Dissertation Series, № 8

\section{Denisa Maria Sologon}

Earning Dynamics in Europe

MGSoG Dissertation Series, № 7

\section{Melissa Siegel}

Money and Mobility: Migration and Remittances

MGSoG Dissertation Series, № 6

Jessica S. Hagen-Zanker

Modest Expectations: Causes and

Effects of Migration on Migrant

Households inSource Countries

MGSoG Dissertation Series, № 5 
2009

\section{Alexis Habiyaremye}

From Primary Commodity

Dependence to Diversification and

Growth: Absorptive Capacity and

Technological Catch Up in Botswana and Mauritius.

UNU-MERIT Dissertation Series, № 60

\section{Yoseph Getachew}

The Role of Public Capital in

Economic Development

UNU-MERIT Dissertation Series, № 59

\section{Sandra Leitner}

Embodied Technological Change and Patterns of Investment in Austrian Manufacturing

UNU-MERIT Dissertation Series, № 58

\section{Semih Akçomak}

The Impact of Social Capital on

Economic and Social Outcomes

UNU-MERIT Dissertation Series, № 57

\section{Abraham Garcia}

The Role of Demand in Technical

Change

UNU-MERIT Dissertation Series, № 56

\section{Saurabh Arora}

Coherence in Socio-technical

Systems: A Network Perspective on the Innovation Process

UNU-MERIT Dissertation Series, № 55

\section{Mirtha R. Muniz Castillo}

Human Development and Autonomy in Project Aid: Experiences from four bilateral projects in Nicaragua and El Salvador

MGSoG Dissertation Series, № 4

\section{Christiane Arndt}

Governance Indicators

MGSoG Dissertation Series, № 3

\section{Britta Augsburg}

Microfinance: Greater Good or Lesser Evil?

MGSoG Dissertation Series, № 2

\section{8}

\section{Rutger Daems}

Medicines for the Developing World UNU-MERIT Dissertation Series, № 54

\section{Johannes Hanel}

Assessing Induced Technology:

Sombart's Understanding of

Technical Change in the History of

Economics

UNU-MERIT Dissertation Series, № 53 


\section{Rifka Weehuizen}

Mental Capital: the Economic

Significance of Mental Health

UNU-MERIT Dissertation Series,

№ 52

\section{Danielle Cloodt}

The Relationship between RED

Partnership Formation, Social

Embeddedness and Innovative

Performance

UNU-MERIT Dissertation Series, № 51

\section{Sabine Fuss}

Sustainable Energy Development

under Uncertainty

UNU-MERIT Dissertation Series, № 50

\section{Geranda Notten}

Measuring and Managing Poverty

Risks

MGSoG Dissertation Series, № 1

2007

\section{Tobias Kronenberg}

Reconciling Environmental

Conservation with Economic

Prosperity: The Feasibility of Double

Dividends in the Short and Long

Run

UNU-MERIT Dissertation Series, № 49

\section{Viktoria Kravtsova}

Assessing the Impact of Foreign Direct Investment in Transition

Economies

UNU-MERIT Dissertation Series, № 48

\section{Suhail Sultan}

The Competitive Advantage of Small and Medium Sized Enterprises: The Case of Jordan's Natural Stone Industry

UNU-MERIT Dissertation Series, № 47

2006

\section{Bulat Sanditov}

Essays on Social Learning and

Imitation

UNU-MERIT Dissertation Series, № 46

\section{Mamata Parhi}

Dynamics of New Technology Diffusion: A Study of the Indian Automotive Industry UNU-MERIT Dissertation Series, № 45

\section{Andreas Reinstaller}

Social Structures and the Innovation Process: Their Role in the Demand of Firms and Consumers

UNU-MERIT Dissertation Series, № 44 


\section{Rose Kiggundu}

Innovation systems and

Development: The Journey of a

Beleaguered Nile Perch Fishery in

Uganda

UNU-MERIT Dissertation Series, № 43

\section{Thomas Pogue}

The Evolution of Research

Collaboration in South African Gold Mining: 1886-1933

UNU-MERIT Dissertation Series, № 42

\section{Geoffrey Gachino}

Foreign Direct Investment, Spillovers and Innovation: The Case of Kenyan Manufacturing Industry UNU-MERIT Dissertation Series, № 41

\section{Önder Nomaler}

Technological Change, International

Trade and Growth: An Evolutionary, Multi-Agents-Based Modeling

Approach

UNU-MERIT Dissertation Series, № 40

2005

\section{Samia Satti Osman Mohamed-}

\section{Nour}

Change and Skill Development in the Arab Gulf Countries

UNU-MERIT Dissertation Series, № 39

\section{Elad Harison}

Intellectual Property Rights:

Economics and Policy Analysis

UNU-MERIT Dissertation Series, № 38

\section{Daniel Dalohoun}

Learning to innovate: agricultural innovation and entrepreneurship: the case of Songhaï farmers in Benin UNU-MERIT Dissertation Series, № 37

\section{Müge Ozman}

Networks, Organizations and

Knowledge

UNU-MERIT Dissertation Series, № 36

\section{Bas Straathof}

Product Variety and Economic

Growth: The Counteracting Effects of Scale and Idiosyncrasy

UNU-MERIT Dissertation Series, № 35

\section{Wilfred Schoenmakers}

Knowledge Flows between

Multinational Companies: A Patent

Data Analysis

UNU-MERIT Dissertation Series, № 34 


\section{Myriam Cloodt}

Mergers and Acquisitions ( $M$ and

As) in High-Tech Industries:

Measuring the Post-M and $A$

Innovative Performance of

Companies

UNU-MERIT Dissertation Series, № 33

2004

\section{Paola Criscuolo}

RED Internationalisation and

Knowledge Transfer: Impact on

MNEs and their Home Countries

UNU-MERIT Dissertation Series,

№ 32

\section{Maarten Verkerk}

Trust and Power on the Shop Floor

UNU-MERIT Dissertation Series, № 31

\section{Gottfried Leibbrandt}

Adoption, Harmonization and

Succession of Network Technologies

across Countries

UNU-MERIT Dissertation Series,

№ 30

\section{Mark Sanders}

Skill Biased Technical change: Its

Origins, the Interaction with the

Labour Market and Policy

Implications

UNU-MERIT Dissertation Series, № 29
2003

Nadine Roijakkers

Inter-firm Cooperation in High-tech

Industries: a Study of RED

Partnerships in Pharmaceutical

Biotechnology

UNU-MERIT Dissertation Series,

№ 28

Viki Sonntag

Speed, Scale and Sustainability

UNU-MERIT Dissertation Series,

№ 27

Masaru Yarime

From End-of-Pipe Technology to

Clean Technology

UNU-MERIT Dissertation Series,

№ 26

Stéphane Malo

The Combinatorial Chemistry

Revolution: Sustaining a Superior

Performance Position through

Technological Learning

UNU-MERIT Dissertation Series,

№ 25

2002

\section{Annelies Hogenbirk}

Determinants of Inward Foreign

Direct Investment: the Case of the

Netherlands

UNU-MERIT Dissertation Series, № 24 


\section{Bastiaan Johan terWeel}

The Computerization of the Labour Market

UNU-MERIT Dissertation Series

2001

\section{John Adeoti}

Technology Investment in Pollution Control in Sub-Saharan Africa: The Case of the Nigerian Manufacturing Industry

UNU-MERIT Dissertation Series, № 23

\section{Edward Huizenga}

Innovation Management: How

Frontrunners Stay Ahead: An

Empirical Study on Key Success

Factors in the ICT sector

UNU-MERIT Dissertation Series, № 22

2000

\section{Machiel van Dijk}

Technological Change and the

Dynamics of Industries: Theoretical Issues and Empirical evidence from Dutch Manufacturing

UNU-MERIT Dissertation Series, № 21

1999

\section{Jan Cobbenhagen}

Managing Innovation at the Company Level: A Study on Non-

Sector-Specific Success Factors UNU-MERIT Dissertation Series, № 20

\section{Marjolein Caniëls}

Regional Growth Differentials: The Impact of Locally Bounded

Knowledge Spillovers

UNU-MERIT Dissertation Series, № 19

\section{8}

\section{Aldo Geuna}

Resource Allocation and Knowledge production: Studies in the Economics of University Research

UNU-MERIT Dissertation Series, № 18

1996

\section{Reinoud Joosten}

Dynamics, Equilibria, and Values UNU-MERIT Dissertation Series, № 17

\section{Hugo Kruiniger}

Investment, $R \mathcal{E} D$, and the Financing Decisions of the Firm

UNU-MERIT Dissertation Series, № 16

1995

\section{Hans van Meijl}

Endogenous Technological Change: The Case of Information Technology, Theoretical Considerations and Empirical Results UNU-MERIT Dissertation Series, № 15 


\section{René Kemp}

Environmental Policy and Technical

Change: A Comparison of the

Technological Impact of Policy

Instruments

UNU-MERIT Dissertation Series,

№ 14

\section{Rohini Acharya}

The Impact of New Technologies on Economic Growth and Trade: A Case Study of Biotechnology

UNU-MERIT Dissertation Series, № 13

\section{Geert Duysters}

The Evolution of Complex Industrial Systems: The Dynamics of Major IT Sectors

UNU-MERIT Dissertation Series, № 12

\section{Marjan Groen}

Technology, Work and Organisation: A Study of the Nursing Process in Intensive Care Units

UNU-MERIT Dissertation Series, № 11

1994

\section{Huub Meijers}

On the Diffusion of Technologies in a Vintage Framework: Theoretical Considerations and Empirical Results

UNU-MERIT Dissertation Series, № 10

\section{Theon van Dijk}

The Limits of Patent Protection:

Essays on the Economics of

Intellectual Property Rights

UNU-MERIT Dissertation Series, № 9

\section{Hans Voordijk}

Naar Integrale Logistiek in

Bedrijfsketens: Ontwikkelingen in de Bouw

UNU-MERIT Dissertation Series, № 8

\section{3}

\section{Paul Diederen}

Technological Progress in Enterprises and Diffusion of Innovation:

Theoretical Reflections and Empirical Evidence

UNU-MERIT Dissertation Series, № 7

\section{Ben Dankbaar}

Economic Crisis and Institutional Change: The Crisis of Fordism from the Perspective of the Automobile Industry

UNU-MERIT Dissertation Series, № 6

\section{Hanno Roberts}

Accountability and Responsibility:

The Influence of Organisation

Design on Management Accounting UNU-MERIT Dissertation Series, № 5 


\section{Bart Verspagen}

Uneven Growth between

Interdependent Economies: An

Evolutionary View on Technology

Gaps, Trade and Growth

UNU-MERIT Dissertation Series,

№ 4

\section{Sjoerd Romme}

A Self-organization Perspective on

Strategy Formation

UNU-MERIT Dissertation Series,

№ 3
John Spangenberg

Economies of Scale, and Atmosphere in Research Organisations

UNU-MERIT Dissertation Series, № 2

1988

John Hagedoorn

Evolutionary and Heterodox

Innovation Analysis: A Study of

Industrial and Technological

Development in Process Control and Information Technology

UNU-MERIT Dissertation Series, № 1 
